\title{
TID. 7675
}

$$
3
$$

\section{PROCEEDINGS OF THE}

\section{PROTACTINIUM CHEMISTRY SYMPOSIUM}

\section{GATLINBURG, TENNESSEE APRIL 25-26, 1963}

UNITED StATES ATOMIC ENERGY COMMISSION

Divisien of Technical Information 


\section{LEGAL NOTICE}

This report was prepared as an account of Government sponsored work. Neither the United States, nor the Commission, nor any person acting on behalf of the Commission:

A. Makes any warranty or representation, expressed or implied, with respect to the accuracy, completeness, or usefulness of the information contained in this report, or that the use of any information, apparatus, method, or process disclosed in this report may not infringe privately owned rights; or

B. Assumes any liabilities with respect to the use of, or for damages resulting from the use of any information, apparatus, method, or process disclosed in this report.

As used in the above, "person acting on behalf of the Commission" includes any employee or contractor of the Commission, or employee of such contractor, to the extent that such employee or contractor of the Commission, or employee of such contractor prepares, disseminates, or provides access to, any information pursuant to his employment or contract with the Commission, or his employment with such contractor.

This report has been reproduced directly from the best available copy .

Printed in USA. Price $\$ 2.75$. Available from the Office of Technical Services, Department of Commerce, Washington 25, D. C. 


\section{DISCLAIMER}

This report was prepared as an account of work sponsored by an agency of the United States Government. Neither the United States Government nor any agency Thereof, nor any of their employees, makes any warranty, express or implied, or assumes any legal liability or responsibility for the accuracy, completeness, or usefulness of any information, apparatus, product, or process disclosed, or represents that its use would not infringe privately owned rights. Reference herein to any specific commercial product, process, or service by trade name, trademark, manufacturer, or otherwise does not necessarily constitute or imply its endorsement, recommendation, or favoring by the United States Government or any agency thereof. The views and opinions of authors expressed herein do not necessarily state or reflect those of the United States Government or any agency thereof. 


\section{DISCLAIMER}

Portions of this document may be illegible in electronic image products. Images are produced from the best available original document. 
PROGEEDINGS OF THE

$P R O T \Lambda C T I N I U M C H E M I S T R Y S Y M P O S I U M$

GATLINBURG, TENNESSEE

APRIL 25-26, 1963

Sessions $1-111$

Issuance Date: February 1964

Sponsored by

OAR RTDGE INATIONAL LABORATORY

operated by

UNION CARBIDE CORPORATION

for the

U. S. ATOMIC ENERGY COMIISSION 
• 
CONTENTS

\section{SESSTON 1}

C. J. Hardy and D. Scargil1 - Protactinium Species in TBP-Nitric Acid Systems . . . . . . . . . . . . . . .

J. G. Moore and R. H. Rainey - Separation of Protactinium from Thorium in Nitric Acid Solutions by Solvent Extraction with Tributyl Phosphate or by Adsorption on Pulverized Unfired Vycor Glass or Silica Gel ...............

C. J. Barton, D. R. Cuneo, M. J. Relly, and J. E. Strain Protactinium Stability in Thorium Nitrate-Nitric Acid Solutions . . . . . . . . . . . . . . . .

G. L. Johnson, D. R. Cuneo, H. F. McDuffie, and M. J. Ke11y Removal of Protactinium and Uranium from Thorium NitrateNitric Acid Solutions .................

\section{SESSION 11}

Lawrence Stein - Protactinium Fluorides . . . . . . . . .

0. L. Keller, Jr. - Chaxacterization of Protactinium Species in Crystals and Solutions by Raman and Infrared Spectroscopy

J. H. Shaffer, G. M. Watson, D. R. Cuneo, J. E. Strain, and M. J. Kelly - Recovery of Uranium and Protactinium from Molten Fluoride Systems by Precipitation as Oxides . . . . .

D. 0. Campbe11 - The Chemistry of Protactinium in Sulfuric Acid Solutions .....................

\section{SESSION 111}

Hans-Ludwig Scherff and Gunter Herrmann - Ionic Species of Protactinium in Hydrochloric Acid . . . . . . . . . .

H. W. Kirby - Hydrolysis and Residue Adsorption of Protactinium

J. M. Chilton - Observations on the Behavior of Protactinium in HC1-HF Solutions ....................

G. Bouissieres, M. C. Ferradini, M. Garcon, R. Guillaumont, M. Hussonois, R. Muxart, H. Pezerat, D. Robertson, and T. Stchouzkoy - The Chemistry of Protactinium . . . . . . 
• 


\title{
ATTENDANCE AT PROTACTINIUM CHEMISTRY SMPOSIUM
}

\author{
Gatlinburg, Tennessee \\ April 25-26, 1963
}

Larned B. Asprey

Los Alamos Scientific Laboratory

Los Alamos, New Mexico

Chorles F. Baes, Jr.

oak Ridge National Laboratory

oak Ridge, Tennessee

C. J. Barton

Oak Ridge National Laboratory

oak Ridge, Tennessee

Julius Berrett

Phillips Petroleum Company

Idaho Falls, Idaho

Robert E. Biggers

Oak Ridge National Laboratory

Oak Ridge, Tennessee

Charles A. Blake

Oak Ridge National Laboratory

ock Ridge, Tennessee

G. E. Boyd

Oak Ridge Nationa1 Laboratory

oak Ridge, Tennessee

K. B. Brown

Oak Ridge Nationa1 Laboratory

Oak Ridge, Tennessee

Stanley Cantor

Oak Ridge Nationa1 Laboratory

oak Ridge, Tennessee

David 0. Carpbe11

Oak Ridge National Laboratory

Oak Ridge, Tennessee

A. Chetham-Strode

Oak Ridge National Laboratory

Oak Ridge, Tennessee

J. M. Chilton

Oak Ridge National Laboratory

Oak Ridge, Tennessee

Edgar L. Compere

Oak Ridge National Laboratory

oak Ridge, Tennessee
J. H. Cooper

Oak Ridge National Laboratory

oak Ridge, Temessee

Dante A. Costanzo

Oak Ridge National Laboratory

Oak Ridge, Tennessee

David R. Cuneo

Oak Ridge National Laboratory

Oak Ridge, Tennessee

Fred W. Davis

Babcock \& Wilcox Company

Lynchburg, Virginia

$\%$ Oak Ridge National Laboratory

oak Ridge, Tennessee

H. J. de Bruin

Australian AEC

Sydney, Australia

\% Oak Ridge National Laboratory

oak Ridge, Tennessee

R. E1son

University of California.

Lawrence Radiation Laboratory

P. 0 . Box 808

Livernore, California

Cyrus Feldman

Oak Ridge National Laboratory

Oak Ridge, Tennessee

D. E. Eerguson

Oak Ridge National Laboratory

Oak Ridge, Tennessee

Clarence J. Hardy

A.E.R.E., Harwel1

Berks, England

H. P. House

Oak Ridge National Laboratory

oak Ridge, Tennessee

T. R. Jones

U. S. Atomic Energy Commission

Washington 25 , D. C. 
(continued)

o. L. Keller, Jr.

Oak Ridge National Laboratory

Ook Ridge, Tennessee

Francois Kertesz

Oak Ridge National Laboratory

Oak Ridge, Tennessee

Harold W. Kirby

Monsunto Research Corporation

Miamisburg, Ohio

Ress E. Leuze

Oak Ridge National Laboratory

Oak Ridge, Tennessee

II. F. McDuffie

Dak Ridge National Laboratory

Oak Ridge, Tennessee

J. G. Moore

Onk Ridge National Laboratory

Oalk Ridge, Tennessee

Richard J. Morrov

University of $\mathrm{Ca}$ ifornda

Lawrence Radiation Laboratory

P. 0. Box 808

Livermore, California

Rol and Muxaxt

Institut du Rodium

Arcueil (Seine), France

Richard J. Nagle

University of California

Lawrence Radiation Laboratory

Livermore, California

James $\forall \cdot$ Nehls

U. 3. Atomic Energy Comission

P. O. Box E

Oak Ridge, Tennessee

John Noakes

oak Ridge Institute of Nuclear Studies

oak Ridge, Tennessee

George W. Parker

Oak Ridge National Laboratory

onk Ridge, Tennessee

Robert II. Rainey

oak Ridge Netional Laboratory

Oak Ridge, Tennessee
Robert Rickard

Oak Ridge National Laboratory

oak Ridge, Tennessee

Elizabeth Rona

Oak Ridge Institute of Nuclear Studies

Oak Ridge, Tennessee

James H. Shaffer

Oak Ridge National Laboratory

Dak Ridge, Tennessee

Arthur J. Shor

Oalk Ridge National Laboratory

Oak Ridge, Tennessee

Lawrence Stein

Argonne National Laboratory

9700 S. Cass Avenue

Argonne, Illinois

R. W. Stoughton

Oak Ridge National Laboratory

Oak Ridge, Tennessee

I. R. Supernar

Oak Ridge Institute of Nuclear Studies

Oak Ridge, Tennessee

Charles D. Susano

Oak Ridge Nacional Laboratory

Oak Ridge, Tennessee

D. R. Vissers

Oak Ridge National Laboratory

ock Ridge, Tennessee

Fritz Veigel

Institute of Inorganic Chemistry

University of Munich

Munchen

Vest Germany

R. G. Wymex

Oak Bidge National Laboratory

Oak Ridge, Tennessee 
C. J. Hardy and D. Scargi11*

1. Introduction

our previous work on the behaviour of protactinium in nitric acid solutions was published in the Joumal Inorg. Nucl. Chem., I, 257 (4958) and showed that reproducible solvent extraction and ion exchange results could be obtained provided that the protactinium concentration was in the range $10^{-4}-10^{-7}$, and the aqueous nitric acid concentram tion was at least $3 \mathrm{H}_{\text {. It }}$. It concluaed that cationic, non-ionic and anionic complexes were present in equilibrium in these solutions, in adjition to some polymeric material rhich was not extractable into solvents.

Further results are now presented on the species of protactinium in nitric acid and TBP phases which have been examined by

(i) extraction of aqueous solutions with 30-50\% TBP in kerosene or xylene as a function of the concentrations of protactinium $\left(10^{-3}\right.$. $10^{-6}$ ), of nitric acid $(1-10 \%)$, the ratio of the volumes of the solvent and aqueous phases, and the temperature; and

(ii) paper chromatography of TBE pheses with methylisobutylketone and solutions of MPP in kerosene as eluting solvents.

\section{Behaviour of protactinium in aqueous nitric acid}

2.1. The variation of $\mathrm{D}_{\mathrm{P}}$ with ageing time after decreasing the Pa concentration in $6 \mathrm{H}_{3} \mathrm{HIO}_{3}$ Dilution of a solution of $2 \times 10^{-3} \mathrm{HP}^{231}$ (prepared and counted as described previously in the J. Inorg. Nucl. Chem.) to $10^{-4} \mathrm{pa}$ at constant nitric acia concentration (6il) leads to a marked increase with ageing time (up to $100 \mathrm{hrs}$ at $21^{\circ} \mathrm{C}$ ) in the forward dictribution coefficient $\left(\mathrm{D}_{\mathrm{Pa}}\right)$ into $30 \% \mathrm{TBP}-x y I$ ene $(F i g .1)$.

\footnotetext{
*Chemistry Division, Atomic Energy Research Establishment, Harwel1, Berkshire, England.
} 


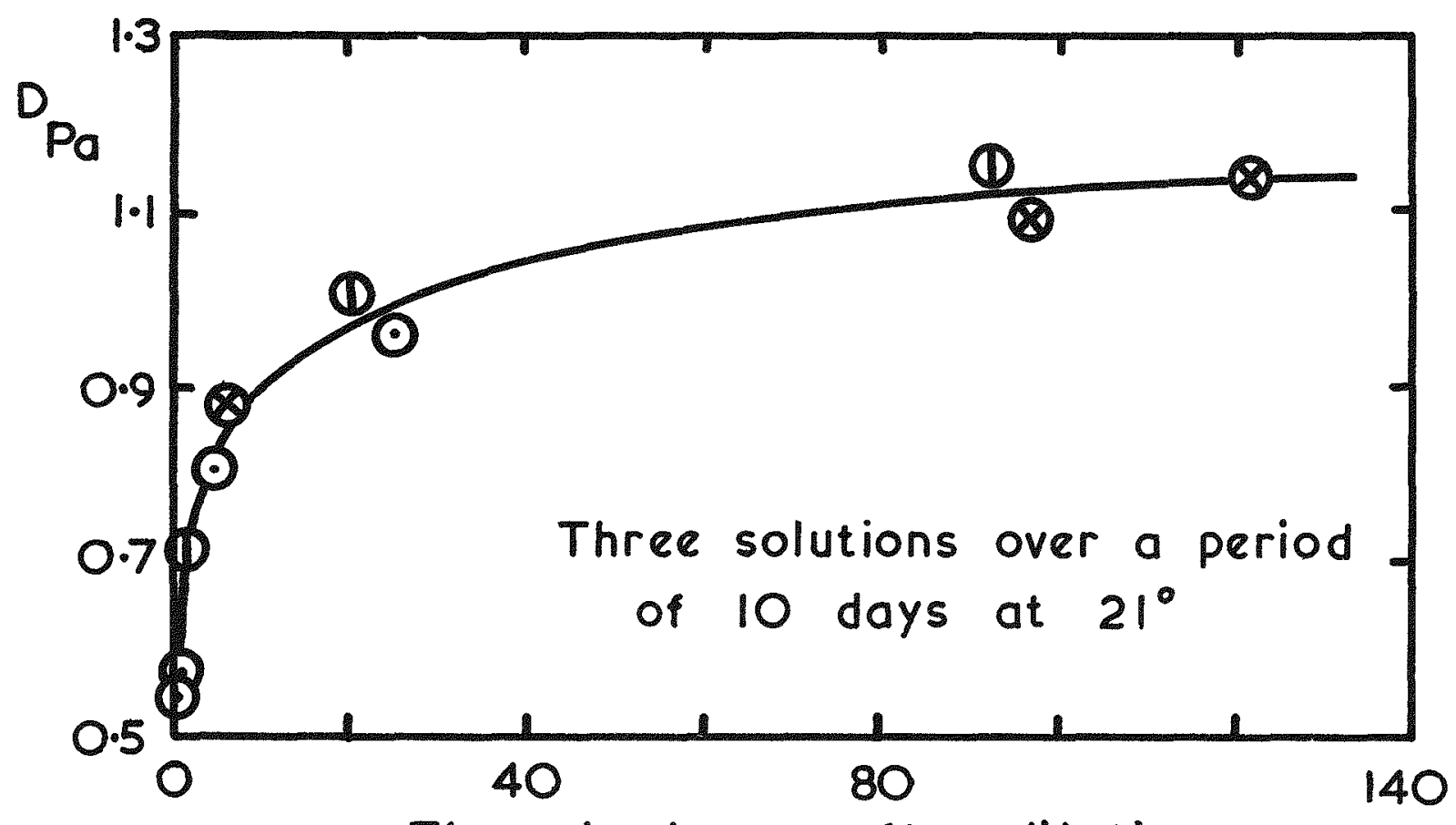

Time in hours after dilution

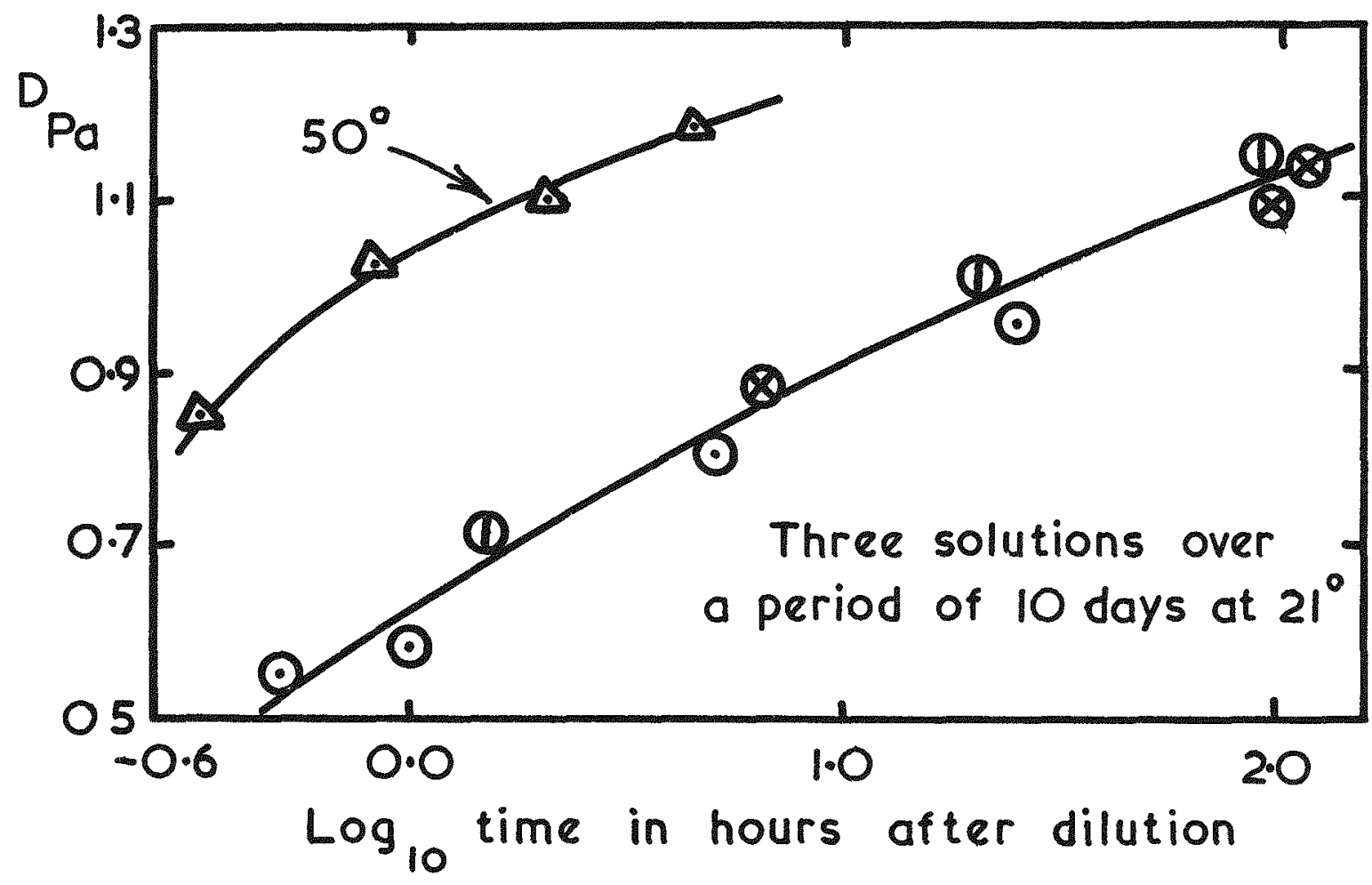

Fig. 1. Variation of $\mathrm{D}_{\mathrm{Pa}}$ (30\% TBP-xylene) with time after dilution of $2 \times 10^{-3} \mathrm{M} \mathrm{Pa}$ to $10^{-4} \mathrm{MPa}$ in $6 \mathrm{M} \mathrm{HNO}_{3}$ at $21^{\circ}$ and $50^{\circ}$. 
The backwash distribution coefficients into $6 \mathrm{H}^{\mathrm{H}} \mathrm{HNO}_{3}$ were found to be approximately constant (about 2.2). Ageing the diluted aqueous solution at $50^{\circ} \mathrm{C}$ increased the value of $\mathrm{D}_{\mathrm{Pa}}$ compared with ageing at $21^{\circ} \mathrm{C}$. (Iower graph, Fig. 1).

The percentage of solvent-inextractable $\mathrm{Pa}$ calculated from the forward and backwash values of the distribution coefficient is given as a function of ageing time in Fig. 2. This percentage decreases with an approx. $t_{\frac{1}{2}}$ of 25 hrs at $21^{\circ} \mathrm{C}$ from about $55 \%$ at $2 \times 10^{-3} \mathrm{Ma}$ to $22 \%$ at $10^{-4} \mathrm{M} \mathrm{Pa}$.

\subsection{The Variation of $\mathrm{D}_{\mathrm{Pa}}$ after decreasing the $\mathrm{Pa}$ concentration \\ in $1 \mathrm{OMN}^{\mathrm{HNO}} 3$}

A solution of $\mathrm{Pa}$ was prepared by dissolution of freshly precipitated protactinium hydroxide in $10 \mathrm{KHNO}_{3}$, heating for $1 \mathrm{hr}$ at $100^{\circ} \mathrm{C}$, cooling and centrifuging.

A sample of this solution $\left(10^{-3}\right.$ H $\left.\mathrm{Fa}\right)$ after ageing for 20 minutes and extraction for 2 minutes with $30 \%$ IBP-kerosene preequilibrated with 1 ON $\mathrm{HNO}_{3}$ gave a value of $\mathrm{D}_{\mathrm{Pa}}$ of 0.34 (Fig. 3 , top). The solution was then diluted to $10^{-5}$ M $\mathrm{Pa}$ with $10 \mathrm{MHNO} \mathrm{H}^{\text {* }}$ Samples were extracted with equal volumes of $30 \%$ TBP-kerosene after ageing for $\frac{1}{2}, 7,10$ and $30 \mathrm{~min}$. and found to have a constant value (3.5) for $\mathrm{D}_{\mathrm{Pa}}$. It therefore appeared that a rapid equilibrium exists between the extractable species and one or more of the inextractable polymeric species, i.e. only about $25 \%$ of the $\mathrm{Fa}$ could be extracted at an initial [Fa] $=10^{-3} \mathrm{M}$, but rapid dilution to $10^{-5} \mathrm{H}$ allowed $\sim 80 \%$ to be extracted, and this amount did not vary with ageing times of $\frac{1}{2}-30 \mathrm{~min}$. 


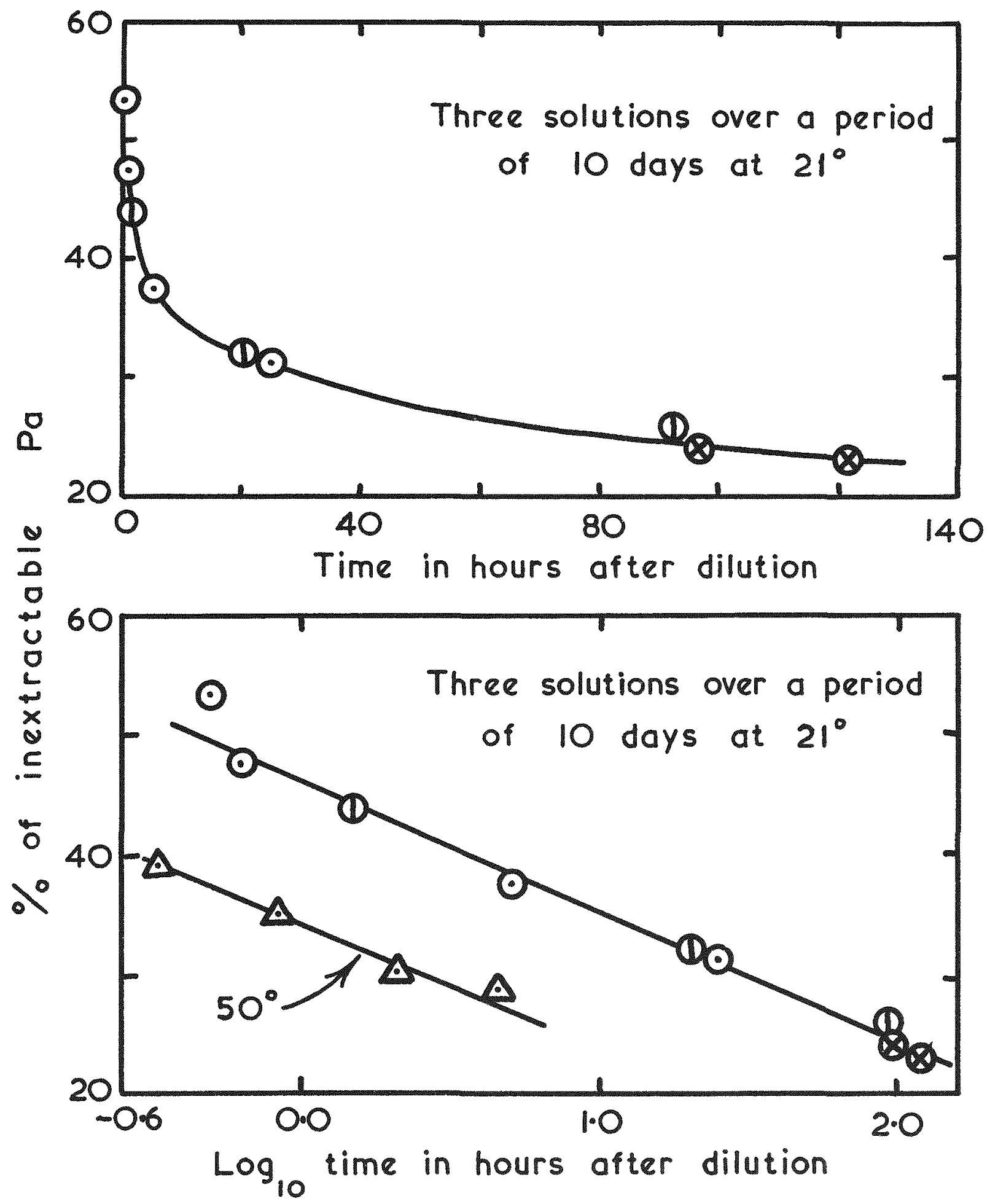

Fig. 2. Variation of percentage inextractable protactinium with time after dilution of $2 \times 10^{-3} \mathrm{MPa}$ to $10^{-4} \mathrm{MPa}$ in $6 \mathrm{HNO}_{3}$ at $21^{\circ}$ and $50^{\circ}$. 


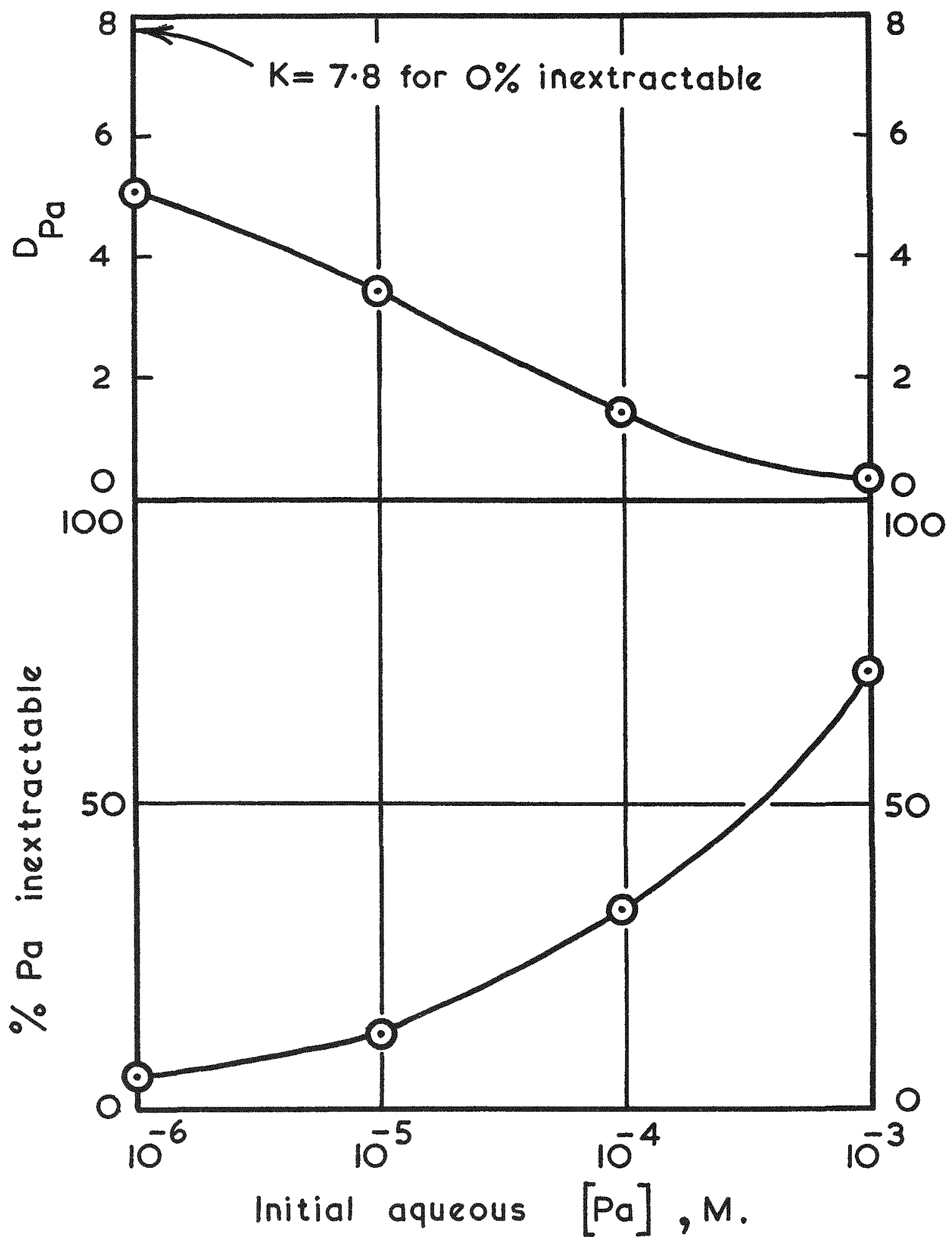

Fi.g. 3. Extraction of protactinium from 1 OM $\mathrm{HNO}_{3}$ by $30 \%$ IBP-kerosene as a function of the protactinium concentration. 
After the $10^{-3} \mathrm{Ma}$ stock solution had been aged 20 hrs, a further series of dilutions to $10^{-4}, 10^{-5}$ and $10^{-6} \mathrm{MPa}$ in $1 \mathrm{OM} \mathrm{HNO}_{3}$ were made and samples of each of these were extracted for 2 minutes with $30 \%$ TBP after the solutions had been aged for about 30 minutes at $21^{\circ} \mathrm{C}$. Values of $\mathrm{D}_{\mathrm{PQ}}$ are given in Fig. 3. The average value of the backwash distribution coefficient from the extractions at $10^{-5}$ and $10^{-6} \mathrm{M} \mathrm{Pa}$ was 7.8 , and with this value and the forward values the $\%$ inextractable $\mathrm{Pa}$ was calculated (bottom of Fig. 3).

The solutions were aged for 2 months and values of $\mathrm{D}_{\mathrm{Pa}}$ for forward extractions found to agree very well with those for 20 hrs ageing, e.g. 3.5 and 3.8 at $10^{-5} \mathrm{Ha}, 5.2$ and 5.1 at $10^{-6} \mathrm{H}$.

\subsection{The variation of $\mathrm{D}_{\mathrm{Pa}}$ with ageing time after decreasing the}

Pa concentration at various acid concentrations from 1-9M FNO

A solution of $10^{-4} \mathrm{Ha}$ in $6 \mathrm{HNO}_{3}$, containing negligible inextractable $\mathrm{Fa}$, was diluted to give solutions of $10^{-5} \mathrm{M} \mathrm{Pa}$ in 1 , 3, 6 and $9 \mathrm{M} \mathrm{HNO}_{3^{\circ}}$. These solutions were aged at $21^{\circ} \mathrm{C}$ and samples removed at various times (from 3 min to $68 \mathrm{hrs}$ ) quickly adjusted to $6 \mathrm{H} \mathrm{HNO}_{3}$ and extracted with an equal volume of $30 \%$ TBP-kerosene

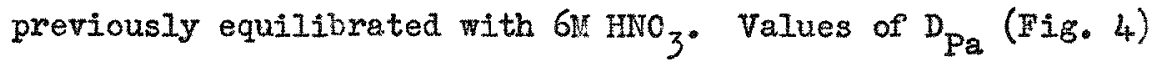
were approximately constant up to $20 \mathrm{hrs}$. for the solutions in 3,6 , and $9 \mathrm{H} \mathrm{HNO}_{3}$, but decreased with ageing tine for the solution in $1 \mathrm{H}^{-\mathrm{NNO}_{3}}$. The mass balances for all the distribution experiments were close to $100 \%$ except for the $1 \mathrm{H}_{1} \mathrm{WNO}_{3}$ solution after 68 hrs ageing. Before centrifugation this solution had deposited about $13 \%$ of its activity on the walls of the container, and after stirring a sample with TBP and centrifuging, 


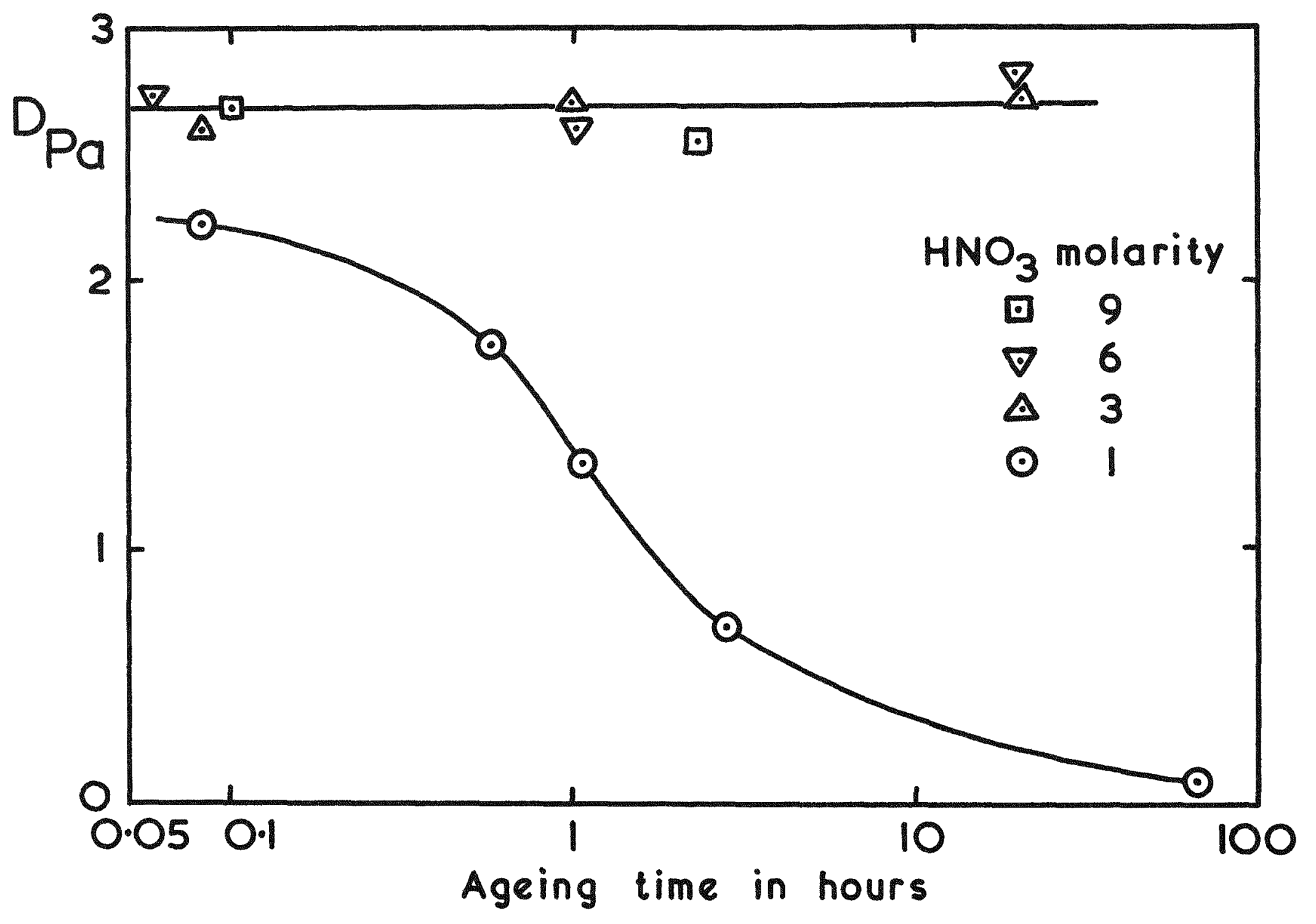

Fig. 4. Variation of $\mathrm{D}_{\mathrm{Pa}}$ with ageing time in $1-9 \mathrm{MNO}_{3}$ at $24^{\circ}$. 
about $50 \%$ of the initial activity was lost. The percentage of inextractable protactinium in solution in $1 \mathrm{HHNO}_{3}$ after $68 \mathrm{hrs}$ was calculated to be about $95 \%$.

\section{Behsviour of protactinium in TBP phases}

3.1. Extraction of protactinium at various ratios (V) of the volumes of the organic and aqueous phases Samples of a solution of $10^{-4} \mathrm{M} \mathrm{Pa}$ aged $7-9$ days in $6 \mathrm{MHNO}_{3}$ were extracted for 2 min. at $21^{\circ} \mathrm{C}$ with various volumes of $30 \%$ TBP-kerosene pre-equilibrated with $6 \mathrm{MNO}_{3}$. The activity of the $\mathrm{Pa}$ in the organic phase was plotted against the activity in the aqueous phase (Fig. 5).

There are two features of importance show by a graph of this type, first, it intersects the aqueous activity axis at a point corresponding to the percentage (5\%) of inextractable $\mathrm{Pa}$, and second, the line is curved, indicating that more than one extractable species is present. A straight line would be obtained (with a slope equal to the aistribution coefficient) if only one species was extracted.

This curve can be fitted by assuming two species with partition coefficients (K) of 2 and 10, but it is not possible to analyse the curve very accurately due to the scatter in the experimental points. Other solutions have given similar curves with calculated values of the $K^{\prime} s$ varying between $1.5-2.5$, and $6-15$, and the percentages of the species varying likewise.

The agreement of $D_{\text {calculated }}$ and $D_{\text {observed }}$ is shown in Figure 6. A further check was made by ze-extracting (with $V=1$ ) 


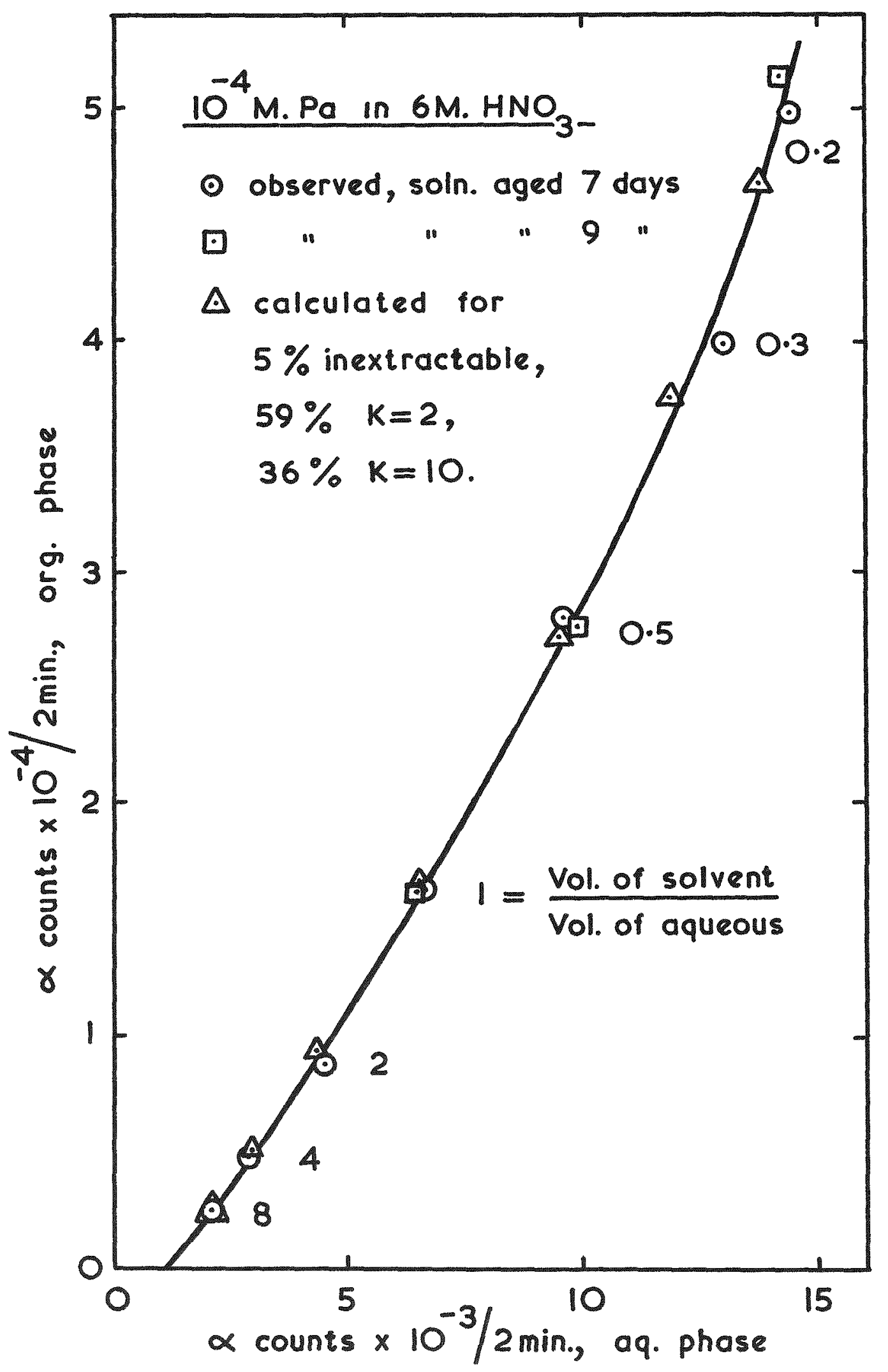

Fig. 5. Extraction of protactinium at various ratios (V) of the volumes of the organic and aqueous phases. 
Comparison of $D_{\text {calc }}$ and $D_{\text {observed }}$

$$
\begin{aligned}
& \begin{array}{llllllll}
V=\frac{\text { solvent }}{\text { aqueous }} & 0.2 & 0.3 & 0.5 & 1 & 2 & 4 & 8
\end{array} \\
& \begin{array}{llllllll}
D \text { obs. } & 3.45 & 3.03 & 2.93 & 2.50 & 1.93 & 1.73 & 1.25
\end{array} \\
& \begin{array}{llllllll}
D_{\text {calc. }} & 3.41 & 3.15 & 2.90 & 2.54 & 2.17 & 1.74 & 1.27
\end{array}
\end{aligned}
$$

Aqueous phase from $V=4$ re-extracted with $V=1$ :

$$
D_{\text {calc. }}=0.72, \quad D_{\text {obs. }}=0.70
$$

Fig. 6. Comparison of $D_{\text {calculated }}$ and $D_{\text {observed }}$ for extraction of $10^{-4} \mathrm{~Pa}$ in $6 \mathrm{NHNO}_{3}$ with $30 \% \mathrm{TBP}$. 
the aqueous phase from the previous $V=4$ extraction, and a good agreement with the calculated $D$ was obtained.

\subsection{Paper chromatography of $\mathrm{Pa}$ in TBP phases}

Elution with methyl isobutylketone The second main piece of evidence for there being more than one extractable species is the separation of the $\mathrm{Pa}$ in the TBP phase into two main peaks by paper chromatography with methylisobutylketone (MIBK) as the eluting solvent.

Fig. 7 shows the chromatogram for a $5 \mu$ sample of $30 \% \mathrm{TBP}-$ kerosene (saturated with $6 \mathrm{MHNO}_{3}$ ) containing freshly extracted $\mathrm{Pa}$, eluted upwards with MIBK saturated with 67 HNO ${ }_{3}$. After elution the paper strip was cut into 12 sections and $a$ counted directly, or after ignition of each section. The same result was obtained

(i) for samples which after addition to the paper were either dried or not aried before elution.

(ii) for TPP solutions aged 20 minutes or 24 hours.

(iii) for freshly prepared or aged MIBK solvent. About $45 \%$ of the $\mathrm{Pa}$ was eluted to the solvent front and $55 \%$ eluted to $R_{f} \sim 0.2$.

\section{Elution with TBP in kerosene}

Samples of 4 uI of the same $30 \%$ TBP-kerosene phase as used above containing $\mathrm{Pa}$ freshly extracted from $6 \mathrm{M} \mathrm{HNO}_{3}$ were eluted upwards with kerosene alone, and kerosene containing 10, 20 and 


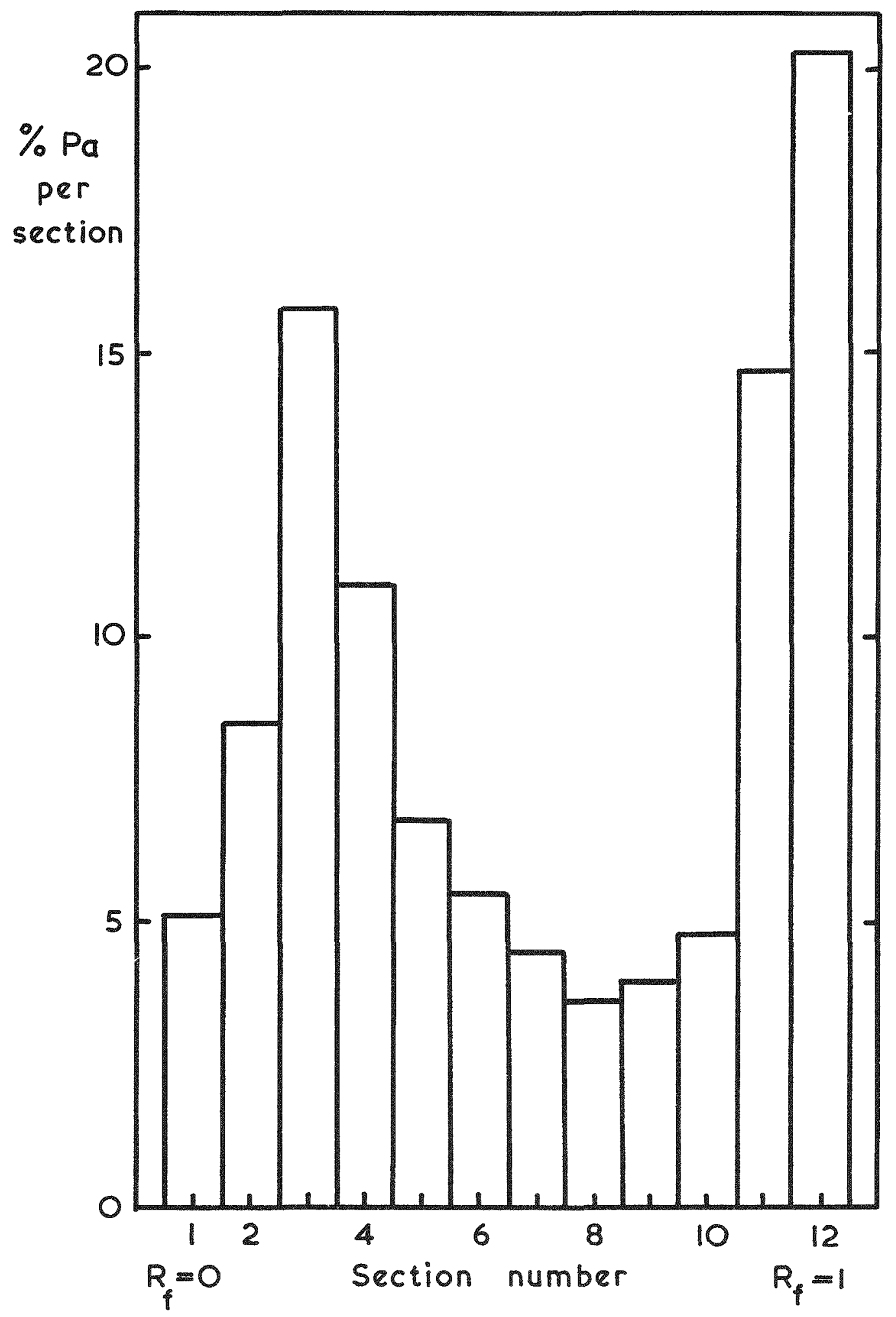

Fig. 7 Blution of protactinium in $30 \%$ mBP-kerosene (saturated with 6 $\mathrm{HNO}_{3}$ ) with $\mathrm{NIBK}-6 \mathrm{NNNO}_{3}$ 
$30 \% \mathrm{~V} / \mathrm{v}$ TBP (each solution pre-equilibrated with $6 \mathrm{HWO}_{3}$ ).

The results (Fig. 8) show that the $\mathrm{R}_{\mathrm{f}}$ value of the main peak increases from about 0.4 with kerosene alone to 0.9 with. $30 \%$ TBP. About $20 \%$ of the $\mathrm{Pa}$ is left on the starting line with kerosene alone, but very little is left when kerosene containing IBP is used. Two different species are clearly seen when the $\mathrm{Pa}$ solution is eluted with $10 \%$ and $20 \% \mathrm{TBP}$, but all the $\mathrm{Pa}$ is eluted to near the solvent front (with bad tailing) when $30 \%$ TBP is used.

The chromatograms with the TBP solvent are different to those with MIBK and we conclude that at least one of the $\mathrm{Pa}$ species in the TBP solution added to the chromatogram must have Its solvated TBP molecules easily replaced, by MIBK for example. At the present, we are only able to say qualitatively that more than one $\mathrm{Pa}$ species occurs in the TBP extracts from nitric acid solutions of $\mathrm{Pa}$.

4. Conclusions

4.1 Species in aqueous nitric acid

The above results are explained in terms of rapid equilibria between one or more monomers (which are probably extracted as byaroxomitrato complexes solvated with $\mathrm{IBP}$ ) which are in slow equilibrium with inextractable polymers. Apparently stable solutions of $\sim 10^{-3} \mathrm{k} \mathrm{Pa}$ in 6 and $10 \mathrm{H} \mathrm{HNO}_{3}$ can be obtained, but $50-70 \%$ of the $\mathrm{Pa}$ is not extractable by TBP in a short period of stirring ( 2 min.). If the $P_{Q}$ in these solutions is diluted at constant $\left[\mathrm{HWO}_{3}\right]$, some but not 211 of the polymexic material depolymexises rapidy (within 30 seconds) and can be extracted by 


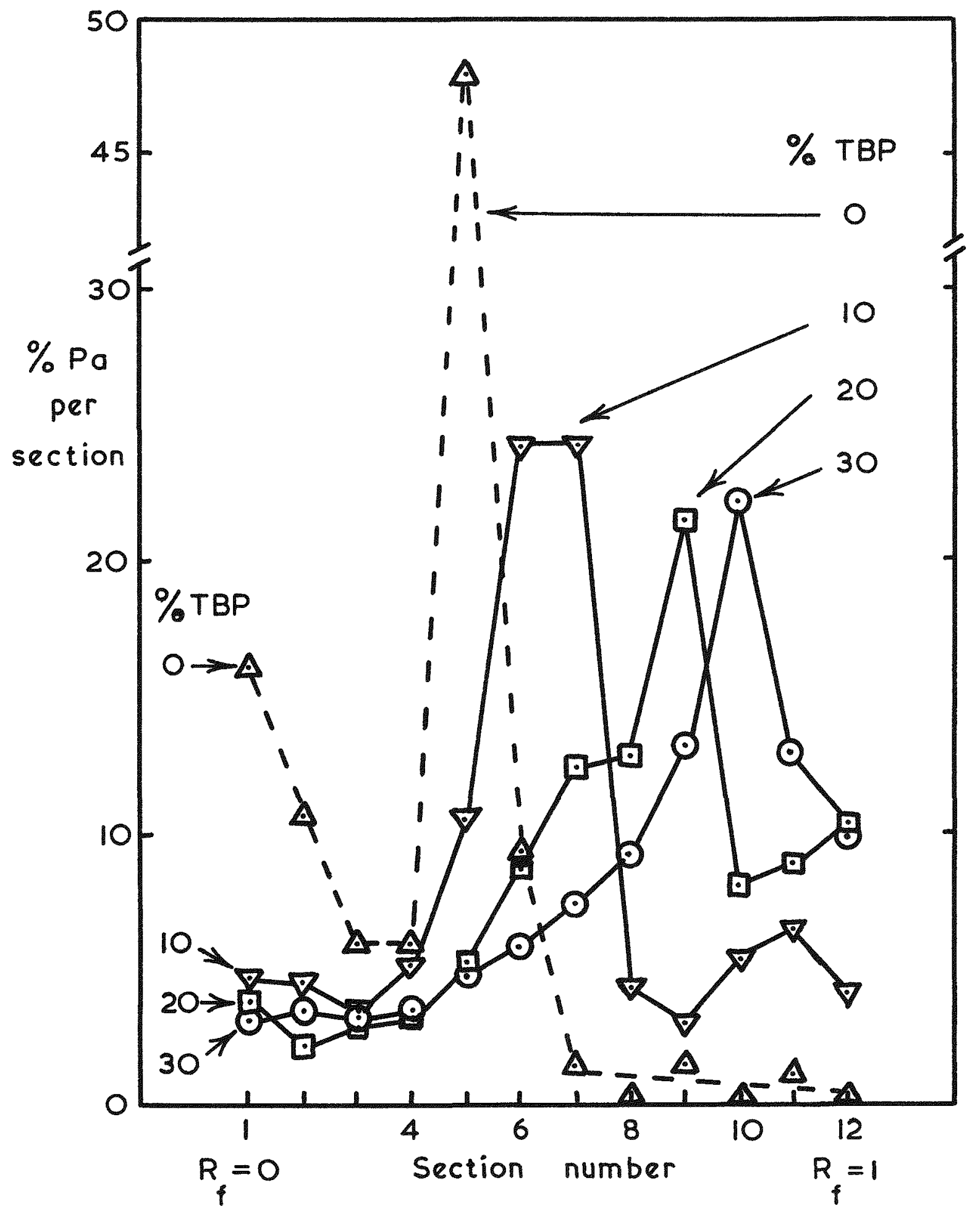

Fig. 8 Elution of protactinium in 30\% IBP-kerosene (saturated with $6 \mathrm{NHNO}_{3}$ ) with solutions of $\mathrm{IBP}$ in kerosene. 
TBP. We therefore think that there are polymers of varying degrees of aggregation but probably of feirly low molecular weight in strong acid. If a solution of $\mathrm{Pa}$ is diluted to a low aciaity, e.g. 1M $\mathrm{HNO}_{3}$, the degree of aggregation increases considerably with time until gravitational settling finally occurs.

\subsection{Species in TBP phases}

The paper chromatography and solvent extraction results show that at least two species of $\mathrm{Pa}$ are extracted by $\mathrm{TBP}$ from a $\mathrm{Pa}$ solution in $6 \mathrm{HNO}_{3^{\circ}}$. At the present, it is only possible to indicate the approximate amounts of these species because

(i) the chromatograms obtained by WIBK and TBP elution do not agree quantitatively, and

(ii) it is not possible to fit accurately the curves obtained by extracting $\mathrm{Pa}$ with different ratios of solvent: aqueous phase volumes. 


\title{
SEPARATION OF PROTACTINIUM FROM THORIUM IN NITRIC ACID SOLUTIONS BY SOLVENT EXTRACTION WITH TRIBUTYL PHOSPHATE OR BY ADSORPTION ON PULVERIZED UNFIRED VYCOR GLASS OR SILICA GEL.
}

\author{
J. G. Moore R. H. Rainey
}

OAK RIDGE NATIONAL LABORATORY

ABSTRACT

Two methods are being investigated for the separation and recovery of protactinium from short-decayed thorium reactor fuels after dissolution in nitric acid solutions. The protactinium may be preferentially adsorbed on pulverized unfired Vycor glass or silica gel, or the protactinium, thorium, and uranium may be coextracted with tributyl phosphate. Major effort has been on the adsorption method, using unfired Vycor glass.

The distribution coefficient of protactinium on Vycor from nitric acid solutions increases as the contact time increases or as the particle size of the glass decreases and is dependent on the concentration of salt or nitric acid in the solution. The adsorbed protactinium may be eluted with oxalic or tartaric acids. At a column loading of $2 \mathrm{mg} \mathrm{Pa} / \mathrm{g}$ glass, more than $99 \%$ of the protactinium was adsorbed from a synthetic feed solution containing $0.5 \mathrm{M} \mathrm{Th}, 11 \mathrm{M} \mathrm{HNO}_{3}, 0.1 \mathrm{M} \mathrm{Al}, 0.05 \mathrm{~g} \mathrm{~Pa}^{231} /$ liter, and less than $0.1 \mathrm{M} \mathrm{F}$. At $5 \mathrm{mg} \mathrm{Pa} / \mathrm{g}$ g Tass, $95 \%$ of the protactinium had been adsorbed. Greater than $99 \%$ was eluted with $0.5 \mathrm{M}$ oxalic acid, $98 \%$ of which was eluted at a concentration of $4.1 \mathrm{mg}$ $\mathrm{Pa}^{231} / \mathrm{ml}$. The protactinium concentrations in the feed solutions were constant on standing one month at room temperature in plastic containers. Column experiments with tracer concentrations of protactinium and unoptimized conditions showed decontamination factors of protactinium from thorium, uranium, ruthenium, zirconium-niobium, and total rare earths of $6 \times 10^{3}, 1.6 \times 10^{4}, 4 \times 10^{3}, 3$, and $5.8 \times 10^{5}$, respectively.

Experiments with tracer concentrations of $\mathrm{Pa}^{233}$ in nitric acid solutions showed distribution coefficient maxima for protactinium of about 1000,325 , and 175 from 6 to $10 \mathrm{M}$ $\mathrm{HNO}_{3}$ for laboratory-prepared silica gel, unfired Vycor, and commercial silica gel, respectively. In batch countercurrent experiments, 30\% tributyl phosphate extracted about $90 \%$ of the $\mathrm{Pa}^{233}$ with the thorium and uranium from $\left.5 \mathrm{M} \mathrm{HNO}_{3^{-1}} \mathrm{MAl} \mathrm{AlNO}_{3}\right)_{3}$ solutions. The decontamination factor from ruthenium, rare earths, and zirconium-niobium was $70,10^{5}$, and 2 , respectively.

\section{INTRODUCTION}

In present processes for the recovery of fissile material from thorium breeder reactor fuels, protactinium is either allowed to decay to $U^{233}$ prior to processing or relegated to a waste stream which may be later processed to recover the $U^{233}$. Therefore, a significant cost reduction could be effected by recovering the protactinium from short-cooled fuel either prior to or simultaneously with the thorium and uranium. Two methods are being

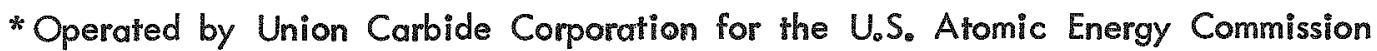


investigated for this purpose. Protactinium may be preferentially adsorbed on unfired Vycor or silica gel, or the uranium, thorium, and protactinium may be simultaneously extracted with 30\% tributyl phosphate (TBP). Although major emphases has been on the adsorption of protactinium on unfired $V y c o r$, laboratory experiments with simulated feed solutions have indicated satisfactory separation of products from the high-cross-section fission products by both of these methods, but neither method has been sufficiently investigated that it may be recommended for processing actual reactor fuels.

Throughout this investigation, solutions simulating those which would be produced in the Acid Thorex processing ${ }^{1}$ of Consolidated Edison Thorium Reactor fuel have been used as examples of solutions which would be encountered in processing thorium breeder reactor fuels. This particular fuel is to be irradiated to an average of $18,000 \mathrm{Mwd} /$ metric ton in a 2-yr cycle. At the time of discharge, the fuel will contain about $66 \mathrm{~kg}$ of uranium, $1 \mathrm{~kg}$ of protactinium, and $18 \mathrm{~kg}$ of fission products per metric ton of thorium. The protactinium in the feed represents about $1.5 \%$ of the potential fissionable material and about half of the activity of the resulting process solutions.

\section{ADSORPTION OF PROTACTINIUM ON UNFIRED VYCOR GLASS}

Unfired Vycor is a leached borosilicate glass manufactured by Corning Glass Works of Corning, New York. This material, which is sometimes referred to as "thirsty" glass, is the porous, unshrunk form of Corning's basic 7900 Vycor glass. The pores average about $4 \mathrm{m \mu}$ in diameter, and the surface area ranges from about 150 to $200 \mathrm{~m}^{2} / \mathrm{g}$. Chemically it is $96 \%$ silica, with the balance mainly boric oxide (Table 1). The successful adsorption of $\mathrm{Nb}^{95}$ on pulverized, unfired Vycor glass from zirconium nitrate-nitric acid solutions containing $\mathrm{Zr}-\mathrm{Nb}$ tracer ${ }^{2}$ led to the study of the adsorption properties of this glass for protactinium from nitrate solutions. Other workers had shown that quartz glass, plastic, and metal surfaces will adsorb protactinium from nitrate solutions, 3 and that silica gel will remove protactinium from dilute 4 and $6 \mathrm{M} \mathrm{HNO}_{3} .^{5}$

Table 1. Specification of Unfired Vycor Glass No. 7930

\begin{tabular}{ll}
\hline & Physical Properties \\
Apparent dry density, $\mathrm{g} / \mathrm{cc}$ & 1.45 \\
Average pore diameter, A & 40 \\
Surface area, $\mathrm{m}^{2} / \mathrm{g}$ & $150-200$ \\
Void space, $\%$ & 28 \\
\multicolumn{2}{c}{ Approximate Composition (anhydrous) } \\
$\mathrm{SiO}_{2}, \% \quad$ & 96 \\
$\mathrm{~B}_{2} \mathrm{O}_{3} \%$ & 3 \\
$\mathrm{R}_{2} \mathrm{O}_{3} \%$ & 0.4 \\
Alkali & trace \\
Arsenic & trace \\
\hline
\end{tabular}

With Vycor, the distribution coefficient of tracer $\mathrm{Pa}^{233}$ from nitric acid solutions is dependent on the nitric acid concentration and the presence of nitrate salts in the solution. In solutions containing only nitric acid, the extraction increased with increasing nitric acid to a maximum of about 3000 in $6 \mathrm{M} \mathrm{HNO}_{3}$. In other $6 \mathrm{M}$ nitrate solutions containing 
$0.1 \mathrm{M} \mathrm{HNO}_{3}$, the coefficient ranged from 2300 with aluminum nitrate to 20 with thorium nitrate. Intermediate values in descending order were obtained with sodium, ammonium, calcium, and lithium nitrate, respectively (Fig. 1). Throughout this report the term "distribution coefficient" is the ratio of the counts per minute per gram of glass to the counts per minute per milliliter of aqueous after contact according to the specified experimental conditions and does not necessarily imply reversibility or equilibria data. For example, the above values were obtained in 60 -min batch contacts of nitrate solutions containing about $5 \times 10^{5}$ counts $\mathrm{min}^{-1} \mathrm{ml}^{-1}$ of $\mathrm{Pa}^{233}$ with $10 \mathrm{~g}$ of 100 - to 200 -mesh unfired $V y$ cor per liter of solution.

Similar batch experiments showed that the distribution of protactinium between unfired Vycor and thorium nitrate-nitric acid solutions was dependent on the nitric acid concentration of the solutions. Solutions containing $0.1 \mathrm{M} \mathrm{HNO}_{3}$ required only about $0.03 \mathrm{M}$ $\mathrm{Th}\left(\mathrm{NO}_{3}\right)_{4}$ to decrease the coefficient by a factor of 2 , whereas $2 \mathrm{M} \mathrm{HNO}_{3}$ solutions $\overline{r e}-$ quired about $0.3 \mathrm{M}$ Th to produce the same effect. After this initial decrease, the effect of additional thorium was approximately the same for both acidities (Fig. 2).

For a contact time equal to or less than $300 \mathrm{~min}$, a decrease in the particle size of $\checkmark y c o r$ increased the extraction of protactinium from nitric acid. A series of batch equilibrations was made by contacting $10 \mathrm{~g}$ of unfired $V y$ cor per liter of $6.1 \mathrm{M} \mathrm{HNO}_{3}$ containing about $9 \times 10^{5}$ counts $\mathrm{min}^{-1} \mathrm{ml}^{-1}$ of $\mathrm{Pa}^{233}$ for 5 to $300 \mathrm{~min}$. The resulting distribution coefficient increased as the contact time increased, or the particle size decreased (Fig. 3).

In the separation and recovery of protactinium from short-decayed thorium fuel dissolved in nitric acid, a major apprehension has been the stability of the thorium-protactiniumnitrate solutions that would be encountered. Accordingly, stable solutions have been prepared in order to simulate those that would be produced in Acid Thorex processing ' of short-cooled 18,000 Mwd/metric ton of Th Consolidated Edison Thorium Reactor fuel. Also, a synthetic dissolver solution equivalent to one that would be obtained in the dissolution of about 10-day-cooled fuel was prepared containing $116 \mathrm{~g} \mathrm{Th} /$ liter, about $70 \mathrm{mg} \mathrm{Pa} 231 / \mathrm{liter}$, $11 \mathrm{M} \mathrm{HNO}_{3}, 0.1 \mathrm{M} \mathrm{Al}$, and 0.03-0.1 M F. In addition, a solvent extraction feed solution having more than twice the maximum concentration of protactinium obtainable with freshly discharged fuel, was made; it contained $40 \mathrm{~g} \mathrm{Th} /$ liter, $90 \mathrm{mg} \mathrm{Pa} 231 /$ liter, $5 \mathrm{M} \mathrm{HNO}$, $1 \mathrm{M} \mathrm{Al}$, and 0.03-0.1 M F. Then, these solutions were allowed to stand one month at room temperature in plastic containers and were analyzed periodically for protactinium. There was no change other than a $\pm 10 \%$ scatter in the analytical values over the entire period. Furthermore, these solutions showed no change in protactinium concentrations after contacting type 347 stainless steel surfaces, with and without welds, for one week at room temperature. The protactinium in these solutions is less than the concentration at which protactinium chemistry has been found to vary with concentration in highly acidic solutions. 6

Protactinium has been successfully recovered from such synthetic Consolidated Edison fuel solutions by adsorption on columns containing $V y c o r$ followed by elution with oxalic acid. A column $1 \mathrm{~cm}$ in diameter and $8.64 \mathrm{~cm}$ long containing $5 \mathrm{~g}$ of 80 to 100 mesh unfired Vycor, adsorbed $7.8 \mathrm{mg} \mathrm{Pa} 231 / \mathrm{g}$ of glass from a solution containing $0.5 \mathrm{M}$ Th, $11.1 \mathrm{M}$

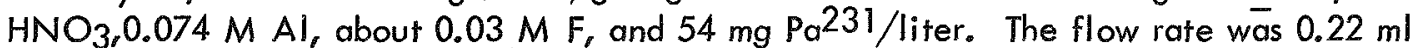
$\mathrm{cm}^{-2} \mathrm{~min}^{-1}$, and the initial Pa231 concentration in the raffinate, according to alpha pulse analyses, was equivalent to about $4 \%$ of the protactinium concentration of the feed. The protactinium concentration in the raffinate was fairly constant until the glass was loaded to about $4 \mathrm{mg} \mathrm{Pa} 231 / \mathrm{g}$, then it slowly increased to $46 \%$ of the initial feed concentration, loading the glass to $7.8 \mathrm{mg} \mathrm{Pa} 231 / \mathrm{g}$. Eighty-five percent of the protactinium was adsorbed. The column was washed with $80 \mathrm{ml}$ of $11 \mathrm{M} \mathrm{HNO}_{3}$, removing $13 \%$ of the protactinium. On eluting with $0.5 \mathrm{M}$ oxalic acid, the first $\overline{5} \mathrm{ml}$ of elutriant removed $95 \%$ of the remaining 


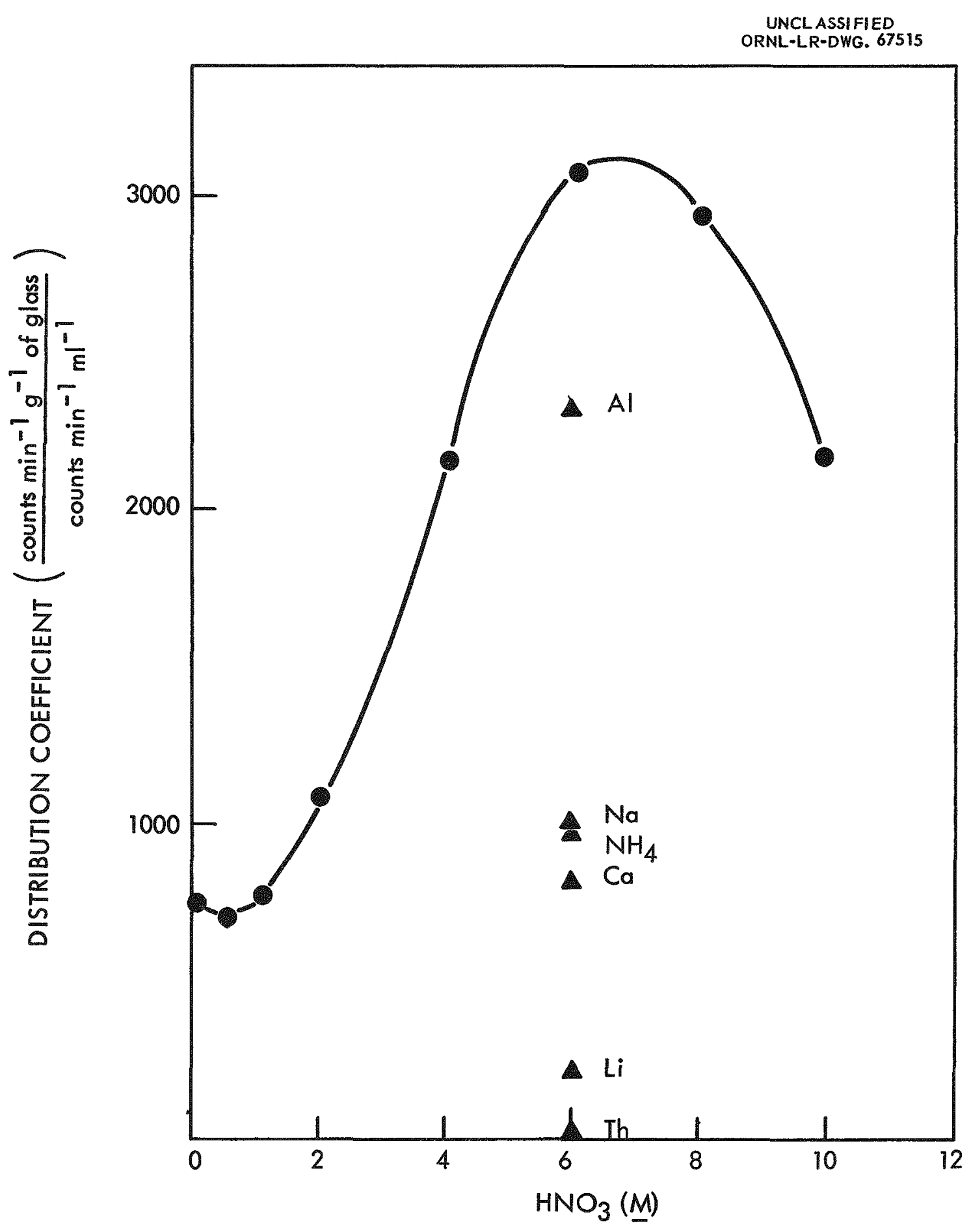

Fig. 1. Adsorption of $\mathrm{Pa}^{233}$ on 100 to 200 Mesh Unfired Vycor. 


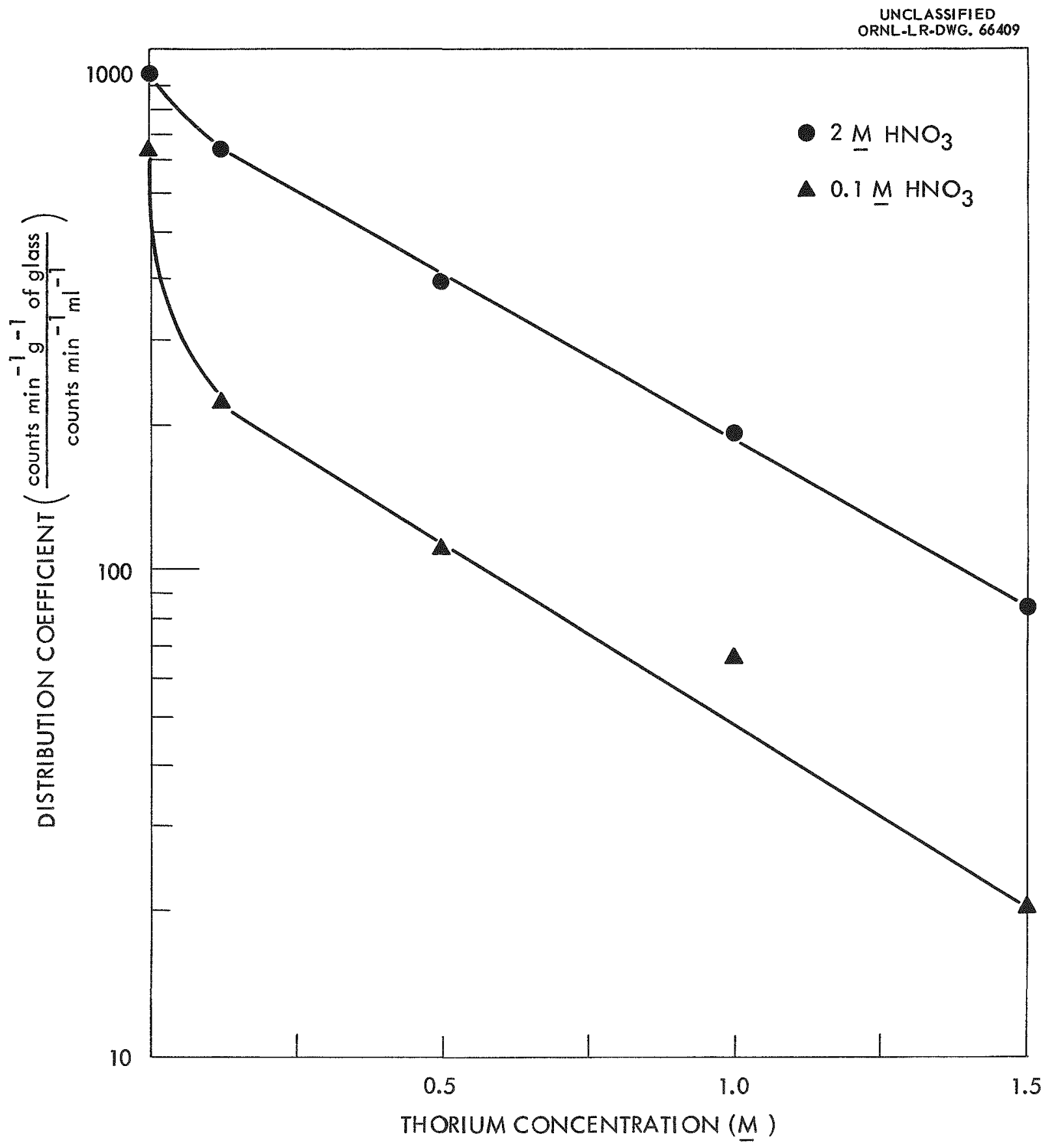

Fig. 2. Effect of Thorium Nitrate on Adsorption of $\mathrm{Pa}^{233}$ on Unfired Vycor from Nitric Acid. 


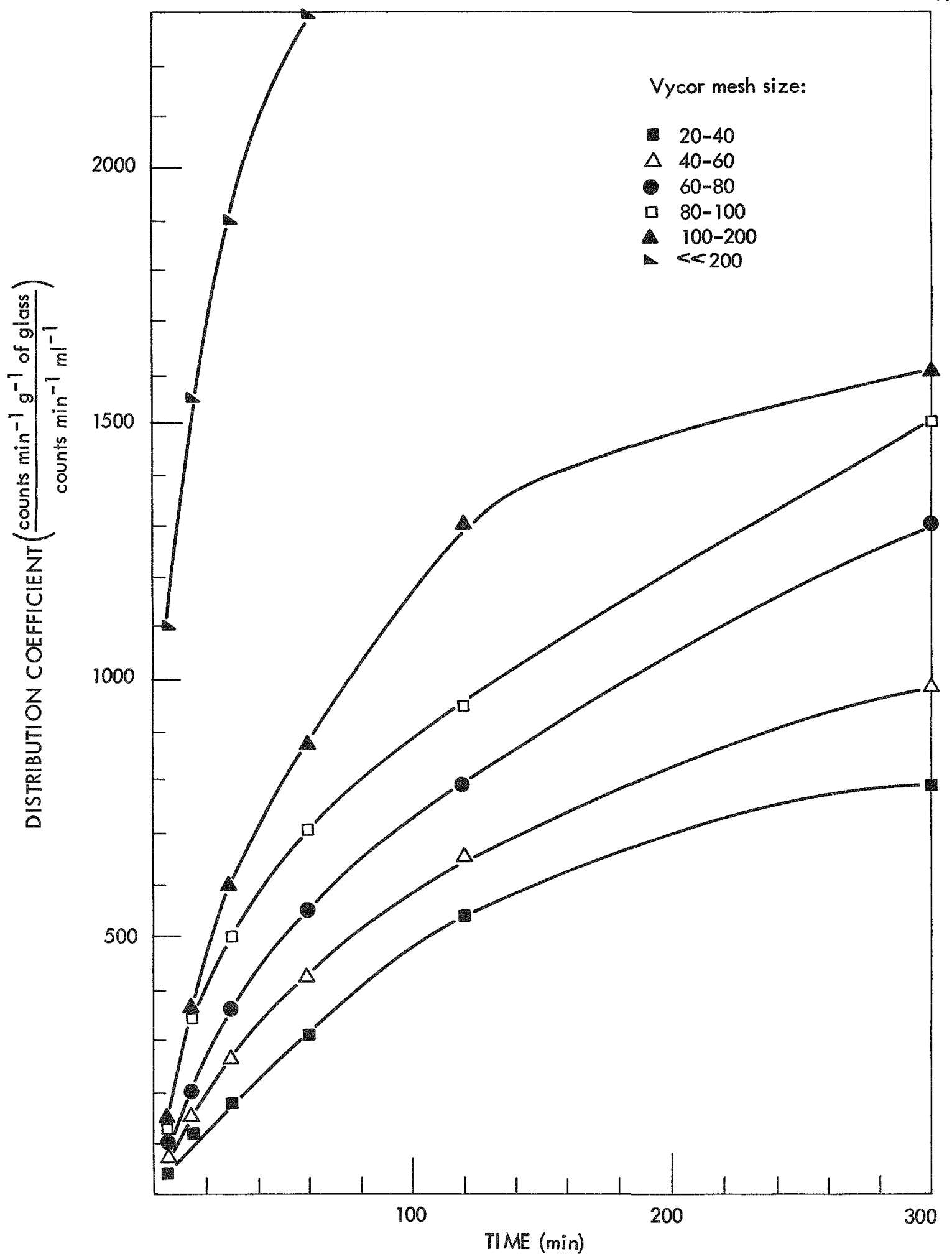

Fig. 3. Effect of Unfired Vycor Particle Size on Adsorption of $\mathrm{Pa}^{233}$ from $6 \mathrm{M} \mathrm{HNO}_{3}$ 
protactinium, yielding a solution containing $6.4 \mathrm{mg} \mathrm{Pa} 231 / \mathrm{ml}$, or about 120 times the concentration of the protactinium in the feed solution. More than $99 \%$ was removed with $30 \mathrm{ml}$ of eluant (Fig. 4). Other experiments showed that maximum loading is greater than $10 \mathrm{mg}$ $\mathrm{Pa} / \mathrm{g}$ of glass and that tartaric acid is probably as effective as oxalic acid for eluting the protactinium.

The initial protactinium breakthrough observed in the preceding experiment was due to part of the protactinium being in an unadsorbable form. This was verified by taking the first $400 \mathrm{ml}$ of the raffinate and passing it through an additional column $1 \mathrm{~cm}$ in diameter and $8.64 \mathrm{~cm}$ long. None of the protactinium adsorbed. However, more than $99 \%$ of the protactinium was initially adsorbed from a fresh feed solution prepared from the product from this run. The oxalic acid was destroyed by boiling with concentrated nitric acid. The solution was then adjusted to $0.5 \mathrm{M}$ Th, $10 \mathrm{M} \mathrm{HNO}_{3}, 0.04 \mathrm{M} \mathrm{F}, 0.1 \mathrm{M} \mathrm{Al}$, and $56 \mathrm{mg} \mathrm{Pa} 231 /$ liter and passed through a dup $\bar{i}$ icate column. At $2 \mathrm{mg} \mathrm{Pa} / \mathrm{g}$ of glass, more than $99 \%$ of the protactinium was adsorbed from the solution. At $5 \mathrm{mg} \mathrm{Pa} / \mathrm{g}$ of glass, a total of $95 \%$ of the protactinium had been adsorbed. About halfway through the run it was necessary to increase the flow rate from about $0.2 \mathrm{ml} \mathrm{cm}^{-2} \mathrm{~min}^{-1}$ to about $1.1 \mathrm{ml} \mathrm{cm}-2 \mathrm{~min}^{-1}$, and this may have caused a premature breakthrough. However the experiment did show that it is possible to achieve almost complete adsorption.

Although the optimum conditions for column operations have not been determined, decontamination factors of protactinium from thorium, uranium, ruthenium, zirconiumniobium, and total rare earths of $6 \times 10^{3}, 1.6 \times 10^{4}, 4 \times 10^{3}, 3$, and $5.8 \times 10^{5}$, respectively, were obtained in a variety of tracer experiments. These should be regarded as minimum values since no effort was made to ensure maximum decontamination through appropriate washing solutions and procedures.

The present proposal for the dissolution of Consolidated Edison Thorium Reactor fuel requires the use of $13 \mathrm{M} \mathrm{HNO}_{3}$ containing about $0.04 \mathrm{M} \mathrm{NaF}$ as a catalyst and 0.04 to $0.1 \mathrm{M} \mathrm{Al}\left(\mathrm{NO}_{3}\right)_{3}$ to decrease the rate of corrosion of plant equipment by the fluoride ions. The question immediately arises as to the effect of the fluoride on the corrosion of the finely divided unfired $V y$ cor glass, and the effect of the aluminum concentration on the adsorption of protactinium from fluoride-nitrate systems.

The corrosion of unfired Vycor by fluoride was decreased by a factor of 50 by the presence of 2.5 moles of $\mathrm{Al} /$ mole F. Solutions of $0.05 \mathrm{M} \mathrm{HF}_{1} 11 \mathrm{M} \mathrm{HNO}_{3}$ with and without $0.12 \mathrm{M} \mathrm{Al}\left(\mathrm{NO}_{3}\right)_{3}$ present were passed through columns $4 \mathrm{~mm}$ diam and $9 \mathrm{~cm}$ long containing $1 \bar{g}$ of 60 to 80 mesh unfired Vycor at a flow rate of about $1 \mathrm{ml} \mathrm{cm}^{-2} \mathrm{~min}^{-1}$. After about $200 \mathrm{ml}$ had passed through the columns, the raffinate with aluminum contained only $0.006 \mathrm{mg} \mathrm{Si} / \mathrm{ml}$, whereas the solution without aluminum contained $0.32 \mathrm{mg} \mathrm{Si} / \mathrm{ml}$.

The presence of fluoride decreased the distribution of protactinium on $V y c o r$. The distribution coefficient was about 1400 in a 24 -hr batch equilibration between $10 \mathrm{M} \mathrm{HNO}_{3}$, $6 \mathrm{~g} \mathrm{Th} /$ liter, $1.7 \times 10^{6}$ counts $\mathrm{min}^{-1} \mathrm{ml}^{-1} \mathrm{~Pa} 233$ and $20 \mathrm{~g} /$ liter of 60 to 80 mesh $\overline{V y c o r}$. This coefficient was decreased by factors of 10,100 and 1000 , respectively, when 0.01 , 0.02 , and $0.03 \mathrm{M} \mathrm{HF}$ was present. With solutions containing $112 \mathrm{~g} \mathrm{Th} /$ liter, the distribution coefficient was reduced only a factor of 3 by the presence of $0.04 \mathrm{M} \mathrm{F}$ (Fig. 5).

About 7.5 moles of aluminum per mole of fluoride were required to overcome the effect of the fluoride on the protactinium distribution from solutions containing $6 \mathrm{~g} \mathrm{Th} / \mathrm{liter}$. This molar ratio of aluminum to fluoride also produced the maximum coefficients with feed solutions containing $112 \mathrm{~g} \mathrm{Th} /$ liter and $0.04 \mathrm{M} \mathrm{F}^{-}$; however, the coefficient was still about $30 \%$ less than the value obtained without fluoride. The coefficient decreased from 1200 with no 


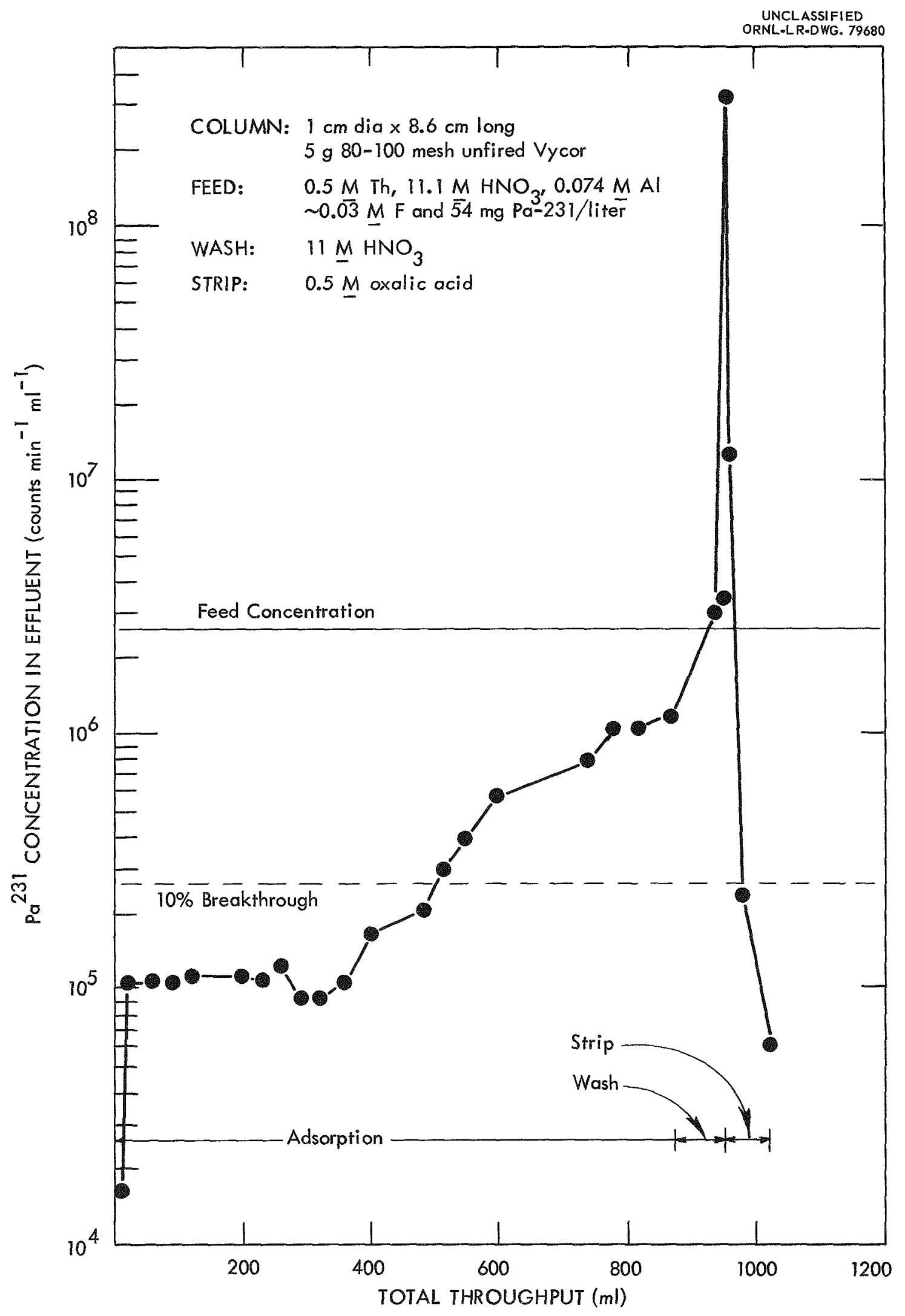

Fig. 4. Sorption of Protactinium with Unfired Vycor. 


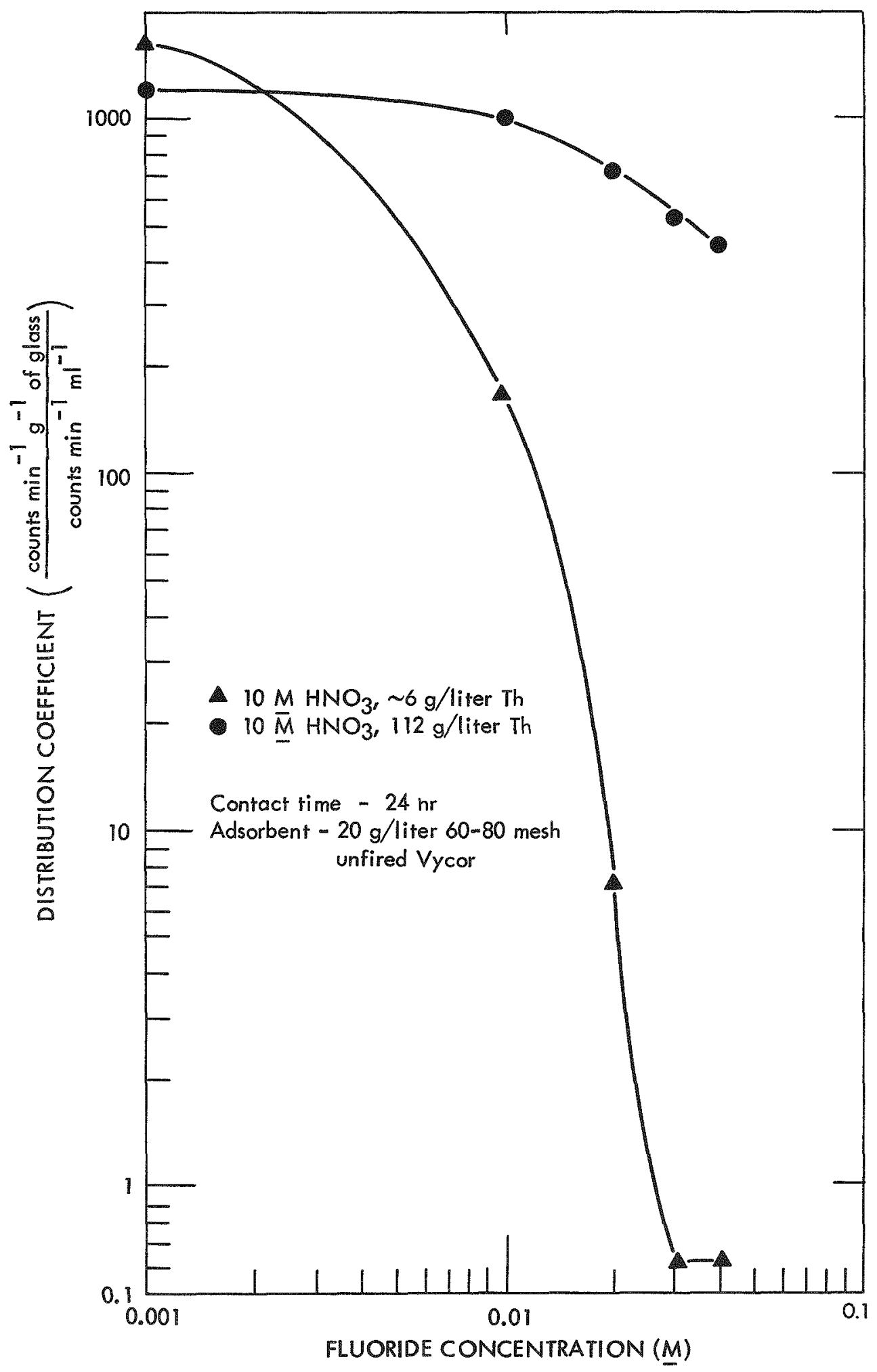

Fig. 5. Effect of Fluoride on Protactinium Adsorption. 
fluoride present to 345 with a fluoride concentration of $0.04 \mathrm{M}$. The presence of 7.5 moles of aluminum per mole of fluoride increased the coefficient to about 800 (Fig. 6).

\section{ADSORPTION OF PROTACTINIUM BY SILICA GEL}

The distribution coefficient obtained with laboratory-prepared silica gel was about 3 times the coefficient obtained with unfired Vycor and more than 5 times the value obtained with commercial silica gel. These results were obtained by contacting $0.3 \mathrm{~g}$ of 20 to 40 mesh adsorbent for $1 \mathrm{hr}$ with $30 \mathrm{ml}$ of nitric acid solution containing about $5 \times 10^{5}$ counts $\mathrm{min}^{-1} \mathrm{ml}^{-1}$ of $\mathrm{Pa} 233$ (Fig. 7).

Large differences were observed in the surface area, hydroxyl content, and sodium content of the adsorbents. The surface area of commercial silica gel was about 3 times that of the laboratory prepared silica gel or unfired Vycor. The hydroxyl and sodium content, however, were much lower in the commercial gel than in the laboratory prepared material (Table 2).

Table 2. Pertinent Physical and Chemical Properties of Vycor and Silica Gels

\begin{tabular}{lccc}
\hline Adsorbent, 20-40 mesh & $\begin{array}{c}\text { Surface Area } \\
\left(\mathrm{m}^{2} / \mathrm{g}\right)\end{array}$ & $\begin{array}{c}\mathrm{OH}^{-} \\
(\mathrm{Meq} / \mathrm{g})\end{array}$ & $\begin{array}{c}\mathrm{Na} \\
(\mathrm{W}+\%)\end{array}$ \\
\hline Unfired Vycor glass & 144.2 & -- &.-- \\
Laboratory-prepared silica gel & 196.0 & 0.12 & 0.55 \\
Commercial silica gel & 567.5 & 0.005 & 0.07 \\
\hline
\end{tabular}

The capacity of the laboratory prepared gel was higher than that of the commercial material. On passing a solution containing $116 \mathrm{~g} / \mathrm{liter} \mathrm{Th}, 70 \mathrm{mg} \mathrm{Pa} 231 /$ iter, $11 \mathrm{M} \mathrm{HNO}$, $0.1 \mathrm{M} \mathrm{Al}$, and a trace of fluoride through a column $0.4 \mathrm{~cm}$ in diameter and $14 \mathrm{~cm}$ Tong containing $1 \mathrm{~g}$ of 20 to 40 mesh silica gel, $95 \%$ of the protactinium was adsorbed. This was equal to a loading of about $3 \mathrm{mg} / \mathrm{g}$ (Fig. 8). Under similar conditions, $1 \mathrm{~g}$ of commercial silica gel removed only $57 \%$ of the protactinium. The amount adsorbed on the commercial gel ranged from $88 \%$ at the beginning of the run to $48 \%$ at the end. About $1.9 \mathrm{mg} \mathrm{Pa} / \mathrm{g}$ of silica gel was adsorbed (Fig. 9). In both experiments the flow rate was about $1 \mathrm{ml} \mathrm{cm}-2 \mathrm{~min}^{-1}$, and the columns were eluted easily with $0.5 \mathrm{M}$ oxalic acid. These data indicate that laboratory-prepared silica gel is at least as good an adsorbent as $V y c o r$ for adsorbing protactinium. However, due to its commercial availability, the major emphasis of the initial part of this program has been on the use of Vycor.

\section{COEXTRACTION OF URANIUM, THORIUM, AND PROTACTINIUM WITH TRIBUTYL PHOSPHATE (TBP)}

The extraction of protactinium nitrate with TBP has been extensively studied at Harwell, ${ }^{5} \mathrm{ORNL}^{4}$ and other laboratories. The data were used to design a coextraction flowsheet (Fig. 10) for high-burnup thorium breeder fuels. Since the recycled thorium from such fuels must be processed in shielded equipment because of the rapid growth of the U232 and $T^{228}$ daughters, it will only be necessary to separate the uranium, thorium, and protactinium from the high-cross-section fission products prior to recycling. 


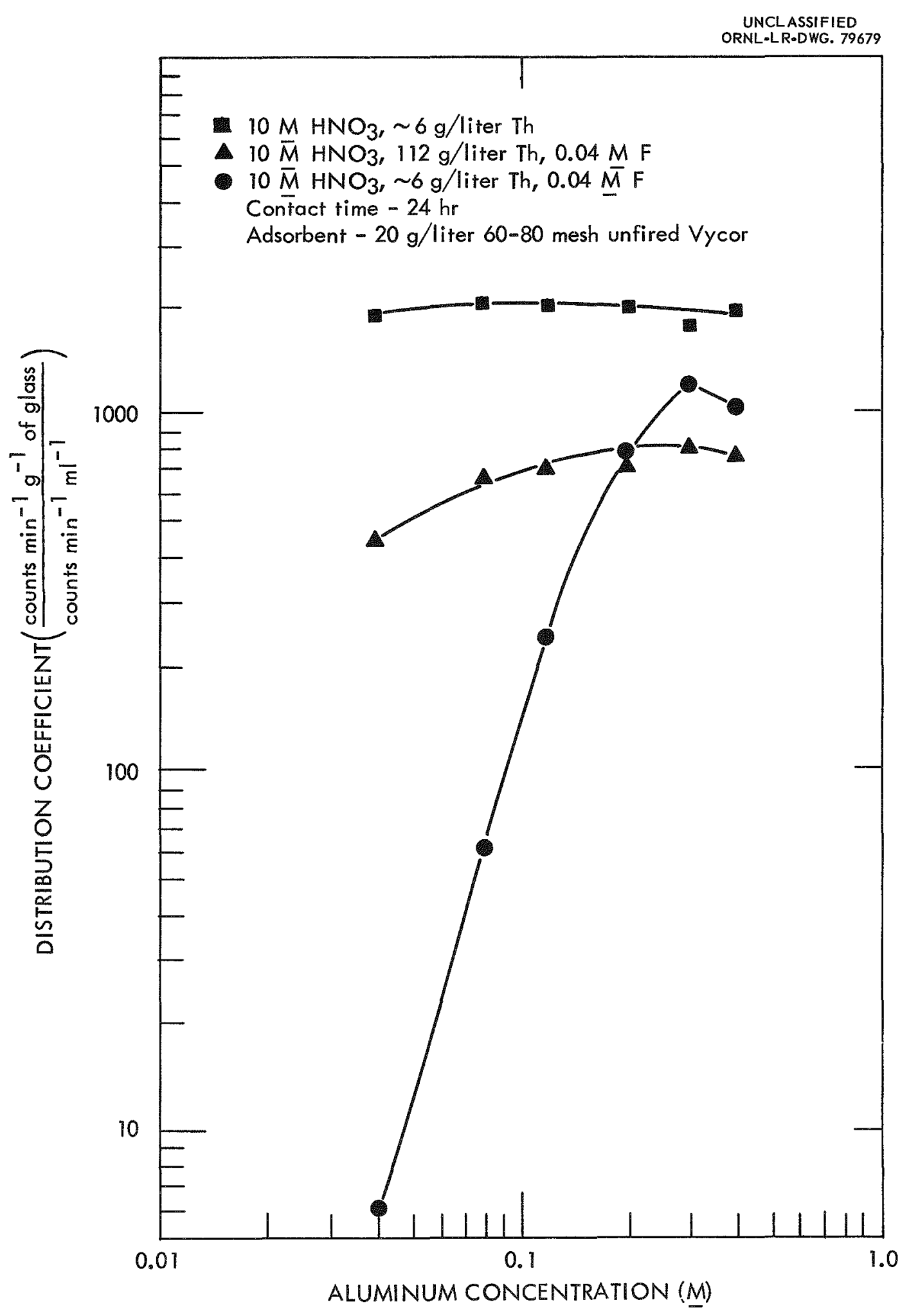

Fig. 6. Effect of Fluoride and Aluminum on Protactinium Adsorption. 


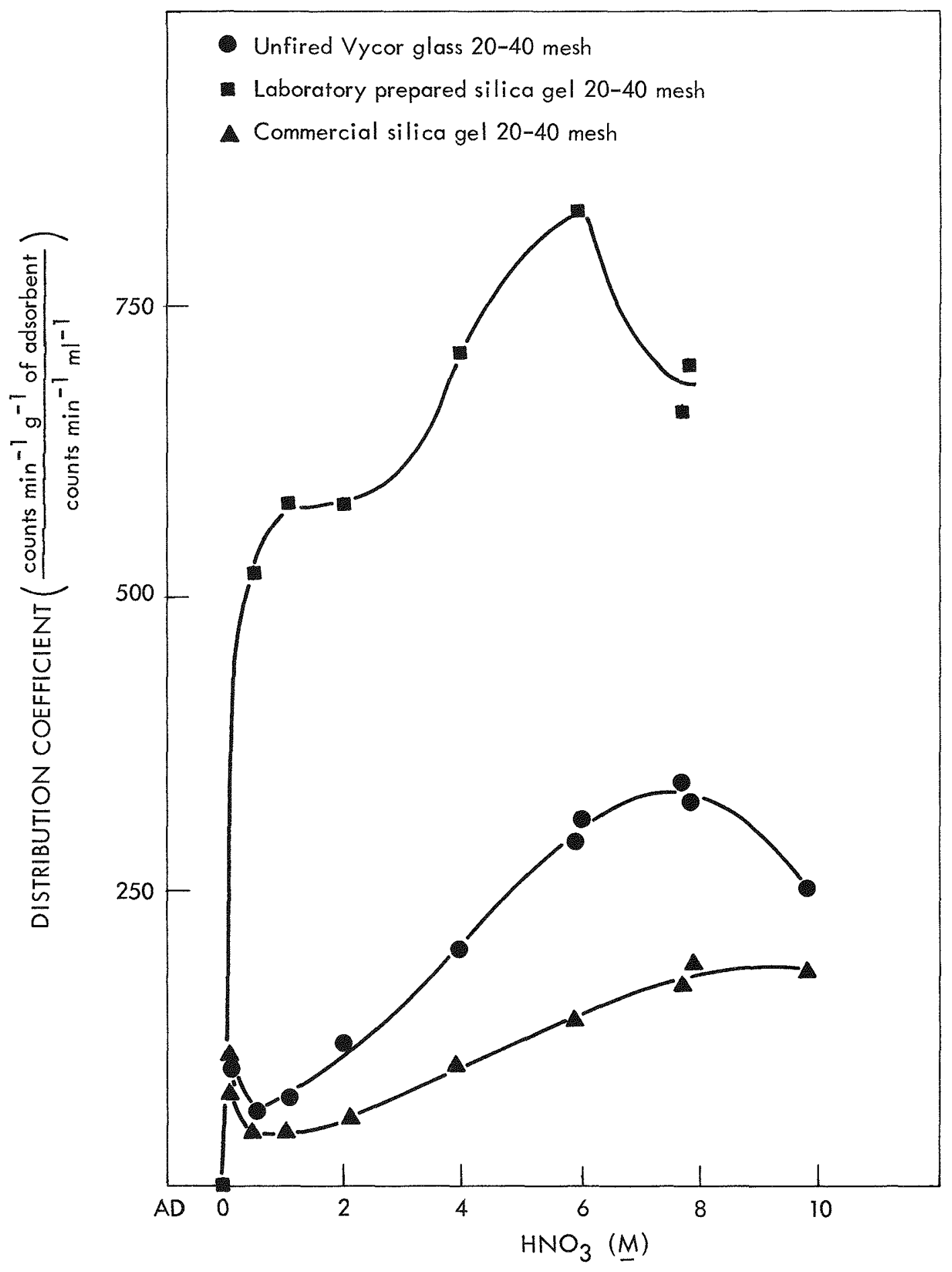

Fig. 7. Adsorption of Protactinium ${ }^{233}$ from Nitric Acid. 


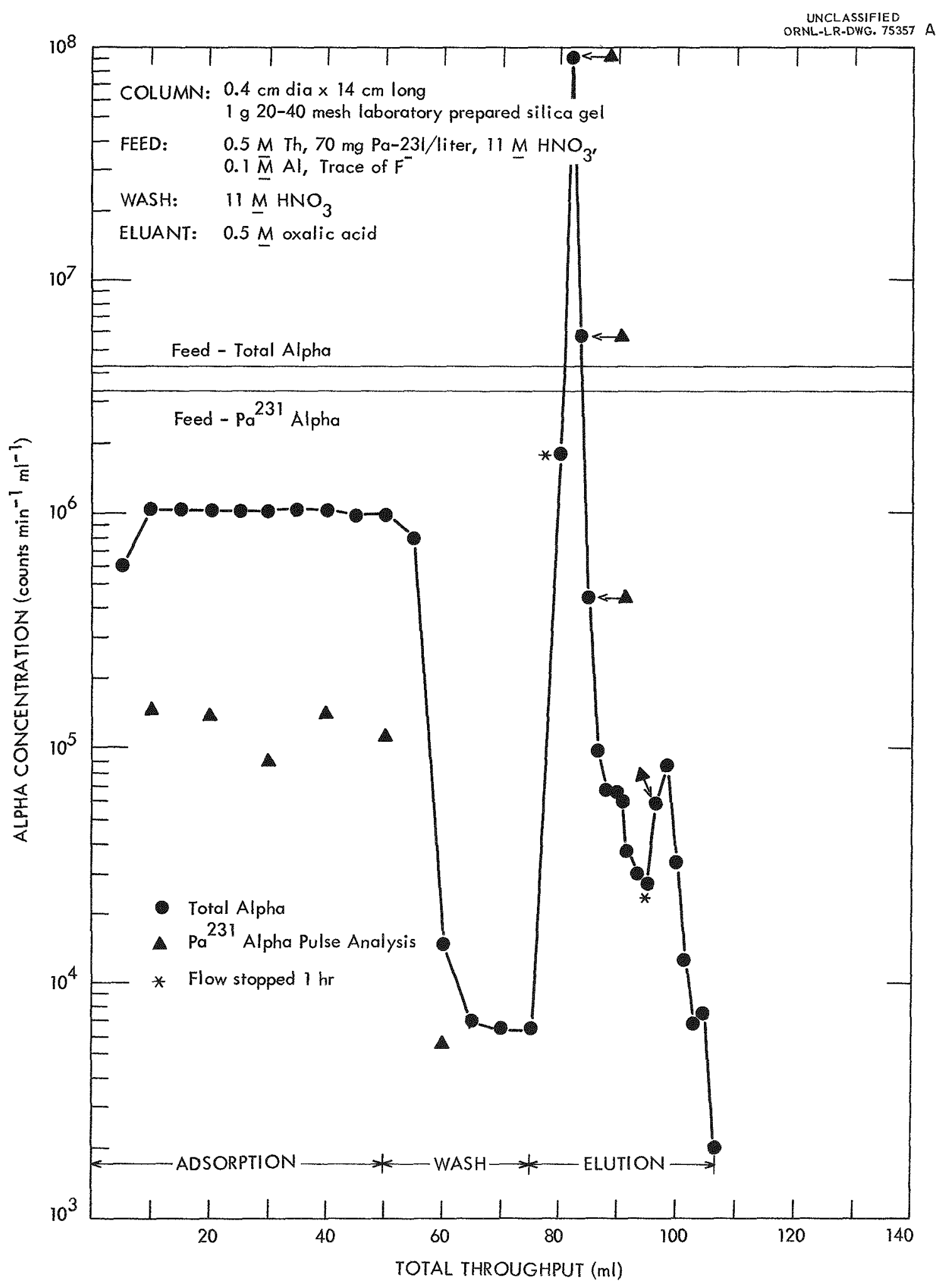

Fig. 8. Sorption of Protactinium with Laboratory-Prepared Silica Gel. 


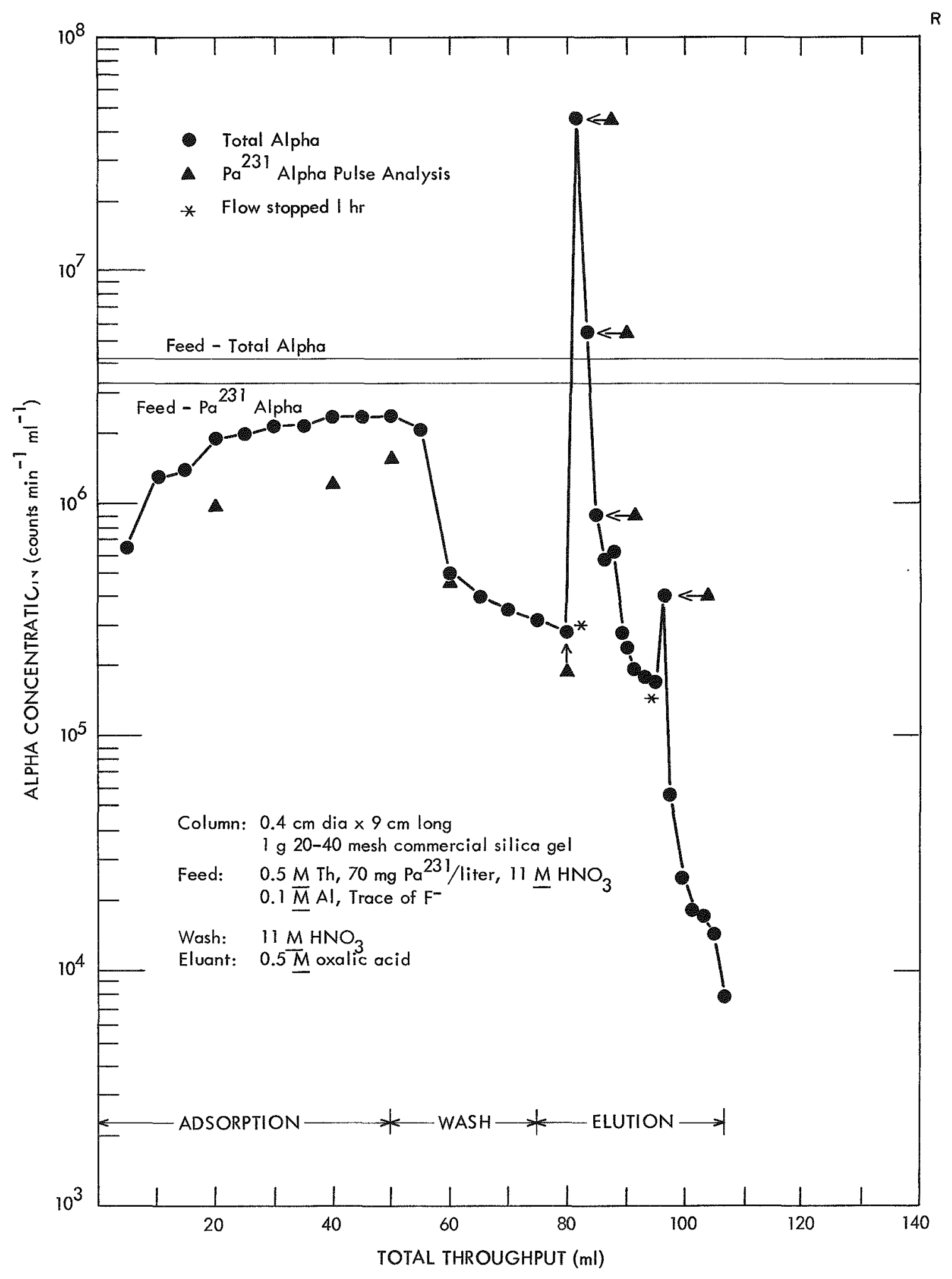

Fig. 9. Sorption of Protactinium with Commercial Silica Gel. 


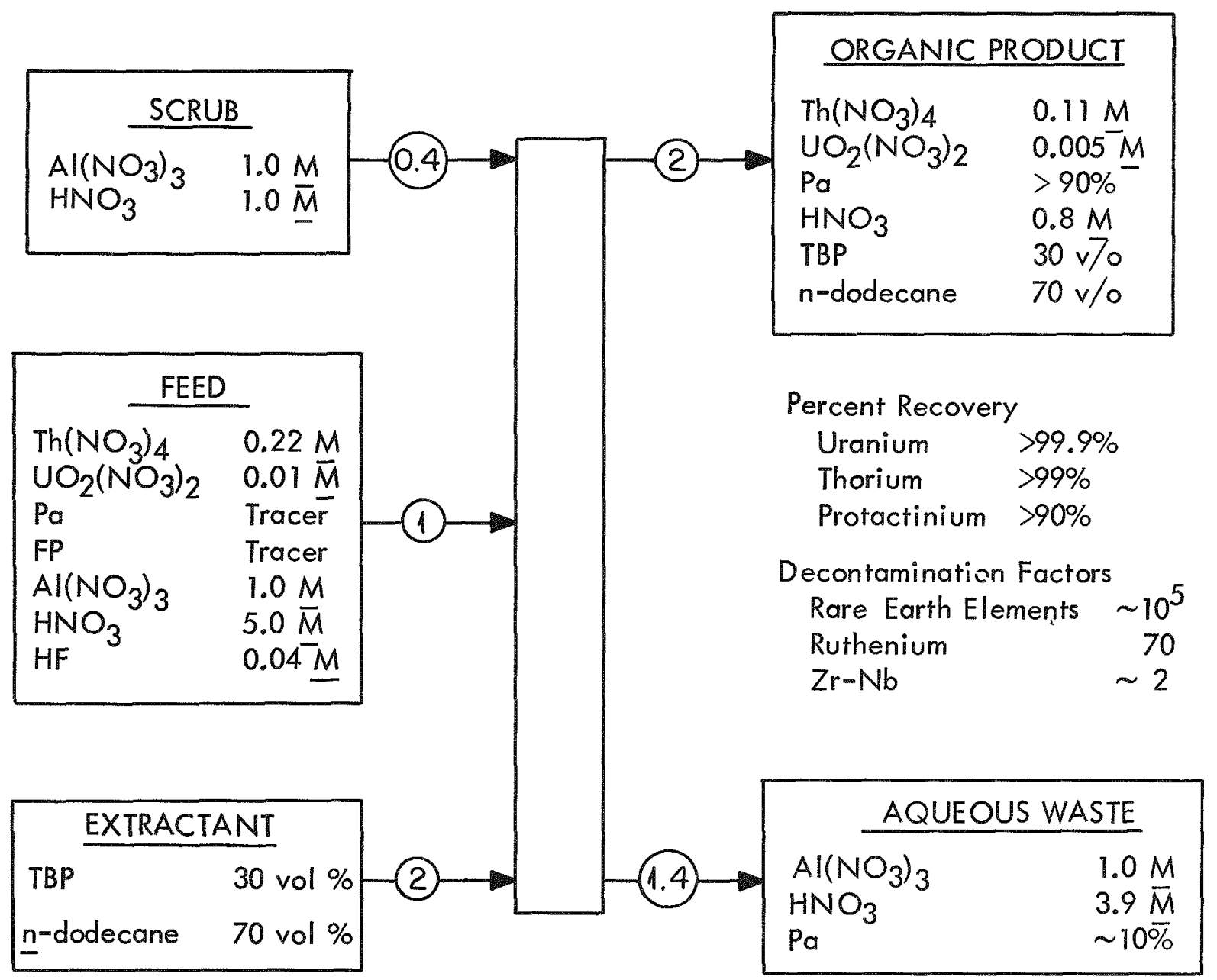

Fig. 10. Co-extraction of Uranium, Thorium, and Protactinium with Tributyl Phosphate. 
The coextraction process when tested at tracer levels of protactinium in laboratory batch countercurrent experiments resulted in the extraction of over $99 \%$ of the uranium and thorium and about $90 \%$ of the protactinium. The remaining $10 \%$ of the protactinium was essentially unextractable. Decontamination factors of 70 and about $10^{5}$ were obtained for the long half-life and high-cross-section ruthenium and rare earth elements. About half of the zirconium-niobium extracted with the product, but this would be of small concern due to their low cross sections and the 65-day half-life of $\mathrm{Zr} 95$. The principal disadvantage of this flowsheet is the large amount of aluminum in the high level aqueous waste (Fig. 10).

Of particular concern in the extraction of protactinium from thorium solutions is the complexing of the protactinium by fluoride. As previously shown, protactinium is strongly complexed by the fluoride to give a complex which is not extracted by TBP 5 or adsorbed by $V y c o r$. As indicated by multiple extraction and Martin-technique ${ }^{7}$ experiments, $\mathrm{Pa}^{233}$ tracer is completely extractable from $5 \mathrm{M} \mathrm{HNO}_{3}$ and has a distribution coefficient of about 4 (Fig. 11). In the presence of $5 \overline{\mathrm{M}} \mathrm{HNO}_{3}$ containing $0.02 \mathrm{M} \mathrm{HF}$, about $94 \%$ of the protactinium is unextractable, and the extractable species has a distribution coefficient of about 0.07 (Fig. 12). In these experiments the amount of protactinium which is unextractable is indicated by the intercept of the extraction line with the aqueous coordinate and the distribution coefficient of the extractable species by the slope of the line.

These data demonstrate that although protactinium is unextractable in nitric-hydrofluoric acid systems, it may be readily extracted in a simulated process system containing thorium and aluminum nitrate.

\section{CONCLUSIONS}

Although there are many unanswered questions concerning the adsorption of protactinium on unfired $V y c o r$, the results of this investigation are encouraging. It was shown that Vycor will preferentially adsorb protactinium from nitrate systems and has a usable capacity of at least $5 \mathrm{mg} \mathrm{Pa} / \mathrm{g}$ glass. The protactinium may be easily eluted from the glass with oxalic acid solutions, yielding a product decontaminated from all contaminants except zirconium-niobium by factors greater than $10^{3}$.

Since all experiments were made with simulated feed solutions, the amount of adsorbable protactinium that would be in solution under actual fuel processing conditions is unknown. Future plans call for small column experiments with high-burnup short-cooled thorium solutions, which should define better the process potentialities as well as limitations. In addition, laboratory work will continue on column conditions necessary for maximum effect, and the adsorption properties of Vycor and silica gel for protactinium from other acidic solutions will be investigated.

The countercurrent batch extraction experiments with TBP show that in the presence of thorium and a large excess of aluminum, protactinium can be satisfactorily extracted. Laboratory experiments are continuing to determine the minimum amount of aluminum that will be required for the process. 


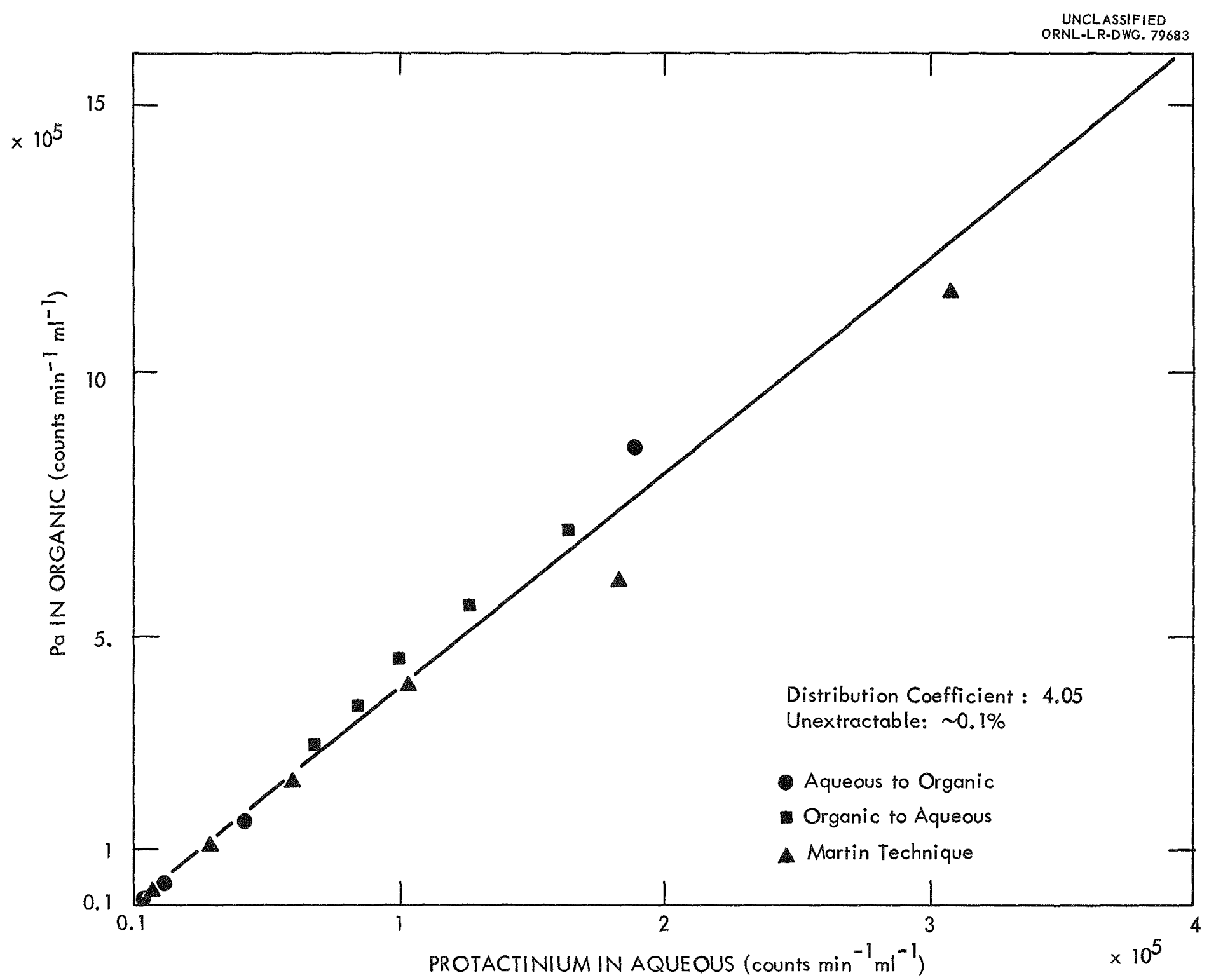

Fig. 11. Extraction of Protactinium from $5 \mathrm{M} \mathrm{HNO}_{3}$ with $30 \mathrm{v} / 0$ Tributyl Phosphate in n-dodecane. 


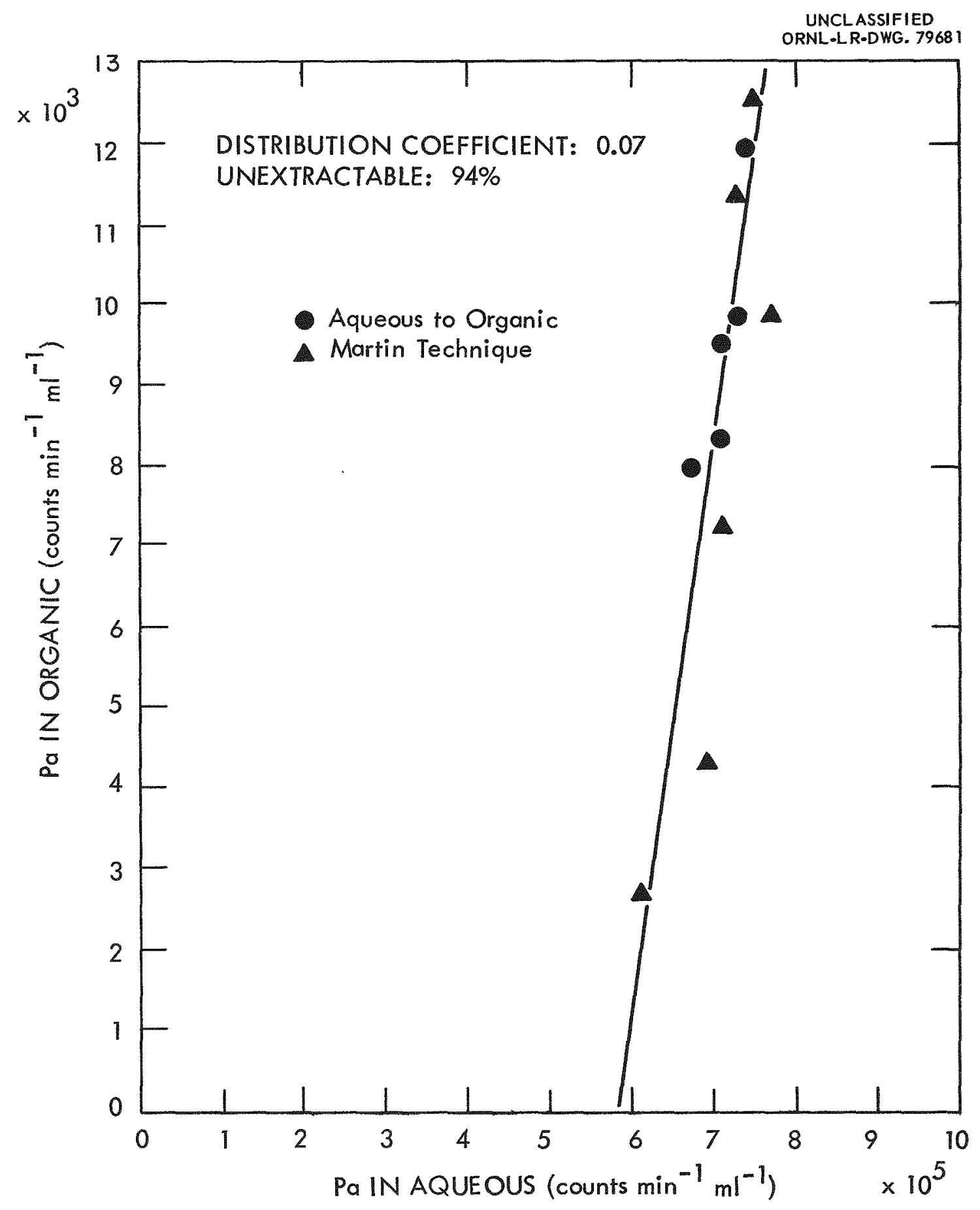

Fig. 12. Extraction of Protactinium from $5 \mathrm{~N} \mathrm{HNO} 3$ Containing $0.02 \mathrm{~N} \mathrm{HF}$ with

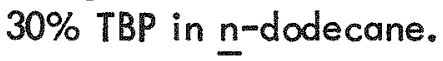




\section{REFERENCES}

1. R. H. Rainey and J. G. Moore, Nucl. Sci. and Eng. 10, 367-71 (1961).

2. J. G. Moore, J. Inorg. Nucl. Chem. 20, 166-67 (1961).

3. 1. E. Starik, L. D. Sheydina, and L. I. IImenkova, Radiokhimia, 4, Issue 1, 44-49 (1962).

4. A. T. Gresky, in Proc. U.N. Intern. Conf. Peaceful Uses At. Energy, 1st Geneva, 1956, Vol 8, p 540.

5. C. J. Hardy, D. Scargill, and J. M. Fletcher, J. Inorg. Nucl. Chem. 7, 257-75 (1958).

6. C. J. Hardy, D. Scargill, Protactinium Species in TBP-Nitric Acid Systems, this symposium.

7. F. S. Martin and G. M. Gillies, The Chemistry of Ruthenium. 1. The Formation and Examination of an Extractable Ruthenium Nitrate in Macroscopic Amounts, AERE-C/R$816(1951)$. 


\section{PROTACTINIUM STABILITY IN THORIUM NITRATE-NITRIC \\ ACID SOLUTIONS \\ C. J. Barton, D. R. Cuneo, M. J. Kelly, and J. E. Strain \\ Reactor Chemistry Division \\ Oak Ridge National Laboratory \\ Oak Ridge, Tennessee}

\section{INTRODUCTION}

A study reported by Lindsey ${ }^{I}$ indicated that thorium nitrate solutions would be attractive for use as a breeder blanket in an aqueous two-region homogeneous reactor if the $\mathrm{N}^{15}$ isotope could be produced at a cost below $\$ 1.25$ per gram. The temperature of hydrolytic precipitation of thorium nitrate and thorium nitratenitric acid solutions has been determined by Marshall et al, ${ }^{2}$ and by Jones and Sowden. ${ }^{3}$ Data reported by the latter investigators showed that a fairly high concentration of nitric acid would be required to prevent hydrolysis of thorium nitrate at temperatures in the proposed operating range of the aqueous homogeneous reactor $\left(280-300^{\circ} \mathrm{C}\right)$. Consequently, Lindsey ${ }^{l}$ suggested that $175^{\circ} \mathrm{C}$ would be a suitable operating temperature for a thorium nitrate-nitric acid breeder blanket solution but he had no information concerning the hydrolytic behavior of protactinium in such solutions. This paper describes the apparatus and procedures used in an exploratory study of the stability of protactinium in thorium nitrate-nitric acid solutions and gives the results obtained. 


\section{EXPERIMENTAL}

\section{Apparatus}

Two experimental arrangements were used in this study which differed mainly in the heating and temperature measuring methods employed. A drawing illustrating the arrangement used in the first tests is shown in Figure 1. The sintered stainless steel filter was employed to remove suspended material from solution samples withdrawn through the valve. The U-shaped capillary tube connecting the bomb and filter units had an I.D. of either 6 or 20 mils, while 6 -mil tubing connected the filter unit to the valve. The bomb and filter were surrounded by a powdered heating medium to minimize the likelihood of dispersion of protactiniumcontaining solution from the high-pressure system in the event of a leak. It was recognized that temperature measurements in such a system by means of a thermometer would not be very accurate but several experiments with this arrangement were made before the magnitude of the temperature gradient in the heating bed was noted. This observation led to the fabrication of the arrangement shown schematically in Figure 2. The furnace was found to have a small temperature gradient within the region occupied by the bomb and filter.

Procedures

Thorium nitrate-nitric acid solutions containing $\mathrm{pa}^{231}$ and $\mathrm{Pa}^{233}$, the latter added as a tracer, were prepared as follows: Several hundred milligrams of solid $\mathrm{Th}\left(\mathrm{NO}_{3}\right) \cdot 4 \mathrm{H}_{2} \mathrm{O}$ were irradiated in the Oak Ridge Research Reactor for about two minutes to produce $\mathrm{Pa}^{233}$. After decaying overnight $\left(\mathrm{Th}^{233} \underset{\mathrm{t} \frac{1}{\bar{z}}=23.5 \mathrm{~m}}{\longrightarrow} \mathrm{Pa}^{233}\right)$ the 


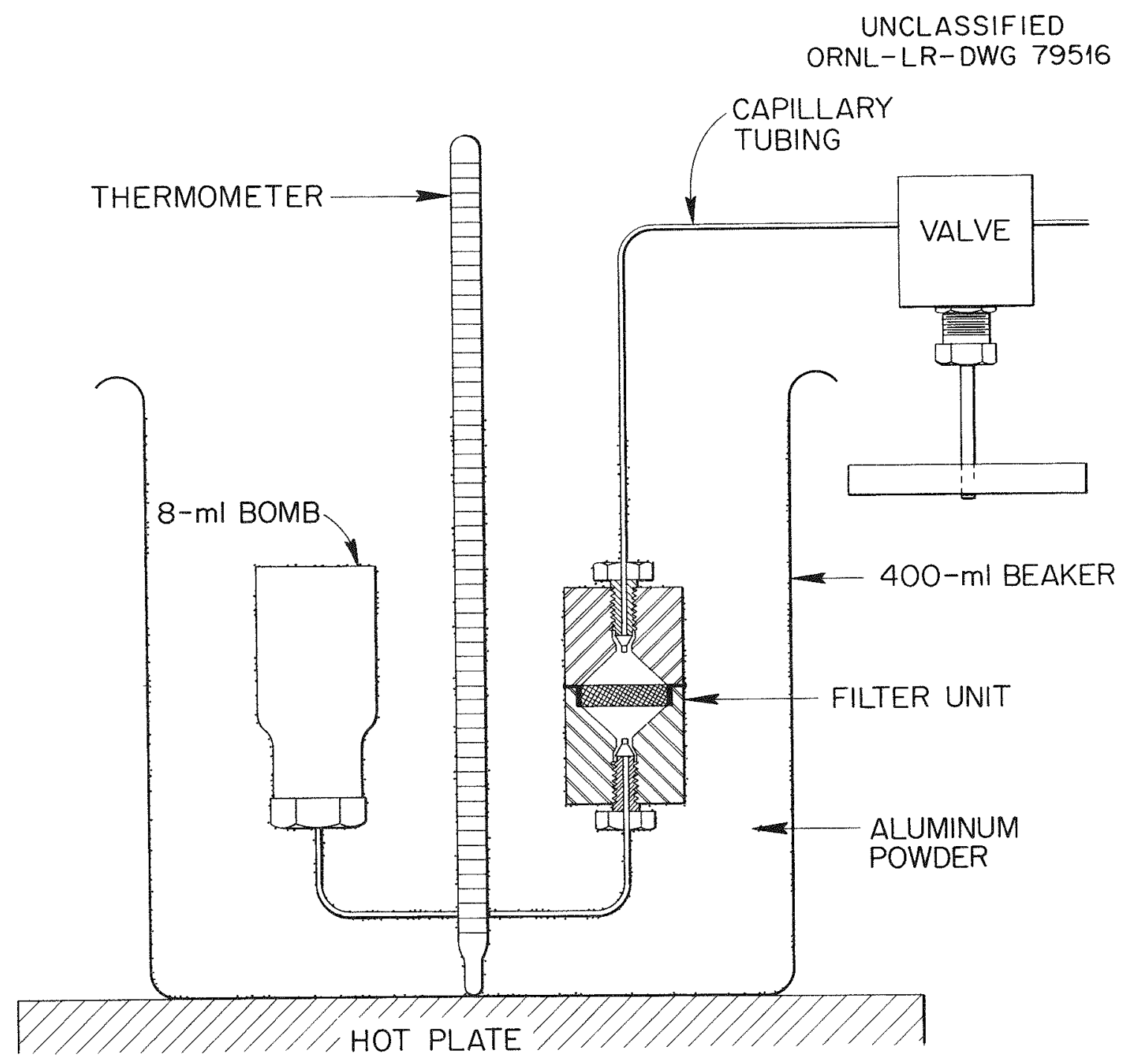

Fig. 1. High-Tenperature Equilipration and Sampling Apparatus 

irradiated material was dissolved in $9 \mathrm{~N} \mathrm{H}_{2} \mathrm{SO}_{4}-6 \mathrm{~N} \mathrm{HCl}$, as recommended by Kirby, ${ }^{4}$ and extracted with a mixture of diisobuty 1 carbinol (DIBC) and xylene (63-37, by volume). The organic layer containing $\mathrm{Pa}^{233}$ was washed twice with $9 \mathrm{~N} \mathrm{H}_{2} \mathrm{SO}_{4}-6 \mathrm{~N} \mathrm{HCl}$ solution and then transferred to a glove box where it was contacted with an aqueous solution containing $\mathrm{Pa}^{231}$ and its daughter products, providing a mixture of $\mathrm{Pa}^{231}$ and $\mathrm{Pa}^{233}$ in DIBC. After washing with $9 \mathrm{~N} \mathrm{H}_{2} \mathrm{SO}_{4}-6 \mathrm{~N} \mathrm{HCl}$, a portion of the DIBC was removed from the glove box for alpha and gamma counts which established a ratio between the $\mathrm{Pa}^{231}$ content of the mixture and the $\gamma$-count produced by the $\mathrm{Pa}^{23}$ tracer. Subsequent analyses were performed by $\gamma$-counting. No $\mathrm{Pa}^{211}$ daughter products could be detected by an $\alpha$-pulse height analysis of a DIBC extract. The $\mathrm{Pa}^{231}-\mathrm{Pa}^{233}$ solution used in each experiment was thus "standardized" by use of this procedure.

The protactinium was washed out of the DIBC by contacting it with a dilute $\mathrm{HNO}_{3}$ solution containing a trace of fluoride ion (or, in Experiment 5, oxalic acid) to complex the protactinium in order to prevent it from hydrolyzing. The protactinium was then precipitated, along with a small amount of thorium carrier, by addition of $\mathrm{NH}_{4} \mathrm{OH}$ and separated from the supernatant liquid by centrifuging and decanting. The precipitate was washed with distilled water, followed by centrifuging and decanting again. The precipitate was dissolved in $4 \mathrm{mI}$ of a Th( $\left(\mathrm{NO}_{3}\right)_{4}-\mathrm{HNO}_{3}$ mixture of the desired composition and an aliquot of the solution was removed for a gamma count of the $\mathrm{Pa}^{233}$ to determine its $\mathrm{Pa}^{231}$ content before transferring the solution to the $8-\mathrm{ml}$ bomb. 
The bomb was connected to the filter' unit and the filter unit to a valve, as shown in Figures 1 and 2, and the assembly was carefully leak-tested by filling it with oxygen at a pressure of approximately $10001 \mathrm{bs} / \mathrm{in}^{2}$ and applying a soap solution around all the joints. After leaks were eliminated, the system was filled with oxygen to a pressure of $6001 \mathrm{bs} / \mathrm{in}^{2}$ at room temperature. The assembly was then placed in the 400-ml beaker, as shown in Figure 1 or, in Experiment 6, in the furnace arrangement shown in Figure 2. Aliquots of the solution in the bomb were withdrawn at intervals for analysis after first flushing the line with a small amount of solution. In addition to gamma counting of the $\mathrm{Pa}^{233}$ to determine the $\mathrm{Pa}^{231}$ content, in one experiment the thorium concentration and the total nitrate content of the aliquots were also determined.

In Experiments 5 and 6, 1/8" lengths of Zircaloy-2 rod, 0.093 inch diameter, were added to the solution in the bomb to simulate the structural material used in the HRT to separate the fuel solution from the blanket. An oxide coating was produced on part of the rods by heating them in air but the weight increase indicated that the coatings were quite thin.

\section{RESULTS AND DISCUSSION}

Very poor temperature control of the solution temperature in the first experiment, resulting in part from the use of sand as the heating medium, resulted in precipitation of a large part of the thorium content of the $2 \mathrm{M} \mathrm{Th}\left(\mathrm{NO}_{3}\right)_{4}-3 \mathrm{M} \mathrm{HNO}_{3}$ solution at a temperature above $200^{\circ} \mathrm{C}$. The $\mathrm{Pa}^{231}$ concentration of this solution, 
which was $5.3 \mathrm{ppm}$ initially, dropped to $2.4 \mathrm{ppm}$ after standing in the bomb at room temperature for 17 hours. A further decrease in $\mathrm{Pa}$ content of the solution, to $0.7 \mathrm{ppm}$, was noted after about two hours at the maximum temperature and the final concentration, after a total residence time in the bomb of 41 hours, with 24 hours at 125 to $>200^{\circ} \mathrm{C}$, was only $0.2 \mathrm{ppm}$. This experiment demonstrated that precipitation of a significant fraction of the thorium content of a solution of this type will remove most of the protactinium. Results obtained in five additional experiments are recorded in Table I. Powdered aluminum was used as the heat transfer medium, as shown in Figure 1, in Experiments 2, 3, 4, and the early part of Experiment 5. Mercury replaced the aluminum during the last 24 hours of Experiment 5, permitting better control of the solution temperature and more accurate temperature measurement. The improved heating and temperature measuring arrangement shown in Figure 2 was employed only in Experiment 6 . Temperatures recorded in Table I for the period in which powdered aluminum was the heat transfer medium are estimates based on the temperature indicated by the thermometer at the bottom of the beaker and the observed temperature gradient. The estimated temperatures may be in error by as much as 10 or $15^{\circ} \mathrm{C}$. During the latter part of Experiment 5 and in Experiment 6, the error in measuring solution temperatures was probably less than $5^{\circ} \mathrm{C}$. This fact, plus the presence of Zircaloy in contact with the solutions, caused the last two experiments to be considered more significant than the others in the series. 
The data in Table I indicate that solutions containing $2 \mathrm{M}$ $\mathrm{Th}\left(\mathrm{NO}_{3}\right)_{4}$ and $3 \mathrm{M} \mathrm{HNO}$ can be heated for many hours in contact with stainless steel surfaces at temperatures as high as about $150^{\circ} \mathrm{C}$ without precipitating protactinium from solution. This also seems to be true for solutions containing $2.5 \mathrm{M} \mathrm{Th}\left(\mathrm{NO}_{3}\right)_{4}$ and $0.5 \mathrm{M} \mathrm{HNO}_{3}$ at temperatures up to approximately $160^{\circ} \mathrm{C}$. Solutions containing $2.5 \mathrm{M} \mathrm{Th}\left(\mathrm{NO}_{3}\right)_{4}$ plus $0.5 \mathrm{M} \mathrm{HNO}_{3}$ or $2.1 \mathrm{M} \mathrm{Th}\left(\mathrm{NO}_{3}\right)_{4}$ plus $0.2 \mathrm{M} \mathrm{HNO}$ showed a drop in protactinium concentration when heated to 175 or $180^{\circ} \mathrm{C}$ in contact with Zircaloy and stainless steel surfaces, but further heating for extended periods produced little, if any, additional change in the protactinium content of the solution. In Experiment 6 , the solution reached a maximum temperature of $210^{\circ} \mathrm{C}$ for short periods, due to a faulty temperature controller. The apparent fluctuation in protactinium concentration during the latter part of this experiment was greater than expected on the basis of previous experience with the analytical method employed for the determination and no explanation could be found for the variable results obtained during this period.

In Experiment 6 , analysis of the initial and final sample solutions showed that the thorium concentration of the solution decreased during the experiment from 2.10 to $2.06 \mathrm{M}$ while the free $\mathrm{HNO}_{3}$ concentration (total nitrate minus 4 times the Th concentration) dropped from 0.24 to $0.16 \mathrm{M}$. The 14 lengths of Zircaloy rod exposed to this solution were rinsed, dried, and $\gamma$-counted individually. There was no significant difference in protactinium content between the pre-oxidized samples and the untreated specimens. 
Table I. Stability of Protactinium in $T$ Th $\left(\mathrm{NO}_{3}\right)_{4}-\mathrm{HNO}_{3}$ Solutions at 21 to $200^{\circ} \mathrm{C}$

\begin{tabular}{|c|c|c|c|c|c|c|c|c|c|c|c|c|c|c|c|}
\hline \multicolumn{4}{|c|}{$\begin{array}{l}\text { Experiment } 2 \\
2 \mathrm{M}_{1} \mathrm{Th}_{3}\left(\mathrm{NO}_{3}\right)_{4}+ \\
3 \mathrm{M} \mathrm{HNO}_{3}\end{array}$} & \multicolumn{3}{|c|}{$\begin{array}{l}\text { Experiment } 3 \\
2 \mathrm{M} \operatorname{Tn}\left(\mathrm{NO}_{3}\right)_{3}+ \\
3 \mathrm{M} \mathrm{HNO}_{3}\end{array}$} & \multicolumn{3}{|c|}{$\begin{array}{c}\text { Experiment } 4 \\
2.5 \mathrm{M}^{4}\left(\mathrm{NO}_{3}\right)_{4}+ \\
0.5 \mathrm{M} \mathrm{HNO}_{3}\end{array}$} & \multicolumn{3}{|c|}{ 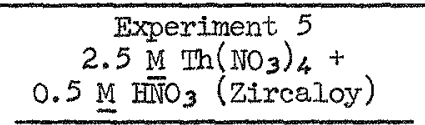 } & \multicolumn{3}{|c|}{$\begin{array}{c}\text { Experiment } 6 \mathrm{a} \\
2.1 \mathrm{M} \mathrm{Th}_{3}\left(\mathrm{NO}_{3}\right)_{4}+ \\
0.2 \mathrm{M} \mathrm{HNO}_{3}(\text { zircaloy })\end{array}$} \\
\hline $\begin{array}{l}\text { Time (hr) } \\
\text { From First } \\
\text { Sample }\end{array}$ & & Temp. & $\begin{array}{l}\text { Conc. } \\
\mathrm{Pa} \\
(\mathrm{ppm})\end{array}$ & $\begin{array}{l}\text { Time (hr) } \\
\text { From First } \\
\text { Sample }\end{array}$ & $\begin{array}{l}\text { Temp } \\
\left(O_{C}\right)\end{array}$ & $\begin{array}{l}\text { Conc. } \\
\mathrm{Pa} \\
(\mathrm{ppm})\end{array}$ & $\begin{array}{l}\text { Time (hr) } \\
\text { From Pirst } \\
\text { Sample }\end{array}$ & $\begin{array}{l}\text { Temp. } \\
\left(\mathrm{o}_{\mathrm{C}}\right)\end{array}$ & $\begin{array}{l}\text { Conc. } \\
\mathrm{Pa} \\
(\mathrm{ppm})\end{array}$ & $\begin{array}{l}\text { Time (hr) } \\
\text { Fron First } \\
\text { Sample }\end{array}$ & $\frac{\text { Temp. }}{\left(O_{C}\right)}$ & $\begin{array}{l}\text { Conc. } \\
\text { pa } \\
\text { (ppm) }\end{array}$ & $\begin{array}{l}\text { Time }(\mathrm{hr}) \\
\text { From First } \\
\text { Sample }\end{array}$ & $\begin{array}{l}\text { Temp. } \\
\left({ }^{\circ} \mathrm{C}\right)\end{array}$ & $\begin{array}{l}\text { Conc. } \\
\mathrm{Pa} \\
(\mathrm{ppm})\end{array}$ \\
\hline 0 & & 21 & 13.5 & 0 & 21 & 109 & 0 & 21 & 23.7 & 0 & 21 & 96 & 0 & 24 & 80 \\
\hline 62 & & 21 & 11.7 & 4 & $2 I$ & 109 & 18 & $2 I$ & 21.6 & 19 & 21 & 104 & 25 & 24 & 82 \\
\hline 66 & $\sim$ & 100 & 11.5 & 7 & $\sim 130$ & 109 & 24 & $\sim 145$ & 22.6 & 43 & $\sim 125$ & 102 & 30.3 & 175 & 30 \\
\hline 68 & $\sim$ & 100 & 11.8 & 25 & $\sim 130$ & 108 & 44 & $\sim 145$ & 21.3 & 50 & $\sim 125$ & 100 & $36.9 \mathrm{c}$ & 175 & 20 \\
\hline 86 & $\sim$ & 100 & 10.9 & 33 & $\sim 150$ & - & 67 & $\sim 145$ & 21.7 & 67 & $\sim 125$ & 92 & 49.2 & 175 & 33 \\
\hline 89 & $\sim$ & 125 & 11.1 & 34 & 21 & 110 & 74 & $\sim 160$ & 20.4 & $74^{b}$ & 181 & 73 & 55.2 & 175 & 23 \\
\hline 92 & $\sim$ & 125 & 11.0 & 49 & 21 & 109 & 101 & $\sim 160$ & 20.8 & 80 & 181 & 67 & 73.2 & 190 & 18 \\
\hline 110 & $\sim$ & 125 & 10.5 & 56 & $\sim 145$ & 109 & & & & 92 & 180 & 68 & 78.7 & 175 & 7 \\
\hline 117 & & 245 & 10.2 & 75 & $\sim 145$ & 104 & & & & 95 & 180 & - & 150 & 24 & 27 \\
\hline & & & & 96 & $\sim 145$ & 109 & & & & 98 & 200 & 29 & & & \\
\hline
\end{tabular}

a Heating arrangement show in Fig. 2.

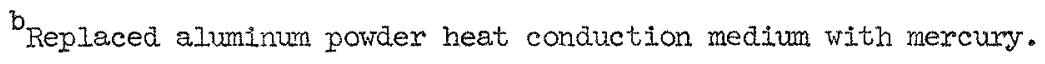

${ }^{C}$ Solution temperature reached a maximum temperature of $210^{\circ} \mathrm{C}$ between samples because of a faulty temperature controlier. 
The protactinium found on the Zircaloy rods represented about $18 \%$ of the amount lost from solution during the experiment.

CONCLUSIONS

Protactinium, in the concentration range 10 to $100 \mathrm{ppm}$, appears to be sufficiently stable in solutions containing up to 2. $5 \mathrm{M} \mathrm{Th}\left(\mathrm{NO}_{3}\right)_{4}$ and as Iittle as $0.2 \mathrm{M}$ free nitric acid at temperature of $180^{\circ} \mathrm{C}$ or less to encourage further consideration of solutions of this type for use as a breeder blanket in two-region aqueous homogeneous reactors. Further experimentation would be required to accurately define permissible operating concentrations and temperatures. 


\section{REFERENCES}

1. E. E. Lindsey, USAEC Report ORNL CF-60-8-150, August 8, 1960 .

2. W. L. Marsha11, J. S. Gi11, and C. H. Secoy, J. Am. Chem. Soc. 13, 4991 (1951).

3. P. G. Jones and R. G. Sowden, UKAEA Report AERE C/M 298, December 1956.

4. H. W. Kirby, The Radiochemistry of Protactinium, Subcommittee on Radiochemistry, National Academy of Sciences - National Research Counci1, NAS-NS 3016, December 1959. 
REMOVAL OF PROTACTINIUM AND URANIUM FROM THORIUM NITRATE-NITRIC ACID SOLUTIONS

G. L. Johnson, D. R. Cuneo, H. F. McDuffie, and M. J. Kel1y

Reactor Chemistry Division

Oak Ridge National Laboratory*

Oak Ridge, Tennessee

\section{INTRODUCTION}

From 1948 through 1960 the Oak Ridge National Laboratory was actively interested in development of the Aqueous Homogeneous Reactor concept. ${ }^{1}$ From the beginning of this program there was a continuing interest in the possibility of using a solution of some soluble thorium compound as a breeder blanket. ${ }^{2}$ In 1960 an engineering evaluation ${ }^{3}$ of possible breeder blanket arrangements suggested that a thorium nitrate solution might be suitable for use as a blanket if certain limitations could be avoided:

(1) If neutron absorption could be minimized by using nitrates made from $\mathrm{N}-15$.

(2) If adequate solubility could be maintained by operating at a temperature as low even as $175^{\circ} \mathrm{C}$.

(3) If unproductive neutron absorption in Pa-233 could be minimized by maintaining a very low concentration of $\mathrm{Pa}$ in the blanket.

(4) If radiolytic decomposition of nitrate to elemental nitrogen (which would require refixation) could be minimized by maintaining a very low concentration of $\mathrm{U}-233$ in the blanket.

The key problem appeared to be the discovery of a way of separating $\mathrm{Pa}-233$ and $\mathrm{U}-233$ from the solution. If $90 \%$ of the protactinium and uranium, at steady-state concentrations of 83 and $2 \mathrm{mg}$ per 1iter, respectively, could be removed from a blanket sidestream, a flow of less than 10 liters per minute would be required. If the steady-state level of protactinium could be maintained at $51 \mathrm{mg}$ per liter instead of 83 , only the removal of protactinium would be required, and the uranium could be ignored.

The $\mathrm{ThO}_{2}-\mathrm{HNO}_{3}-\mathrm{H}_{2} \mathrm{O}$ system has been studied by several groups of workers. ${ }^{4}$ These studies show that adequate solubility of thorium for use in an effective breeder blanket (greater than $500 \mathrm{gms}$ thorium per liter) could be achieved at a temperature of $175^{\circ} \mathrm{C}$.

\footnotetext{
* Operated by Union Carbide Corporation for the U. S. Atomic Energy Commission.
} 
The cost of N-15 enrichment, the rate of production of elemental nitrogen by radiation decomposition of nitrate, and the problem of recovering this nitrogen by fixation have been discussed by Lindsey. ${ }^{3}$

Studies of the solubility of $\mathrm{pa}$ in thorium nitrate-nitric acid solutions ${ }^{5}$ indicated that concentrations of $\mathrm{Pa}$ in the range 10 to $100 \mathrm{ppm}$ may be stable at $180^{\circ} \mathrm{C}$.

For a number of reasons, peroxide precipitation was tested as a possible technique for side-stream processing to remove $\mathrm{Pa}$ :

(1) Pa peroxide had been reported to be insoluble but not intractable.

(2) Peroxide (made from heavy water) should not add any contaminating impurities to the system. Decomposition would provide oxygen, a desirable gas.

(3) Experience with uranium did not suggest that any unexpected radiation effects might be encountered.

(4) The reagent might be added to the side stream conveniently for remote operation.

(5) The precipitate should be easily removable by hydraulic cyclones of the type developed for removal of solids from the core solution of the HRT. ${ }^{6}$

(6) Complete purification of the $\mathrm{Pa}$ would not be really necessary; segregated $\mathrm{Pa}$, mixed with a small volume of thorium nitrate solution could be permitted to decay to U-233 out of the reactor and then be processed for uranium.

(7) Uranium peroxide was known to be quite insoluble -- its removal would be so much the better.

\section{EXPERIMENTAL}

For the expeximental investigation, laboratory-scale tests were chosen. Polyethylene equipment was used to avoid the problem of $\mathrm{Pa}$ adsorption on container walls. The temperature of the test solutions was controlled in the range $55-75^{\circ} \mathrm{C}$ by means of a water bath. Thorium concentrations tested were $2 \mathrm{M}$ and $3 \mathrm{M}$. Nitric acid was present in concentrations from 0.0 to $2 . \overline{25} \mathrm{M}$. Initial concentrations of hydrogen peroxide ranged from $0.1^{-}$to $0.45 \mathrm{M}$.

Two sources of thorium nitrate were used. The first experiments were made with a pentahydrate obtained at ORNL; later experiments were made with the B\&A reagent grade tetrahydrate. No effect of changing the source of thorium was noted. The compositions of the various test solutions were confirmed by chemical analysis. The thorium content was determined by igniting a sample of solution in a platinum crucible for 30 minutes at $800^{\circ} \mathrm{C}$ and weighing the resulting $\mathrm{ThO}_{2}$; the nitrate content was determined by passing the solution through a Dowex-50 ion exchange column in the acid form, exchanging the thorium for hydrogen ions, and titrating the nitric acid in the effluent liquid with standard base according to the method of Day et a1 ${ }^{7}$ the peroxide content was determined by titration with ceric sulfate in the presence of ferroin as an indicator.

A11 experiments in this series were performed at the tracer level with the use of Pa-233 tracer which was prepared by irradiating a small amount of the solid thorium nitrate hydrate in the ORNL graphite pile and then dissolving the thorium, with the 
contained Pa-233 tracer, in a minimum amount of $1 \mathrm{M}$ nitric acid. Gamma counting of the 310 kev peak was used for añalysis. Typical counts at the beginning of experiments were $40,000 \mathrm{c} / \mathrm{min}$; background counts from the thorium solutions were around $2,000 \mathrm{c} / \mathrm{m}$.

In a typical experiment, $20 \mathrm{ml}$ of a test solution of thorium nitrate plus nitric acid was placed in a polyethylene container and $0.5 \mathrm{mI}$ of $\mathrm{Pa}$ tracer solution was added. Agitation was provided by means of a conventional magnetic stirrer assembly. Then, 0.5 $\mathrm{ml}$ of $30 \%$ hydrogen peroxide solution was added to start the reactions. At appropriate time intervals thereafter, samples were removed from the reaction flask and centrifuged to remove any suspended solids. The supernatant solutions were counted to determine the $\mathrm{Pa}$ tracer content and analyzed for peroxide content.

\section{RESULTS AND DISCUSSION}

An example of the success of the technique for removing pa is shown in Figure 1. The initial decrease in soluble peroxide content is attributed to the precipitation of a maximum of $3 \%$ of the available thorium from solution. The simultaneous abrupt decrease in the fraction of $\mathrm{Pa}$ present in solution is attributed to co-precipitation or adsorption of $94 \%$ of the Pa. When, after 300 minutes in this run, the relatively slow peroxide decomposition had lowered the peroxide concentration to the point that the thorium began to return to solution, the $\mathrm{Pa}$ also returned to solution and reached its original concentration. Following the return of the thorium to solution the decomposition of peroxide continued at a rate which is first order in peroxide concentration.

Tables 1 and 2 summarize the experiments which were performed at $55^{\circ}$ and $65^{\circ} \mathrm{C}$ (with one value at $75^{\circ} \mathrm{C}$ ). Figure 2 shows, for two concentrations of thorium, how the threshold peroxide concentration (below which $\mathrm{Pa}$ returned to solution) varied with the concentration of added acid. The higher the acidity, the higher the peroxide threshold level for $\mathrm{Pa}$ return. Generally, the more peroxide added initially, the more thorium was precipitated. However, the threshold level for $\mathrm{Pa}$ return did not seem to be affected by the initial peroxide concentration at any one level of acid.

In one experiment $75 \mathrm{ppm}$ uranium was added to a $2 \mathrm{M}$ thorium nitrate $2 \mathrm{M}$ nitric acid solution at $48.9^{\circ} \mathrm{C}$ before using the peroxide precipitation technique; no uranium was removed from the solution when some of the thorium was precipitated. Nevertheless, in an identical expeximent to which tracer Pa was added, the Pa was removed as successfully in the presence of uranium as if it had been absent.

As noted on Fig. 1 and as indicated by Fig. 3, peroxide decomposes in thorium nitrate-nitric acid solutions in what appears to be a process which is first order in peroxide concentration (as does uranium). The activation energy calculated from these data is $22 \mathrm{kcal}$, quite similar to that in uranium solutions. The rate of decomposition in thorium solutions was increased by increasing the acidity.

The composition of the precipitated thorium peroxide became of interest and details of this work are to be presented elsewhere. The evidence, summarized in Table 3, suggests that the stoichio- 


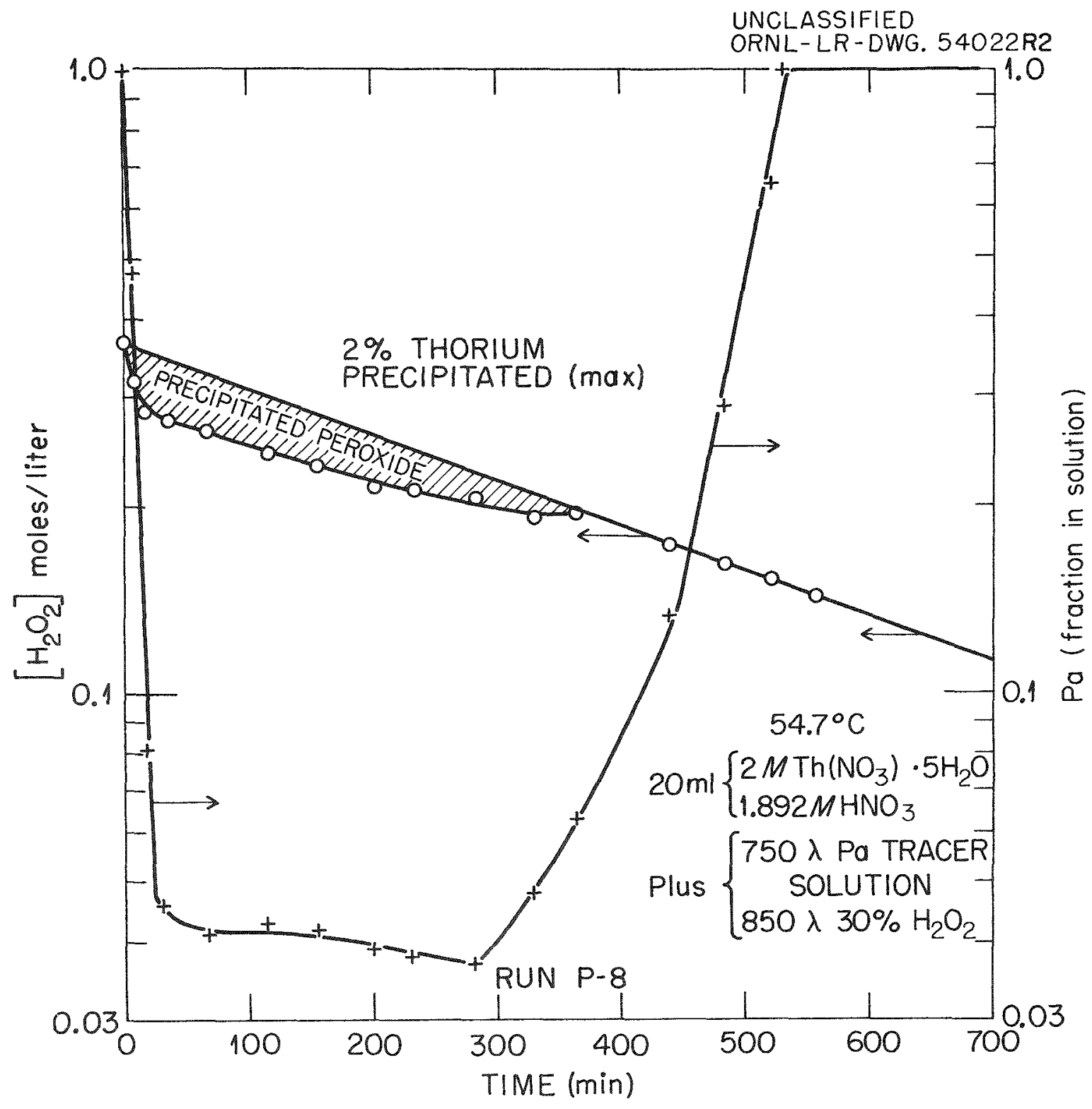

Co-precipitation of $\mathrm{Pa}-233$ tracer with thorium peroxide.

Fig. 1 . 
Table I. Experimental Studies of Protactinium Precipitation From 2 Molar Thorium Nitrate at $55^{\circ} \mathrm{C}$

\begin{tabular}{|c|c|c|c|c|}
\hline $\begin{array}{c}\text { Added } \\
\mathrm{HNO}_{3} \\
\underline{\mathrm{M}}\end{array}$ & $\begin{array}{l}\text { Initial } \\
\mathrm{H}_{2} \mathrm{O}_{2} \\
\stackrel{\mathrm{M}}{ }\end{array}$ & $\begin{array}{c}\% \mathrm{~Pa} \\
\text { Removed }\end{array}$ & $\begin{array}{l}\text { Estimated } \\
\% \mathrm{Th} \\
\text { pptd. }\end{array}$ & $\begin{array}{c}\text { Threshold Peroxide } \\
\text { Level for Pa } \\
\text { Return } \\
\text { M }\end{array}$ \\
\hline \multirow[t]{3}{*}{0.00} & 0.115 & 89 & 0.7 & 0.075 \\
\hline & 0.224 & 97 & 4.2 & 0.08 \\
\hline & .0 .234 & $\sim 100$ & 3.6 & 0.076 \\
\hline \multirow[t]{3}{*}{0.62} & 0.115 & 55 & $\sim 0.0$ & -- \\
\hline & 0.234 & 97 & 1.0 & 0.115 \\
\hline & 0.239 & 97 & 1.3 & 0.12 \\
\hline \multirow[t]{4}{*}{1.23} & 0.232 & 70 & $>0.0$ & 0.22 \\
\hline & 0.353 & 97 & 1.6 & 0.21 \\
\hline & 0.391 & 97 & 2.3 & 0.21 \\
\hline & 0.385 & 96 & 4.7 & 0.21 \\
\hline \multirow[t]{3}{*}{2.24} & 0.564 & 43 & 0.5 & -- \\
\hline & 0.464 & 43 & $<1.0$ & 0.40 \\
\hline & 0.872 & 94 & 2.4 & 0.35 \\
\hline
\end{tabular}


Table II. Experimental studies of Protactinium Precipitation at $65^{\circ} \mathrm{C}$

\begin{tabular}{|c|c|c|c|c|}
\hline $\begin{array}{c}\text { Added } \\
\mathrm{HNO}_{3} \\
\underline{\mathrm{M}}\end{array}$ & $\begin{array}{l}\text { Initial } \\
\mathrm{H}_{2} \mathrm{O}_{2} \\
\underline{M}\end{array}$ & $\begin{array}{c}\% \mathrm{~Pa} \\
\text { Removed }\end{array}$ & $\begin{array}{l}\text { Estimated } \\
\% \text { Th } \\
\text { pptd. }\end{array}$ & $\begin{array}{l}\text { Threshold Peroxide } \\
\text { Level for Pa } \\
\text { Return } \\
\text { M }\end{array}$ \\
\hline \multicolumn{5}{|c|}{2 Molar Thorium Nitrate } \\
\hline 0.0 & 0.239 & 98 & 2.5 & 0.083 \\
\hline 0.62 & 0.232 & 98 & 1.4 & 0.12 \\
\hline \multirow[t]{4}{*}{1.23} & 0.346 & 93 & 0.6 & 0.21 \\
\hline & 0.387 & 94 & 3.0 & 0.21 \\
\hline & 0.473 & 97.5 & 4.7 & 0.18 \\
\hline & $0.56 I$ & 98.5 & 7.0 & 0.24 \\
\hline 2.24 & 0.465 & 86 & 2.5 & 0.33 \\
\hline$(2.24$ & 0.469 & 76 & 2.8 & $0.35) 75^{\circ} \mathrm{C}$ \\
\hline 3 Molar & - Thorium Nitrate & & & \\
\hline \multirow[t]{2}{*}{1.23} & 0.470 & 93.5 & 5.0 & 0.12 \\
\hline & 0.580 & 95 & 9.6 & 0.11 \\
\hline \multirow[t]{2}{*}{2.24} & 0.466 & 92.5 & 3.2 & 0.17 \\
\hline & 0.584 & 92.5 & 5.1 & 0.17 \\
\hline
\end{tabular}


UNCLASSIFIED

ORNL-DWG 63-7181

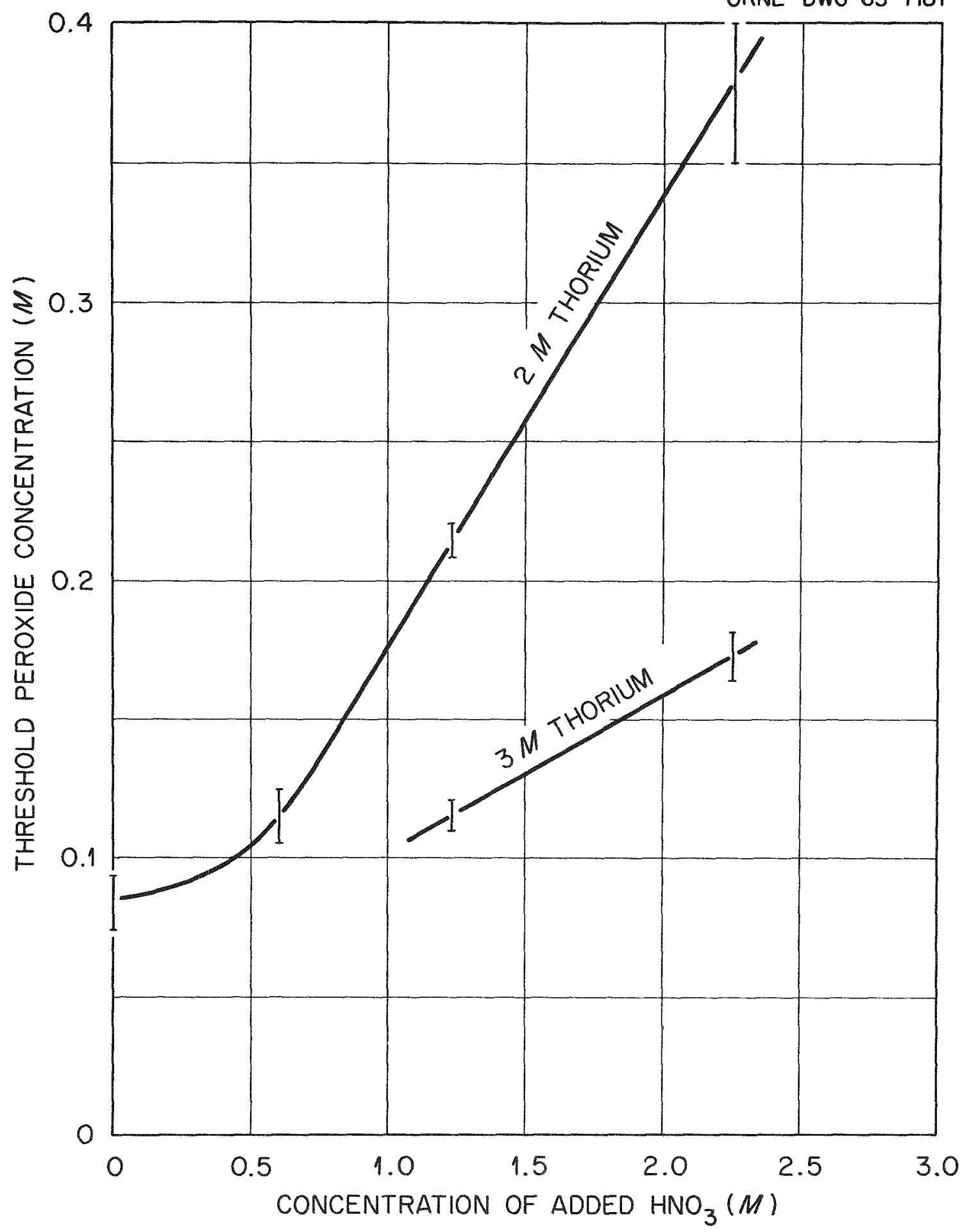

Fig. 2. Effect of Added Nitric Acid on Threshold Peroxide Concentration. (ORNL-LR-Dwg. 63-7181). 


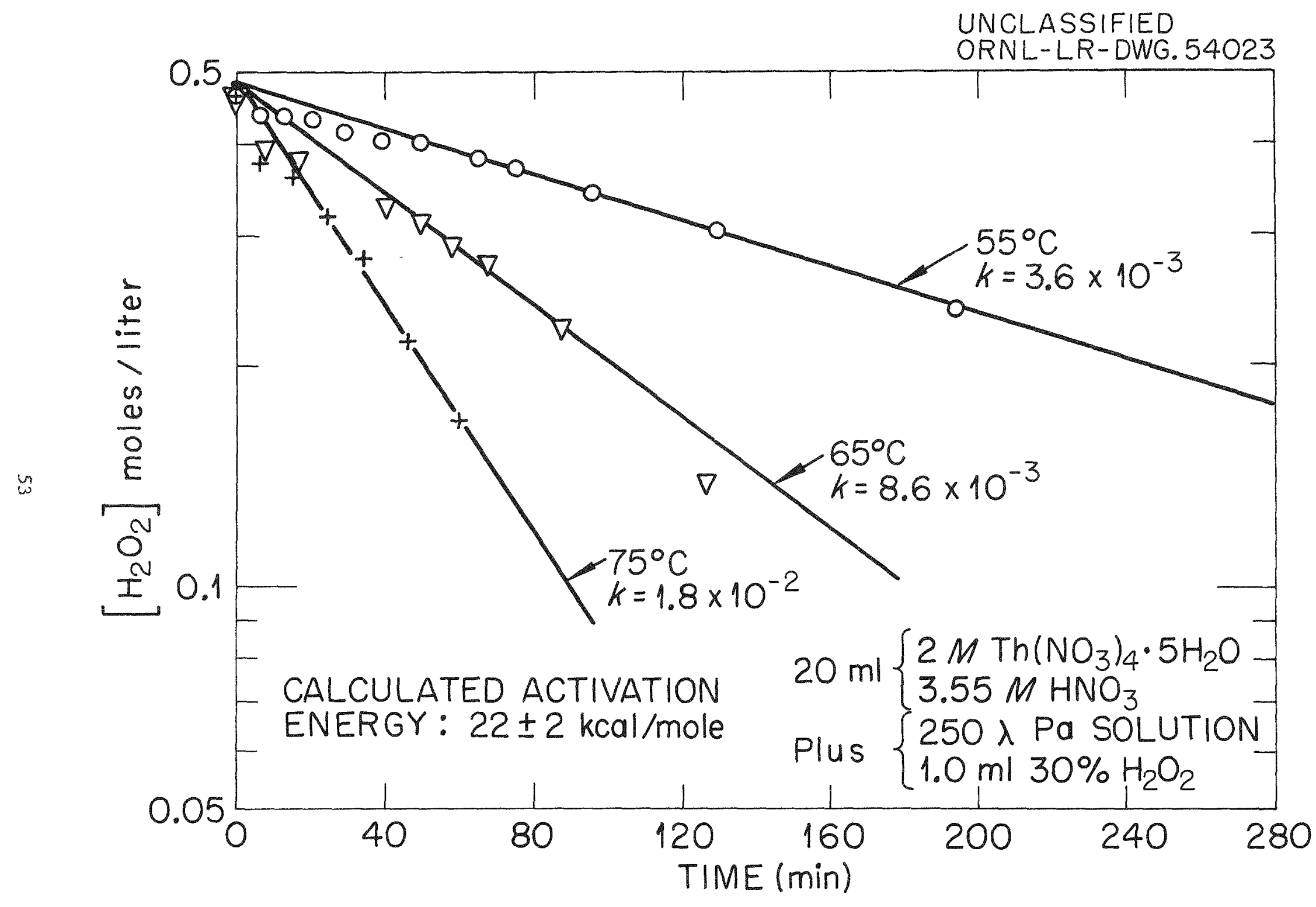

Effect of temperature on peroxide decomposition. 
Table III. Thorium Peroxide Composition

\begin{tabular}{lccc}
\hline & $\begin{array}{c}\text { Solids } \\
\text { Analysis }\end{array}$ & $\begin{array}{c}\text { Solution } \\
\text { Analysis }\end{array}$ & Theoretical (a) \\
\hline $\mathrm{Th}^{+4}$ & 1 & 1 & 1 \\
$\mathrm{O}_{2}^{-2}$ & 1.65 & $1.73 \pm 0.1$ & 1.67 \\
$\mathrm{NO}_{3}^{-1}$ & 0.65 & 1.68 & 0.67 \\
$\mathrm{H}_{2} \mathrm{O}^{(\mathrm{b})}$ & & $3.4 \pm 0.1$ & 1.67 \\
$\mathrm{H}^{+1}$ (formed) & & & 3.33 \\
\hline
\end{tabular}

(a) $\mathrm{Th}_{6}(\mathrm{OO})_{10}\left(\mathrm{NO}_{3}\right)_{4} \cdot 10 \mathrm{H}_{2} \mathrm{O}$.

(b) $\mathrm{H}_{2} \mathrm{O}$ by Difference. 
metry corresponds actually to the presence of 6 thoriums, 10 peroxides, 4 nitrates and 10 molecules of water.

In every case in which sufficient peroxide was present to cause precipitation of some of the thorium, and when the particulate material reached a size which could be satisfactorily centrifuged from the solution, the $\mathrm{Pa}$ was removed with the precipitate. The Pa did not all reappear so long as any observable precipitate was present. It is reasonable to assume that the $\mathrm{Pa}$ peroxide may be even less soluble than the thorium peroxide and that concentrations as low as 5 ppm might be maintained by precipitating, from a breeder blanket solution, a very small quantity of the thorium which would carry or co-precipitate with the protactinium. 
1. Fluid Fuel Reactors, edited by Lane, MacPherson, Maslan; Part I. Aqueous Homogeneous Reactors, Addison Wesley, New York, 1958.

2. M. H. Lietzke and W. L. Marshal1, "Present Status of the Investigation of Aqueous Solutions Suitable for Use in a Thorium Breeder Blanket," USAEC Report ORNL-1711 (May 19, 1954).

3. E. E. Lindsey, "Thorium Nitrate as a Breeder Blanket. Analysis of Low Blanket Temperature, Low $U$ and Pa Concentrations, and use of Nitrogen 15," USAEC Report ORNL-CF-60-8-150 (Aug. 8, 1960).

4. W. L. Marshal1, J. S. Gi11, and C. H. Secoy, J. Am. Chem. Soc. 73,4991 (1951).

J. R. Ferraro, L. I. Katzin, and G. Gibson, J.Am. Chem. Soc. 76,909 (1954).

W. L. Marshall et a1, Reactor Chemistry Division Ann. Prog. Rept. for Period Ending Jan. 31, 1962, ORNL-3262, p 63-64. P. G. Jones and R. G. Sowden, "Thorium Nitrate Solution as a Breeder Blanket in the H.A.R," Report AERE-C/M-298 Part I. Thermal Stability. Great Britain Atomic Energy Research Establishment, 1956.

W. L. Marshall and C. H. Secoy, Homogeneous Reactor Project Quart. Progr. Rept. for the Period Ending Oct. 31, 1954, ORNL-1658, p 93-96.

5. C. J. Barton, D. R. Cuneo, M. J. Kelly, and J. E. Strain, "Protactinium Stability in Thorium Nitrate-Nitric Acid Solutions," Protactinium Chemistry Symposium, Gatlinburg, Tenn., April 25-26, 1963.

6. P. A. Haas, "Hydraulic Cyclones for Application to Homogeneous Reactor Chemical Processing," USAEC Report ORNL-2301 (1957).

7. H. O. Day, Jr., J.S. Gi11, E. V. Jones, and William L. Marsha11, Ana. Chem. 26, 611 (1954). 


\section{Protactinium Fluorides ${ }^{1}$ \\ by Lawrence Stein \\ Argonne National Laboratory}

\section{Abstract:}

The following reactions have been studied with 5 to $200 \mathrm{mg}$. amounts of Pa23I; most products have been identified by $x$-ray powder patterns and chemical or radiochemical analyses:

$$
\begin{aligned}
& \mathrm{Pa}_{2} \mathrm{O}_{5}(\mathrm{~s})+8 \mathrm{HF}(\mathrm{g})+\mathrm{H}_{2}(\mathrm{~g}) \underset{500^{\circ}}{\longrightarrow} 2 \mathrm{PaF}_{4}(\mathrm{~s})+5 \mathrm{H}_{2} \mathrm{O} \text { (g) } \\
& \mathrm{PaF}_{4}(\mathrm{~s})+\frac{1}{2} \mathrm{~F}_{2}(\mathrm{~g}) \underset{700^{\circ}}{\longrightarrow} \operatorname{PaF}_{5} \text { (s) } \\
& 2 \mathrm{PaF}_{4}(\mathrm{~s})+\frac{1}{2} \mathrm{O}_{2}(\mathrm{~g}) \frac{\mathrm{F}_{2}}{600^{\circ}} \mathrm{Pa}_{2} \mathrm{OF}_{8} \text { (s) } \\
& \mathrm{Pa}_{2} \mathrm{O}_{5}(\mathrm{~s})+4 \mathrm{~F}_{2}(\mathrm{~g}) \underset{550^{\circ}}{\longrightarrow} \mathrm{Pa}_{2} \mathrm{OF}_{8}(\mathrm{~s})+2 \mathrm{O}_{2}(\mathrm{~g}) \\
& \mathrm{Pa}_{2} \mathrm{O}_{5}(\mathrm{~s})+8 \mathrm{HF}(\mathrm{g}) \frac{\mathrm{O}_{2}}{500^{\circ}} \mathrm{Pa}_{2} \mathrm{OF}_{8}(\mathrm{~s})+4 \mathrm{H}_{2} \mathrm{O} \text { (g) } \\
& \mathrm{Pa}_{2} \mathrm{OF}_{8} \text { (s) } \underset{800^{\circ}}{\longrightarrow} \mathrm{PaF}_{5}(\mathrm{~s})+\text { unidentified solid }
\end{aligned}
$$

Protactinium tetrafluoride is obtained as dark brown, monoclinic, needlelike crystals on heating Pa205 in a mixture of $\mathrm{HF}$ and $\mathrm{H}_{2}$. It is non-volatile in vacuum up to $800^{\circ} \mathrm{C}$ and is virtualIy insoluble in water and mineral acids, even in the presence of oxidizing agents and fluoride complexing agents. When the tetrafluoride is heated with purified fluorine, it is converted to the pentafluoride, which is a white solid isomorphous with the $\beta$ form of UF5 (tetragonal crystal structure). The pentafluoride is less volatile than its homologues $\mathrm{VF}_{5}$, NbF5, and TaF5, but can be distilled in vacuum above $500^{\circ}$. It is slightly soluble in water and very soluble in aqueous hydrofluorjc acid. 
When protactinium tetrafluoride is heated with fluorine containing oxygen impurity, an oxyfluoride is obtained which appears to have the composition PazOF8. This is a white solid, slightly volatile in vacuum above $500^{\circ}$, isomorphous with $\mathrm{U}_{2} \mathrm{~F}_{9}$ (body-centered cubic structure). The same product is obtained when protactinium pentoxide is heated with fluorine or with a mixture of hydrogen fluoride and oxygen. At approximately $800^{\circ}$, the oxyfluoride partly decomposes to $\mathrm{PaF}_{5}$ and other unidentified solids.

When protactinium pentoxide is dissolved in aqueous hydrofluoric acid and the solution is evaporated to dryness at $110^{\circ}$, colorless needlelike crystals of the approximate composition $\mathrm{PaF}_{5} \cdot 2 \mathrm{H}_{2} \mathrm{O}$ are obtained. The crystals decompose on further heating at $160^{\circ}$, yielding $\mathrm{Pa}_{2} \mathrm{OF} 8$.

\section{Introduction}

In the earliest studies of protactinium fluorides, Grosse ${ }^{2}$ prepared the double fluoride with potassium, $\mathrm{K}_{2} \mathrm{PaF}$, and a pentafluoride hydrate of unspecified composition. A double fluoride with ammonium was reported by Emmanuel-Zavizziano 3 and subsequentIy a double fluoride with barium was described by, Golden and Maddock 4 . Sellers, Fried, Elson, and Zachariasen 5 prepared the tetrafluoride, $\mathrm{PaF}_{4}$, by hydrofluorination of $\mathrm{PaO}_{2}$ and found it to be isomorphous with ThF4, UF4, $\mathrm{NpF}_{4}$, and PuF4. Haissinsky and Bouissieres reduced $\mathrm{Pa}(\mathrm{V})$ to $\mathrm{Pa}(\mathrm{IV})$ in a fluoride solution and obtained a precipitate which was also believed to be $\mathrm{PaF}_{4}{ }$

Very little information is found in the literature conceming volatile fluorides or oxyfluorides of protactinium. Emeleus, Maddock, Miles, and Sharpe 7 heated tracer quantities of $\mathrm{Pa} 233$ and $\mathrm{Pa} 231$ with $\mathrm{BrF}_{3}$ but found no indication that a volatile fluoride was formed. At Brookhaven National Laboratory, the distillation of tracer Pa233 from neutron irradiated ThF4 was studied. When the $\mathrm{ThF}_{4}$ was strongly heated in a stream of $\mathrm{F}_{2}$ or CIF 3 , a slightly volatile protactinium compound was formed which condensed below $500^{\circ}$. A more volatile protactinium fluoride or oxyfluoride was obtained by Sellers, Fried, Elson, and Zachariasen 5 on heating protactinium oxide to $600^{\circ}$ with either $\mathrm{BrF}_{3}$ or $\mathrm{BrF}_{5}$; the product distilled in vacuum at $150^{\circ}$ but subsequently decomposed due to hydrolysis or reaction with the quartz vessel.

The present study indicates that a slightly volatile oxyfluoride, Pa 0 F8, is formed under a variety of conditions. Several reactions yielding protactinium fluorides are described, and analytical and crystallographic data are reported which further identify the tetrafluroide, pentafluroide, and hydrated pentafluoride.

Experimental Procedures; Results

Protactinium-231 in the form of the hydrated pentoxide was obtained from the Atomic Energy Research Establishment, Harwel1, England. In most experiments, the oxide was used without further 
purification, since spectrographic analyses indicated the initial purity to be 99.7 per cent9. Recently it was found that this material contains approximately 4 per cent niobiumlo, which was overlooked in the very complex spectrum of protactinium in photographic plates made both at Harwell and at Argonne. The niobium probably has no effect on the reactions described here. However, in the analyses of the products, it introduces an apparent error of approximately 0.5 per cent in the composition of each compound. The required composition is stated for each compound in the pure state, with no correction for niobium.

$\mathrm{PaF}_{4}$

Protactinium tetrafluoride was prepared by heating the pentoxide in an approximately equimolar mixture of hydrogen and hydrogen fluoride with the apparatus shown in Figure 1 . The oxide was contained in a platinum boat inside a nickel furnace tube. The gas mixture flowed slowly through the tube into a bubbler containing 48 per cent hydrofluoric acid which was used as a flowmeter. A polyethylene catch bottle prevented the liquid from backing into the reaction vessel during a pressure drop, which sometimes occurred during cooling. Off gases passed from the bubbler through a soda Iime trap, then into the fume hood.

The cube furnace was heated slowly from room temperature to $500^{\circ} \mathrm{C}$ in about one hour, then maintained at $500^{\circ}$ for another two hours. During cooling, the hydrogen fluoride supply was turned off, and the system was flushed out with hydrogen before the boat was removed. Under these conditions, good yields of PaF 4 were obtained; in four experiments, 20 to $230 \mathrm{mg}$. quantities were prepared. (In one experiment, in which the temperature was allowed to rise quickly to $700^{\circ}$, most of the protactinium volatilized, presumably as the oxyfluoride.) The hydrofluorination reaction is as follows:

$$
\begin{aligned}
& \mathrm{Pa}_{2} \mathrm{O}_{5}(\mathrm{~s})+8 \mathrm{HF}(\mathrm{g})+\mathrm{H}_{2}(\mathrm{~g}) \\
& \underset{500^{\circ}}{\longrightarrow} 2 \mathrm{PaF}_{4}(\mathrm{~s})+5 \mathrm{H}_{2} \mathrm{O}(\mathrm{g})
\end{aligned}
$$

The dark brown, finely divided crystals of PaF4 were shown by $x$-ray powder photographs to be monoclinic and therefore isomorphous with ThF4, UF4, NoF4, and PuF4, as previously reported5. The crystals were slightly hygroscopic in air. They could not be dissolved in water or the following solutions, hot or coldli: $48 \% \mathrm{HF}$; $2 \mathrm{M} \mathrm{NH} 4 \mathrm{~F} \cdot \mathrm{HF} ; 12 \mathrm{M} \mathrm{HNO} ; 8 \mathrm{M} \mathrm{HCI}, 0.6 \mathrm{~N} \mathrm{AICI}$; $8 \mathrm{M} \mathrm{HCl}$, I M HF. The addition of $\mathrm{H}_{2} \mathrm{O}_{2}$ to the last two solutions also had no effect. In hot $2 \mathrm{M} \mathrm{KOH}$, a slight amount of hydrolysis occurred, but most of the solid remained undissolved after several hours. When $\mathrm{PaF}_{4}$ was fused with solid $\mathrm{NaOH}$ in a nickeI crucible and the resulting cake dissolved in $6 \mathrm{M} \mathrm{HCl,} \mathrm{a} \mathrm{clear}$ green solution was obtained. However, attempts to analyze the solution for fluoride by the lead chlorofluoride method were unsuccessful. A semi-micro pyrohydrolysis method was then adopted, which yielded satisfactory results. [Found: $\mathrm{Pa} 75.2$; 


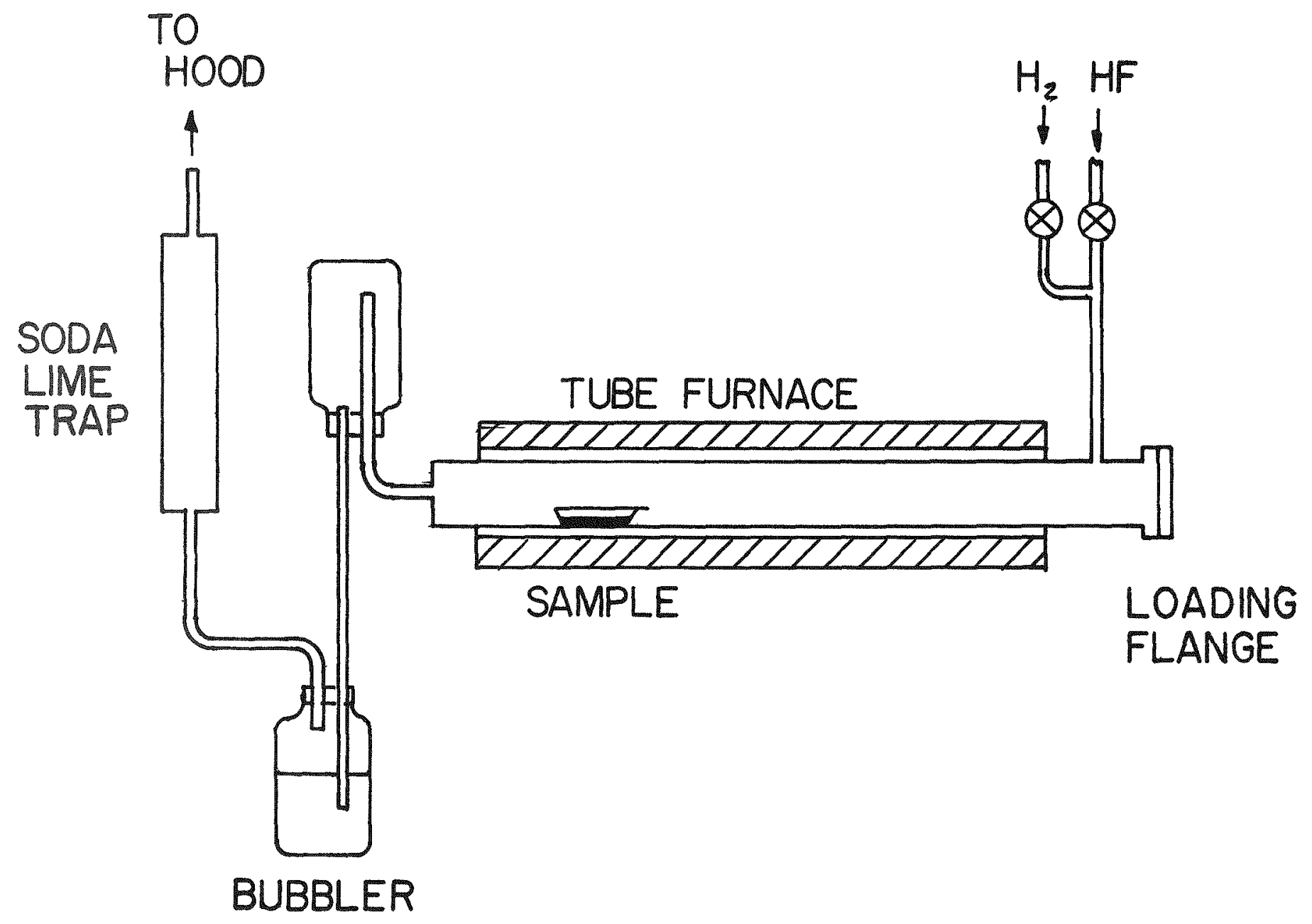

Fig. 1

Hydrofluorination Apparatus 
F, 24.5, 25.3\%. Required for $\mathrm{PaF}_{4}:$ Pa 75.2; F, 24.8\%.]

The tetrafluoride was heated in vacuum up to $800^{\circ}$ without volatilizing. When it was contained in a platinum boat inside a quartz vessel, considerable decomposition occurred, and both the platinum and quartz were attacked. In nickel apparatus, it appeared also to decompose at elevated temperatures, but the radioactivity did not move from the initial site.

$\mathrm{PaF}_{5}$

The reaction of $\mathrm{PaF}_{4}$ with $\mathrm{F}_{2}$, shown in equation (2a) below, was first studied with apparatus consisting of a nickel reaction chamber in train with two Pyrex cold traps.

$$
\mathrm{PaF}_{4}(\mathrm{~s})+\frac{1}{2} \mathrm{~F}_{2}(\mathrm{~g}) \underset{700^{\circ}}{\longrightarrow} \mathrm{PaF}_{5} \text { (s) }
$$

Any $\mathrm{PaF}_{5}$ that was formed was expected to distill into the first trap, which was at $-78^{\circ}$. However, it was found that the slightly volatile product condensed before reaching the trap, even in a vacuum of approximately $10^{-6} \mathrm{~mm}$. Hg; it could be moved only by flaming the metal lines with a torch to $500^{\circ}-700^{\circ}$. The apparatus shown in Figure 2 was then designed and found to be somewhat more suitable.

The PaF4, was contained in a 3/8-inch O.D. nickel test tube through which $F_{2}$ gas flowed at a slow rate. The position of the $\mathrm{Pa} 231$ in the apparatus could be readily determined by counting the $\gamma$ activity externally with a portable $\beta-\gamma$ meter. When the test tube was heated electrically to $700^{\circ}$, some activity began to appear in the exit tube, which was slightly above room temperature. The $F_{2}$ flow was then stopped, the system was evacuated, and the exit line was flamed with a torch to move the activity into a 3/8-inch $O . D$. cylindrical nickel chamber. Inside the chamber, a platinum tube, which had been previously weighed, fitted loosely around the end of the exit line. The volatile Pa231 product issuing from the line condensed in a ring on the inside of the tube. The fluorination - evacuation process was repeated several times, with Fa flowing for 15 minute intervals, until most of the $\gamma$ activity had been moved from its original site to the sliding tube. (To avoid the formation of platinum fluorides, the flaming operation was carried out only in the absence of $F_{2} \cdot$ ) The tube containing the product was moved into the adjacent quartz or Pyrex section, which was then sealed off with a torch. It was later reopened in a dry box to obtain samples for $x$-ray and chemical analysis. The apparatus was modified subsequently by replacing the nickel test tube with a "U" shaped chamber, but the method of operation remained the same.

In five experiments, 8 to $20 \mathrm{mg}$. quantities of PaF4 were fluorinated. Two grades of fluorine were used, one of 99.9 per cent purity, obtained by low temperature distillation 12 , and the other a commercial grade of approximately 99 per cent purity, 


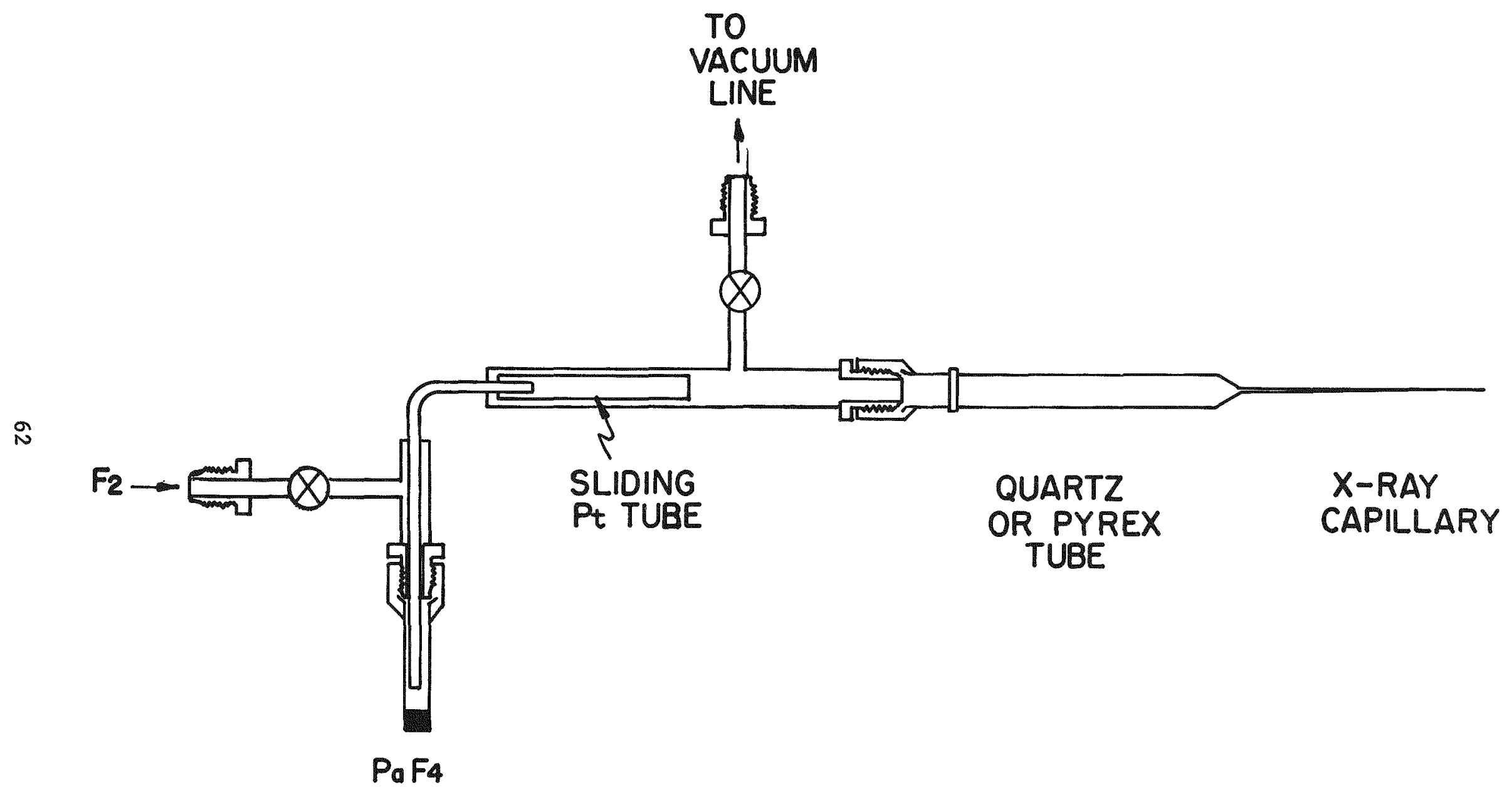

Fig. 2

Fluotination Apparatus 
containing oxygen, nitrogen, and other gases. When the purified fluorine was used and care was exercised to exclude moisture, the product was identified as PaF5. Yields of 40 to 95 per cent were obtained. [Found: Pa, 69.5,72.0; F, 30.2\%. Required for $\left.\mathrm{PaF}_{5}: \mathrm{Pa}, 70.9 ; \mathrm{F}, 29.1 \%.\right]$

The compound is white, hygroscopic, and isomorphous with the $\beta$ form of UF5 (tetragonal crystal structure). It dissolves in water to some extent, but dissolves more readily in $1 \mathrm{M}$ or stronger hydrofluoric acid. It is much less volatile than its homologs VF5, NbF5, and $\mathrm{TaF}_{5}$, but sublimes or distills in vacuum above $500^{\circ}$. Quartz and Pyrex are both attacked by PaF5 at elevated temperatures; attempts to distill the compound into $x$-ray capillaries were therefore unsuccessful and a dry box filling technique was substituted.

The PaF5 was shown by alpha pulse analysis (hydrolyzed samples) to be almost free of $\mathrm{Pa}^{231}$ daughters, whereas the starting $\mathrm{PaF}_{4}$ contained 12.3 per cent daughter activity. The volatilization process therefore has some merit as a radiochemical purification method. Decontamination factors of 15 to 300 were observed in the present experiments; no doubt much higher factors can be achieved. (Although the Pa23I daughters contributed significantly to the total radioactivity of the $\mathrm{Pa} 205$, $\mathrm{PaF} 4$, and other compounds, their effect on the chemical purity was entirely negligible.)

$\mathrm{Pa}_{2} \mathrm{OF}_{8}$

In two experiments in which $\mathrm{PaF}_{4}$ was heated with impure fluorine, a different product was obtained which was later found to be the oxyfluoride, PacOF8. Although it is possible that the pentafluoride was formed initially and hydrolyzed, thus,

$$
2 \mathrm{PaF}_{5}(\mathrm{~s})+\mathrm{H}_{2} \mathrm{O}(\mathrm{g}) \rightarrow \mathrm{Pa}_{2} \mathrm{OF}_{8}(\mathrm{~s})+2 \mathrm{HF}(\mathrm{g})
$$

it seems more probable that oxygen in the fluorine reacted directly, as follows:

$$
2 \mathrm{PaF}_{4}(\mathrm{~s})+\frac{1}{2} \mathrm{O}_{2}(\mathrm{~g}) \underset{600^{\circ}}{\stackrel{\mathrm{F}_{2}}{\longrightarrow}} \mathrm{Pa}_{2} \mathrm{OF}_{8}(\mathrm{~s})
$$

It was found that the same oxyfluoride could be prepared by heating protactinium pentoxide with luorine or with an equimolar mixture of hydrogen fluoride and oxygen. The reactions are as follows (gaseous products not analyzed) 13 :

$$
\begin{aligned}
& \mathrm{Pa}_{2} \mathrm{O}_{5}(\mathrm{~s})+4 \mathrm{~F}_{2}(\mathrm{~g}) \underset{550^{\circ}}{\longrightarrow} \mathrm{Pa}_{2} \mathrm{OF}_{8}(\mathrm{~s})+2 \mathrm{O}_{2}(\mathrm{~g}) \\
& \mathrm{Pa}_{2} \mathrm{O}_{5}(\mathrm{~s})+8 \mathrm{HF}(\mathrm{g}) \frac{\mathrm{O}_{2}}{500^{\circ}} \mathrm{Pa}_{2} \mathrm{OF}_{8}(\mathrm{~s})+4 \mathrm{H}_{2} \mathrm{O}(\mathrm{g})
\end{aligned}
$$

Samples of the oxyfluoride prepared by each method were shown to be identical by $x$-ray powder photographs. A total of $140 \mathrm{mg}$. of the compound was prepared. [Found: Pa, 72.7, 74.0; F, 23.9\%. 
Required for $\left.\mathrm{Pa}_{2} \mathrm{OF}_{8}: \mathrm{Pa}, 73.33 ; 0,2.54 ; \mathrm{F}, 24.13 \%.\right]$

The oxyfluoride is a white solid, isomorphous with $\mathrm{U}_{2} F_{9}$ (body centered cubic structure). It is interesting to note that the black color of. U2F9 is attributed to resonance of uranium between +4 and higher valence states 14, in Pa20F8, protactinium exhibits its normal t5 valence, and the color is light as expected. The oxyfluoride is hygroscopic, dissolves to a slight extent in water, and dissolves more readily in hydrofluoric acid solutions. It is volatile in vacuum above $500^{\circ}$. At $800^{\circ}$ and higher temperatures, partial decomposition of Pa $20 \mathrm{~F}_{8}$ to $\mathrm{PaF}_{5}$ has been observed:

$$
\mathrm{Pa}_{2} \mathrm{OF}_{8} \text { (s) } \underset{800^{\circ}}{\mathrm{PaF}_{5}} \text { (s) + unidentified solid }
$$

The chemical and phase relationships between Pa2OF8 and PaF5 at high temperatures are very poorly understood at present.

$\mathrm{PaF}_{5} \cdot 2 \mathrm{H}_{2} \mathrm{O}$.

The pentafluoride hydrate previously described by Grosse ${ }^{2}$ was made by dissolving $\mathrm{Pa}_{2} \mathrm{O} 5$ in 48 per cent hydrofluoric acid and evaporating the solution to dryness at $110^{\circ}$. The solution was contained in a platinum boat inside a copper tube, which was flushed out with a slow current of dry air during the evaporation. A solid mass of colorless, needlelike crystals was obtained.

Chemical analysis (for protactinium and fluorine only) indicates that this material is probably the dihydrate $\mathrm{PaF}_{5} \cdot 2 \mathrm{H}_{2} \mathrm{O}$. [Found: $\mathrm{Pa}, 62.5 ; \mathrm{F}, 25.4,25.7 \%$. Required for $\mathrm{PaF} 5 \cdot 2 \mathrm{H}_{2} \mathrm{O}: \mathrm{Pa}$, 63.81; F, 26.24; H, 1.11; 0, 8.84\%.] The crystals are hygroscopic and have a wax-like consistency. Attempts to load samples into $x$-ray capillaries were unsuccessful, since the crystals smeared when touched with a spatula.

The translucent crystals decomposed when heated for several. hours at $160^{\circ}$ in a stream of dry air. A powdery white solid was obtained, which was shown by $x$-ray analysis to be Pa.OF8. Equations (7) and (8) indicate the reactions yielding the dihydrate and oxyfluoride (gaseous products not analyzed).

$$
\begin{aligned}
& \mathrm{Pa}_{2} \mathrm{O}_{5}(\mathrm{~s})+\left[\mathrm{HF}, \mathrm{H}_{2} \mathrm{O}\right](\mathrm{aq}) \underset{25^{\circ}}{\rightarrow} \text { Solution } \underset{110^{\circ}}{\rightarrow} 2 \mathrm{PaF}_{5} \cdot 2 \mathrm{H}_{2} \mathrm{O}(\mathrm{s}) \\
& \quad 2 \mathrm{PaF}_{5} \cdot 2 \mathrm{H}_{2} \mathrm{O}(\mathrm{s}) \underset{160^{\circ}}{\longrightarrow} \mathrm{Pa}_{2} \mathrm{OF}_{8}(\mathrm{~s})+2 \mathrm{HF}(\mathrm{g})+\mathrm{H}_{2} \mathrm{O}(\mathrm{g})
\end{aligned}
$$

The aqueous route allows the volatile oxyfluoride and pentafluoride to be prepared [reactions (8) and (6)] without the use of fluorine or other vigorous fluorinating agents. It may therefore have some utility for both chemical and radiochemical separations. 


\section{Analytical Methods}

The pyrohydrolysis apparatus used for fluoride analyses is shown in Figure 3. Its design was similar to that of others described in the literature15-17. The steam generator consisted of a $500 \mathrm{ml}$. Pyrex flask heated by a Glas-Col mantle (not shown). The weighed sample ( 5 to $30 \mathrm{mg}$. of compound) was contained in a smal1 platinum boat inside a nickel tube, 9 inches long and $3 / 8$ inch in outer diameter, which was heated by a tube furnace. A welded nickel side-arm tube, cooled by a water jacket, delivered condensate to a flask containing standard NaOH solution. The sample was pyrohydrolyzed for approximately 30 minutes, and the $\mathrm{NaOH}$ solution was replaced every 10 minutes, so that the total condensate was obtained in three parts. The excess $\mathrm{NaOH}$ in each solution was back titrated with standard HCl to determine the amount of HF collected. Generally 95 per cent or more of the total HF appeared in the first flask.

In the pyrohydrolysis of uranium tetrafluoride and other non-volatile fluorides, a temperature of $1000^{\circ} \mathrm{C}$ or higher is required. When the first sample of $\mathrm{PaF}_{4}$ was rapidly pyrohydrolyzed at $1000^{\circ}$, very little oxide was found afterwards in the boat. Presumably the volatile oxyfluoride was formed as an intermediate, which decomposed downstream in the nickel tube, since the correct amount of $\mathrm{HF}$ was recovered. Subsequently the fluoride samples were inserted in the tube at approximately $300^{\circ}$, and the temperature was raised to $700^{\circ}$ during the first 10 minutes of pyrohydrolysis. Under these conditions, negligible losses occurred, and the oxide residues were recovered. It was found that $\mathrm{PaF}_{5}$, $\mathrm{Pa} 2 \mathrm{OF} 8$, and $\mathrm{PaF}_{5} \cdot 2 \mathrm{H}_{2} \mathrm{O}$, as well as $\mathrm{PaF} 4$, could be pyrohydrolyzed in this manner. In some instances, weighed deposits of $\mathrm{PaF}_{5}$ and $\mathrm{Pa}_{2} \mathrm{OF} 8$ in platinum tubes were inserted directly in the apparatus, eliminating the transfer to platinum boats.

The recovered protactinium oxide was weighed and dissolved in 48 per cent hydrofluoric acid. After several large dilutions with 6 to 12 M hydrofluoric acid (made on a weight rather than a volume basis), aliquots of solution were plated on platinum discs by the method of $\mathrm{E}$. F. Westrum, Jr.I8 Alpha pulse analyses were made of the discs, and the total amount of $\mathrm{Pa} 231$ was calculated, using a half-life of 34,000 years. The amount of Pa231 determined gravimetrically, assuming the oxide formed by pyrohydrolysis to be $\mathrm{Pa}_{2} \mathrm{O}_{5}$, was generalIy lower by 2 to 3 per cent than that determined by alpha counting. The radiochemical results were used in calculating the amounts of protactinium in the fluorides 19 .

\section{Crystallographic Data}

The $\mathrm{X}$-ray powder data for PaF4, $\mathrm{PaF}_{5}$, and $\mathrm{Pa} 2 \mathrm{OF} 8$ are given in Tables I, II, and III, respectively. Photographs were made with a $9 \mathrm{~cm}$. camera, using copper radiation. 


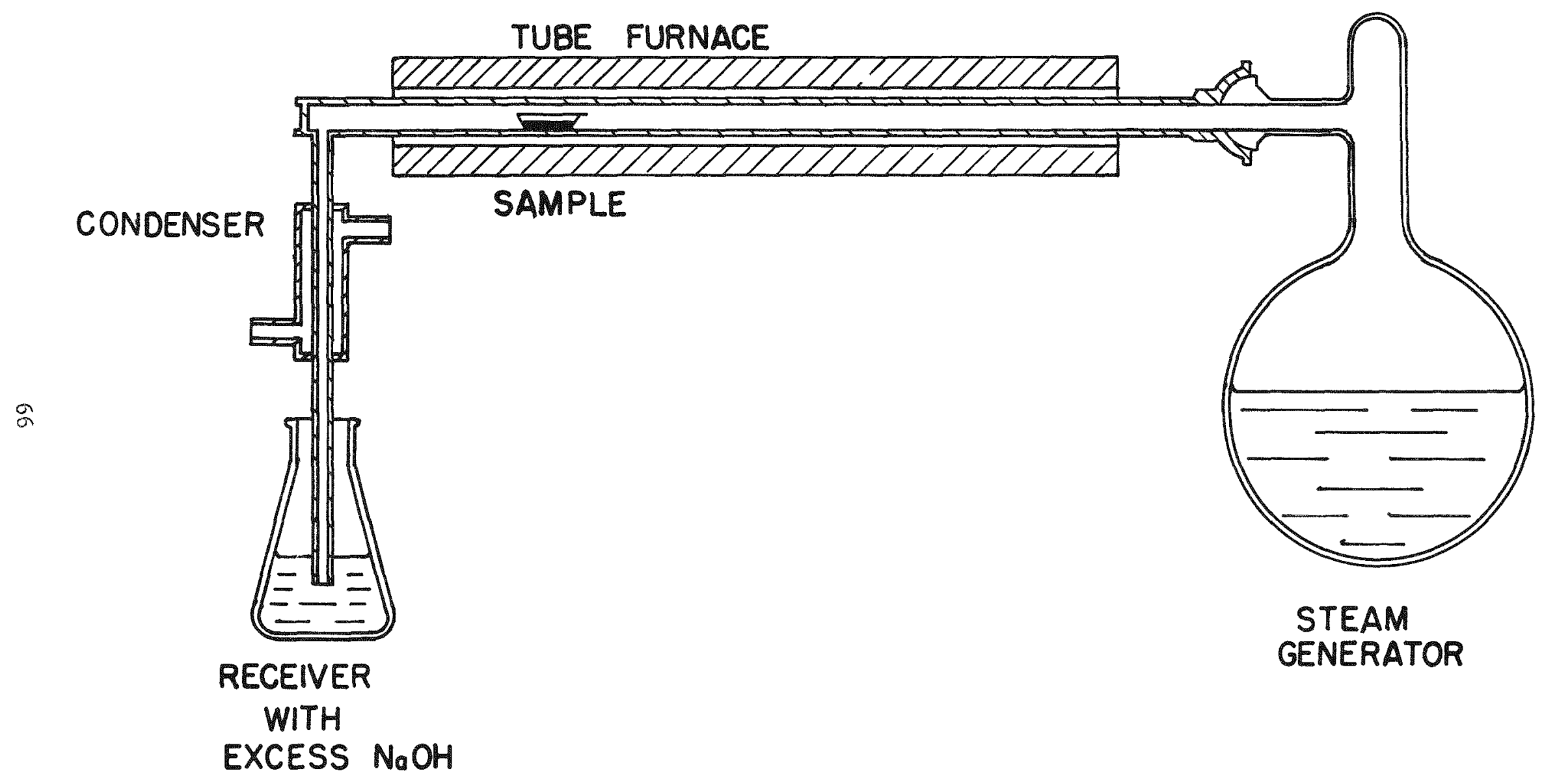

Fig. 3 Pyrohydrolysis Mpparatus 
Table I

$\mathrm{PaF}_{4}$; monoclinic (isostructural with $\mathrm{UF}_{4}$ )

\begin{tabular}{llll}
$I_{0}$ & $\sin ^{2} \theta$ & $I_{0}$ & $\sin ^{2} \theta$ \\
\hline$M$ & .03385 & & \\
$W$ & .03861 & $V W$ & .09538 \\
$M$ & .04377 & $V V W$ & .13235 \\
$W$ & .04618 & $W$ & .14148 \\
$W$ & .05365 & $W$ & .15564 \\
$W$ & .08066 & $W$ & .16416 \\
$W$ & & $V W$ & .17537
\end{tabular}


Table II

$\mathrm{PaF}_{5}$; tetragonal (isostructural with $\beta \mathrm{UF}_{5}$ )

$$
\begin{aligned}
& a_{0}=11.53 \pm 0.01 \AA \\
& c_{0}=5.19 \pm 0.01 \AA
\end{aligned}
$$

\begin{tabular}{|c|c|c|c|c|c|}
\hline$I_{0}$ & hkI & $\sin ^{2} \theta$ & $I_{0}$ & $h k I$ & $\sin ^{2} \theta$ \\
\hline W & 101 & .02648 & W & 541 & .20611 \\
\hline$W$ & 220 & .03576 & W & 700 & .21946 \\
\hline S & 211,310 & .04467 & VW & 522 & .24064 \\
\hline$W$ & & .05007 & $W$ & 721 & .26029 \\
\hline VW & 321 & .08077 & $W$ & 622 & .26686 \\
\hline VVW & 420 & .09099 & W & 413 & .27350 \\
\hline$W$ & 112,411 & .09811 & $\ddot{W}$ & 651 & .29522 \\
\hline VW & 202 & .10599 & $W$ & 712 & .31251 \\
\hline W & 501,431 & .13434 & VVW & 642 & .32152 \\
\hline VVW & & .14959 & Ft & 750 & .33763 \\
\hline$W$ & 521,530 & .15256 & W & 840 & .35790 \\
\hline VW & Bon & .16060 & VW & 543 & .38006 \\
\hline VW & 600 & .16840 & Ft & 822 & .39514 \\
\hline VVW & 620,422 & .18164 & Ft & 930 & .40245 \\
\hline VVW & 611 & .18829 & Ft & 752 & .42070 \\
\hline
\end{tabular}


Table III

$$
\begin{aligned}
\mathrm{Pa}_{2} \mathrm{OF}_{8} ; \text { body-centered cubic } \\
\left(\text { similar to } \mathrm{U}_{2} \mathrm{~F}_{9}\right) \\
\mathrm{a}_{\mathrm{O}}=8.4065 \pm 0.0004 \mathrm{~A} ; \mathrm{z}=4
\end{aligned}
$$

\begin{tabular}{|c|c|c|c|c|c|}
\hline$I_{0}$ & hkI & $\sin ^{2} \theta$ & $I_{0}$ & $h k 1$ & $\sin ^{2} \theta$ \\
\hline W & 110 & .01667 & VW & 800 & .53923 \\
\hline $\begin{array}{l}\text { MW } \\
\text { M }\end{array}$ & 200 & .03376 & $W$ & $811,7^{1}$ & .55603 \\
\hline $\begin{array}{l}\mathrm{M} \\
\mathrm{VW}\end{array}$ & 211 & .05105 & & 554 & \\
\hline $\begin{array}{l}\text { VW } \\
\text { VW }\end{array}$ & $\begin{array}{l}220 \\
370\end{array}$ & .06762 & VW & 820,644 & .57277 \\
\hline $\begin{array}{l}\text { VW } \\
\text { VWW }\end{array}$ & 310 & .08480 & VVW & 653 & .58860 \\
\hline $\begin{array}{l}\text { VWW } \\
\text { VW }\end{array}$ & $\begin{array}{l}222 \\
321\end{array}$ & .10147 & VW & 822,660 & .60677 \\
\hline $\begin{array}{l}\text { VW } \\
\mathrm{S}\end{array}$ & $\begin{array}{c}321 \\
411,330\end{array}$ & .11861 & VVW & 831,750, & .62292 \\
\hline$W$ & $\begin{array}{c}41,330 \\
332\end{array}$ & .18602 & VW & 662 & .63793 \\
\hline VW & 422 & .20266 & VW & 921,761 & .72435 \\
\hline $\begin{array}{l}\text { VW } \\
\text { VWW }\end{array}$ & 510,431 & .21958 & & 655 & \\
\hline $\begin{array}{l}\text { VVW } \\
\text { W }\end{array}$ & $\begin{array}{c}521 \\
530,433\end{array}$ & $\begin{array}{r}.25270 \\
28708\end{array}$ & VW & $\begin{array}{c}930,851 \\
754\end{array}$ & .75636 \\
\hline$W$ & 600,442 & .30373 & VW & 932,763 & .78949 \\
\hline $\begin{array}{l}W \\
V W\end{array}$ & 611,532 & .32065 & MW & $941,853,1$ & 2501 \\
\hline $\begin{array}{l}\text { VW } \\
\text { VW }\end{array}$ & $\begin{array}{l}620 \\
541\end{array}$ & .33781 & & 770 & 84 \\
\hline$V W$ & 541 & .35412 & VW & 860 & \\
\hline VW & 622 & .37062 & W & $10,11,772$ & .85840 \\
\hline VW & 631 & .38725 & WW & $10,20,862$ & .87283 \\
\hline VW & 444 & .40539 & Ft & 950,943 & .89068 \\
\hline WW & $\begin{array}{c}710,550, \\
543\end{array}$ & .42200 & $\begin{array}{l}\text { Ft } \\
W\end{array}$ & $\begin{array}{r}10,22,666 \\
10,31,\end{array}$ & $\begin{array}{l}.90655 \\
.92589\end{array}$ \\
\hline MW & 721,633, & .45494 & & 952,765 & \\
\hline VW & 642 & .47 & & 774 & \\
\hline WW & 732,651 & .52 & & & \\
\hline
\end{tabular}




\section{Acknowledgement:}

I am much indebted to Dr. S. Siegel and Mrs. E. G. Sherry for the $x$-ray analyses and to Mr. D. J. Henderson for the alpha pulse analyses. I also wish to express my thanks to Dr. $K$. W. Bagnall of the Atomic Energy Research Establishment, Harwell, England, for providing initial samples of $\mathrm{Pa}^{23 I}$ and the inducement to undertake the present line of research. The work was begun during a visit to Harwell in 1959 and was later completed. at Argonne.

\section{References:}

(1) Based on work performed under the auspices of the U. S. Atomic Energy Commission and the U. K. Atomic Energy Authority.

(2) A. V. Grosse, Science, 80, 513 (1934).

3 H. Emmanuel-Zavizziano, Compt. rend., 202, 1053 (1936). J. Golden and A. G. Maddock, J. Inorg. Nữ . Chem., 2, 46 (1956).

(5) P. A. Sellers, S. Fried, R. E. Elson, and W. H. Zachariasen, J. Am. Chem. Soc., 76, 5935 (1954).

(6) $\bar{M}$. Haissinsky and G. Bouissieres, Bull. Soc. chim. France, 18,146 (1951).

(7) H. J. Emeleus, A. G. Maddock, G. I. Miles, and A. G. Sharpe, J. Chem. Soc., 1948, 1991.

(8) F. T. Miles, R. J. Heus, and R. H. Wiswall, Jr., Report BNI 482 (T-109), November 1954.

(9) N. Jackson, F.J.G. Rogers, and J. F. Short, Report AERER3311, November 1960.

(10) A.J.'Walter, Report AERE-MI165, February 1963.

(1I) R. Muxart of the Institut du Radium has indicated that the compound prepared by reduction of $\mathrm{Pa}(\mathrm{V})$ in fluoride solutions, as described in reference (6), is white. It is doubtful that this material is the tetrafluoride, since not only the color but also the solubility is different.

(12) L. Stein, E. Rudzitis, and J. I. Settle, Report ANI-6364, June 1961.

(13) S. Cantor of Oak Ridge National Laboratory has remarked. that the free energy change for reaction (5) may be positive with the reactants and products shown. The number of moles of $\mathrm{HF}$ consumed and $\mathrm{H}_{2} \mathrm{O}$ Iiberated is the same as in the hydrofluorination of two moles of uranium dioxide:

$$
2 \mathrm{UO}_{2}(\mathrm{~s})+8 \mathrm{HF}(\mathrm{g}) \underset{550^{\circ}}{\longrightarrow} 2 \mathrm{UF}_{4}(\mathrm{~s})+4 \mathrm{H}_{2} \mathrm{O}(\mathrm{g})
$$

If it is assumed that bond energies of protactinium oxides and fluorides do not differ greatly from those of similar uranium compounds, reaction (5) is expected to have a small negative free energy change.

(14) W. H. Zachariasen, J. Chem. Phys., 16, 425 (1948).

(15) J. C. Warf, W. D. CIine, and R. D. Tevebaugh, Anal. Chem., 26,342 (1954).

(16) H. P. Silverman and J. F. Bowen, ibid., 31, 1960 (1959). 
(17) J. G. Surak, D. J. Fisher, C. I. Burros, and I. C. Bate, ibid., 32, 117 (1960).

(18) Whe Transuranium Elements," National Nuclear Energy Series, G. T. Seaborg, J. J. Katz, and W. M. Manning, Editors, McGraw-Hil1 Book Company, Inc., New York, 1949, Vol. I4B,

(19) A vart II, $p \cdot 1185$. $32,480^{\circ}$ years has recently been reported for the half-life of $\mathrm{Pa} 23]$ [H. W. Kirby, J. Inorg. Nucl. Chem., ra, 8 (1961)]. If this is used in the calculations, the gravimetric assay. The niobium impurity introduces a further complication, since it affects the two methods unequally. 


\section{Characterization of Protactinium \\ Species in Crystals and Solutions by Raman \\ and Infrared Spectroscopy}

O. L. KeIIer, Jr.

Oak Ridge National Laboratory*

\footnotetext{
* Operated by Union Carbide Nuclear Company for the U. S. Atomic Energy Commission.
}

Fundamental to the study of the chemistry of an element is the determination of the species it forms in aqueous and non-aqueous solutions. Until the species are determined, the chemist cannot write down the reactions that are characteristic of that element in solution, nor can he study reaction kinetics or make many of the other studies which ultimately result in an understanding of the chemistry of that element.

As far as I know, there is no species of protactinium which has been definitely characterized in aqueous solution. The usual thermodynamic methods cannot be applied to systems of interest for Pa because it hydrolyzes unless it is in fairly strong acid. In concentrated electrolytes, the problem of computing activity coefficients is too difficult to allow thermodynamic methods to be derinitive.

In thinking about the determination of $\mathrm{Pa}$ species in the specific system Pa-hydrofluoric acid, I would Iike to consider the use of Raman spectroscopy and infrared spectroscopy. 
Since water does not have any important Raman lines in the regions of general interest for inorganic species, Raman spectroscopy looks particularly promising. Identification of ions in solution can be accomplished simply by comparing the Raman spectra of the solutions with the Raman spectra of crystals of known composition and structure.

In working out the techniques for this method, I have looked at niobium species formed in HF solutions. We developed first of aII a $-\infty$ cell, Fig. 1, made from Kel-F which has a sapphire end window of good optical quality. The cell fits in the Raman machine so that the exciting mercury line enters through the Kel-F wall, and the Raman Iines leave the cell through the sapphire end window. In order to get good transmission of the mercury exciting line into the cell, the Kel-F tube was machined to a thickness of about 15 mils.

Using this cell we obtained Raman spectra of solutions of $\mathrm{K}_{2} \mathrm{NDF}_{\mathrm{r}}$ in solution from 0 to $50 \% \mathrm{HF}$. (1) In $40 \% \mathrm{HF}$ for example, we found a strong line at $685 \mathrm{~cm}^{-1}$ and a line of medium intensity at $275 \mathrm{~cm}^{-1}$. This spectrum is compared in Fig. 2 to that of crystals of $\mathrm{CsNbF}_{6}$ which shows a strong line at $683 \mathrm{~cm}^{-1}$, a line of medium intensity at $280 \mathrm{~cm}^{-1}$ and a weak line at $562 \mathrm{~cm}^{-1}$. In this way the $\mathrm{NbF}_{6}^{-}$ion is identified as being present in $40 \%$ HF solution.

The Raman spectrum of a solution of $\mathrm{K}_{2} \mathrm{IbF}_{7}$ in $1 \% \mathrm{HF}$ is quite different from that in $40 \%$ HF. A strong line appears at $920 \mathrm{~cm}^{-1}$, another strong line at $290 \mathrm{~cm}^{-1}$ and a weak line at $595 \mathrm{~cm}^{-1}$. The

(1) O. L. Keller, Jr., Inorg. Chem., 2, 783 (1963). 


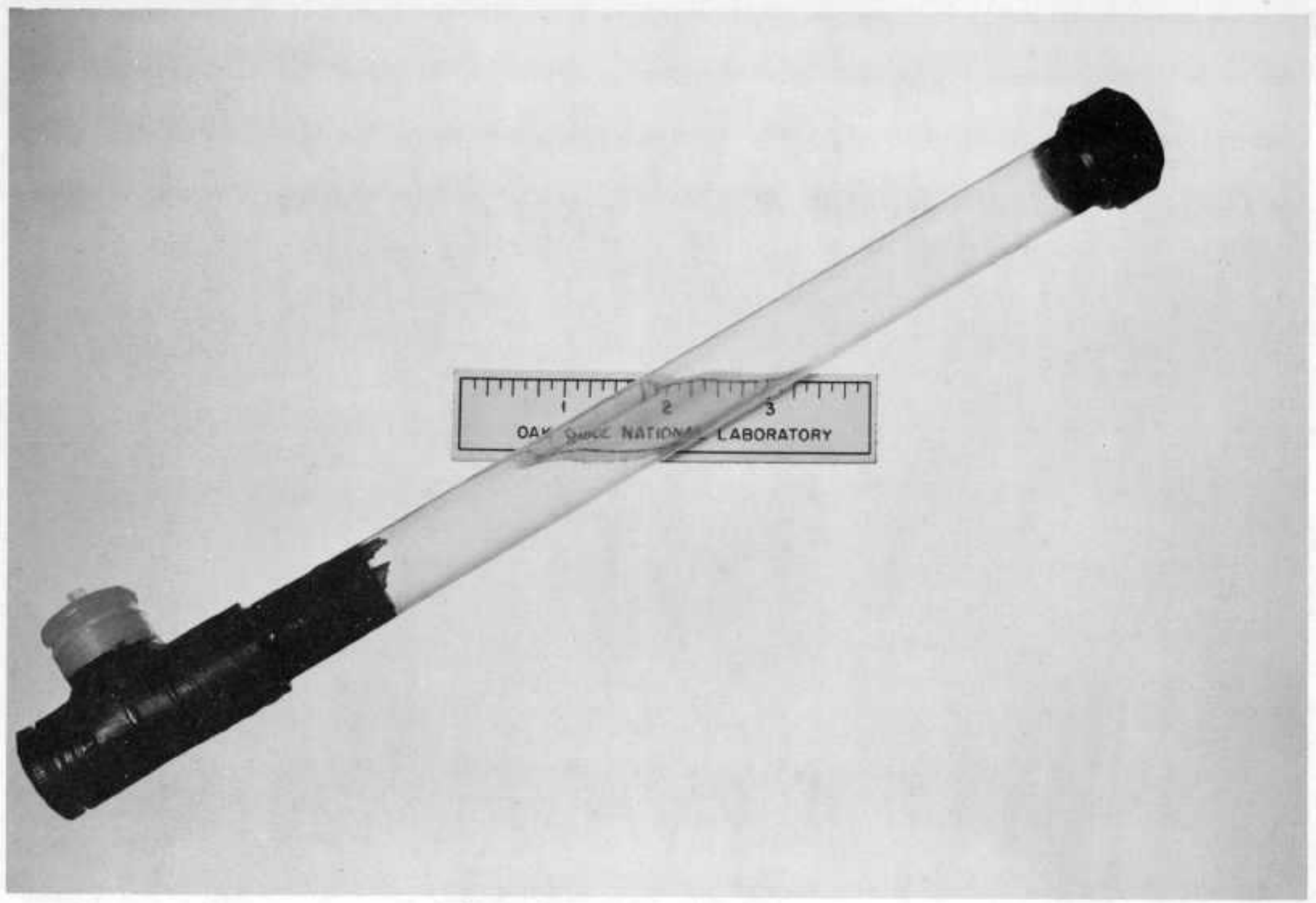

Ke1-F Raman Cell with Sapphire End Window for HF Solutions

Figure 1

- 


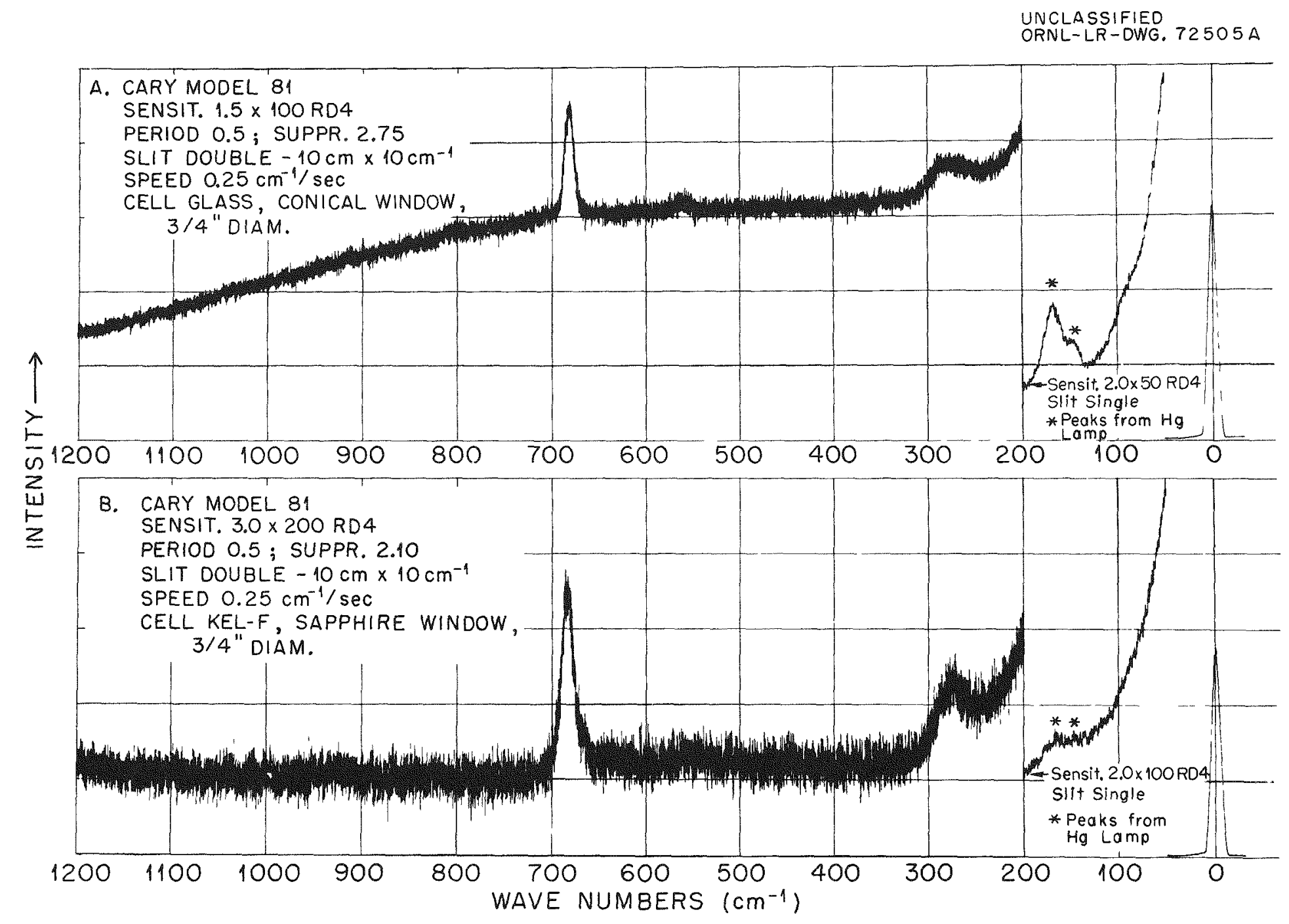

A. Poman Spectmon of Crystalline CoNbF

B. Reman Spectrum of $\mathrm{K}_{2}$ NhE , wh $4 \mathrm{C} \%$ HF solution 
solution spectrum is compared in Fig. 3 to that of $\mathrm{K}_{2} \mathrm{MbOF}_{5} \mathrm{H}_{2} \mathrm{O}$

which shows a strong Iine at $935 \mathrm{~cm}^{-1}$, another strong line at $295 \mathrm{~cm}^{-1}$ and a very weak line at $600 \mathrm{~cm}^{-1}$.

The salt $\mathrm{K}_{2} \mathrm{NbOF}_{5} \cdot \mathrm{H}_{2} \mathrm{O}$ could contain the $\mathrm{NbOF}_{5}{ }^{2-}$ ion plus water of hydration or it could contain the $\mathrm{Nb}(\mathrm{OH}) 2^{\mathrm{F}_{5}}{ }^{2-}$ ion. If we show that water of hydration is present, then we also show that the $\mathrm{NbOF}_{5}{ }^{2-}$ ion is present. In the infrared, the bending mode occurs for water of hydration at $1600-1630 \mathrm{~cm}^{-1}$. In our infrared spectrum, Fig. 4, we see this Iine occurring at 1626, so we know that in the crystals and in $1 \% \mathrm{HF}^{\prime}$, niobium is present as the species $\mathrm{NbOF}_{5}^{2-}$.

In adapting the Raman method to protactinium, it is necessary to develop smaller cells. I have first of all developed small cells for the crystal spectra. The cells used in the niobium problem have volumes of 5 to $15 \mathrm{mIs}$. The cell pictured in Fig. 5 has a capacity of $0.7 \mathrm{mIs}$ and gives quite good spectra for test compounds we have run. The celI is two concentric cones, and the crystals fit between these cones. The exciting mercury line enters the crystals through the outside cone and the Raman scattered Iight leaves the cell through the inner cone.

In choosing a crystalline compound of protactinium to get the first Raman spectrum, the obvious choice is $\mathrm{K}_{2} \mathrm{PaF}_{7} \cdot \mathrm{K}_{2} \mathrm{NbF}_{r}$ is the most easily prepared compound of niobium. It is formed by adding KF to a solution of $\mathrm{lWb}$ in strong $\mathrm{HF}$, and can be recrystallized easily from strong HF since it is much more soluble in hot solution than in cold. Similarly $\mathrm{K}_{2} \mathrm{TaF}_{7}$ is the most readily prepared compound of tantalum. Furthermore, in 1934 A. V. Grosse ${ }^{(2)}$ reported the preparation

(2) A. V. Grosse, J. Am. Chem. Soc., 56, 2501 (1934). 


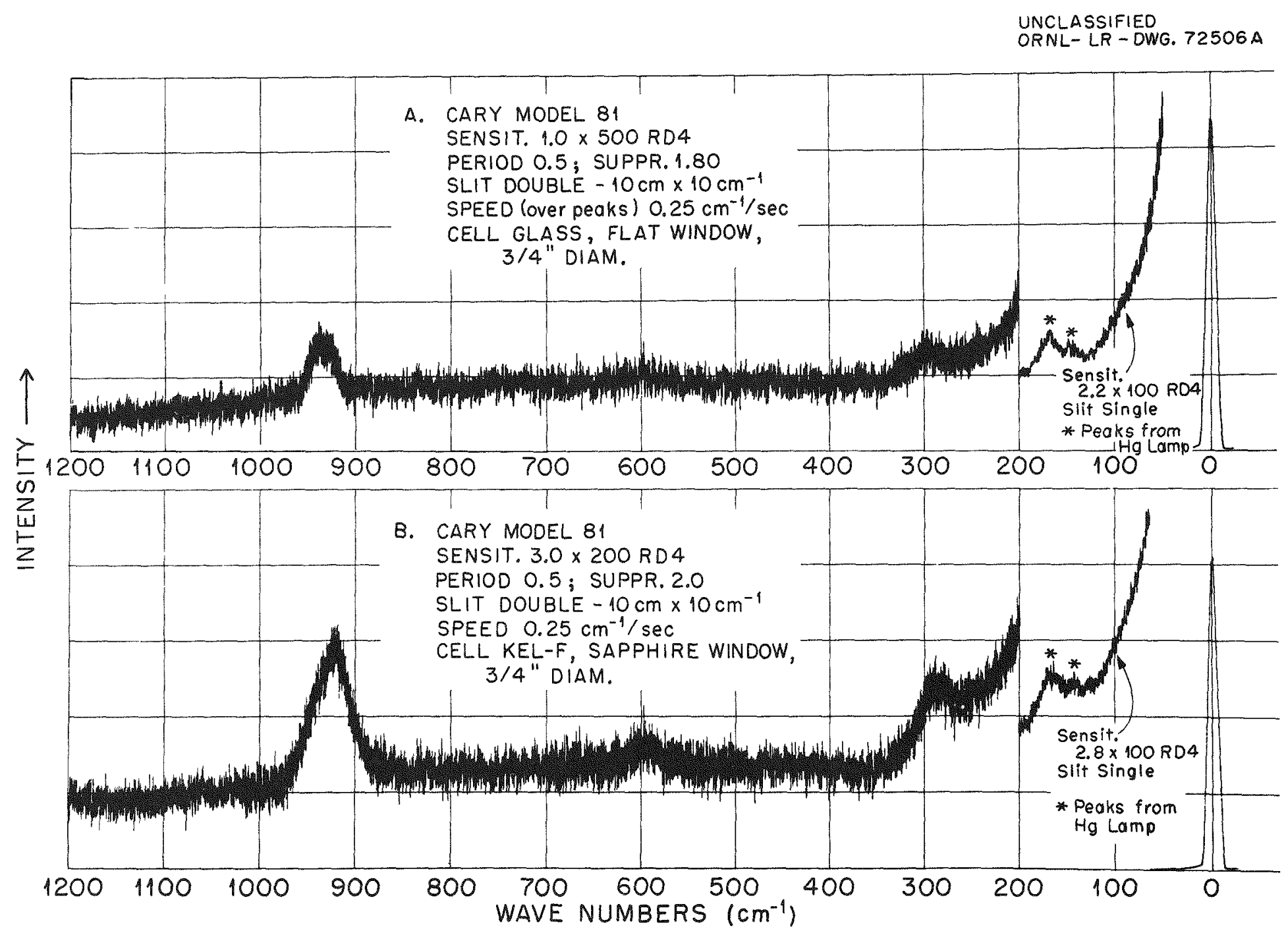

A. Raman Spectrum of $\mathrm{Crystalline} \mathrm{K}_{2} \mathrm{NbOF}_{5} \cdot \mathrm{H}_{2} \mathrm{O}$

B. Raman spectrum of $\mathrm{K}_{2} \mathrm{NbF}_{7}$ in $1 \%$ HF solution 
UNCLASSIFIED

ORNL-LR-DWG. 72507
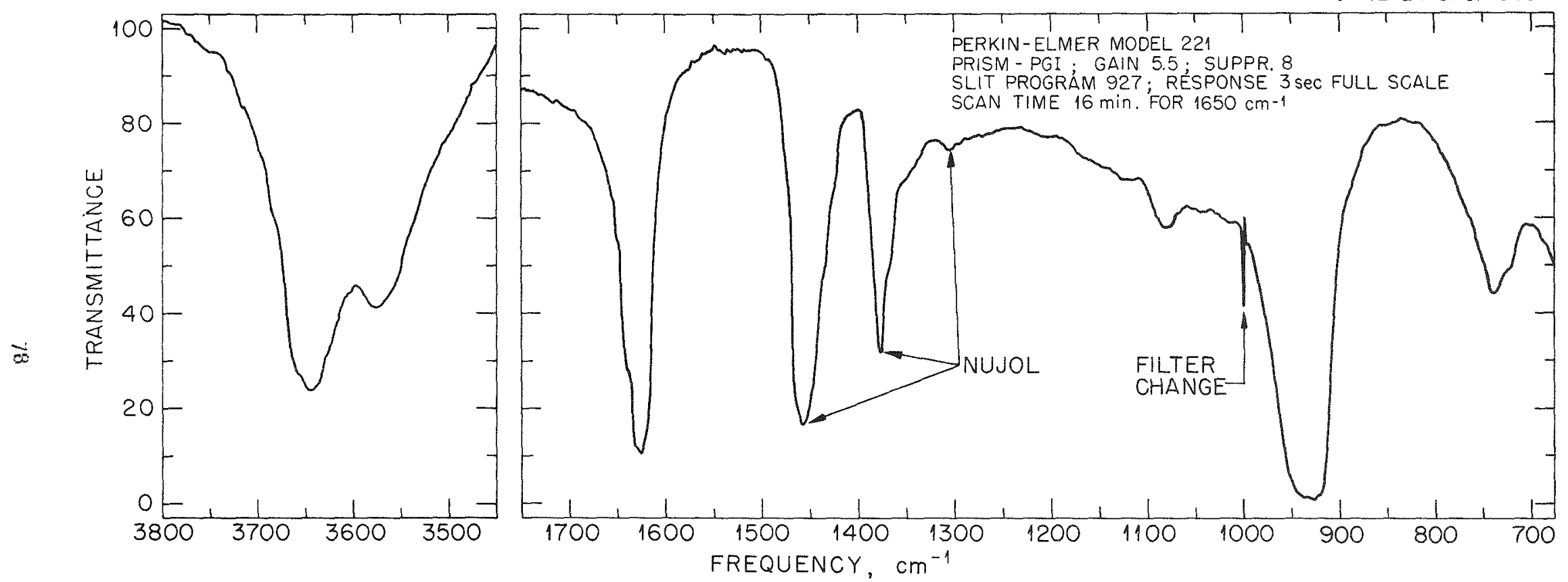

Infared Spectrun of Crystalline $\mathrm{K}_{2} \mathrm{NDOF}_{5} \cdot \mathrm{H}_{2} \mathrm{C}$

Figure

$I_{5}$ 


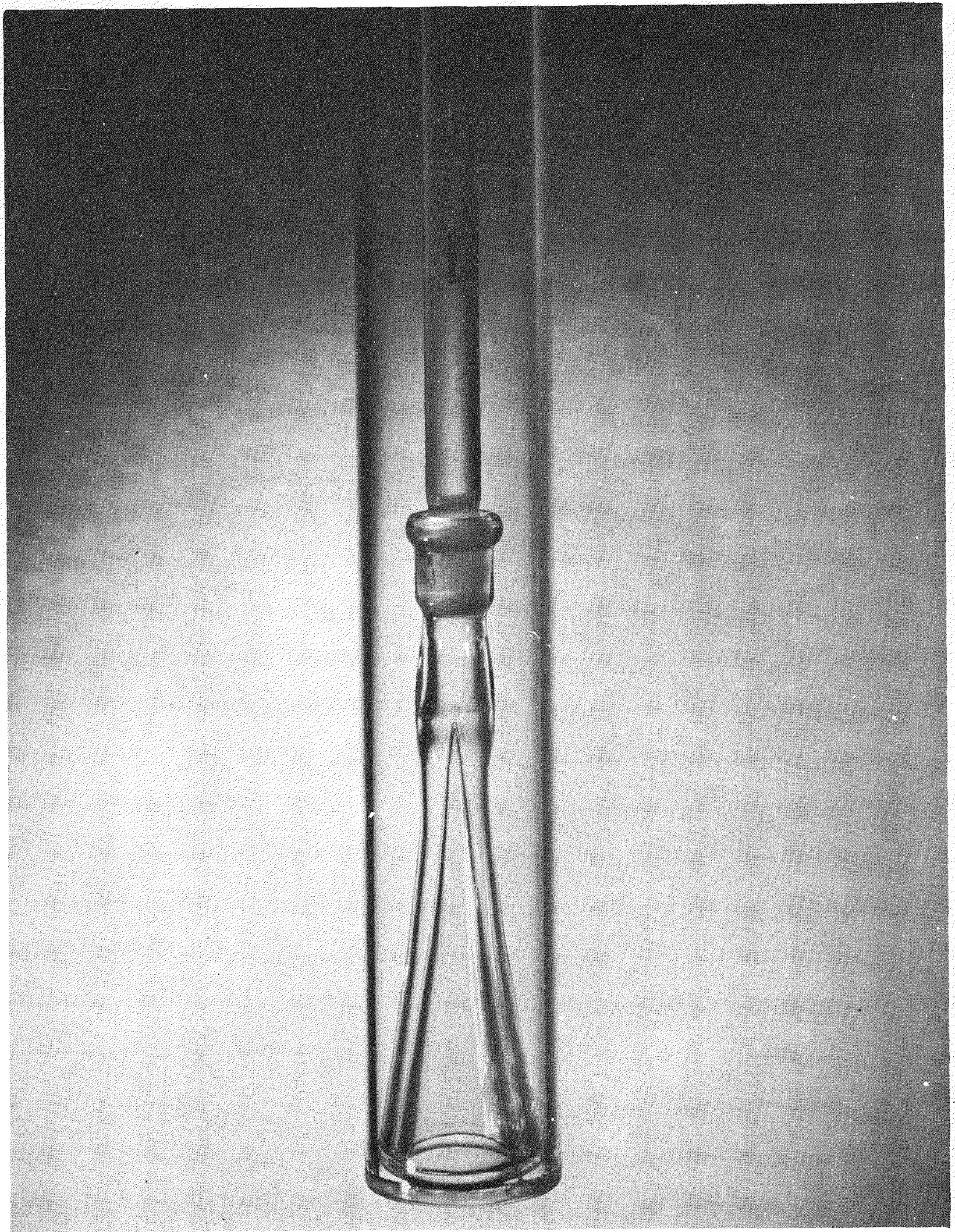

Conical Cell for Raman Spectra of Porders

Figure 5 
and analysis of $\left(\mathrm{K}_{2} \mathrm{PaF}_{7}\right)$ and said it was prepared just like $\mathrm{K}_{2} \mathrm{TaF}_{7}$

I made a preparation by dissolving $\mathrm{Pa}_{2} \mathrm{O}_{5}$ in $35 \% \mathrm{HF}$ and crystallizing by adding $\mathrm{KF}$. The crystals obtained were dissolved in a minimum amount of $25 \% \mathrm{HF}$ at $75^{\circ}$ and allowed to crystallize by cooling to $0^{\circ}$ in ice.

The Raman spectrum of $\mathrm{K}_{2} \mathrm{NbF}_{7}$ is shown in $\mathrm{Fig}$. 6. This spectrum has a very strong sharp line at $630 \mathrm{~cm}^{-1}$, a line of medium intensity at $388 \mathrm{~cm}^{-1}$ and a weak line at $782 \mathrm{~cm}^{-1}$. The spectrum of the $\mathrm{Pa}$ compound, Fig. 7, shows no similarity to the $\mathrm{K}_{2} \mathrm{NbF}_{7}$. The very broad peak which occurs at 3100 to $3200 \mathrm{~cm}^{-1}$ suggests a hydrolytic polymeric species. The line at $545 \mathrm{~cm}^{-1}$ may be due to the presence of $\mathrm{K}_{2} \mathrm{PaF}_{7}$.

Examination of the crystals under a microscope showed some needlelike crystals, which by analogy with needle-like $\mathrm{K}_{2} \mathrm{NbF}_{7}$ and $\mathrm{K}_{2} \mathrm{TaF}$ were almost certainly $\mathrm{K}_{2} \mathrm{PaF}_{7}$. Mixed with the needles were waxylooking ill-formed crystals.

Another crystallization was made by dissolving the crystals in $50 \% \mathrm{HF}$, letting the solution sit overnight, and crystallizing by adding a small amount of solid KF. Since it might be that heating the solution of $\mathrm{Pa}$ in $\mathrm{HF}$ will cause hydrolysis, neither the solutions nor the crystals were heated at any time. The crystals obtained were exceedingly fine and powdery. Their Raman spectrum was taken and is similar to that obtained from the $25 \%$ HF recrystallization.

I do not believe the preparations we have made so far give a true view of the chemistry of $\mathrm{Pa}$, but rather reflect that oxides of heavy metals age and HF, even $50 \%$ HF, does not completely break them down. 


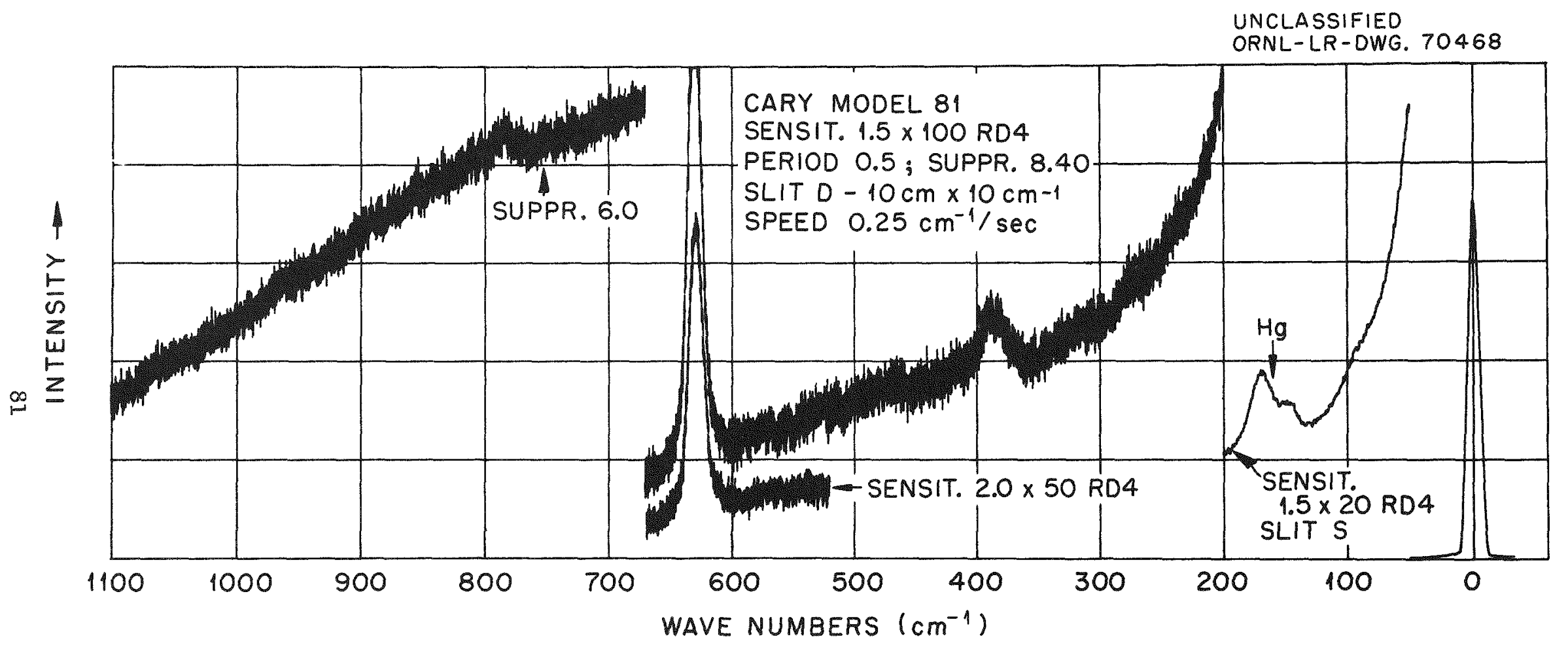

Raman Spectrum of Crystalline $\mathrm{K}_{2} \mathrm{NbF}_{7}$

Figure 6 

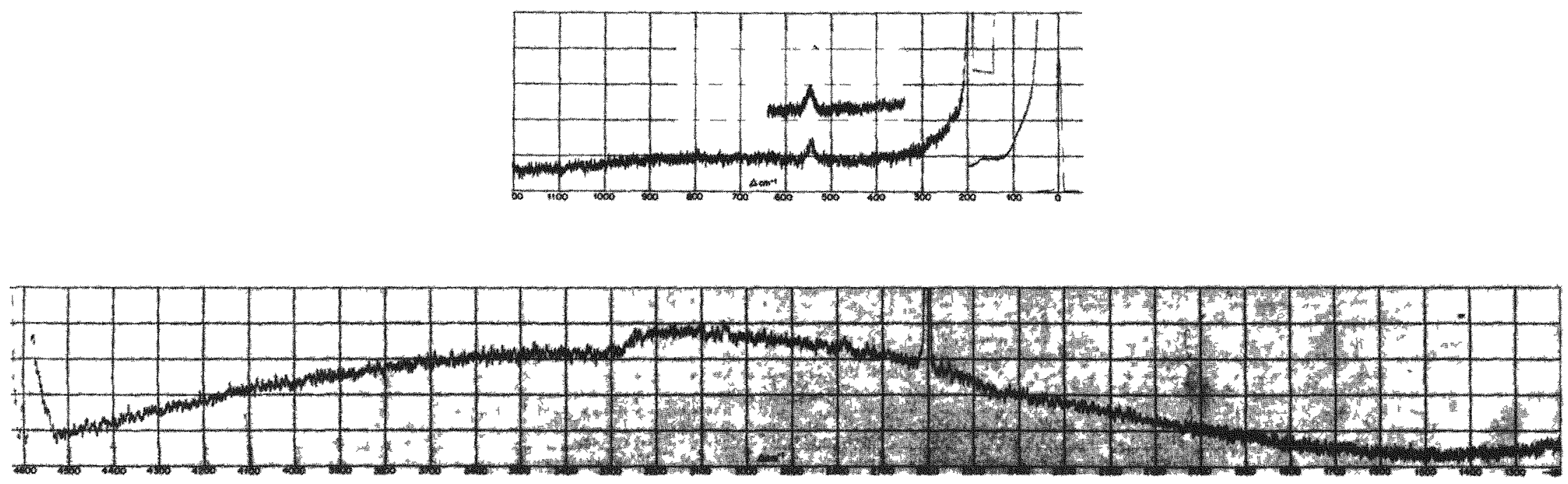

Raman Spectrum of Protactinium Salt Crystallized from HF (see text).

\section{Figure 7}


In line with this idea, I have one more result to report. Some few milligrams of $\mathrm{Pa}$ which we have were sent to us by Harold Kirby of Mound Laboratory. The $\mathrm{Pa}$ was dissolved in sulfuric acid. This Pa should be in a form which would readily allow $\mathrm{K}_{2} \mathrm{PaF}_{r}$ to be prepared in the conventional way. A preparation was made from this $P a$ by recrystallizing from $10 \% \mathrm{HF}$. A photomicrograph, Fig. 8 , of the resulting crystals shows that we have the needle-like crystals expected for $\mathrm{K}_{2} \mathrm{PaF}_{7}$ but also many smaller crystals of another shape, which suggests that we have a mixture of two different compounds. An x-ray powder picture of the crystals was taken by R. I. Sherman. Eleven of the 28 lines found had $\sin ^{2} \Phi$ ratios consistent with a body centered cubic structure. Since $\mathrm{KNbF}_{6}$ and $\mathrm{KTaF}_{6}$ have body centered cubic structures, the $x$-ray results suggest that $\mathrm{KPaF}_{6}$ is present along with $\mathrm{K}_{2} \mathrm{PaF}_{r}$. The crystals were analyzed by $\alpha$-counting the $\mathrm{Pa}$ in a known weight of the crystals. For $\mathrm{K}_{2} \mathrm{PaF}_{7}$ the ratio of $\mathrm{Pa}$ to $\mathrm{K}_{2} \mathrm{PaF}_{7}$ is 0.5224 . For $\mathrm{KPaF}_{6}$ the ratio is 0.6014 . A ratio of 0.5597 was found experimentally so that a mixture of about $50-50 \mathrm{~K}_{2} \mathrm{PaF}_{7}$ and $\mathrm{KPaF}_{6}$ is suggested. In order to proceed with our Raman work, we must, of course, surmount these preparative problems.

There is one final aspect of this method which I think is of interest since many people here are interested in solvent extraction. One might think, for example, that determining that $\mathrm{NbF}_{6}^{-}$is the dominant species in $40 \%$ HF would insure that this is the species which would be extracted in a solvent extraction experiment. Actually this is not the case, and the Raman spectra of both the aqueous and non-aqueous phases would have to be studied. That this would be the case has been 


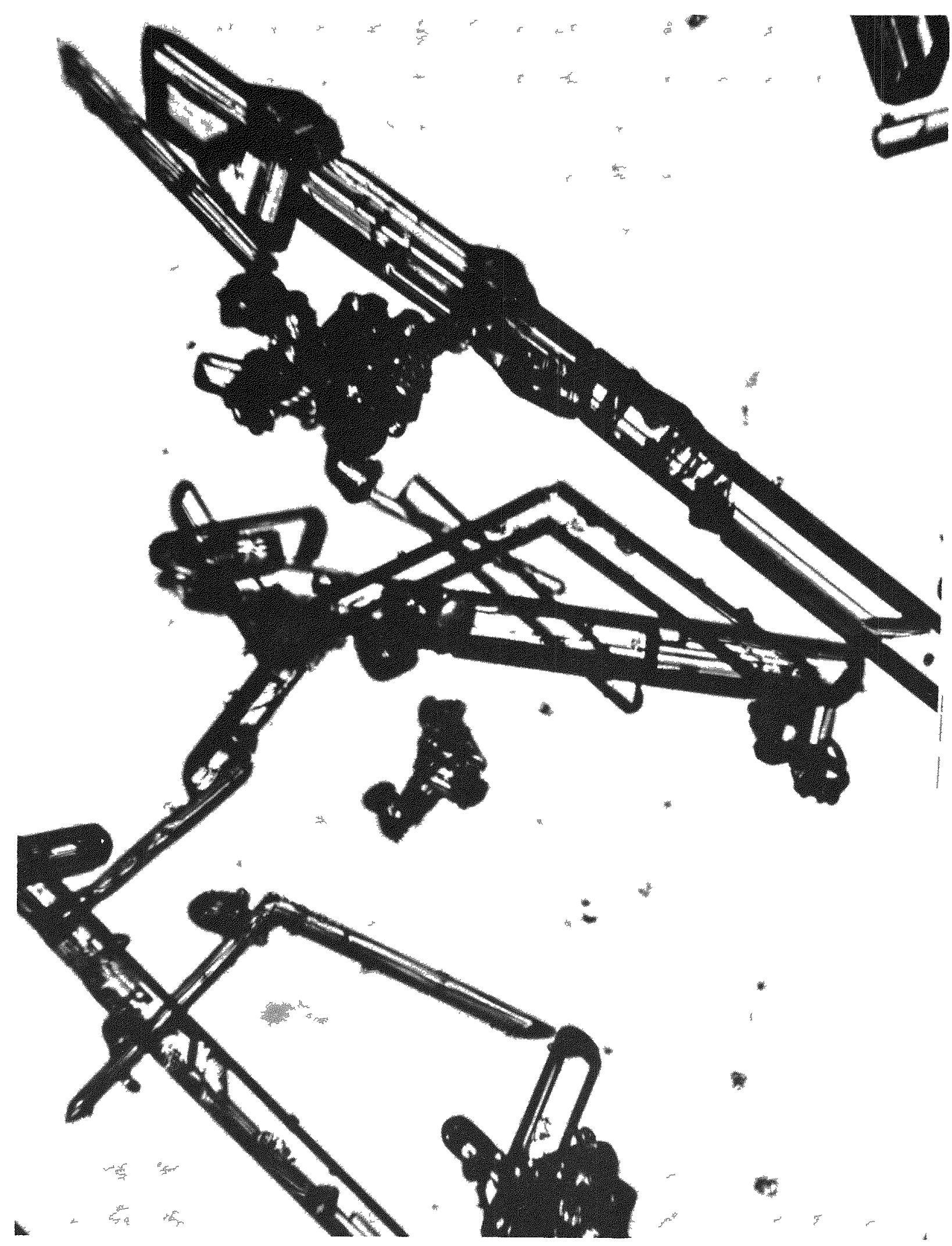

Photomicrograph of Protactinium Salt Crystallized from HF (see text).

Figure 8 
demonstrated in a beautifuI and definitive way by $\mathrm{S}$. Lindenbaum and G. E. Boyd at the Oak Ridge National Laboratory for a number of transition metal ion complexes. (3) For example, tri-iso-octyl amine, extracts the blue tetra coordinated $\mathrm{CoCl}_{4}^{-2}$ ion from I M HCI whose color is due to the hexa coordinated aquo ion, $\mathrm{Co}\left(\mathrm{H}_{2} \mathrm{O}\right)_{6}^{+2}$. One can telI by eye that the dominant species in the aqueous phase must be the aquo ion rather than the chloro ion, but Lindenbaum and Boyd found with their Cary 14 that there is no detectable $\mathrm{CoCl}_{4}{ }^{-2}$ ion in the aqueous phase. Similarly tri-iso-octyl amine extracts yellow $\mathrm{CuCl}_{4}{ }^{2-}$ from a solution of $\mathrm{CuCl}_{2}$ in water. The species present in the water solution is shown by the spectra to be $\mathrm{Cu}\left(\mathrm{H}_{2} \mathrm{O}\right)_{6}^{2+}$, which gives the solution its characteristic blue color. $\mathrm{No} \mathrm{CuCl}_{4}^{2-}$ is detectable in the water solution.

Therefore, to determine species of $\mathrm{Pa}$ meaningful in solvent extraction studies, Raman spectra of both the aqueous and non-aqueous phases will have to be taken.

(3) S. Lindenbaum and G. E. Boyd, J. Phys. Chem., 67, 1238 (1963). 


\title{
RECOVERY OF URANIUM AND PROTACTINIUM FROM MOLTEN FLUORIDE SYSTEMS BY PRECIPITATION AS OXIDES
}

J. H. Shaffer, G. M. Watson, D. R. Cuneo, J. E. Strain, M. J. Ke11y Oak Ridge National Laboratory

Operated by Union Carbide Corporation for the U. S. Atomic Energy Commission

\begin{abstract}
*
Fissionable $\mathrm{U}^{233}$ will be recovered from the blanket as the decay product of $\mathrm{Pa}^{233}$ in the conceptual two-region molten-salt breeder reactor. Equilibrium concentrations of $\mathrm{Pa}^{233}$ in the blanket mixture would result in appreciable parasitic neutron absorptions because of half-life and neutron absorption cross-section values. A method of precipitating uranium and protactinium as oxides from solution in a molten fluoride solvent was examined to demonstrate the possibility of exploiting the thermal-breeding potential of a molten-salt breeder reactor. Protactinium, present initially either in concentrations of about $1 \mathrm{ppb}$ or $50 \mathrm{ppm}$, was removed from molten mixtures of LiF-BeF $2-\mathrm{ThF}_{4}$ (67-18-15 mole \%) by the addition of 1 to $2 \mathrm{wt} \%$ solid beryllium or thorium oxides, apparently by precipitation of protactinium on the surface of the added oxide. The effective removal of approximately $2000 \mathrm{ppm}$ uranium from solution in the same solvent was also acconplished by the addition of 3 wt \% beryllium oxide $\mathrm{O}_{1}$ by the use of comparable amounts of $\mathrm{ThO}_{2}$ as the solid oxide precipitant.
\end{abstract}

*Paper to be published in Nuclear Science and Engineering. 


\title{
THE CHEMISTRY OF PROTACTINIUM IN SULFURIC ACID SOLUTIONS
}

\author{
D. 0. Campbe11
}

Oak Ridge National Laboratory*

The investigations reported here are concerned exclusively with sulfate and sulfuric acid solutions of protactinium. The two common inorganic acid systems in which protactinium is reasonably soluble are sulfuric and hydrofluoric. Hydrofluoric acid, usually mixed with hydrochloric acid, has been used for recovery and processing of appreciable amounts of protactinium. On the other hand, more fundamental studies of chemical behavior have generally been carried out with hydrochloric or nitric acid solutions. Since protactinium does form stable solutions in sulfuric acid it is surprising that more work has not been done with it. The major published investigation is that of Brown, Sato, Smith and Wilkins ${ }^{1}$ of Sheffield, and this includes references to earlier studies.

The most important knowledge gained from our experiments has been, in many cases, how to obtain better results if the experiment is repeated. Much of our early data will not be reported because of this. The major problem has been the reasonably precise determination of protactinium in the many samples. This is done by alpha counting, but such a count may not be correct unless the fraction of the activity that is due to protactinium is determined for the same sample plate by an alpha energy pulse analysis. This fraction may actually vary with duplicate samples prepared from the same solution because of variations in plate preparation. A method used by many investigators has been to start with carefully purified protactinium and assume that all activity measured subsequently is protactinium. But in distribution measurements in which the extraction is quite large the aqueous phase may contain predominantly protactinium daughter activity even though th original material was greater than $99 \%$ protactinium.

As better alpha pulse analyzers have been developed and as we have learned more about the behavior of protactinium and how to handle it we have been able, in most cases, to obtain results that are quite reproducible. However, occasional unexplained behaviox does still occur.

The species in solution or mechanisms of reaction have not been worked out for any portion of the sulfuric acid-protactinium system, but some of the major problem areas have been defined and methods have been developed to attack these problems. During these studies quite a bit has been learned about the behavior of protactinium in such solutions, and this behavior encourages speculation about the species that may be present and the mechanisms that may be operating.

Solubility. The initial work was an attempt to measure the solubility of $\mathrm{Pa}_{2} \mathrm{O}_{5}$ in sulfuric acid. Many of the samples were not pulse analyzed in this early work and little confidence can be placed in some of the results. In general, however, the measured solubilities were in accord with previously

*operated by Union Carbide Corporation for the U. S. Atomic Energy Comission. 
reported values, ${ }^{2}$ although perhaps somewhat larger. The solubility decreased smoothly from about $6 \mathrm{mg} / \mathrm{ml}$ in $9 \mathrm{~N} \mathrm{H}_{2} \mathrm{SO}_{4}$ to 1 to $2 \mathrm{mg} / \mathrm{ml}$ in $18 \mathrm{~N}$ acid. It appears to remain in this range as the acid concentration is increased to about $27 \mathrm{~N}$, at which point the solubility drops abruptly to about 0.10 to $0.15 \mathrm{mg} / \mathrm{ml}$ and remains near this range for higher acid concentrations.

At lower concentrations, below about $8 \mathrm{~N}$, reproducible results were not obtained generally. In some cases the "solution" became quite viscous and had the appearance of a gel. This is reported with some reservation because it is a casual observation from some very early work and it is not clear whether this effect resulted from the protactinium or something else.

Amine Extraction. Most of our work has been concerned with amine extraction experiments. The effects of amine concentration, acid concentration and type of amine have been investigated. Distribution coefficients decrease with increasing acid concentration, the effect being greater at higher acid concentrations (Fig. 1). All amines were dissolved in diethylbenzene, in this case to a concentration of $0.1 \mathrm{~N}$. The organic solutions were scrubbed repeatediy with water, sulfuric acid, sodium carbonate, and finally sulfuric acid again before use. Protactinium concentrations were determined by direct sampling and alpha counting with alpha pulse analysis, and aqueous acidities were determined by standard titrations.

Initially protactinium was in the aqueous phase and extracted into the organic. Subsequently distribution measurements were made by removing the aqueous and replacing it with fresh sulfuric acid solutions, thus back extracting the protactinium. Results were essentially the same for extractions in either direction.

of the three amines in Fig. 1 Primene $\mathrm{JM}-\mathrm{T}$, a primary amine with a tertiary carbon adjacent to the nitrogen, gave the highest extraction, and Alamine 336 , a symmetrical tertiary amine with straight chains, gave the lowest. All three gave curves of similar shape, with a change of slope around 8 to $9 \mathrm{~N}$ acid. The acid dependence is large in the higher acid concentration range, between fifth and eighth power.

Amines of the same type may have greatly differing extraction power as shown by the results for three secondary amines at $0.3 \mathrm{~N}$ concentration (Fig. 2). Highest extraction was obtained with $\mathbb{N}$-benzylheptadecyl amine with the aromatic benzyl group bonded to the nitrogen. Intermediate was IA-1 with a tertiary carbon adjacent to the nitrogen and a conjugate double bond, and lowest was S-24 with both chains having secondary carbons bonded to the nitrogen. The results with the amines that have been tested indicate a correlation between extraction strength and base strength of the amine.

The effect of amine concentration as well as acid concentration was investigated, and in all cases distribution coefficients increase smoothly with amine concentration ( $\mathrm{Fig}, 3$ ). N-benzylheptadecyl amine was used with a phase ratio of two organics to one aqueous and an initial protactinium concentration (aqueous) of $10^{-2} \mathrm{mg} / \mathrm{ml}$. For low amine concentrations the extraction coefficient increases approximately linearly with amine concentration, but the rate of increase tends to decrease above about $0.1 \mathrm{~N}$ amine. Similar curves were obtained for several other amines.

All the curves are approximately parallel except the highest one, for which the distribution coefficient dropped at the highest amine concentration. Two different sets of experiments of this same sort and with the same amine were run at different times, and in every case the same effect was observed. In both the other sets the acid concentration was $3.7 \mathrm{~N}$, and the distribution coefficient was lower with $0.3 \mathrm{~N}$ amine than $0.1 \mathrm{~N}$. It appears that this drop 


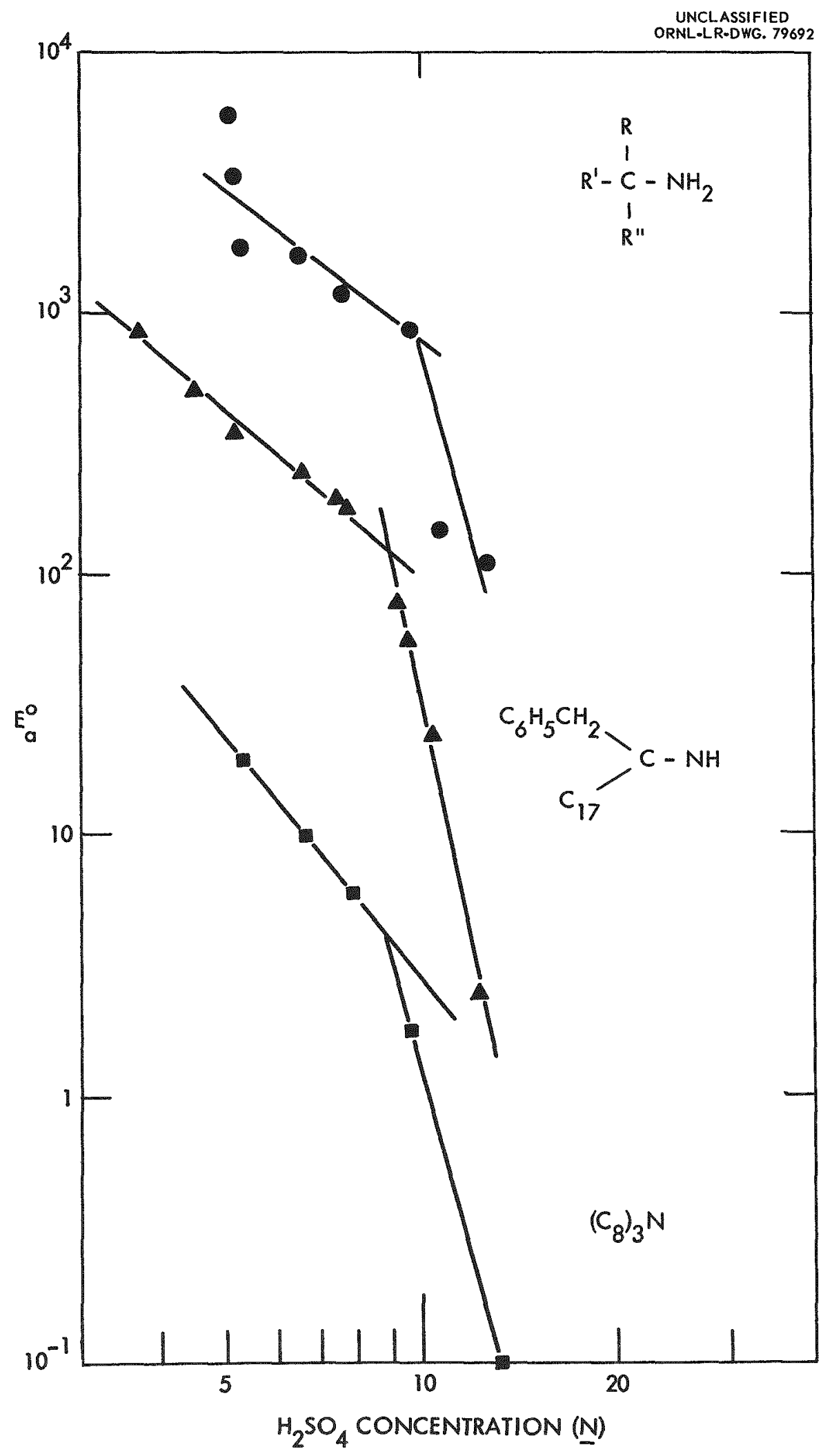

VARTATION OF EXTRACIION COEFFICIENT WTTH $\mathrm{H}_{2} \mathrm{SO}_{4}$ CONCENTRATION

Fig. 1 


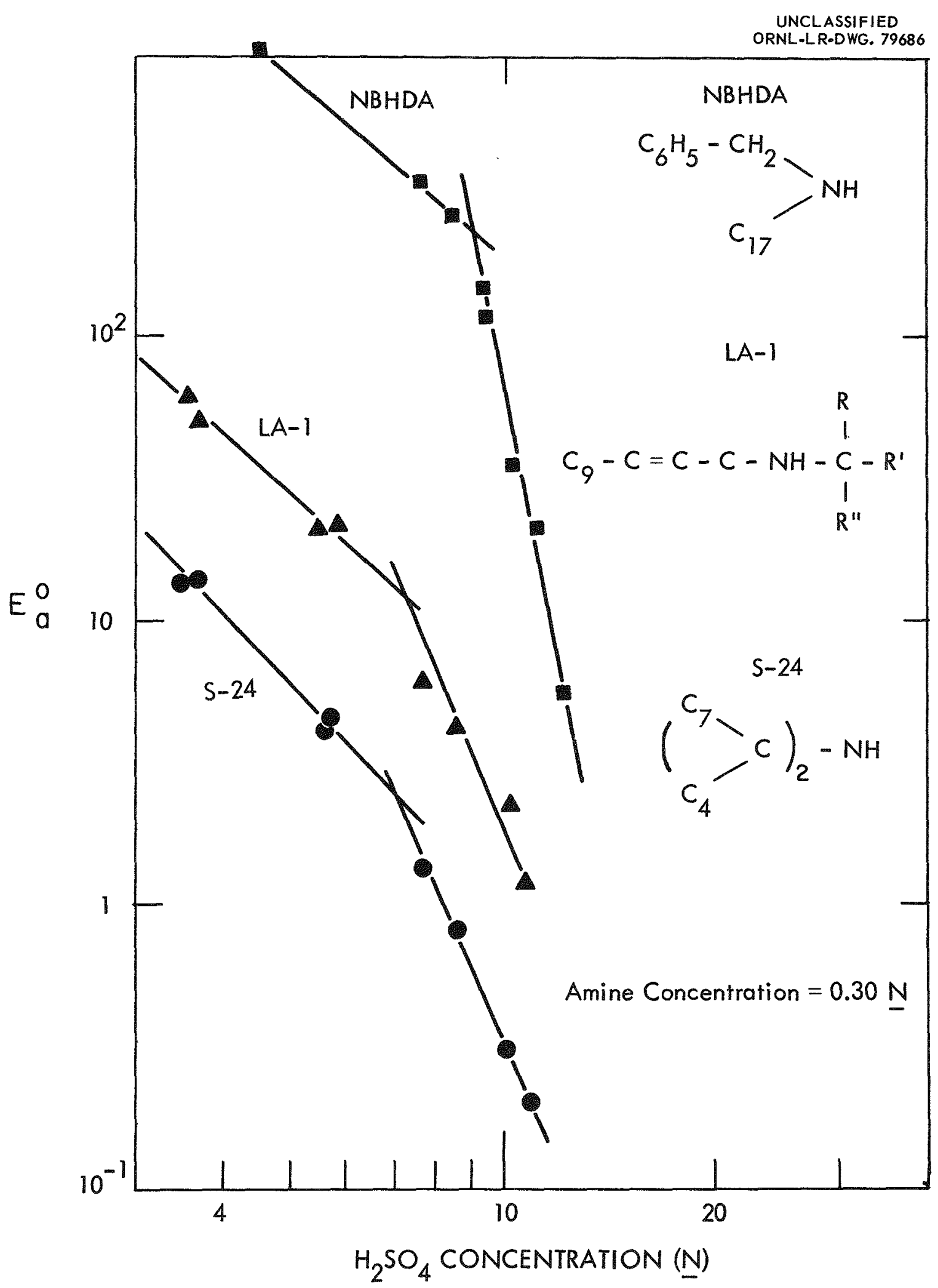

PROTACTINTUM EXTRACTTON BY SECONDARY AMINES

Fig. 2 


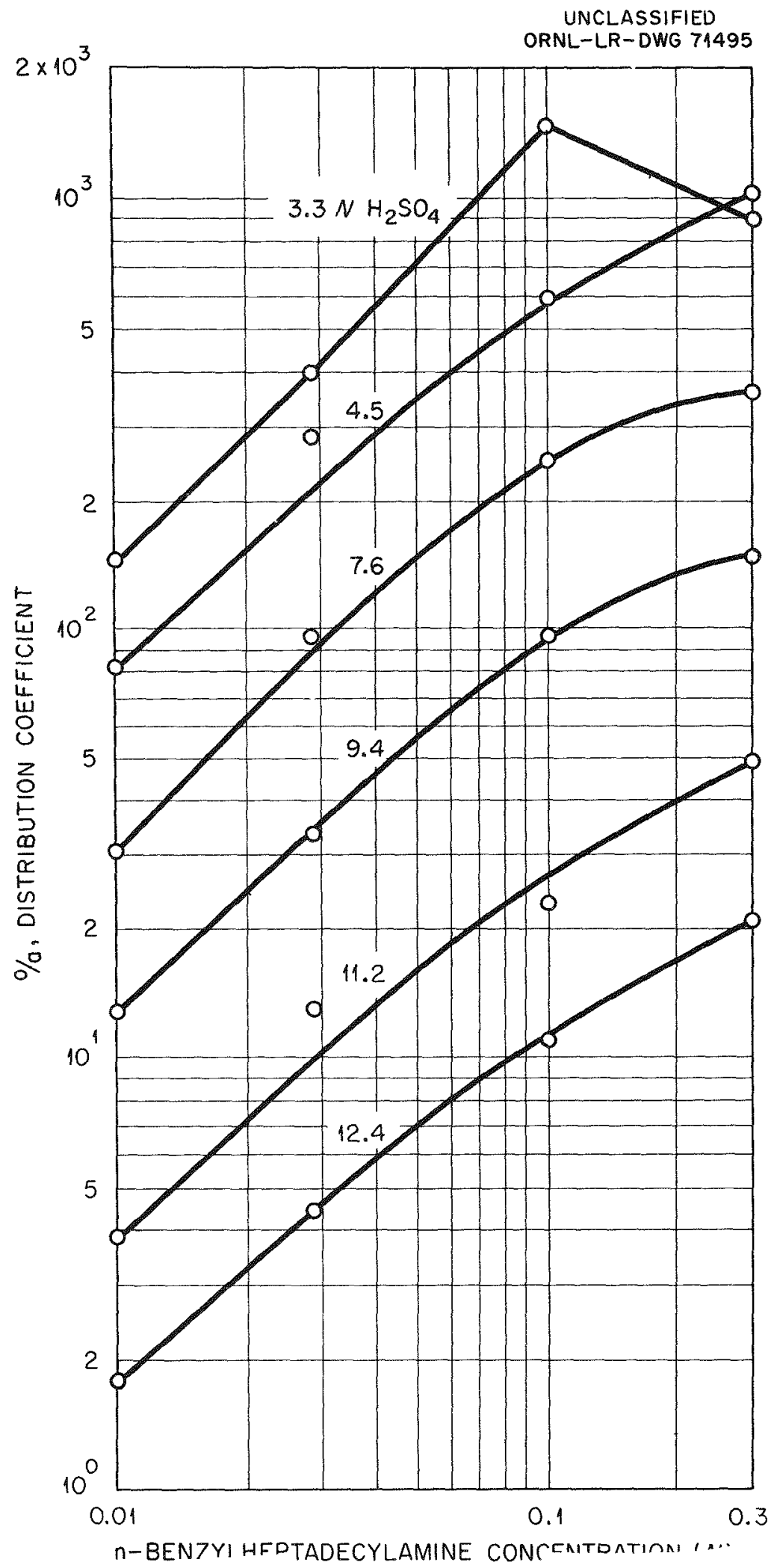

Fig. 3 
in distribution coefficient is real and not an experimental error. No explanation is offered.

When considering these results, particularly the decrease in extraction as acid concentration increases, one tends to think primarily of the aqueous phase because that is the one in which the acidity is changed. However, the acidity of the organic phase changes also. Amine is present in two forms, the bisulfate (amine $\mathrm{H}^{+}$) ( $\mathrm{HSO}_{4}{ }^{\prime}$ ) and the sulfate (amine $\left.\mathrm{H}^{+}\right)_{2}\left(\mathrm{SO}_{4}{ }^{3}\right)$ if amine polymerization is neglected. The ratio of bisulfate to sulfate increases with the acidity of the aqueous phase in equilibrium. These changes in the organic phase could strongly affect the extraction of protactinium, and it is necessary to separate these effects in order to draw any conclusions concerning the behavior or nature of the protactinium in the aqueous phase. This last is the sort of information generally derived or at least sought from distribution measurements.

For example, suppose that the aqueous protactinium complex, whatever it is, will exchange with sulfate ion associated with the amine much more readily than with bisulfate ion. Then as the acidity of the aqueous phase increases there is also an increase in the bisulfate concentration in the organic phase and a decrease in the sulfate. On the basis of the supposition this would decrease the extraction coefficient since there would be a lower concentration of the diamine sulfate which is more effective for extracting protactinium.

A titration procedure was developed which permitted determination of the amount of sulfate and bisulfate in the amine phase. Briefly, it involved a potentiometric titration of the amine in acetone solvent, first with a standard chloride solution (although other anions such as nitrate would be equally good) which first replaces sulfate in the organic phase and then replaces bisulfate giving a sharp endpoint, and secondly with standard sodium hydroxide to determine bisulfate independently.

In equilibrium with sulfuric acid above $5 \mathrm{~N}$ concentration only a small fraction of the amine is associated with sulfate (for example, less than $10 \%$ for amine S-24), and errors in determining these small concentrations becone 1arge. However, some of the data was treated on this basis, and the correlation between extraction coefficient and concentration of sulfate in the organic phase is striking (Fig. 4). This is the same data as shown on the lower curve of Fig. 2, but the abscissa has been changed from aqueous sulfuric acid concentration to organic sulfate concentration.

This approach has not been pursued further, majnly because so much work is involved in getting the data. The amount of sulfate and of bisulfate in the amine phase is a function of both the amine concentration and the aqueous acid concentration in the equilibrium phase, so a large number of titrations are necessary to define a single line such as Fig. 4. The titrations are as much an art as a science and they require great care and considerable time.

A few experiments were done with extractions from solutions of sulfuric acid and ammonium sulfate of constant total sulfate concentration of $3 \mathrm{M}$. As the acidicy is decreased by adding $3 \mathrm{M}\left(\mathrm{NH}_{4}\right)_{2} \mathrm{SO}_{4}$ to $3 \mathrm{M} \mathrm{H}_{2} \mathrm{SO}_{4}$ the extraction coefficient decreases very rapidly to a broad minimum centered about the conposition corresponding to ammonium bisulfate, and then it increases again as the dianmonium sulfate composition is approached. Thus, decreasing acidity by diluting $3 \mathrm{M}$ sulfuric acid with water causes an increase in extraction of protactinium, but decreasing acidity by adding ammonium sulfate at the same total. sulfate concentration causes a decrease in extraction.

Ion Exchange. The results of distribution measurements with Dowex 1 resin clearly show that the apparent extraction coefficient is dependent on the protactinium concentration (Fig. 5). On the left side of the figure the extraction 


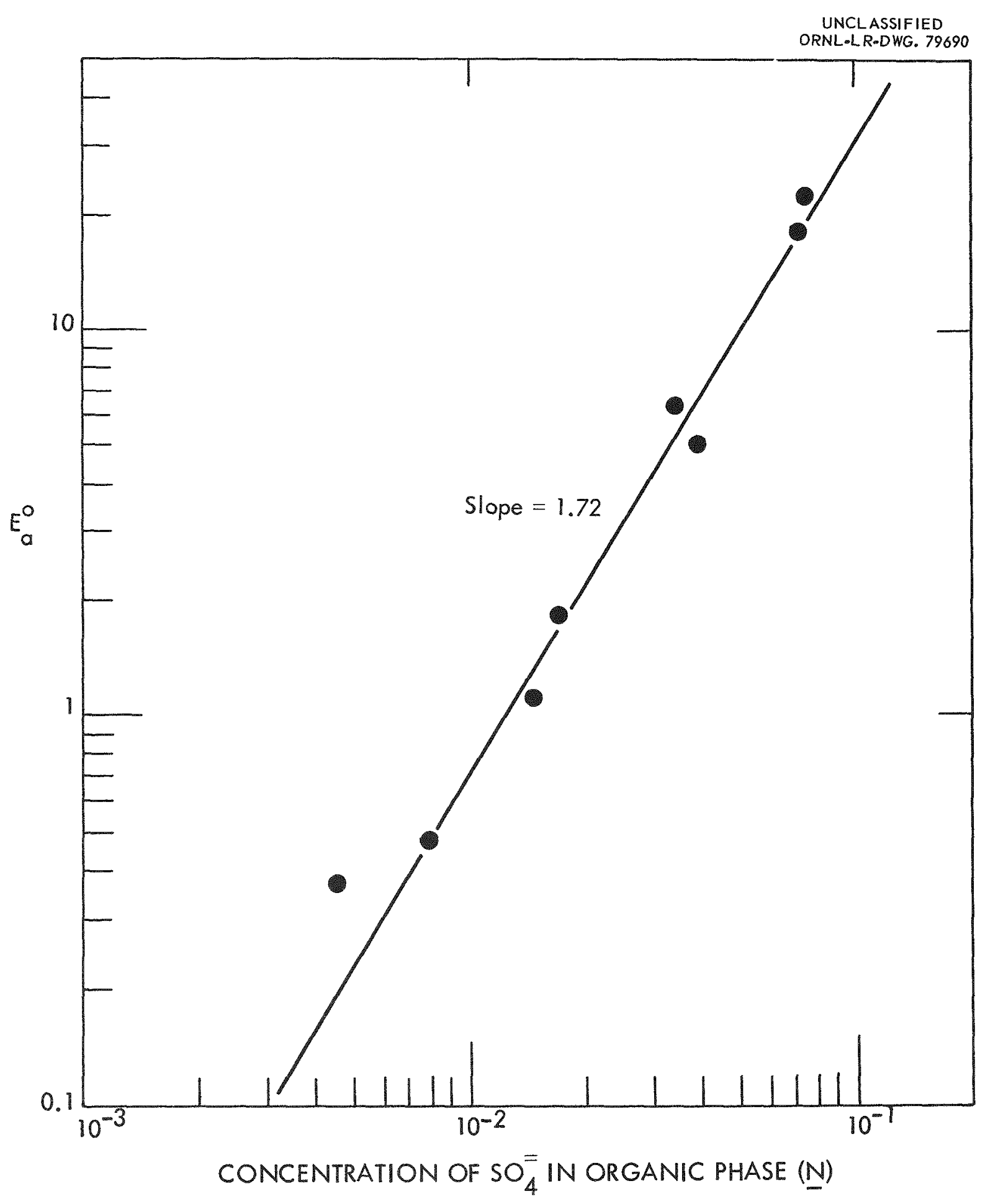

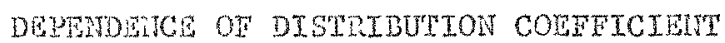

OH COICEMTRATIOH OT SULFATE IN ORGAIIC PHASE

Fig. 4 


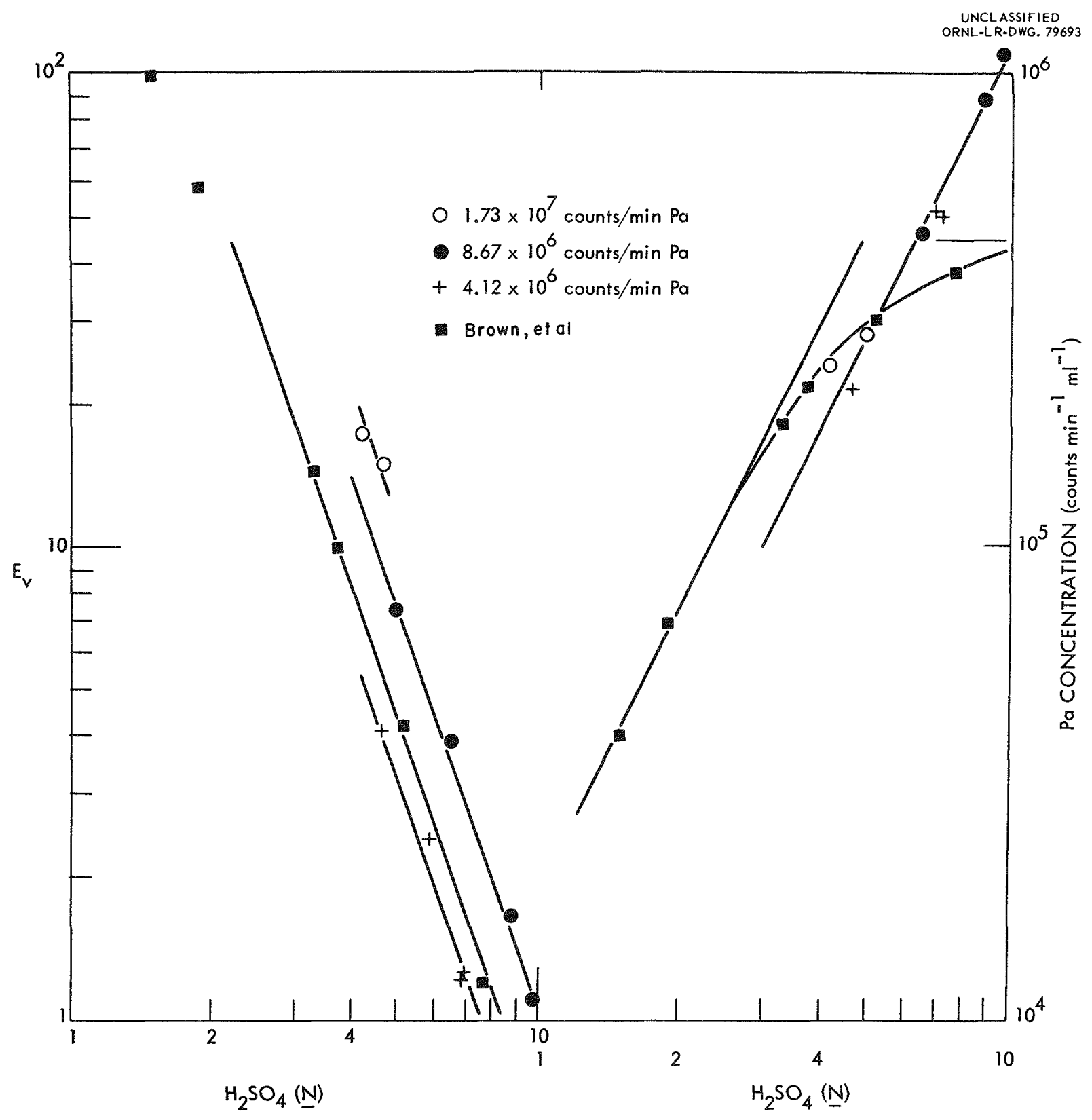

PROTACTINIUM EXTRACTION WITH DOWEX 1 RESIN

Fig. 5 
coefficients obtained by Brown et al. ${ }^{1}$ with the resin Deacidite $F F$ is shown along with our results. Three different sets of solutions, each with a different protactinium concentration, were used in our work; and each set gave a curve parallel to but displaced from Brown's. Our data was calculated in units of counts min $^{-1} \mathrm{ml}^{-1}$ resin because Brom's data was reported in those units, but our results were actually obtained in units of counts $\min ^{-1} \mathrm{~g}^{-1}$ of dry resin. This conversion may have shifted our results somewhat, but all by the same amount.

Examination of the data indicated that the protactinium concentration in the aqueous phase correlated reasonably well with the acid concentration, regardless of the protactinium concentration in the resin, and this is shown on the right side of Fig. 5. The straight lines are drawn with a slope of 2 . Here, also, the aqueous protactinium concentration has been estimated from Brown's reported distribution data, and there could well be a systematic error in the estimate. His data curves over as the aqueous protactinium concentration approaches the value at which all the protactinium would be in the aqueous and none in the organic, or the extraction coefficient would be zero, which is clearly a limiting case. Our data for the three different amounts of protactinium falls reasonably well on a single line. Results of this sort are somewhat similar to solubility data.

A number of distribution measurements vere made at various acidities, and the observed aqueous protactinium concentration correlated well with the aqueous acid concentration (Fig. 6). The corresponding protactinium concentrations in the resin fell generally in the vicinity of four values which are shown in the figure. The linear correlation over such a wide range of acid concentration, from 1.5 to $10 \mathrm{~N}$, is rather surprising since there are substantial changes in activity coefficients if nothing else.

Since the apparent extraction coefficient depends on the protactinium concentration, a sexies of extractions was run with varying protactinium concentration (Fig. 7). The points at the upper end of the curve (marked with a *) were obtained by changing the phase ratio to increase the protactinium concentration in the resin, but the rest of the points represent varying protactinium concentration and constant phase ratio. The data are plotted in two ways; both the concentration in the organic and the extraction coefficient are plotted against the protactinium concentration in the aqueous. In the first case the slope is one greater than in the second. In all cases the acid concentration was $5.0 \mathrm{~N}$.

The points at the lower part of the curve fit a straight line reasonably well, but the extraction coefficient increases slowly with protactinium concentration. There is a rather abrupt change in slope at an aqueous protactinium concentration of about $2 \times 10^{5}$ counts $\mathrm{min}^{-1} \mathrm{ml}^{-1}$ (about $2 \times 10^{-5} \mathrm{M} \mathrm{Pa}$ ), and above this the protactinium concentration in the organic and the extraction coefficient both increase rapidly with the aqueous protactinium concentration. The slope of the line based on concentrations increases from about 1.3 at the lower end to about 5. Finally, it should be pointed out that the highest point is to the right of the line drawn. This was thought to be an error initially, but repeated sampling indicate that this is real, and the significance will be discussed 1ater.

The points along the steep portion of the curve represent the same sort of data that was plotted in Fig. 6 . There, the aqueous protactinium concentration was plotted against the acidity for cases with high protactinium concentrations in the resin and, in general, this aqueous protactinium concentration increased with the square of the acidity. Figure 7 shows that it should also increase slowly with organic protactinium concentration, which might account for some of the scatter on Fig. 6. A further implication of this is that the steep portion. of Fig. 7 should move up and to the right as the acid concentration is increased. 


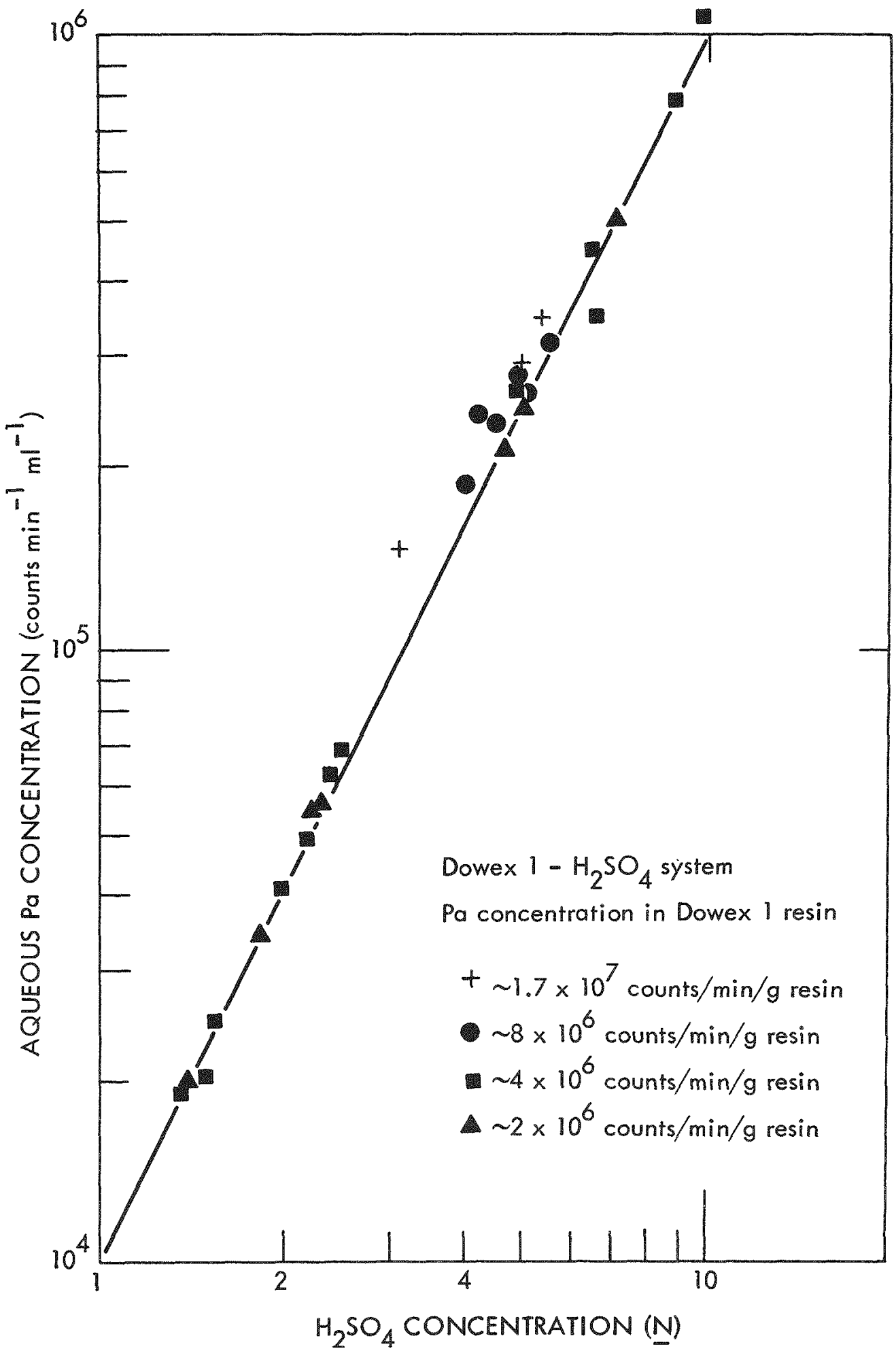

AQUEOUS RROTACTINIUM CONCENTRATION IN EQUILIBRIUM WITH DOWEX I RESIN

Fig. 6 


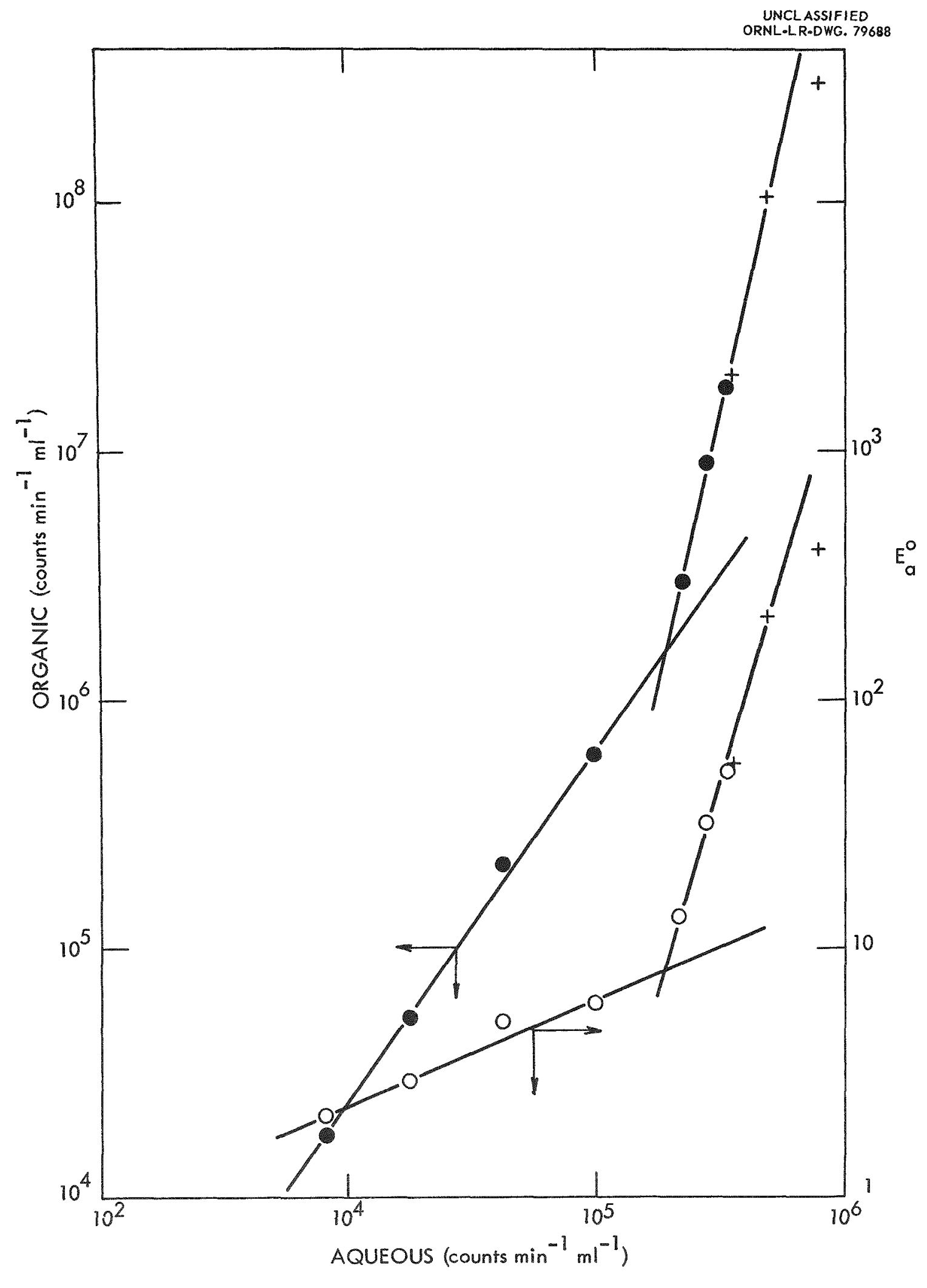

IFTECT OF PROTACTTNTUA CONCENTRATION

ON EXTRACTTON TNTO DOTEX 1 
The acid concentration of these same solutions was increased to $7.4 \mathrm{~N}$ to test the effect of increasing acidity (Fig. 8). The previous curve is also shown for reference. At $7.4 \mathrm{~N}$ acidity the steep portion of the curve should occur above $6 \times 10^{5}$ counts min ${ }^{-1} \mathrm{ml}^{-1}$ protactinium concentration in the aqueous, from Fig. 6, and the data did not go much above this value. There is some indication of curvature for the top two points, but no definite conclusion is possible. The surprising thing about these results is that they fall right along with the $5 \underline{N}$ acid data for lower protactinium concentrations. That is, the extraction coefficient in the low protactinium concentration range appears to be independent of acid concentration. This observation requires further verification.

These same solutions were finally diluted back to $5 \underline{\mathbb{N}}$ acid and data consistent with the original set was obtained. Therefore, these points were reversibly changed from one curve to the other and back again by changing the acid concentration. The effect causing the curvature in these lines is reversible with respect to changing acid concentration.

Since Dowex 1 is quite different from organic solutions in a number of respects, a similar experiment was done with amine extraction (Fig. 9). In previous solvent extraction work extraction coefficients vere generally large and aqueous protactinium concentrations vere always well below the levels at which this sort of curvature occurred. A solution of $0.03 \mathrm{~N}$ trilauryl amine in diethylbenzene was chosen for the solvent since it should give a distribution coefficient in the low protactinium concentration range of about 1 , a convenient value to work with. Just as with Dowex 1 resin, there are two portions asymptotic to straight lines. At low protactinium concentrations the slope is slightly greater than 1, about 1.3 (that is, the extraction coefficient increases slowly with protactinium concentration), and at higher protactinium concentrations the slope is 3.2 , so the distribution coefficient increases with the 2.2 power of the aqueous protactinium concentration. Initially the protactinium vas in the aqueous phase and it transferred into the organic. In various tests the aqueous and organic were each diluted and the results obtained fell along the line shown. Thus, the exchange reaction is reversible with respect to changes in protactinium concentration as well as acid concentration.

The intersection of the two straight lines drawn occurs at an aqueous protactinium concentration of $2.2 \times 10^{5}$ counts min-1 $\mathrm{ml}^{-1}$ for the trilauryl amine and $1.8 \times 10^{5}$ for Dowex 1 , very nearly the same. Howevex, the organic concentrations are quite different, $2.2 \times 10^{5}$ and $1.1 \times 10^{6}$, respectively. For both solvents the slope of the line for low protactinium concentrations is about 1.3, so the extraction coefficients increase slowly with protactinium concentration. At higher concentrations the slope is much larger, 3.2 for trilauryl amine and 5 for Dowex 1 .

Some peculiar rate effects have been observed in these distribution studies. Most of the protactinium extracts very quickly, in minutes or less, but several days are required before steady values are reached. Then after several weeks distribution coefficients slowly decrease, by perhaps $10 \%$. These changes are not large, but they do appear to be beyond experimental error since careful work results in material balances and reproducibility of results in the range of $1 \%$. These long term experiments are further complicated by changes in composition, perhaps due to evaporation of solvent or vater.

It is clear that more study of this is required, particularly experiments of this type at varying amine concentrations and acidities and including a vider range of protactinium concentrations. In spite of this it is interesting to speculate about what might be happening in these solutions. It vill not be stated what the species are or what the mechanism is, but a mechanism that is approximately consistent with the results vill be suggested. 


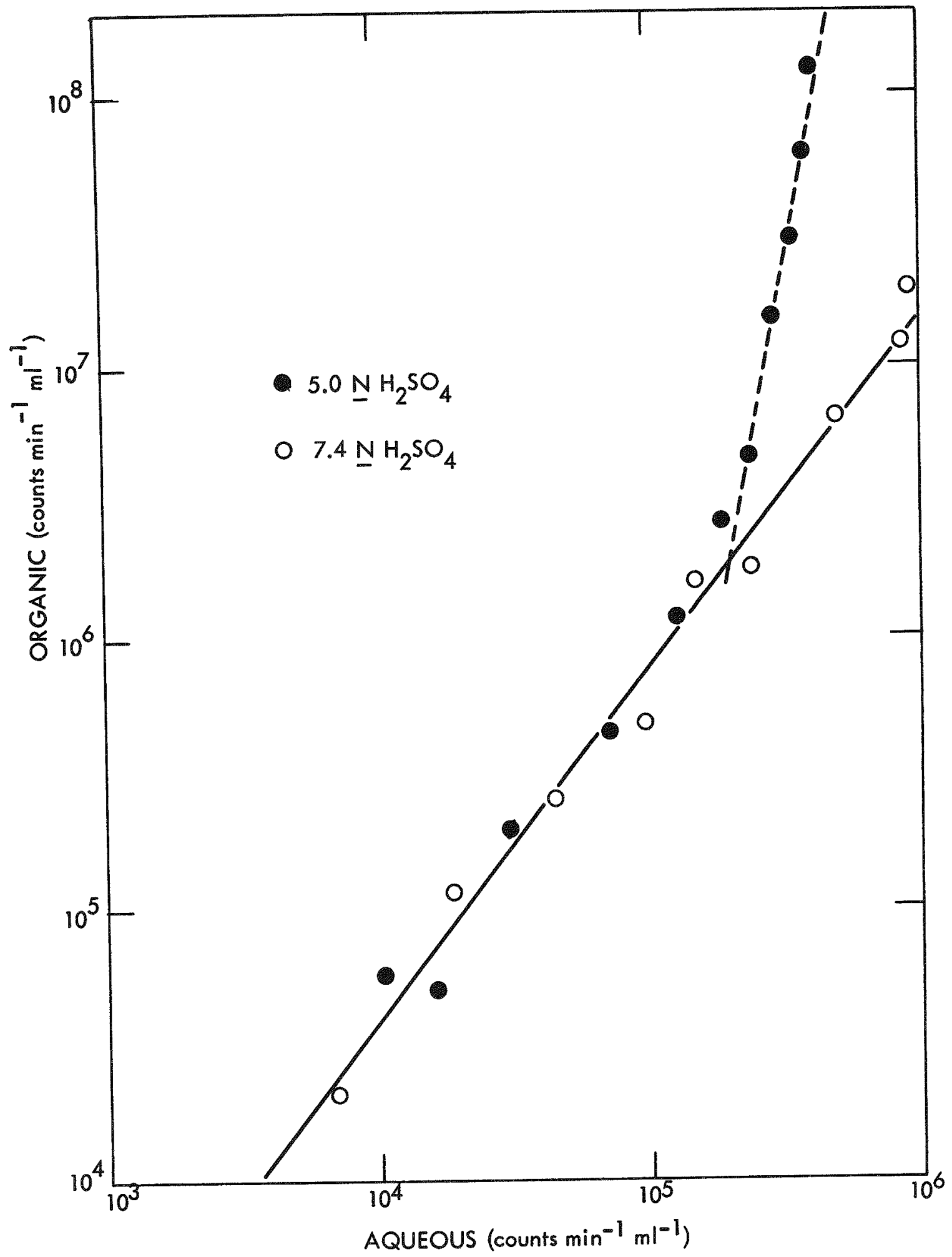

EFFECT OF ACID AND PROTACTINIUM

CONCENTRATION ON EXTRACTION INTO DOWEX-1

Fig. 8 


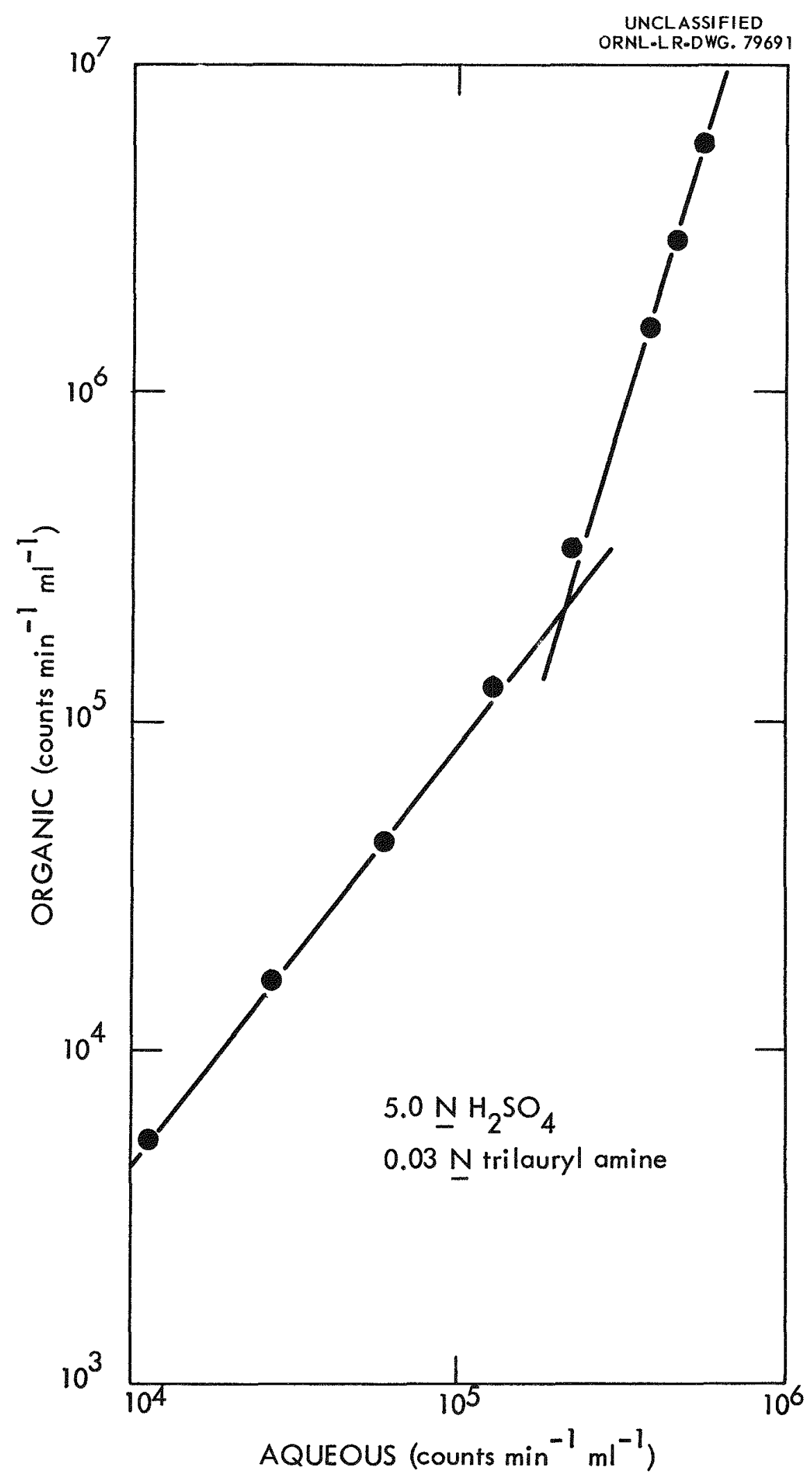

EFFECT OF PROTACTINIUM CONCENTRATION ON EXTRACTION

Fig. 9 
The proposed equilibria are as follows:

$$
\begin{aligned}
& { }^{(\mathrm{Pa})}{ }_{\mathrm{aq}} \rightleftharpoons{ }^{(\mathrm{Pa})} \text { org } \quad \mathrm{K}_{1} \\
& \left(\mathrm{~Pa}_{\mathrm{n}}\right)_{\text {aq }} \rightleftharpoons\left(\mathrm{Pa}_{\mathrm{n}}\right)_{\text {org }} \quad \mathrm{k}_{2} \\
& \mathrm{n}(\mathrm{Pa})_{\mathrm{aq}} \rightleftharpoons\left(\mathrm{Pa}_{\mathrm{n}}\right)_{a q} \quad \mathrm{~K}_{3}
\end{aligned}
$$

This mechanism assumes a polymerization in one or both phases but it is shom only in the aqueous phase. Formally it cannot be stated which phase the polymerization takes place in because the equilibrium constant for a polymerization reaction in the organic phese can be written in terms of $\mathrm{K}_{1}, \mathrm{~K}_{2}$, and $\mathrm{K}_{3}$. Another possible mechanism could involve extraction of a simple species followed by polymerization of it in the organic phase with the polymer not being back extracted.

To be consistent vith experimental observations it is assumed that the polymer is small and it is formed reversibly with respect to both the protactinium concentration and acid concentration. The equations show protactinium as a monomer and a polymer, but there is really no information about what the species actually are. The simpler species is a protactiniun complex anion which may not in fact be monomeric, but this is what is meant by the symbol used. Whatever it is, it polymerizes to form the more complex species, and the only information obtainable from distribution data alone is the relative difference between these two species.

Both species, the polymer and the simpler one, extract into the organic, and the polymer is assumed to be the more extractable. With proper choice of equilibrium constants the assumed mechanism gives an S-shaped distribution curve (Fig. 10). At low protactinium concentrations the simple species extraction is controlling as there is practically no polymer. $K_{1}$ is chosen to be 1 , in approximate agreenent with the trilauryl amine data. This gives a line of slope 1 , in the lower corner of Fig. 10. Actually, the slope for both Dowex 1 and trilauryl amine was greater than 1 . This line represents the limiting values for low protactinium concentrations.

At high protactiniun concentrations the polymer extraction is controlling. Three values have been chosen for $\mathrm{K}_{2}, 10,100$, and 1000, which give three 1imiting curves in the upper corner of $F$ ig. 10. It is not really known what $\mathrm{K}_{2}$ is except that it is substantially larger than $\mathrm{K}_{1}$.

Between these two extxemes where only one species is controlling the extraction the polymerization equilibrium $\left(\mathrm{K}_{3}\right)$ determines the amount of both the simpler species and the polymer and both extract. According to this mechanisn the polymerization is related to the slope of the steep portion of the curves of Figs. 7, 8, and 9. The polymerization number, $\mathrm{n}$, is chosen to be larger than the highest slope observed, which is 5 . Therefore, $n$ is chosen to be 6 , making the polymer a hexamer of the simpler species. This equilibrium determines the steep portion of the curves, connecting the two ends vith slope of 1 . The value of $\mathbb{R}_{3}$ was chosen to cause the curvature to occur at approximately the proper aqueous protactinium concentration, about $2 \times 10^{5}$ counts min-1 $\mathrm{ml}^{-1}$. The asymptotic straight lines are shom on the figure, but the actual calculated values follow the dashed curves.

The shape of these curves is fixed by $K_{3}$ and the ratio $k_{2} / k_{1}$, and the ratio should be different for different solvents. Changing the $\mathrm{K}^{\mathrm{t}} \mathrm{s}$ without changing their ratio merely moves the curves up or down; it does not change their shape. However, $\mathrm{K}_{3}$ is determined by the aqueous phase properties only, as the mechanism is written, so the lower curvature should occur at nearly the same aqueous protactiniun concentration regardless of the extractant. On the other hand, the organic protactinium concentration may be quite different. 


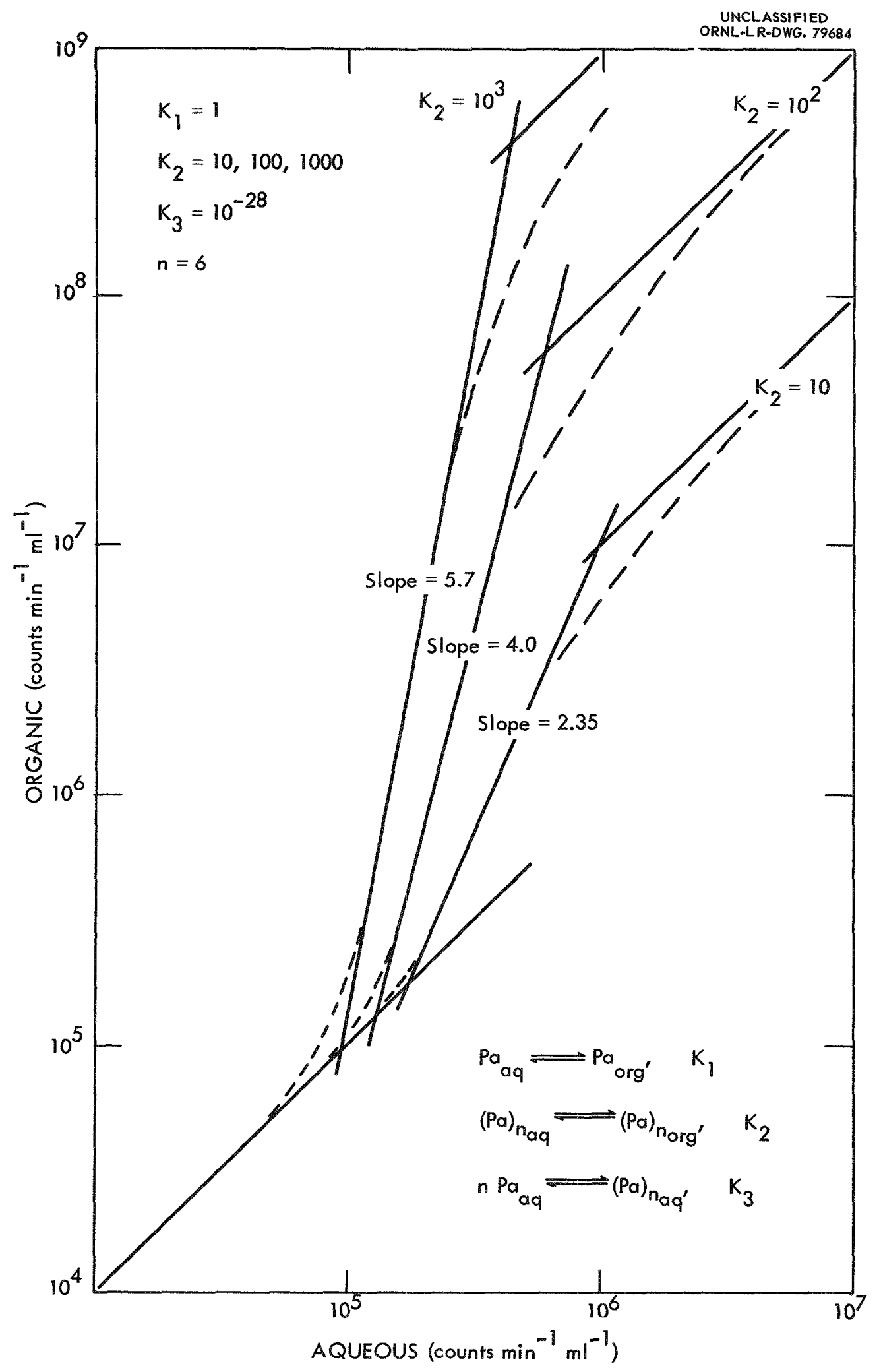

CALCUTATED EXTRACTION OF PROTACTINIUM

Fig. 10 
As the polymer extracts better relative to the monomer, or as $\mathrm{K}_{2}$ increases on this figure, the intermediate portion of the curve becomes steeper, approaching a slope of 6 , the polymerization number. At the same time the intersection of the asymptotic lines occurs at a lower aqueous protactinium concentration. It should be emphasized that a single polymer can account for different asymptotic slopes in the middle region of the curves of Fig. 10, depending on the ratio $\mathrm{K}_{2} / \mathrm{K}_{1}$.

The observed data covers only about half the range of the calculated curves, up to somewhere in the steep portion, and it is quite consistent with the lines of Fig. 10. For trilauryl amine $\mathrm{K}_{2}$ would have to be around 20 to 40 and the points of Fig. 9 would fall quite well on the curve except for some departure at the low end where the slope is greater than 1 . For Dowex 1 the entire curve must be shifted upward since $\mathrm{K}_{1}$ is larger than 1 . But the data of Fig. 7 fit well to the general shape of the curves.

Aside from the fit of the data one correlation in particular should be pointed out. The higher slope was obtained with Dowex 1 ; it was 5 compared to 3.2 for trilauryl amine. Dowex 1 also gave the lower aqueous protactinium concentration at the intercept of the asymptotic lines, in exact accord with the model. This would mean that the polymer extracts relatively better into the resin than into trilauryl amine in diethylbenzene. Also, the highest point of the data for Dowex 1, Fig. 7, was to the right of the curve. This might indicate that the reverse curvature at the upper end of Fig. 10 is starting.

It should be repeated that other mechanisms are also consistent with the observations, and much more data is needed to clarify this matter. In order to further verify the particular mechanism one would like to obtain points farther up the curve and observe the reverse curvature (if it exists) at the upper part of Fig. 10, where polymer extraction becomes controlling. However, it appears that this occurs only when the organic loading is quite high and interpretation of the data would be complicated by this. The maximum loading of the organic in these experiments was of the order of only a few percent.

It should be emphasized that the purpose of this work to date has not been to delineate completely the behavior of protactinium in sulfuric acid solutions, to demonstrate species or verify mechanisms. Additional methods would be necessary for these things. Instead, our approach has been to look at a number of aspects of the sulfuric acid--protactinium system and to obtain some information about the behaviox undex a variety of conditions. Some very interesting behavior has been uncovered, and techniques have been developed to study it. We now have a handle on several areas in the problem of the behavior of protactinium in sulfuric acid. These studies clearly lead to some very interesting chemistry. However, sulfuric acid is a much more complex solvent than acids like hydrochloric or nitric, and such studies become quite difficult. A great deal of work will be required before enough knowledge is gained to permit generalization, and other methods of investigation will be needed to obtain specific information.

The observations and suggestions in this report should not be extended to experimental conditions other than those stated herein. Since this is a current report of a continuing study some of the observations are preliminary and the suggestions tentative. Further verification of some of the reported observations is definitely needed, and other and more direct evidence for polymerization, in particular, is required. 
1. D. Brown, T. Sato, A. J. Smith, and R. G. Wilkins, J. Inorg. Nuc1. Chem. 23, 91 (1961).

2. R. Thompson, AECD-2488 (1946) and AECD-1897 (1948). 


\section{IONIC SPECIES OF RROTACTINIUM IN HYDROCHLORIC ACID*}

Hans-Ludwig Scherff*t: and Ginter Hermann

Institut für Anorganische Chemie und Kernchemie, Universität Mainz

The solvent extraction of protactinium from hydrochloric acid by diisobutylcarbinol "DIBC," (i-but) ${ }_{2} \mathrm{CH}-\mathrm{OH}$, was investigated and an attempt was made to evaluate protactinium species from the partition data. DIBC was chosen as solvent from the following reason: For work on the chemistry and nuclear chemistry of protactinium, Professor otto Hahn kindly provided us with weighable amounts of $\mathrm{Pa}^{231}$, isolated in 1934 by Grave and Käding. Part of this material was a concentrate in zirconium phosphate, containing about $10 \%$ of $\mathrm{Pa}^{231}$. DIBC allows a very simple Pa-Zr-separation as demonstrated in Fig. 1 which shows partition-coefficients $\mathrm{K}_{\mathrm{D}}$ of $\mathrm{Pa}, \mathrm{Zr}$ and fission products plotted vs. the HClconcentration $\mathrm{C}_{\mathrm{HCl}} \mathrm{-W}$ in aqueous phase. At $6 \mathrm{~N}$ HCl the Pa-Zr-separation factor is about $10^{7}$.

\section{PARTITION OF HYDROCHLORIC ACID}

For evaluating the protactinium data we need some information about the partition of HCl between vater and DIBC, in particular the composition of the HCI-species in DIBC and its thermodynamic activity. Therefore the partition of HC1 and water between DIBC and water was investigated.*iti If the HC1-concentration in DIBC is plotted"vs." the nean ionic activities of $\mathrm{H}^{+}$and $\mathrm{Cl}^{-}$in water on a $\log -10 \mathrm{~g}$ scale, a straight line of slope 2.0 results at 1 ow and medium HC1concentrations corresponding to an equilibrium

$$
\mathrm{H}_{\mathrm{w}}^{+}+\mathrm{CI}_{\mathrm{w}}^{-} \rightleftharpoons \mathrm{HCl}_{\mathrm{org}}
$$

with undissociated HCl in the organic phase. A more detailed analysis leads to the extracted species

$$
\left.+\mathrm{H}_{2} \mathrm{O}\right)_{2}(\mathrm{DIBC})_{2}-\dot{\mathrm{Cl}}
$$

which is an undissociated ion pair. This conclusion is based on the following observations:

1. The maximum HCl-concentration in the organic phase is $2.92 \mathrm{M}$. Since pure DIBC is $5.72 \mathrm{M}$, this concentration corresponds to a DIBC/HC1-molar-ratio of nearly 2 .

2. Each molecule of HCl is accompanied by exactly 2 molecules of water. No decrease of this number was found even at high HC1-concentrations. Likewise the solubility of DIBC in aqueous HCl of various concentrations can be explained by the partition-mechanism assumed.

\footnotetext{
*Presented by $F$. Weige1, München.

*wom a dissertation of Hans-Ludwig Scherff, Mainz 1962.

*tok For details see a publication of the authors, to be submitted to Ber. Bunsengesellschaft physik. Chemie. 


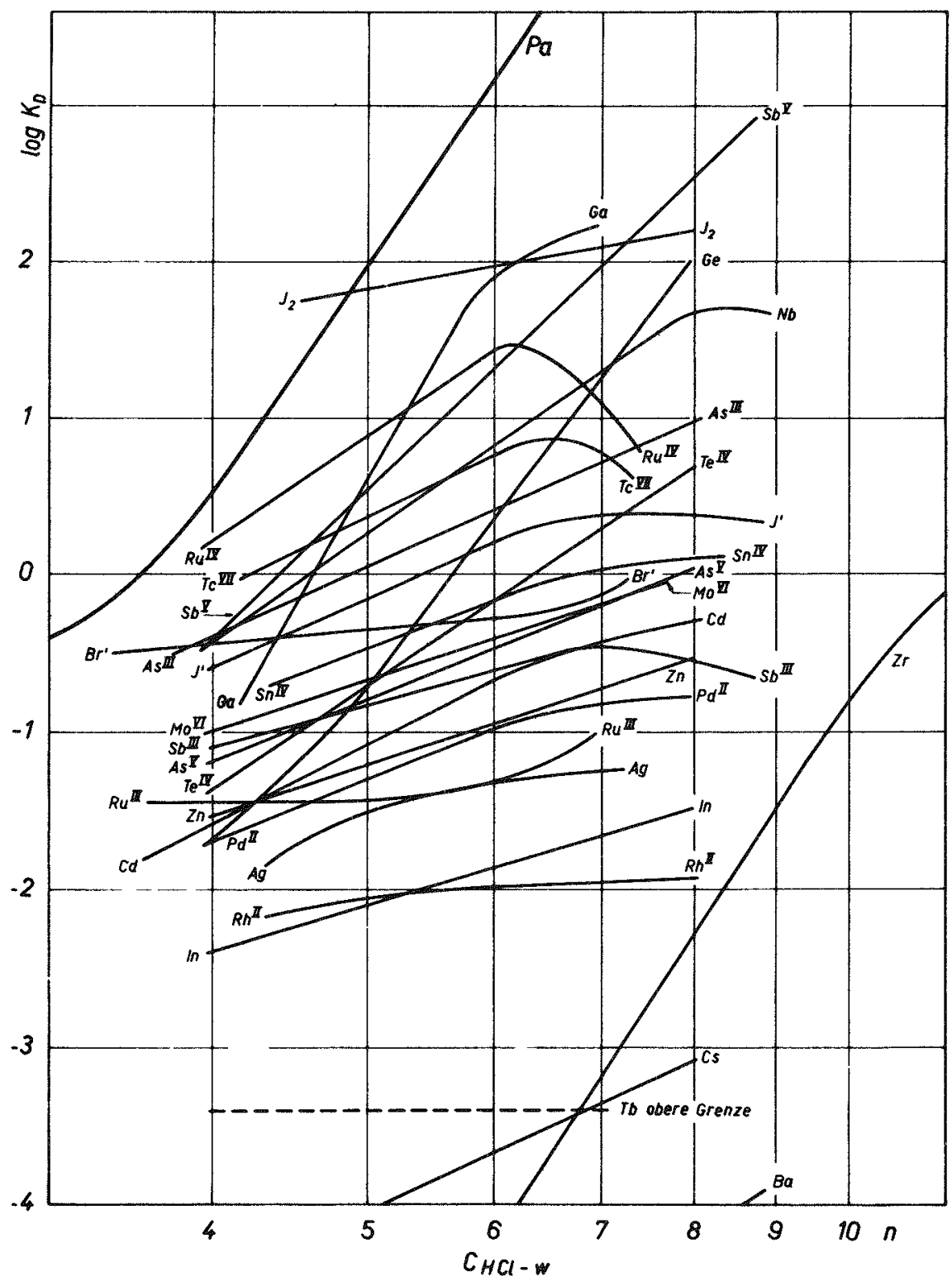

Fig. 1. Partition coefficients $K_{D}$ of protactinium, zirconium and fission products between diisobutylcarbinol and hydrochloric acid, plotted vs. HCl-concentration in the aqueous phase. 
3. According to the HCl-species postulated the following equation should describe the partition data:

$$
\log c_{H C 1-0}=\log K+\log \frac{a_{+H C 1-W}^{2} \times c_{D I B C-0}^{2}}{a_{H_{2} O-W}^{2}}+\log \frac{\gamma_{D I B C-0}^{2}}{\gamma_{H C 1-0}}
$$

where $c$ are concentrations, a thermodynamic activities, $\gamma$ activity coefficients, and $\mathrm{K}$ a constant; indices $-o$ and $-\mathrm{w}$ refer to the organic and aqueous phase, respectively. A plot of $\log c_{\mathrm{HC} 1-\mathrm{Q}}$ vs. the second term ( $c_{\mathrm{DIBC}-\mathrm{o}}$ taken as $\left.5.72-2 \times c_{H C 1-O}\right)$ leads to $\log \left(\gamma_{\mathrm{DIBC}-\mathrm{O}} / \gamma_{\mathrm{HC1}-\mathrm{O}}\right)$ as deviation of the curve obtained from a straight line of unit slope. This expression may be solved into $\log \gamma_{\mathrm{DIBC}-\mathrm{O}}$ and $\log \gamma_{\mathrm{HC} 1-\mathrm{O}}$ by use of the Gibbs-Duhem equation. The activity coefficient of DIBC calculated is about 1 over the whole range of HC1concentrations investigated which seems to be reasonable. $\gamma_{\mathrm{HC} 1-\mathrm{O}}$ increases with $\mathrm{c}_{\mathrm{HC} 1-\mathrm{O}}$.

4. The viscosity of $\mathrm{HC} 1-\mathrm{DIBC}-$ solutions increases considerably with increasing HCl-concentration. The relative viscosity (normalized to that of pure DIBC) agrees reasonably with values expected for the postulated species in the framework of Vands ${ }^{1}$ theory of viscosity in solutions of strongly solvated electrolytes and of large nonelectrolyte molecules.

5. IR-spectra of HC1-DIBC-solutions show the characteristic broadening and shift of the $\mathrm{OH}-\mathrm{b}$ and occurring by the formation of hydrogen-bridges.

6. A determination of the dissociation constant of HC1 in DIBC by conductance measurements failed because of the very $10 \mathrm{w}$ conductance below $0.2 \mathrm{M}$ solutions. A very rough estimate of $\mathrm{K}_{\mathrm{diss}}$ may be made using the conductances at $0.2 \mathrm{M}$ and at infinite dilution which are $1 \times 10^{-6}$ and $10 \Omega^{-1} \mathrm{~cm}^{2}$ mole $\mathrm{e}^{-1}$, respectively; the latter value is estimated by Walden's rule. This leads to a dissociation constant of $<10^{-14}$. This value is in the order of magnitude expected from the low dielectric constant of 3.3 for water-saturated DIBC.

\section{EXPERIMENTAI RESULTS ON PROTACTINIUM PARTITION}

Most data were obtained with $\mathrm{Pa}^{233}$ at tracer concentrations. Experiments at analytical concentrations were carried out with $\mathrm{Pa}^{231}$ or, if the counting rates of $\mathrm{Pa}^{231}$ were too low, with mixtures of both nuclides. To avoid errors in the partition coefficients caused by hydrolysis of protactinium the follow ing procedure was used: All stock solutions of protactinium were kept in $1 \mathrm{M} H F$. Immediately before partitioning the required amount was adjusted to $6 \mathrm{M} \mathrm{HCl}--0.1 \mathrm{M} \mathrm{HF}$ and saturated with $\mathrm{AlC1} \mathrm{3}^{\circ} 6 \mathrm{H}_{2} \mathrm{O}$. This solution was extracted by DIBC. Then the DIBC was washed twice with HC1 of the desired concentration and the final equilibration was made. At low distribution coefficients the solution of the desired concentration was used only in the final partition. Samples of both phases were taken and counted in an $\alpha$ or $\gamma$-countex; HCl was determined by titration of the aqueous phase.

Figure 2 shows the partition coefficient of protactinium $\mathrm{K}_{\mathrm{D}-\mathrm{Pa}}$, i.e., the ratio of protactinium concentrations in both phases: $\mathrm{K}_{\mathrm{D}-\mathrm{Pa}}=\mathrm{c}_{\mathrm{Pa}-\mathrm{O}} / \mathrm{c}_{\mathrm{Pa}-\mathrm{W}}$. $\mathrm{K}_{\mathrm{D}-\mathrm{Pa}}$ is plotted $\mathrm{vs}$. HCl-concentration and -activity in the aqueous phase. It depends strongly on HCl-concentration, whereas partitions at low and high Paconcentrations gave identical results. At medium $a_{+} \mathrm{HCl}$ the partition curve $\log \mathrm{K}_{\mathrm{D}-\mathrm{Pa}}$ vs. $\log \mathrm{a}^{2}+\mathrm{HC} 1-\mathrm{w}$ may be represented by a straight 1ine of slope 2.7; smaller slopes are approached at lower and higher $a_{ \pm H C 1}$.

Figure 3 shows more clearly that $\mathrm{K}_{\mathrm{D}-\mathrm{Pa}}$ does not depend on $\mathrm{Pa}$-concentration over many orders of magnitude if the HCl-concentration is kept constant. The Pa-concentrations given are those after partition. HCl-concentrations are 


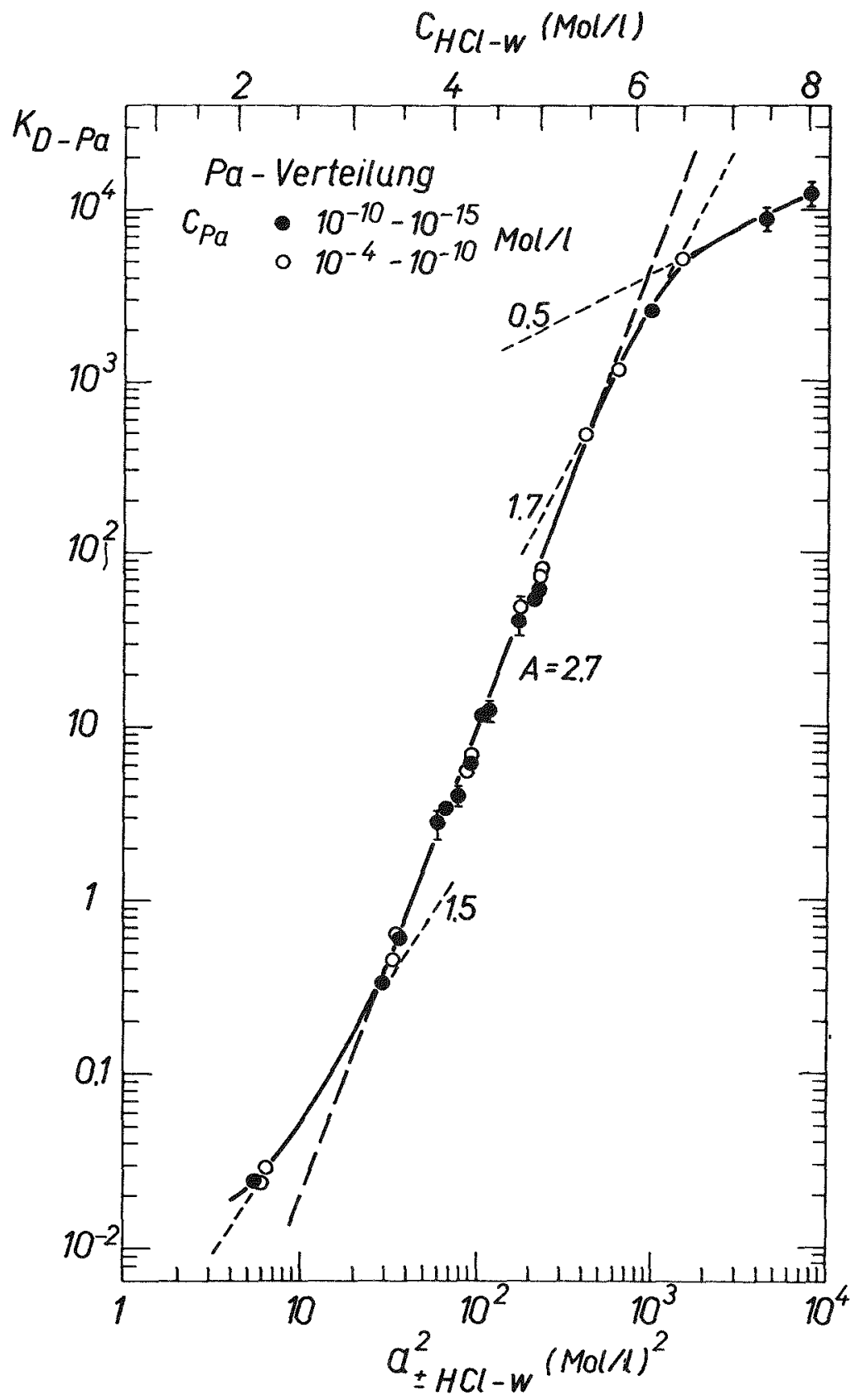

Fig. 2. Partition coeft-icient $K_{D-P a}$ of protactinium between disobutylcarbinol (DIBC) and hydrochloric acid as function of the mean ionic activity a ${ }_{+\mathrm{HCl}-\mathrm{W}}$ of $\mathrm{HCl}$ in the aqueous phase. The corresponding $\mathrm{HCl}$-contrations $\mathbf{c}_{\mathrm{HCl}-\mathrm{w}}$ are indicated at top. $K_{D-P a}$ was measured at tracer and at analytical Pa-concentrations. A and numbers are the slopes of the straight 1 ines shown. 


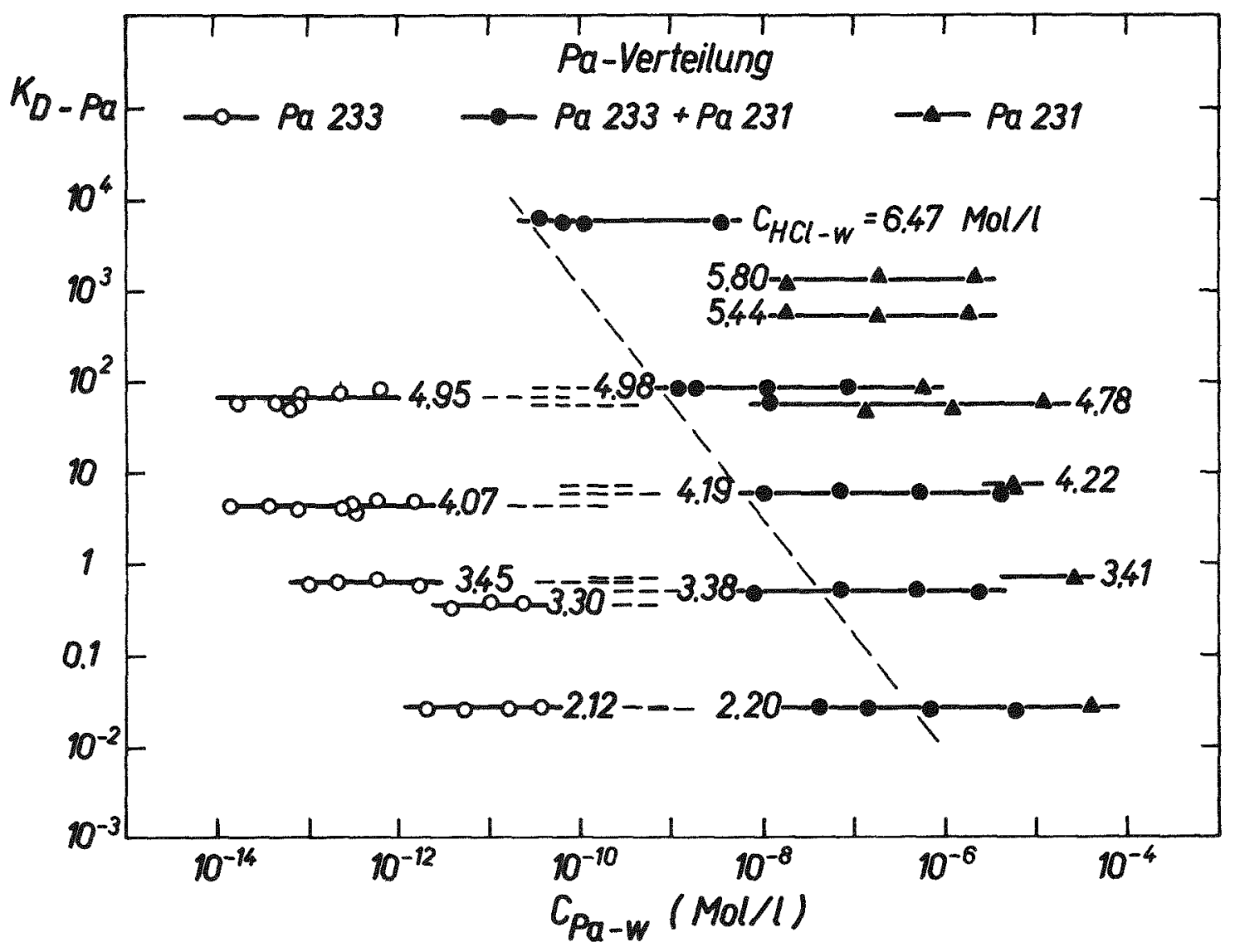

Fig. 3. Partition of Pa at various Pa-concentrations $\mathbf{c}_{\mathrm{Pa}-\mathrm{W}}$ and selected $\mathrm{HCl}$-concentrations $\mathrm{c}_{\mathrm{HCl}-\mathrm{w}^{\text {" }}}$ the latter are given as numbers at the straight lines. For explanation of the dashed line see text. 
indicated by the numbers at the straight lines. The dashed line marks those Pa-concentrations which are equal to the $\mathrm{Cl}^{-}$-concentrations from the weak HCIdissociation; both refer to the organic phase.

The change of $\mathrm{K}_{\mathrm{D}-\mathrm{Pa}}$ with $\mathrm{a}_{+\mathrm{HCl}-\mathrm{w}}$ is difficult to be interpreted since it contains two factors which are varied simultaneously: the $\mathrm{H}^{+}{ }_{-}$and the $\mathrm{CI}^{-}-$ activity. To separate them, partitions vere carried out with NaC1-HC1-mixtures of constant Cl-concentration, i.e., constant ionic strength $\mu$, but variable HC1content. In Fig. 4, at right, $\mathrm{K}_{\mathrm{D}-\mathrm{Pa}}$ is plotted vs. HCl-concentration on a loglog-scale. The thin solid line and the points on it correspond to $\mathrm{K}_{\mathrm{D}}{ }^{3} \mathrm{~s}$ in pure HC1. As will be discussed later the data are only meaningful under certain conditions which may be checked by HCl-partitions: The slopes of $10 \mathrm{~g} \mathrm{c}_{\mathrm{HC}} 1-\mathrm{O}$ vs. Iog $\mathrm{C}_{\mathrm{HCl}}-\mathrm{W}$ found in $\mathrm{HC1}-\mathrm{NaCl}$ should be equal to the slopes $10 \mathrm{~g} \mathrm{C}_{\mathrm{HCl}} \mathrm{O}$ - vs. $\log a^{2}+\mathrm{HCl}-\mathrm{W}$ observed with pure HCl in the same range of $\mathrm{CHC1}_{\mathrm{HCO}}$. Therefore the straight lines drawn for the HCl-partitions (Fig. 4, at left) are taken from the partition curve of pure HCl. The condition mentioned seems to hold except for mixtures with small NaCl-content or high values of $\mu(>3)$, respectively.

Figure 5 shows $\mathrm{K}_{\mathrm{D}-\mathrm{Pa}}$-values obtained with diluted $\mathrm{DIBC}$, plotted $\mathrm{vs}$. the DIBC-concentration $C_{D I B C}$; benzene was used as diluent. The selected HC1-concentrations are indicated by $c_{\mathrm{HC} 1-\mathrm{W}}$, together vith the slopes found which are nearly 2.0 at all HCI-concentrations investigated. The arrow marks $\mathrm{K}_{\mathrm{D}-\mathrm{Pa}}$-values in undiluted DIBC.

Finally we determined the $\mathrm{Cl}$-content of Pa-species in the organic phase by chemical analysis: organic phases containing some milligrams of $\mathrm{Pa} 231$ were back-extracted into water. The precipitating Pa-hydroxide was fully hydrolyzed by $\mathrm{NaOH}$ of known content. Then protactinium was determined gravimetricaliy as $\mathrm{Pa}_{2} \mathrm{O}_{5}$, whereas in the filtrate of the Pa-hydroxide $\mathrm{H}^{+}$was titrated by $\mathrm{NaOH}$ and $\mathrm{Cl}^{-}$by $\mathrm{Ag}^{+}$. Both titrations yield $\mathrm{b}$, the number of $\mathrm{Cl}$-atoms per Pa-atom:

$$
\mathrm{H}_{a} \mathrm{PaCl}_{b}(\mathrm{OH})_{c}+(\mathrm{b}-\mathrm{a}) \mathrm{H}_{2} \mathrm{O}=\mathrm{Pa}(\mathrm{OH})_{5}+\mathrm{b} \mathrm{H}^{+}+\mathrm{bCl}^{-} \text {. }
$$

In deriving this equation one takes into account that the number of negatively charged Iigands and of positive charges in the Pa-species are equal, i.e., $\mathrm{b}+\mathrm{c}=5+\mathrm{a}$. Table 1 shows our results. In the range investigated the average number of $\mathrm{Cl}$-atoms per Pa-atom changes from about 4 to about 6 . The 1 atter seems to be identical with the maximum Cl-coordination of Pa-species in the organic phase. The large errors are caused by the fact that the $\mathrm{H}^{+}-$and $\mathrm{Cl}^{-}-$ contents are obtained as differences of two comparable numbers that are the HC1contents of organic phases in presence and in absence of protactinium. This limits the range of HCl-concentration which can be covered by such experiments.

Table 1. Chemical Analysis of Protactinium-Species in HC1-Containing Diisobutylcarbino1

\begin{tabular}{|c|c|c|c|c|}
\hline \multicolumn{3}{|c|}{ HC1-Concentration (M) } & \multirow[b]{2}{*}{$\begin{array}{c}\text { Pa-Concentration } \\
(M)^{b}\end{array}$} & \multirow[b]{2}{*}{$\begin{array}{c}\text { Cl-Atoms Per } \\
\text { Pa-Atom }\end{array}$} \\
\hline $\begin{array}{l}\text { Aqueous } \\
\text { Phase }\end{array}$ & $\begin{array}{l}\text { Organic } \\
\text { Phase }\end{array}$ & $\begin{array}{c}\text { Due to } \\
\text { Pa-Species }\end{array}$ & & \\
\hline $\begin{array}{l}4.87 \\
5.55 \\
6.22\end{array}$ & $\begin{array}{l}0.347 \\
0.591 \\
0.86\end{array}$ & $\begin{array}{l}0.038 \pm 0.005 \\
0.113 \pm 0.003 \\
0.125 \pm 0.020\end{array}$ & $\begin{array}{l}0.0252 \pm 0.0002 \\
0.0234 \pm 0.0002 \\
0.0205 \pm 0.0001\end{array}$ & $\begin{array}{l}3.5 \pm 0.2 \\
4.0 \pm 0.15 \\
6.1 \pm 1.0\end{array}$ \\
\hline
\end{tabular}

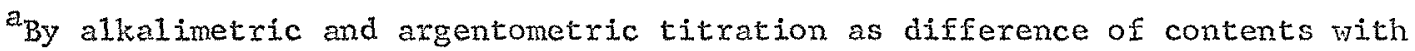
and without protactinium present.

$\mathrm{b}_{\mathrm{By}}$ gravimetry as $\mathrm{Pa}_{2} \mathrm{O}_{5}$ after hydrolysis. 


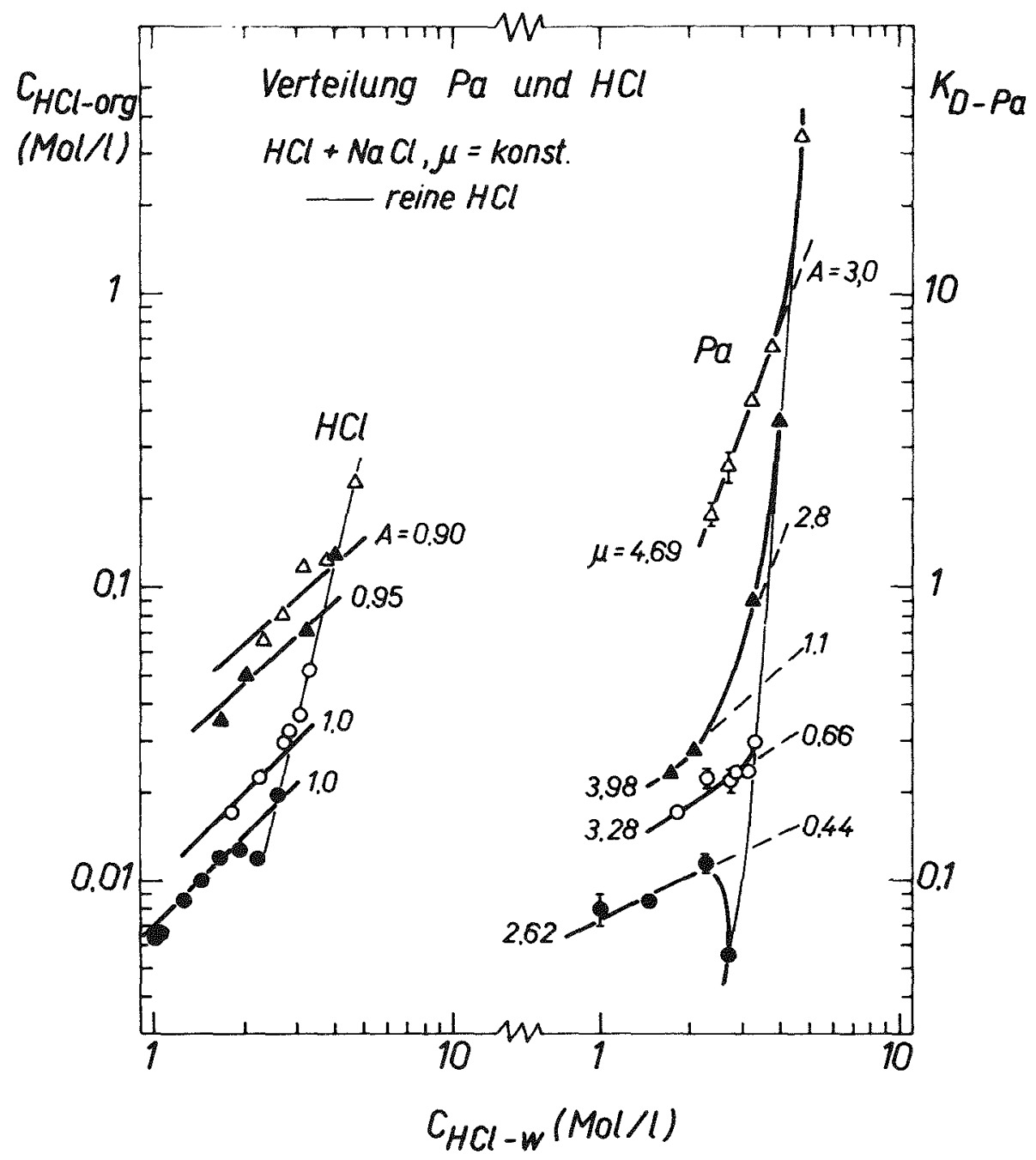

Fig. 4. Partition of $\mathrm{Pa}$ and $\mathrm{HCl}$ from $\mathrm{HCl}-\mathrm{NaCl}-\mathrm{mixtures}$ of constant ionic strength $\mu$, but variable composition: Partition coefficients $\mathrm{K}_{\mathrm{D}-\mathrm{Ha}}$ and $\mathrm{K}_{\mathrm{D}-\mathrm{IICl}}$ as functions of $\mathrm{HCl}$-concentrations $\mathrm{c}_{\mathrm{HCl}-\mathrm{W}}$. A: slopes of straight lines. Further details see text。 


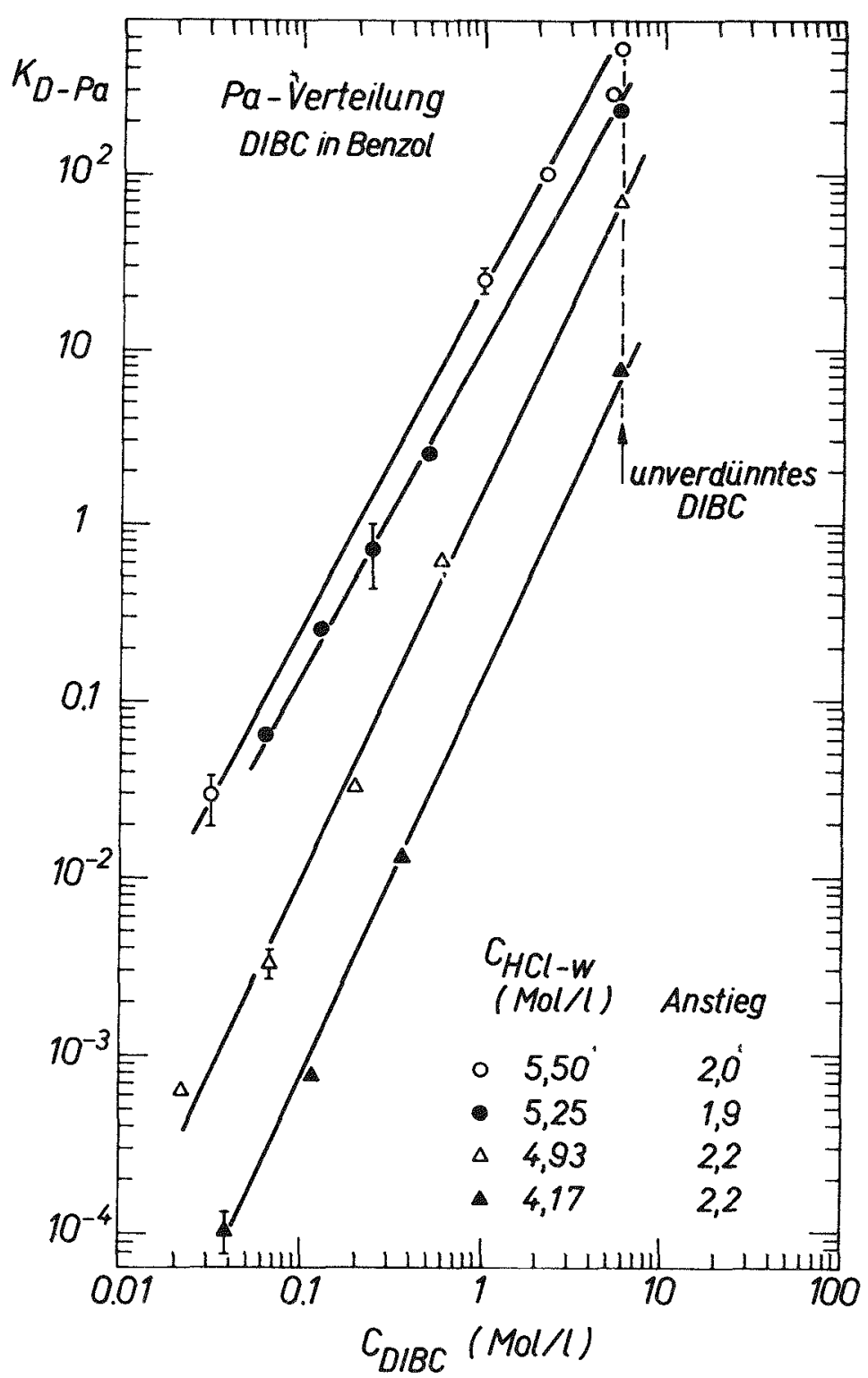

Fig. 5. Partition of Pa into DIBC-benzene-mixtures from selected HClconcentrations $\mathrm{c}_{\mathrm{HCl}-\mathrm{W}} \cdot \mathrm{K}_{\mathrm{D}-\mathrm{Pa}}$ is plotted vs. DIBC-concentration $c_{D I B C} \cdot$ Slopes obtained are shown as insert. The arrow indicates undiluted DIBC. 
The method used in evaluating the data is that of Poskanzer ${ }^{2}$ with some minor modifications. It shall be illustrated for a specific case which involves two assumptions concerning the Pa-species to be proved below: (1) the species in both phases contain only one Pa-atom, and (2) the species in the organic phase are uncharged. In Poskanzer's unusual but convenient notation, the general formulas of species considered are:

aqueous phase $(\mathrm{HCl})_{h}\left(\mathrm{PaCl}_{5}\right) \mathrm{Cl} \mathrm{I}_{-z}$ with charge $z$,

organic phase $(\mathrm{HCl})_{\underline{h}} \mathrm{PaCl}_{5}$ uncharged.

Underlined symbols refer to the organic phase. In is the coordination number of protactinium against $\mathrm{H}$, $\mathrm{OH}$ and $\mathrm{O}$ : for $\mathrm{H}, \mathrm{h}$ is taken positive, for $\mathrm{OH}$ negative and for 0 as $-h / 2$. The ionic charge $z$ can have both signs.

The species in the aqueous phase are formed in the hypothetical reaction

$$
\mathrm{PaCl}_{5}+\mathrm{h} \mathrm{HCl}-\mathrm{z} \mathrm{Cl}^{-} \rightleftharpoons(\mathrm{HCl})\left(\mathrm{PaCl}_{5}\right) \mathrm{Cl}_{-\mathrm{z}},
$$

converted to the species existing in the organic phase and transferred into this phase by the reaction

(2) $(\mathrm{HCl})_{h}\left(\mathrm{PaCl}_{5}\right) \mathrm{Cl} 1_{-z}+z \mathrm{Cl}^{-}+\underline{\mathrm{HCl}} \rightleftharpoons(\mathrm{MCl})_{\underline{1}} \underline{\mathrm{PaCl}}_{5}+(\mathrm{h}-\underline{\mathrm{h}}+1) \mathrm{HCl}$.

As will be discussed later, one molecule of HC1 from the organic phase takes part in this reaction; therefore $\underline{\mathrm{HCl}}$ is introduced at the left side.

The following equilibrium corresponds to reaction (1):

$$
c_{h, z}=k_{h, z} \times a_{P_{a C l}} \times a^{h}{ }_{H C 1} \times a_{C 1}^{-z}
$$

which is simplified by use of the dissociation-equilibrium of HCl in the aqueous phase $a_{\mathrm{C} 1}=\left(\mathrm{a}_{\mathrm{HC} 1} / \mathrm{K}_{\mathrm{diss}}\right)^{1 / 2}$ to

$$
c_{h, z}=k_{h, z}^{\prime} \times a_{\mathrm{PaCl}_{5}} \times \mathrm{a}_{\mathrm{HCl}}^{\mathrm{h}-\mathrm{z} / 2} \text {. }
$$

$c$ are concentrations, a activities and $k$ formation constants.

The species existing in the organic phase are formed in the equilibrium

$$
c_{\underline{h}}=k_{\underline{h}} \times c_{h, z} \times a \frac{h-h-1}{\mathrm{HCl}} \times a_{\mathrm{Cl}}^{z} \times \underline{a}_{\mathrm{HC} 1} \text {; }
$$

by introducing equation (4) and substituting ${ }^{a} \mathrm{c} 1$ it follows:

$$
c_{\underline{h}}=k_{\underline{h}}^{\prime} \times a_{\text {PaCl }_{5}} \times a_{\frac{h}{H C I}} \times \underline{a}_{\text {HCI }} \text {. }
$$

Finally, Nernst's partition law is applied with the partition coefficient $\beta$ of the specific species considered:

$$
\underline{c_{\underline{h}}}=\beta_{\underline{h}} \times c_{\underline{h}} .
$$

The measured partition coefficient $\mathrm{K}_{\mathrm{D}-\mathrm{Pa}}$ is the ratio of total Pa-concentrations in both phases:

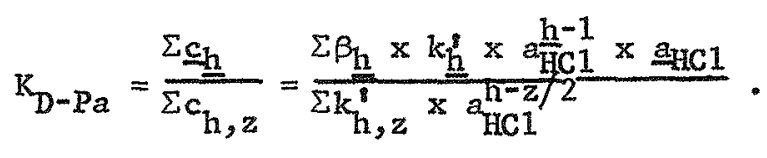


As Poskanzer showed such sums of power-functions can be solved by logarithmic differentiation explained by the following general example:

$\frac{d \log \sum k_{n} \times a^{n}}{d \log a}=\frac{a}{\sum k_{n} \times a^{n}} \times \frac{d \sum k_{n} \times a^{n}}{d a}=\frac{a \sum n \times k_{n} \times a^{n-1}}{\sum k_{n} \times a^{n}}=\frac{\sum n \times k_{n} \times a^{n}}{\sum k_{n} \times a^{n}}=\bar{n}$.

The result is the mean coordination number $\bar{n}$, for $\Sigma k_{n} x a^{n}$ is the total concentration of the metallic species and $\Sigma_{n} x k_{n} \times a^{n}$ the total concentration weighted by the coordination numbers $\mathbf{n}$. Applying this principle to equation ( 8 ) one obtains the final formula for the slope of a $\log -10 g-p l o t \mathrm{~K}_{\mathrm{D}-\mathrm{Pa}}$ vs. $\mathrm{a}_{\mathrm{HCl}}$ :

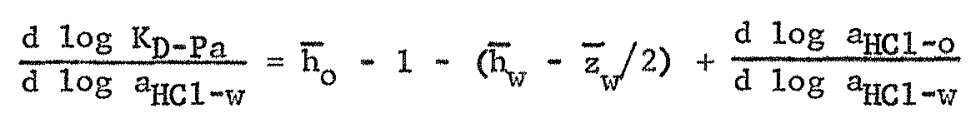

The equation contains three unknorns $\bar{h}_{\mathrm{O}}, \bar{h}_{\mathrm{V}}$ and $\bar{z}_{\mathrm{V}}$ which are the mean coordination numbers against $\mathrm{H}$ or $\mathrm{OH}$ in both phases and the mean ionic charge in the aqueous phase. (d $\log \mathrm{K}_{\mathrm{D}-\mathrm{Pa}} \mathrm{d} \log \mathrm{a}_{\mathrm{HC} 1-\mathrm{W}}$ ) is read from the partition curve of protactinium whereas $\left(\mathrm{d} \log a_{\mathrm{HCl}-\mathrm{O}} / \mathrm{d} \log \mathrm{a}_{\mathrm{HCl}-\mathrm{w}}\right.$ ) can be obtained from HCI partitions. In many cases the latter slope is very nearly one so that equation (9) simplifies to

$$
\frac{\mathrm{d} \log \mathrm{K}_{\mathrm{D}-\mathrm{Pa}}}{\mathrm{d} \log \mathrm{a}_{\mathrm{HC1}}-\mathrm{W}}=\overline{\mathrm{h}}_{\mathrm{O}}-\overline{\overline{\mathrm{W}}}_{\mathrm{W}}+\bar{z}_{\mathrm{w}} / 2,
$$

the formula derived by Poskanzer ${ }^{2}$ who apparently considered this simplification as general valid.

Similar considerations lead to the following formulas: ${ }^{2}$ If $\mathrm{K}_{\mathrm{D}-\mathrm{Pa}}$ is measured as a function of Pa-concentration at constant HCl-concentration, the slope is

$$
\frac{\mathrm{d} \log \mathrm{K}_{\mathrm{D}-\mathrm{Pa}}}{\mathrm{d} \log \mathrm{c}_{\mathrm{Pa}-\mathrm{W}}}=\left(\overline{\mathrm{m}}_{\mathrm{o}} / \overline{\mathrm{m}}_{\mathrm{W}}\right)-1
$$

provided that the species in organic phase are uncharged and undissociated or that the $\mathrm{Pa}-$ concentration in the organic phase is small compared to the $\mathrm{H}^{+}-$and $\mathrm{Cl}^{-}$-concentration in that phase. $\overline{\mathrm{m}}$ is the average number of Pa-atoms per species or average degree of polymerization. Partition data vith diluted DIBC give $\bar{s}_{\mathrm{o}}$, the mean solvation number of $\mathrm{Pa}$ by DIBC:

$$
\frac{D \log K_{D \sim P a}}{d \log C_{D I B C}}=\bar{s}_{O} \text {. }
$$

Partitions in acid-salt-mixtures of constant ionic strength $\mu$ give a slope

$$
\frac{d \log k_{D-P a}}{d \log c_{H C 1-W}}=\hbar_{O}-\bar{h}_{W}-1+\left(\frac{d \log a_{H C 1-O}}{d \log c_{H C 1-W}}\right)_{\mu} \text {. }
$$

If

$$
\frac{d \log a_{H C 1-o}}{d \log a_{H C 1-v}}=\left(\frac{d \log a_{H C 1-0}}{d \log c_{H C 1-w}}\right)_{\mu}
$$

which means that all activity coefficients remain constant in spite of changing acid-salt-ratio, it follows from equations (10) and (13):

$$
\frac{\mathrm{d} \log \mathrm{K}_{\mathrm{D}-\mathrm{Pa}}}{\mathrm{d} \log \mathrm{a}_{\mathrm{HC} 1-\mathrm{W}}}-\left(\frac{\mathrm{d} \log \mathrm{K}_{\mathrm{D}-\mathrm{Pa}}}{\mathrm{d} \log \mathrm{C}_{\mathrm{HCI}}-\mathrm{W}}\right)_{\mu}=\bar{z}_{W} / 2 \text {. }
$$


Thus $\bar{z}_{W}$, the mean ionic charge of species in aqueous phase, may be obtained as difference of two experimentally available slopes.

\section{DISCUSSION OF PROTACTINIUM SPECIES}

The most simple case is the partition in diluted DIBC, Fig. 5. As pointed out above, the slope is two: the organic species contain two DIBC-molecules per Pa-atom. The same solvation number was found for HCl in DIBC. Solvation of Pa-species by two solvent-molecules was observed with amylacetate, 3 tri-nbutylphosphate $e^{4}$ and tri-n-octylamine, 5 whereas tri-n-benzylamine ${ }^{6}$ gives 0.6 and diisopropyl- and diisobutyl-keton ${ }^{3}$ about 5 as solvation number.

The partition data at various pa-concentrations show a zero slope (Fig. 3). Thus according to equation (11) $\bar{m}_{0}=\bar{m}_{w}$. The lowest Pa-concentration applied was $10^{-14} \mathrm{M}$. It seems very improbable that protactinium polymerizes at such low concentration. Therefore $\bar{m}_{0}$ and $\bar{m}_{w}$ are one over the whole range studied, $i . e$. , up to $10^{-5} \mathrm{M}$ in aqueous and $0.01^{\mathrm{M}}$ in organic phase. Furthermore a constant $\mathrm{K}_{\mathrm{D}-\mathrm{Pa}}$ indicates uncharged and undissociated $\mathrm{Pa}-$ species in the organic phase. Otherwise a "common-ion" effect should occur: if the dissociation of Pa-species contributes measurably to the chloride-concentration in the organic phase, $\mathrm{K}_{\mathrm{D}-\mathrm{Pa}}$ should drop. For strongly dissociated Pa-species, the drop should occur in the region of the dashed line in Fig. 3 which shows $C_{P a-O} \approx c_{C 1-0}$ with $\mathrm{c}_{\mathrm{C} 1-\mathrm{o}}$ calculated using a dissociation constant of $1 \times 10^{-14}$ for $\mathrm{HC} 1$ in DIBC. In our data no drop is observed even at $\mathrm{c}_{\mathrm{Pa}-\mathrm{O}} \approx 0.01 \mathrm{M}$ and $\mathrm{c}_{\mathrm{HCI}-\mathrm{O}} \approx 1 \mathrm{M}$. This leads to the following very rough estimate of the dissociation constant of Paspecies $\mathrm{K}_{\mathrm{diss}-\mathrm{Pa}}<0.01 \times \mathrm{K}_{\text {diss }}-\mathrm{HCl}$. As pointed out above, $\mathrm{K}_{\mathrm{diss}-\mathrm{HCl}}<10^{-14}$ is estimated at $\mathrm{c}_{\mathrm{HC} 1-\mathrm{O}}=0.02 \mathrm{M}$, corresponding to $\mathrm{c}_{\mathrm{HCl}-\mathrm{W}}=2.5 \mathrm{M}$. Thus $\mathrm{K}_{\mathrm{diss}}-\mathrm{Pa}$ must be very small, even if we assume considerable increase of $\overline{\mathrm{K}}_{\mathrm{diss}-\mathrm{HCl}}$ at higher $\mathrm{c}_{\mathrm{HCl}-\mathrm{O}}$ because of an increasing dielectric constant of DIBC at higher HC1-water content. Goble et al. ${ }^{7}$ observed a drop of $\mathrm{K}_{\mathrm{D}-\mathrm{Pa}}$ by about a factor of 10 at high Pa-concentrations in solvents like nitrobenzene and dichlorodiethylether where $\mathrm{K}_{\mathrm{diss}}-\mathrm{HCl}$ is about $10^{-7} .8$

From the foregoing discussions we conclude remarkable similarities between the species of protactinium and of hydrochloric acid in DIBC; both contain the same number of DIBC-molecules per $\mathrm{Pa}$ or HCl and both are uncharged. Thus a reaction quite analogous to an anion-exchange seems to be the basic mechanism of transference into the organic phase:

$$
(\mathrm{DIBC})_{2 \mathrm{HCl}}+\mathrm{PaX}_{6}^{-} \rightleftharpoons(\mathrm{DIBC})_{2} \mathrm{HPaX}_{6}+\mathrm{CI}^{-}
$$

The unknowns $\bar{h}_{\mathrm{O}}, \bar{h}_{\mathrm{W}}$ and $\bar{z}_{\mathrm{W}}$ of equation (9) can be solved in the following manner: The correction term ( $\left(\mathrm{log} a_{\mathrm{HCl}-\mathrm{O}} / \mathrm{d} \log a_{\mathrm{HCl}-\mathrm{W}}\right.$ ) is available from HClpartitions. The analysis of organic phase shown in Table 1 yields the mean $\mathrm{C} 1 / \mathrm{Pa}$-ratio b which is equal to $\overline{\mathrm{h}}_{\mathrm{o}}-5$. $\bar{z}_{\mathrm{w}}$ is obtained by equation (14) from partition data with and without constant ionic strength. Finally equation (9) gives $h_{W}$.

Figures 6-8 demonstrate how equation (9) is solved by using the experimental data given above. In Fig. $6 a$ the slope $\log \mathrm{K}_{\mathrm{D}-\mathrm{Pa}} \mathrm{vs}$. $\log \mathrm{a}_{\mathrm{HCl}-\mathrm{w}}$ is shown as obtained from Fig. 2 without and with correction for (d $\log a_{H C 1-o} / d$ log $a_{H C 1-W}$ ) - 1; this term (Fig. 6b) is calculated from HC1-partitions. Figure 7 gives the dependence of $\bar{h}_{\mathrm{o}}$ from the aqueous HCl-concentration. Although the range covered experimentally is rather smal1-- from 4.8 to $6.2 \mathrm{M}$ HC1--a reasonable extrapolation to higher and lower concentrations is possible. For example, we may assume that $h_{0}$ can never exceed +1 , corresponding to the species $\mathrm{HPaCl}_{B}$ in the organic phase. At low HCl-concentrations, $h_{0}=-3$ seems to be a reasonable lower limit, corresponding to the rather highly oxygenated monobase complex acid $\mathrm{HPaO}_{2} \mathrm{Cl}_{2}$. 


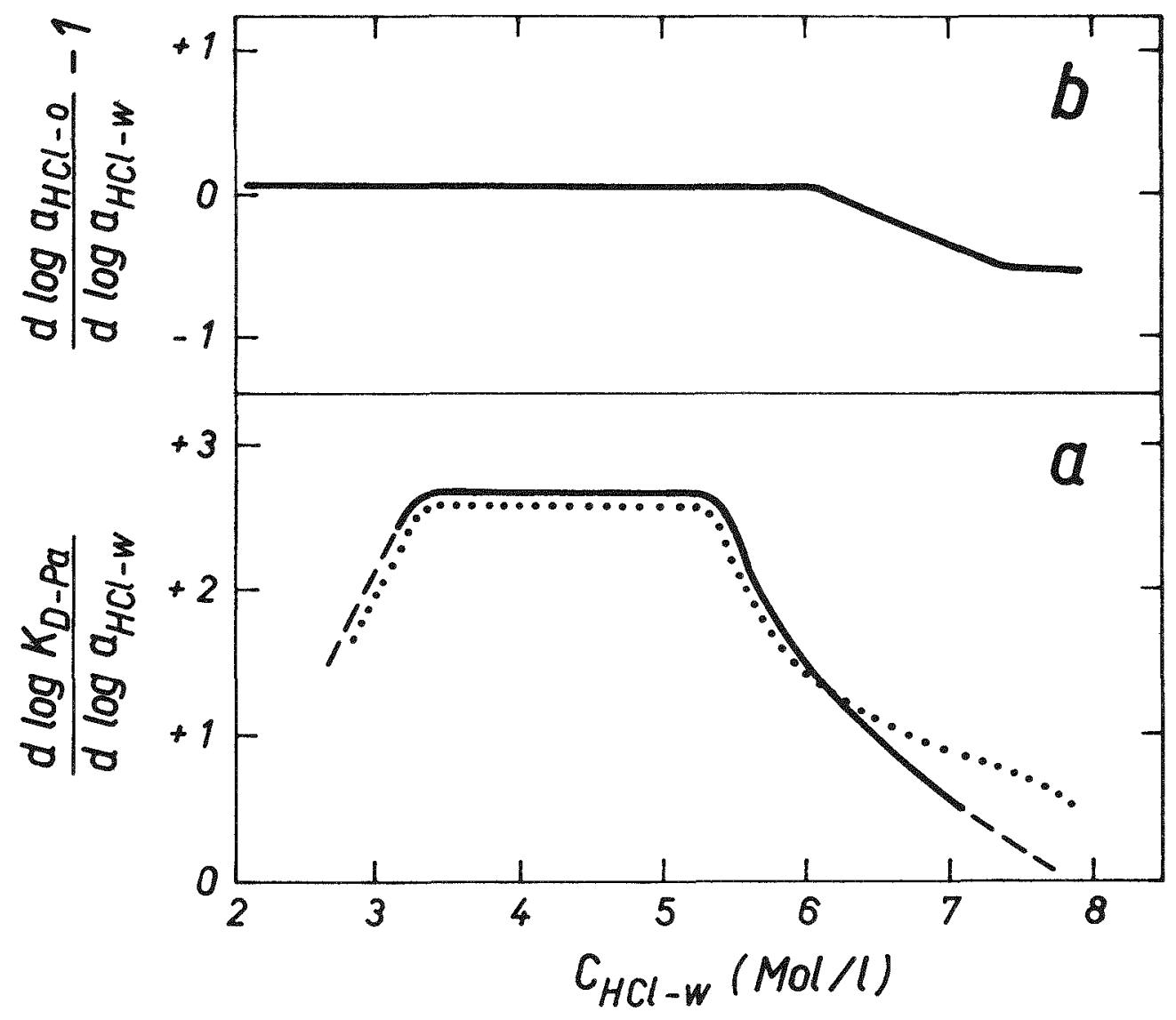

Fig. 6. a) Slopes of the partition curve Fig. 2 vs. Hcl-concentration in the aqueous phase; - supported by experiment, -.-- extrapolated, ... corrected by curve $6 \mathrm{~b}$ ).

b) Correction term $\left(d \log a_{H C l-o} / d \log a_{H C l-w}\right)-1$, obtained from $\mathrm{HCl}$-partitions not shown in detail. 


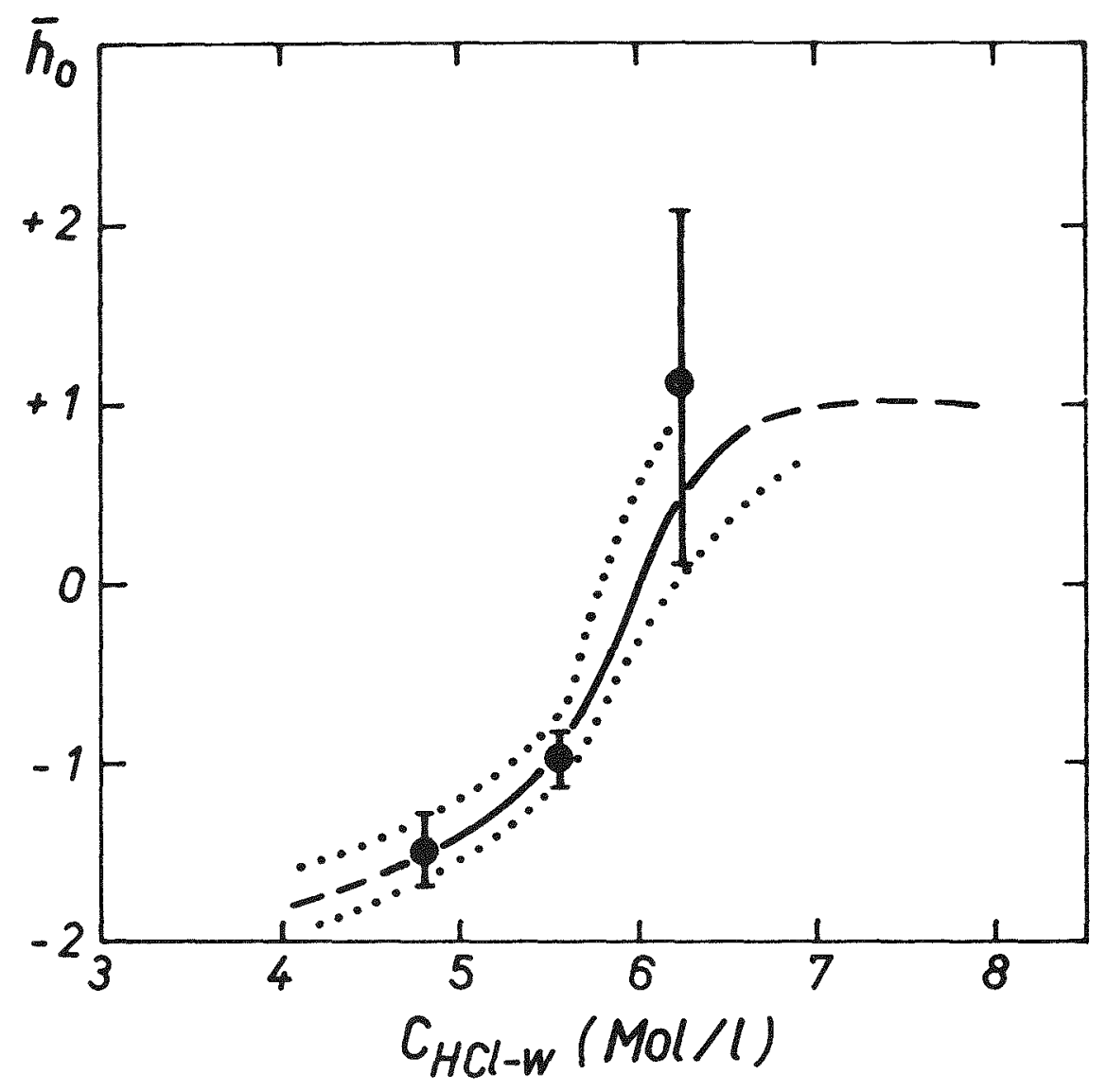

Fig. 7. Mean corrdination number $\bar{h}_{0}$ against $\mathrm{H}^{+}$and $\mathrm{OH}^{-}$of Pa-species in the organic phase $\mathrm{Vs}$. the corresponding HCl-concentration $c_{\mathrm{HCl}-\mathrm{w}}$ in the aqueous phase. $\bar{h}_{0}$ is calculated from data given in Table 1. Concerning the extrapolations made see text. 


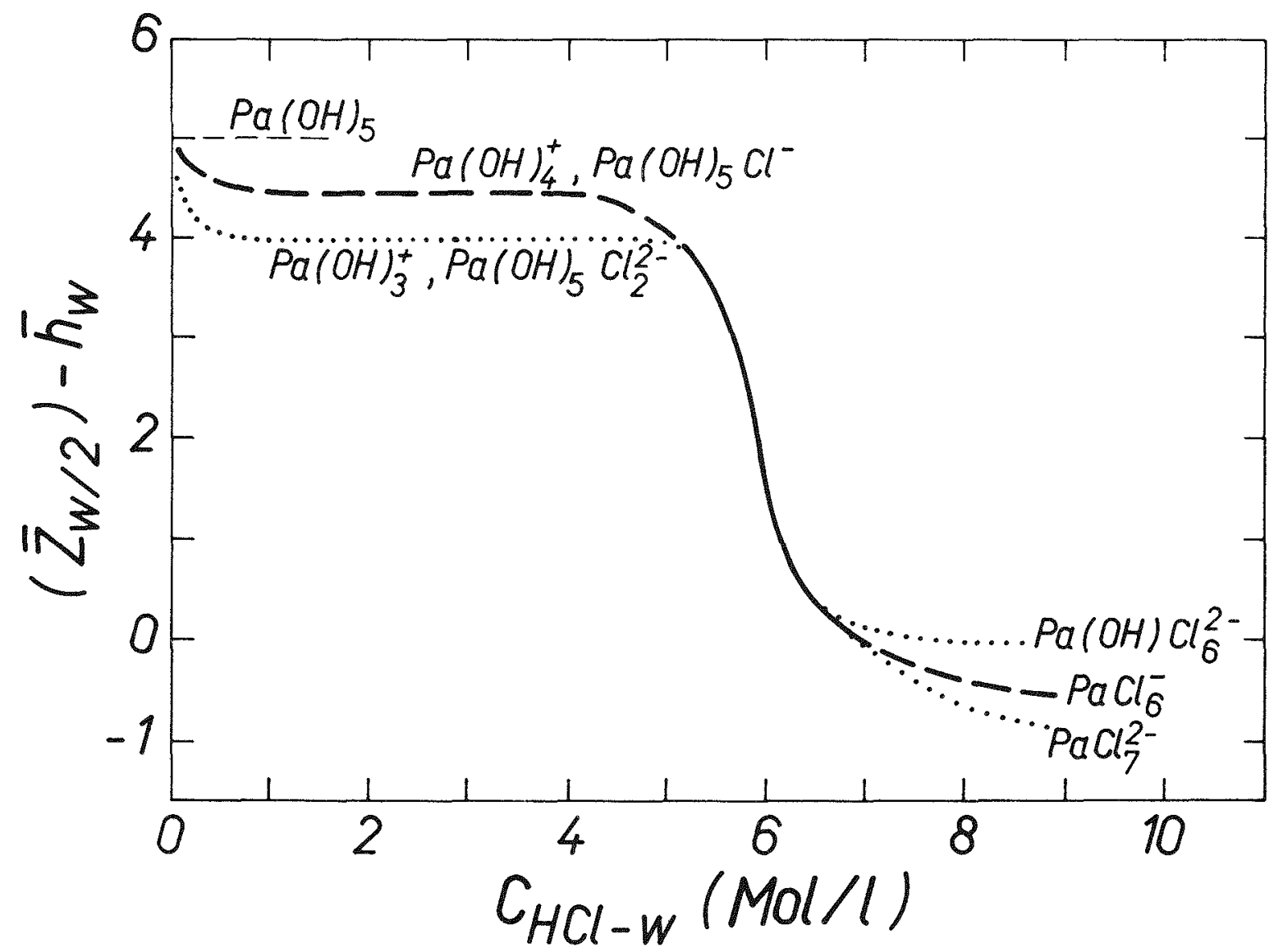

Fig. 8. Mean coordination number $\bar{h}_{w}$ against $\mathrm{II}^{+}$and $\mathrm{OH}^{-}$and mean ionic charge $\bar{z}_{w}$ of Pa-species in aqueous HCl, plotted vs. HCl-concentration $c_{\mathrm{HCl}-\mathrm{W}}$. Fossible species in the extrapolated regions are indicated; for details see text. 
Subtraction of $\bar{h}_{0}$ from the corrected slope values of Fig. 6 a leads to a new function given in Fig. 8 which is equal to $\bar{z}_{\mathrm{w}} / 2-\bar{h}_{\mathrm{W}}$, as can be seen from equation (9). Within the region covered by experimental $\bar{h}_{0}$-values it varies considerably, whereas at high $(>8 \mathrm{M})$ and low $(<4 \mathrm{M}) \mathrm{HCl}$ concentrations constant values are approached. By varying $z_{\mathrm{W}}$ within reasonable 1 imits $(-2$ to +5$)$ one estimates $h_{\mathrm{w}}$ for possible extrapolations of $z_{\mathrm{w}} / 2-h_{\mathrm{w}}$ to high and low HC1 concentrations. The corresponding Pa-species are indicated in Fig. 3. Though there are several possibilities for each value of $z_{W} / 2-h_{W V}$, those species written remain as the on $1 y$ ones if we consider uncharged species $\left(z_{W}=0\right)$ and those having both protons and a positive charge $\left(z_{\mathrm{W}}>0, h_{\mathrm{w}}>0\right)$ as improbable in the aqueous phase. At high HCl-concentrations there remain only anionic complexes with high chloride coordination numbers similar to the complex acid $H P a C l_{6}$ postulated for the equilibrium organic phase. At low concentrations, however, one gets too highly oxygenated species which might be cationic or anionic, depending on the value of $z_{w}$ chosen. To decide between both possibilities, equation (14) is used. Table 2 shows the results: At low HC1-concentrations $\bar{z}_{W}$ is about +2 ; negative values are definitely excluded. Thus, $\mathrm{Pa}(\mathrm{OH}) 3^{+}$is the most probable species, perhaps in mixture with $\mathrm{Pa}(\mathrm{OH})+$, particularly at still lower concentration. In spite of considerable errors in the estimation of $\bar{z}_{\mathrm{W}}$ at and above $4 \mathrm{M} \mathrm{HCl}$, Table 2 shovs clearly a sudden drop of $\bar{z}_{\mathrm{w}}$ in this region which is in accordance with the decrease of $\bar{z}_{\mathrm{w}} / 2-\bar{h}_{\mathrm{w}}$ shown in Fig. 8. From these two observations one has to conclude a transition from cationic to anionic protactinium-species at about $4 \mathrm{M} \mathrm{HCl}$.

Table 2. Evaluation of the Mean Ionic Charge $\bar{z}_{W}$ of Protactinium Species in Aqueous Hydrochloric Acid

\begin{tabular}{|c|c|c|c|c|}
\hline \multirow{2}{*}{$\begin{array}{l}\text { Ionic } \\
\text { Strength }\end{array}$} & \multicolumn{2}{|c|}{ Slope of $\log \mathrm{K}_{\mathrm{D}-\mathrm{Pa}}$ vs. $\log \mathrm{x}$} & \multicolumn{2}{|l|}{ Corresponding $f$} \\
\hline & $x=c_{H C 1-w}{ }^{a}$ & $\mathrm{x}=\mathrm{a}_{\mathrm{HC} 1-\mathrm{w}}$ & $\mathrm{c}_{\mathrm{HC} 1-\mathrm{W}}(\mathrm{M})$ & $\bar{z}_{W}$ \\
\hline 2.62 & 0.44 & $1.6 \pm 0.5^{\mathrm{C}}$ & 2.9 & $+2.3 \pm 1.0$ \\
\hline 3.28 & 0.66 & $1.6 \pm 0.5^{c}$ & 3.2 & $+1.9 \pm 1.0$ \\
\hline 3.98 & $\sim 1.1^{d}$ & 2.7 & 3.3 & $\sim+3.2$ \\
\hline & $\sim 2.6^{d}$ & & 3.5 & $\sim 0.2$ \\
\hline 4.69 & $\sim 2.8^{\mathrm{e}}$ & 2.7 & 4.0 & $\sim 0.2$ \\
\hline
\end{tabular}

From Fig. 4.

brom Fig. 2, see Fig. 6a.

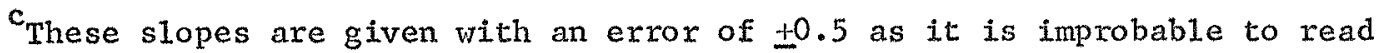
from Fig. 2 a more exact value.

${ }^{d}$ At this ionic strength the slope $\log \mathrm{K}_{\mathrm{D}-\mathrm{Pa}}$ vs. $\log \mathrm{c}_{\mathrm{HCl}-\mathrm{W}}$ (Fig. 4) varies strongly with HC1-concentration. The partition curve was approximated by two straight lines.

${ }^{e_{T}}$ The conditions for equation (14) no longer hold; results are only an approximation.

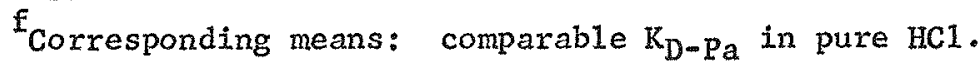

Table 3 is a review of protactinium-species evaluated for both phases. Only some limiting species are listed in the transition region where composition varies strongly. However, it should be kept in mind that $\bar{z}_{W}$ and $\bar{h}_{\mathrm{W}}$ are average numbers so that some of the species listed for this region may not be real. Also it should be pointed out that $\mathrm{Pa}(\mathrm{OH})_{4}^{+}$may be $\mathrm{PaO}{ }_{2}^{+}, \mathrm{Pa}(\mathrm{OH}) \frac{2+}{3}$ may be $\mathrm{PaO}(\mathrm{OH})$, etc.

Considering first the organic species in equilibrium with aqueous HC1, their composition changes from $\mathrm{HPaO}_{2} \mathrm{Cl}_{2}$ - or $\mathrm{HPa}(\mathrm{OH})_{4} \mathrm{Cl}_{2}$ - to $\mathrm{HPaCl}_{6}$. As pointed out above, the $\mathrm{H}^{+}$-ion is part of the HCI-species in DIBC, bound to two DIBCmolecules. 
Table 3. Protactinium-Species in Aqueous Hydrochloric Acid and in Dilsobutylcarbinol in Equilibrium with Hydrochloride Acid

\begin{tabular}{|c|c|c|}
\hline \multirow{2}{*}{$\begin{array}{l}\text { Aqueous HCI } \\
\text { Concentration } \\
\text { (M) }\end{array}$} & \multicolumn{2}{|c|}{ Protactinium-Species } \\
\hline & Organic Phase & Aqueous Phase \\
\hline$\leqslant 2$ & $\mathrm{HPaO}_{2} \mathrm{Cl}_{2}$ & $\mathrm{~Pa}(\mathrm{OH}) 3_{3}^{2+}, \mathrm{Pa}(\mathrm{OH})_{4}^{+}$ \\
\hline 3 & & $\mathrm{~Pa}(\mathrm{OH}) \frac{2+}{3}$ \\
\hline 4 & & $\mathrm{~Pa}(\mathrm{OH}) 3^{2+}+$ others \\
\hline 5 & & 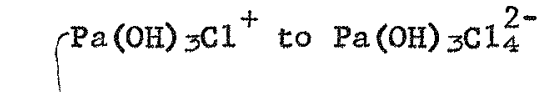 \\
\hline & $\stackrel{\downarrow}{\mathrm{HPaOC} 1_{4}}$ & $a^{2} \mathrm{~Pa}(\mathrm{OH})_{2}^{3+}$ to $\mathrm{Pa}(\mathrm{OH}) \mathrm{Cl}_{5}^{2-}$ \\
\hline 6 & & $\begin{array}{l}\mathrm{Pa}(\mathrm{OH})^{4+} \text { to } \mathrm{Pa}(\mathrm{OH}) \mathrm{Cl}_{6}^{2-} \\
\mathrm{Pa}(\mathrm{OH}) \mathrm{Cl}_{6}^{2-}\end{array}$ \\
\hline 7 & $\mathrm{HPaCl}_{6}$ & $\mathrm{PaCl}_{6}^{-}$ \\
\hline 8 & $\mathrm{HPaCl}_{6}$ & $\operatorname{PaCl} 2_{7}^{2-}$ \\
\hline
\end{tabular}

aransition region with strong1y changing compositions.

In the aqueous phase positively charged, $\mathrm{Cl}$-free species exist at low HC1 concentrations. Between 4 and $5 \mathrm{M}$ HCl substitution by chlorine sets in, but the species hold part of their OH groups even at rather high HC1 concentration up to about $7 \mathrm{M}$ HC1, where OH-free species begin to predominate with the ultimate species PaC12-; a maximum coordination number of 7 in $\mathrm{Pa}-\mathrm{Cl} 1$-species seems reasonable. The surprisingly high number of $\mathrm{OH}$ groups at low and medium HCI concentration suggests $\mathrm{PaO}-$ and $\mathrm{PaO}_{2}^{-}$instead of $\mathrm{Pa}(\mathrm{OH})_{2}^{-}$and $\mathrm{Pa}(\mathrm{OH})_{4}^{- \text {species; }}$ odd OH numbers may result from $O(\mathrm{OH})$-species. On the other hand, species with at least two oH groups would explain the strong tendency of ixreversible hydrolysis, which protactinium shows even in strong HC1, $3,7,9$ as polycondensation of of groups forming chain molecules with O-bridges between Pa-atoms.

The transition from positively to negatively charged species at about $4 \mathrm{M}$ HCI is supported by earlier ${ }^{10}$ and recent ${ }^{11}$ transference-experiments in an electric field.

The adsorption on anion-exchangers from HCl starts at about 4 to $5 \mathrm{M} \mathrm{HC1}, 12$ i.e., in the same region where negatively charged species occur in oux analysis. The adsorption increases with increasing HC1 concentration even above $7 \mathrm{M} \mathrm{HCI}$ in contrast to the partition into $\mathrm{DIBC}$. In this region $\mathrm{PaCl} \mathrm{T}^{-}$is supposed to predominate; according to Table 3 this species is not transferred into the organic phase but may be adsorbed on anion exchangers. The optical absorption spectra change significantly at about $6 \mathrm{M} \mathrm{HC1}, 13$ just in the region where OHrich species vanish. Concerning the ultimate species in weak acid solutions, different results are reported. From adsorption on cation exchangers the protactinyl ion $\mathrm{PaO}_{2}^{++}$was postulated, ${ }^{14}$ which is equivalent to $\mathrm{Pa}(\mathrm{OH})+$. In contrast other authors 15 interpreted their partition data with various solvents in terms of a species $\mathrm{Pa}(\mathrm{OH}) 3$ !

In conclusion we would like to point out that oux analysis of protactinium species is not free from assumptions but it involves---in our opinion---1ess 
assumptions than made in previous discussion of this kind, e.g., ref. (6). In most cases we are forced to assumptions not from fundamental difficulties but in 1ack of data. Thus an extension of partition experiments to regions not covered and more precise data may lead to a more satisfactory knowledge of the behavior of protactinium in hydrochloric acid.

\section{ACKNOWLEDGMENTS}

The authors express their gratitude to Professor F. Strassmann for his encouragement and the facilities he has provided, to Professor 0 . Hahn for the $\mathrm{Pa}^{231}$ sample, and to the Bundesministerium für wissenschaftliche Forschung der Bundesrepublik Deutschland for financial support.

\section{REFERENCES}

1. V. Vand, J. Physic. Chem. 52, 277 (1948); see also R. A. Robinson and R. H. Stokes, Electrolyte Solutions, 2nd ed., p. 305, London, 1959.

2. A. M. Poskanzer, Ph.D. Thesis, Massachusetts Inst. of Technol. (1957).

3. A. G. Goble and A. G. Maddock, Canad. J. Chem. 34, 284 (1956).

4. C. J. Hardy and D. Scargi11, J. Inorg. Nuc1. Chem. I, 287 (1958).

5. W. E. Keder and J. C. Sheppard, ibid. 12, 327 (1960).

6. A. T. Casey and A. G. Maddock, ibid. 10, 289 (1958).

7. A. G. Goble and A. G. Maddock, ibid. I, 94 (1958).

8. W. D. Schumb and R. D. Evans, J. Amer. Chem. Soc. 61, 3453 (1939). J. M. Schalch1i and E. Rudzitis, Ph.D. Theses Massachusetts Inst. of Techno1. (1955, 1957), see also ref. (2).

9. A. T. Casey and A. G. Maddock, J. Inorg. Nuc1. Chem. 10,58 (1958).

10. Unpublished work of Sullivan, Sellers and Janda, quoted in G. T. Seaborg and J. J. Katz, The Actinide Elements, p. 122, New York, 1954.

11. J. Shankar, K. S. Venkateswarlu and G. Gotinathan, J. Inorg. Nuc1. Chem. 25, 62 (1963).

12. A. G. Maddock and W. Pugh, ibid. 2, 114 (1956).

S. Kahn and D. E. Hawkinson, ibid. 3, 155 (1956).

R. A. Kraus and G. E. Moore, J. Amer. Chem. Soc. 72, 4293 (1950).

13. D. Brown, A. J. Smith and R. G. Wilkins, J. Chem. Soc. 1959, 1463.

14. G. A. Welch, Nature 172,458 (1953).

K. Kimura and Y. Yokoyama, Japan Analyst 6, 637 (1957).

15. W. A. Michailow, Zh. neorg. Khim. 3, 1959 (1958). Radiokhim. 1, 395 (1958).

T. Ishimori and E. Nakamura, J. Atom. Energy Japan 3, 590 (1962).

A. M. Poskanzer and B. M. Foreman, J. Inorg. Nucl. Chem. 16, 313 (1961). 


\title{
HYDROLYSIS AND RESIDUE ADSORPTION \\ OF PROTACTINIUM
}

\author{
H。W. Kirby
}

Mound Laboratory, Miamisburg, Ohio, operated for the Atomic Energy Commission by Monsanto Research Corporation under contract AT-33-1 - GEN-53

One of the most frequently cited characteristics of protactinium is its tendency to hydrolyze in aqueous solution and to deposit on the sides of glassware and other containing vessels.

This behavior is illustrated in Figure 1. Spectrum A is a typical gamma spectrum of protactinium-231 immediately after dilution and mixing.

However, when the solution was allowed to stand undisturbed for two days and sampled again, the gamma spectrum (Spectrum B) showed that the protactinium had hydrolyzed although there was no visible precipitate, and the concentration was only $7 \mathrm{\mu g} / \mathrm{ml}$.

This is seen more clearly in Figure 2. Here, the protactinium solution was shaken up and a sample was filtered through a coarse glass wool filter.

The lower spectrum (A) is that of the filtrate and shows the characteristic gamma photopeaks of the actinium-227 decay chain. The upper spectrum (B) is a typical spectrum of protactinium-231, showing the principal photopeaks at 27,95, and $300 \mathrm{kev}$, and represents the protactinium -231 removed from solution by the coarse glass wool filter. 


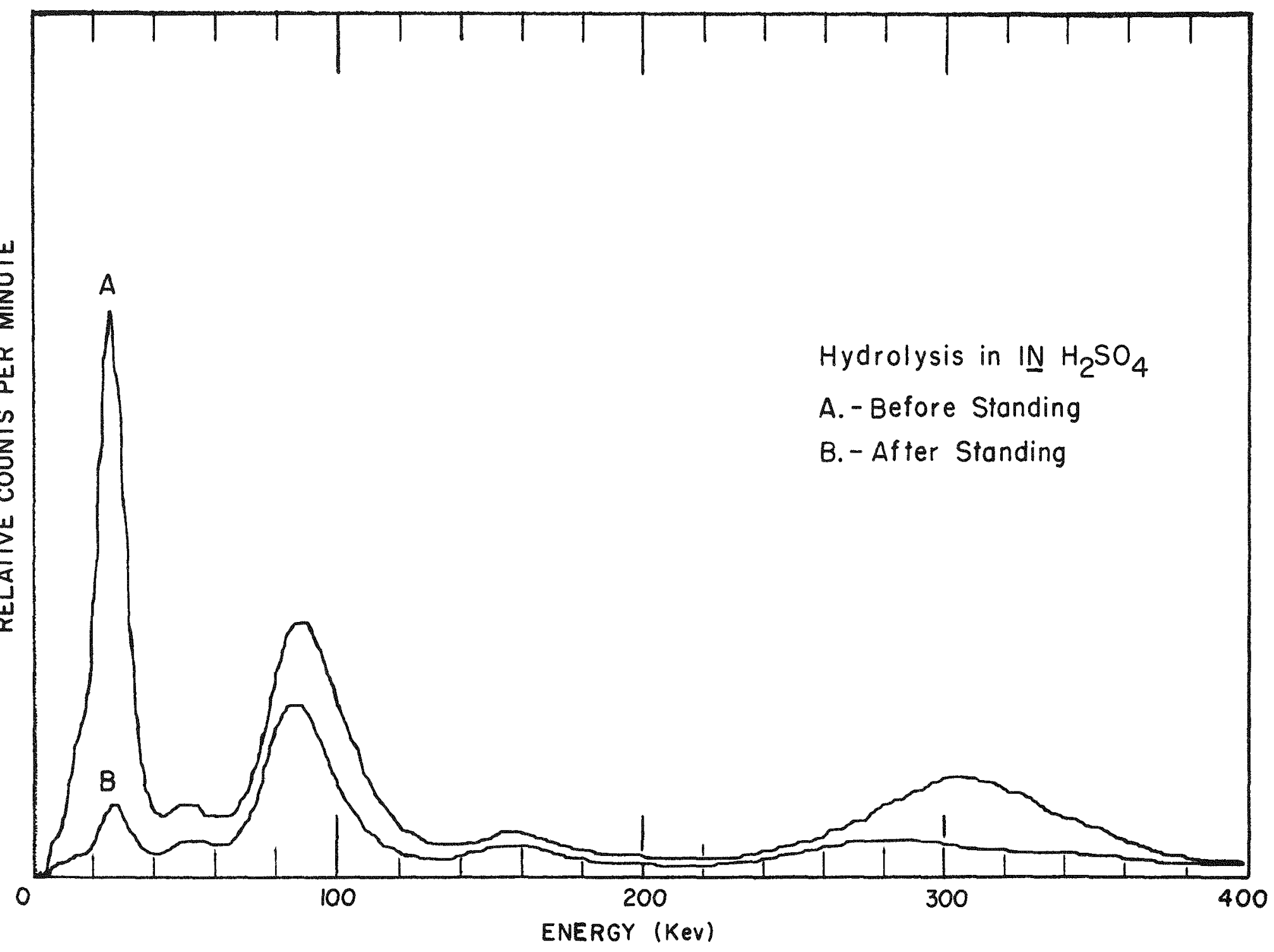

Figure 1 


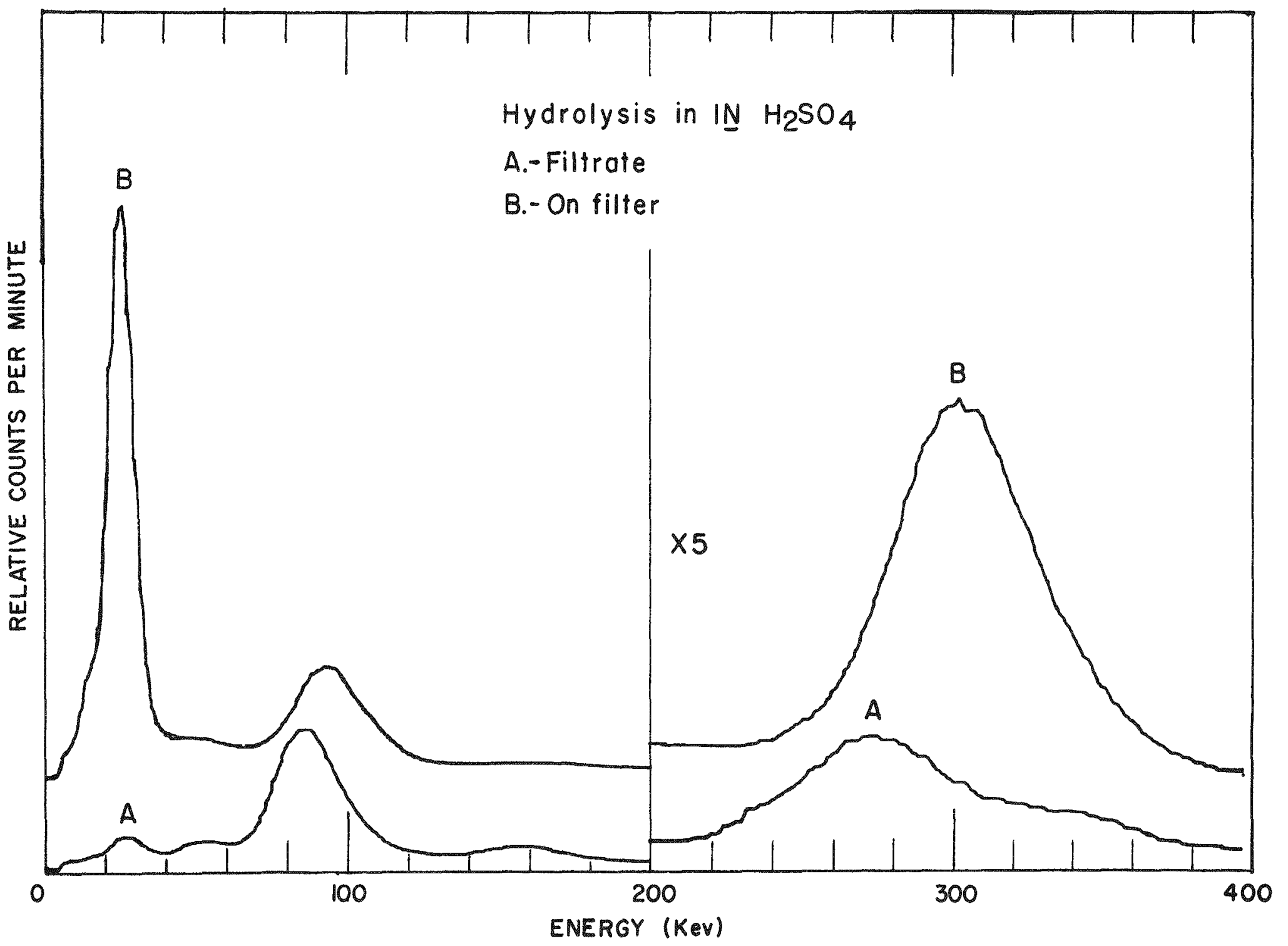

Figure 2 
The degree of separation is shown by the near absence of the 27 kev peak in Spectrum $A$ and the near absence of peaks at $50 \mathrm{kev}$ and $156 \mathrm{kev}$ in Spectrum B。

The original protactinium solution, before dilution, had had a concentration of approximately $1.5 \mathrm{mg} / \mathrm{ml}$ of protactinium and had been stable for 18 months in fairly concentrated sulfuric acid。 There was no visible precipitate.

Was the hydrolysis due to the dilution of the protactinium? Was it due to the dilution of the sulfuric acid? Was it due to trace impurities leached from the glassware during the $1-1 / 2$ years of storage?

To answer these questions a three milliliter sample of the $1 \underline{\mathrm{N}}$ $\mathrm{H}_{2} \mathrm{SO}_{4}$ solution of protactinium was evaporated to its minimum volume at $100^{\circ} \mathrm{C}$ (about 10 microliters) then cooled and diluted with $6 \mathrm{~N} \mathrm{H}_{2} \mathrm{SO}_{4}$ to its original volume. The solution was stoppered and allowed to stand undisturbed for four days then filtered through a glass wool filter as before.

The results are shown in Figure 3, where we see the same effect as before, with protactinium separated from its decay products. In this case, however, the positions are reversed. The protactinium passed quantitatively through the glass wool filter while the decay products were adsorbed.

The upper spectrum (A) shows the presence of thorium-227 and radium-223, but the lower spectrum (B) is almost entirely free of the $27 \mathrm{kev}$ peak of protactinium. 


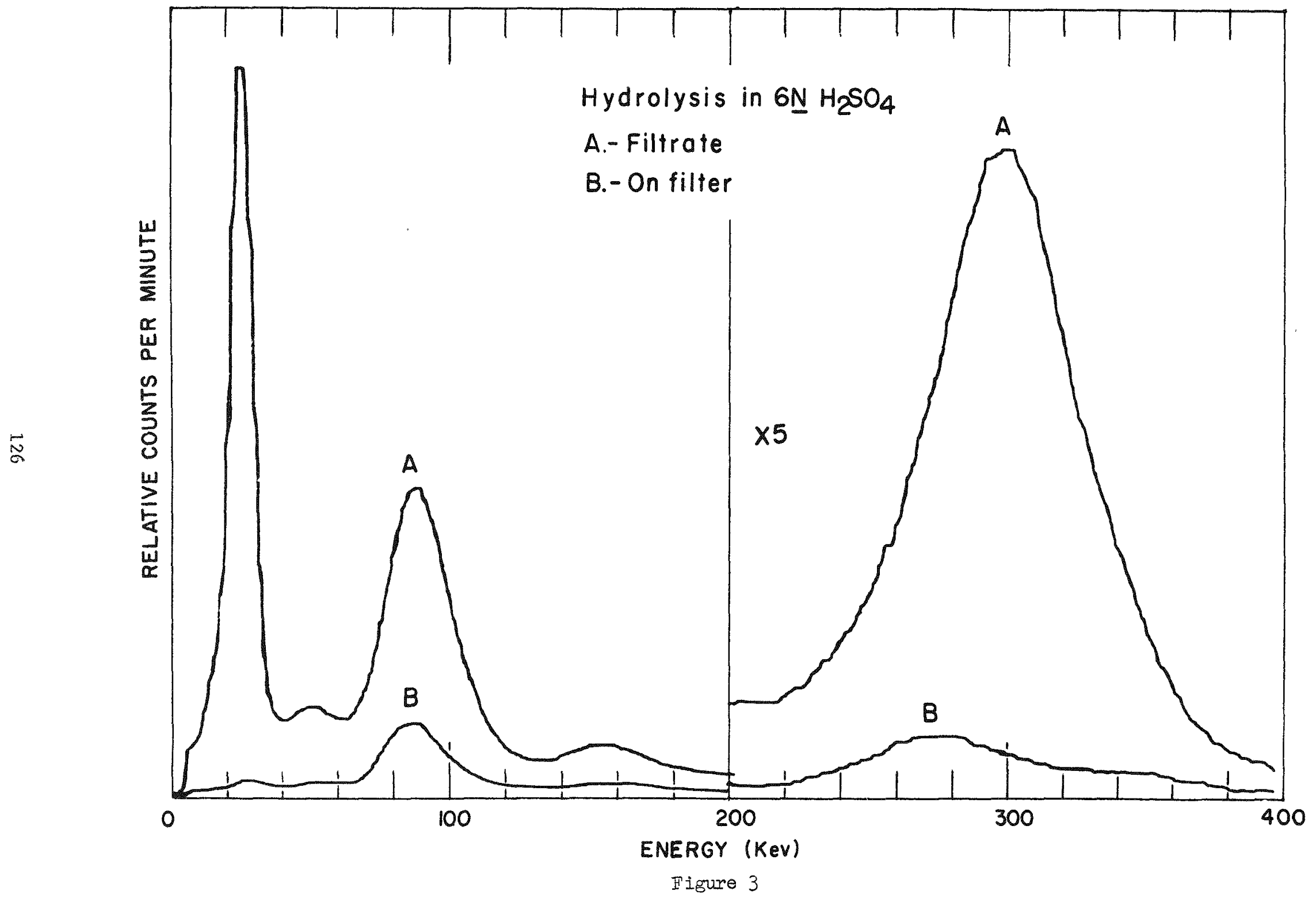


It should be noted that these spectra were run approximately one month after the separation and that immediately after separation, the protactinium was nearly free of radium-223 represented by the peak at $156 \mathrm{kev}$. However, the $50 \mathrm{kev}$ peak representing thorium-227 was present indicating that in the $6 \mathrm{~N} \mathrm{H}_{2} \mathrm{SO}_{4}$ thorium at the trace level behaves like protactinium.

However, the most signiflcant conclusion to be derived from this experiment and the preceding ones is that trace level hydrolysis is not a characteristic which is unique to protactinium. As Figure 3 shows, even the alkaline earth elements, represented by radium-223 at the picogram level, can be made to exhibit adsorption under appropriate conditions.

As a result of experiments and observations similar to these, some years ago I began to develop a method for determining the age of a sample of protactinium-231 based on the hydrolysis of protactinium-231 ana its separation from its decay products。

I soon found that it was not necessary to filter the protactinium. Under appropriate conditions, protactinium could be made to adhere to the walls of a glass vial which could then be washed with common reagents without removing the protactinium.

Untortunately, thorium-227 and, to some extent, actinium-227 also adhered to the glassware, Even radium-223 could not always be quantitatively separated.

It aiso turned out that it was not necessary to use a vessel of any kind. A flat plate would serve equally we11; and if the protactinium solution was dried on a flat plate of glass, stainless steel, platinum, Teflon, or almost any other material, the plate could be 
washed vigorously under a stream of water without any significant loss of protactinium.

However, the same was true of thorium-227 and actinium-227 under certain conditions. So it soon became apparent that the separaticn. was going to require considerable preliminary study.

I chose to work with a relatively simple system--strontium-90 and yttrium-90-- and, as a result of this work, I have developed a method of separation which I call residue adsorption. The results of the strontium-90 work will appear shortly in the Journal of Inorganic and Nuclear Chemistry, and I am now developing this technique for the sequential separation of protactinium-231 from actinium-227, thorium -227 and radium -223 .

I should like to devote the remainder of this discussion to the work that is now in progress on the residue adsorption technique as applied to the separation of protactinium-231 and its decay products.

The technique is quite simple; but for the sake of uniformity, I have developed a standardized preparation procedure to eliminate as many variables as possible (Figure 4-9).

The flat plate, in this case stainless steel, is first cleaned by agitation for five minutes in a solution of alcoholic potassium hydroxide, It is rinsed thoroughly in distilled water and dried with absorbent paper.

A small glass vial, $15 \mathrm{~mm}$. in diameter, $1 \mathrm{~s}$ placed in the center of the disk, and the disk is sprayed with a solution of methyl methacrylate (Figure 4). The sole purpose of the plastic spray is to provide a hydrophobic retaining ring and limit the area to be covered by the aqueous solution. 
The methyl methacrylate dries rapidly in air; but as a rule, after removing the glass vial, I heat the disk on a hot plate for one or two minutes to insure complete dryness. The outlines of the plastic ring can be seen in Figure 5.

As a rule, I prepare two or more plates simultaneously depending on the kind of experiment to be performed.

Again, to avoid unnecessary variables, I usually avoid preparing a large number of disks very long in advance of the experiment.

As part of the cleaning procedure, I deposit a solution of $1 \mathrm{~N}$ HNO, on the open area of the disk, heat it for two minutes at $90^{\circ} \mathrm{C}$, then rinse it away under the distilled water tap. The disk is then dried on the hot plate and is ready for the experimental solution.

Solutions are added with a micropipet in the usual manner (Figure 6). The area shown here can hold $0.3 \mathrm{ml}$. of aqueous solution comfortably. If less than that amount is used, additional solvent is usually added to insure that the entire unmasked surface is covered.

The radioactive solution is now allowed to evaporate to dryness at whatever temperature has been selected. I usually work at $90^{\circ} \mathrm{C}$ to avoid the possibility that the solution will boil and spatter the radioactivity out of the standard area. It takes seven minutes for $0.25 \mathrm{ml}$. of $\mathrm{H}_{2} \mathrm{O}$ or $1 \mathrm{~N} \mathrm{HNO} \mathrm{H}_{3}$ to evaporate to dryness at this temperature in a fume hood with a mild draft.

When the radioactive solution has evaporated to dryness, the residue is covered with $0.5 \mathrm{ml}$ o of previously bolled and cooled distilled water. This volume of solution overlaps the unmasked area and insures that the edges are covered. As the solution evaporates, it 





$\bullet$ 
gradually is drawn together by surface tension, and the final evaporation takes place in the standardized area. It takes about 12 minutes to evaporate $0.5 \mathrm{ml}$. of $\mathrm{H}_{2} \mathrm{O}$ under these conditions.

The purpose of the water is to eliminate the last traces of adsorbed acid solution from the residue. As further insurance, the dry disk is heated for an additional five minutes after the last trace of moisture has disappeared.

Figure 7 shows an experiment in progress. The radioactive solution has been dried on the disk at the left and has been covered with distilled water and dried again. The residue has been covered with $0.5 \mathrm{ml}$. of the selected reagent, and this solution has been heated for two minutes (or five minutes, depending on the experiment.) The solvent is shown as it is being transferred to the disk at the right. For this purpose, I use a medicine dropper which has been drawn down to a small tip. Medicine droppers are convenient because they are cheap, expendable and easily worked in a flame.

Figure 8 shows an alternative method. Instead of transferring the solution to another disk, one can transfer to a vial or a beaker. This has the advantage of permitting the use of larger volumes and more washings.

I estimate that, under the standard conditions, I can transfer all of the solution from a stainless steel plate with a loss of not greater than $5 \%$ per transfer. With platinum, which is more hydrophobic, the loss is even less。

For transferring to a vial I usually use a two minute heating period and wash the surface at least twice, sometimes three or four times, 


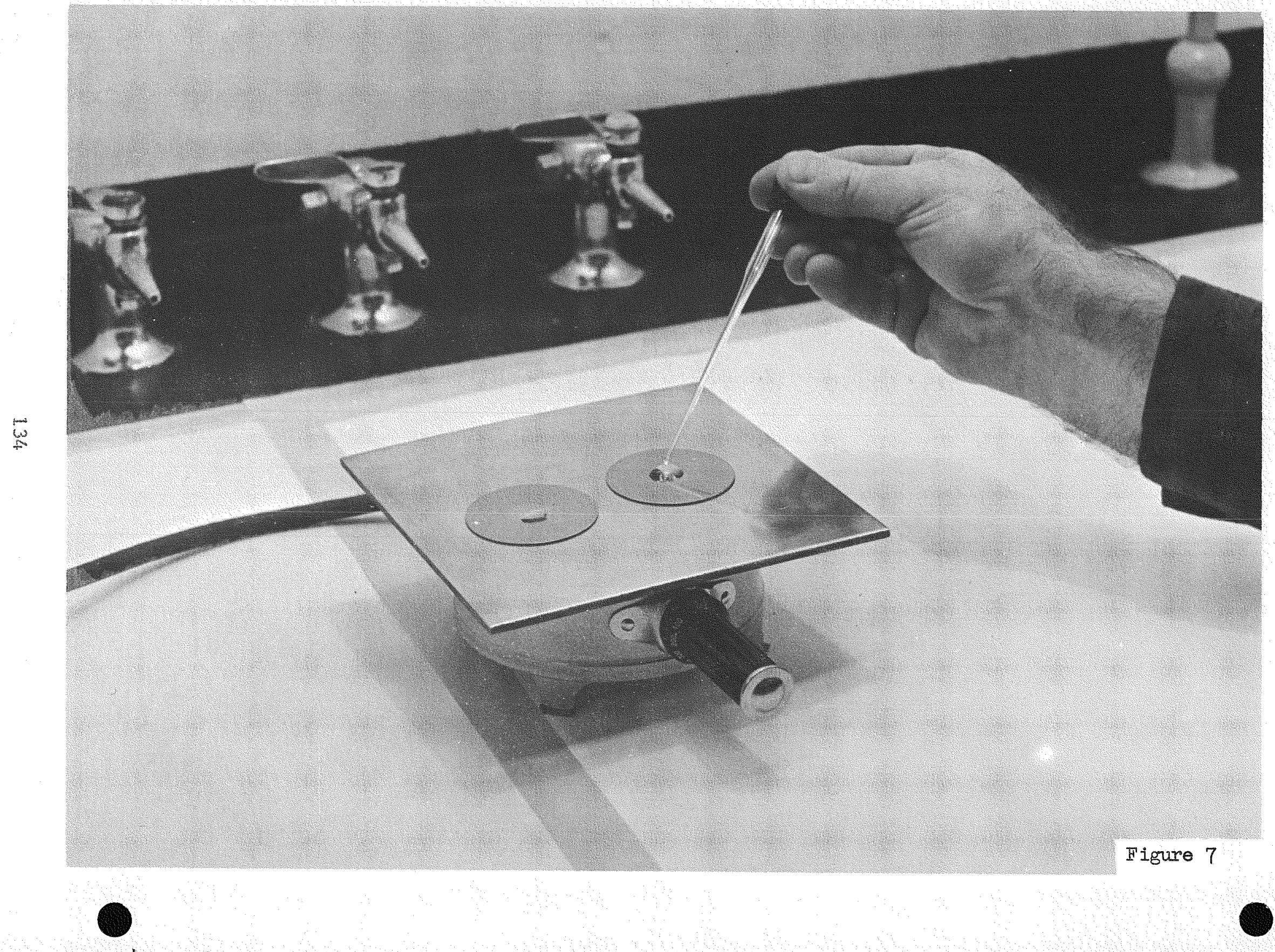



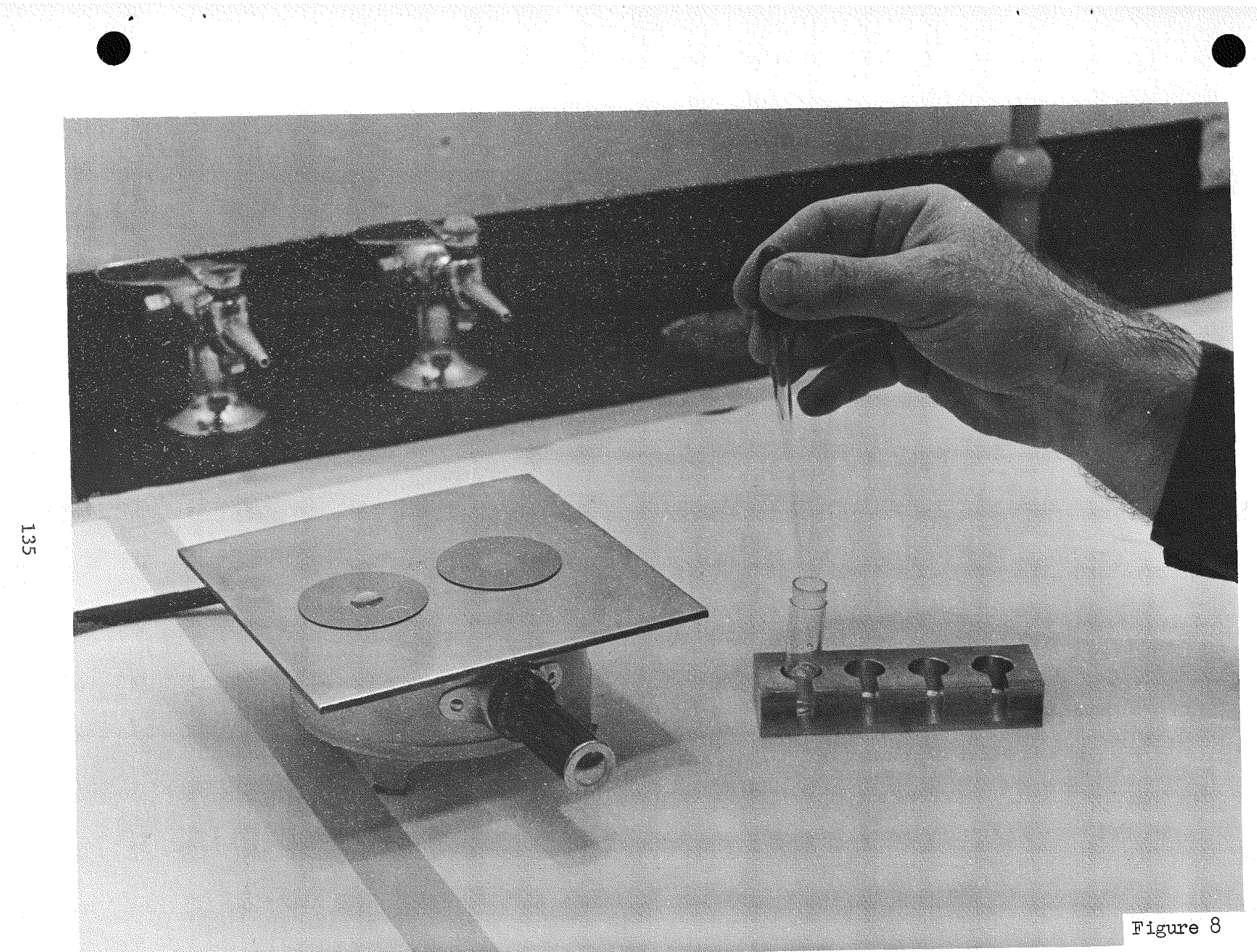
with $0.5 \mathrm{ml}$ of the reagent under study, For transferring from one plate to another I usually use a five minute heating period and wash only once. This limits the amount of solution to be transferred and avoids piling up too much solution at one time on a single plate. A flat plate is used for a receiver when I intend to make successive transfers: that is, when the activity is to be transferred successively from the first to a second and from the second to a third plate and so on.

Table I shows the results of a series of experiments on the desorption of protactinlum from platinum by various reagents. The prow tactinium was purified by hydrolysis in $1 \mathrm{~N} \mathrm{H}_{2} \mathrm{SO}_{4}$ followed by $\mathrm{fil}$ tration through glass wool. The purified protactinium was recovered from the glass wool in $0.01 \mathrm{~N} \mathrm{HF}$.

In each series $9.3 \mathrm{H}$ 。 of protactinium in $0.1 \mathrm{ml}$ of $0.01 \mathrm{~N}$ HF was deposited or à platinum disk, previously cleaned and masked as usual: and the usual water addition and evaporation was carried out. 
Table I

\% DESORPTION OF PROTACTINIUM FROM PLATINUM

\begin{tabular}{|c|c|c|c|c|c|}
\hline Normality & $\mathrm{HNO}_{3}$ & $\mathrm{HCl}$ & $\mathrm{H}_{2} \mathrm{SO}_{4}$ & $\mathrm{H}_{2} \mathrm{C}_{2} \mathrm{O}_{4}$ & $\mathrm{HF}$ \\
\hline 0.00 & 3.4 & $-\infty$ & 4.9 & - & 5.7 \\
\hline 0.01 & 0.9 & 5.7 & 1.5 & 9.8 & 96.2 \\
\hline 0.1 & 0.3 & 0.9 & 2.6 & 33.0 & 92.6 \\
\hline 1 & 1.6 & 3.2 & 63.1 & 66.0 & $\infty$ \\
\hline 3 & 4.2 & 9.3 & 73.2 & -- & - \\
\hline 6 & 10.8 & 76.3 & 33.8 & $=$ & $-\infty$ \\
\hline Residual & 80.2 & 19.4 & 6.0 & 18.0 & 0.3 \\
\hline
\end{tabular}


The protactinium residue was leached successively with increasing concentrations of the same acid-two $1 / 2 \mathrm{ml}$. leachings for each concentration. However, a different sample of protactinium was used for each different acid.

The leachings were transferred to styrene vials and gamma-counted. The residual protactinium on each disk, indicated at the bottom of each column, was determined by alpha-counting.

Each number in the table except the residual value represents the percentage of protactinium as compared with the amount left by the last previous concentration. Therefore, the tota 1 s are over $100 \%$ in all cases.

There are several points of interest in this table. First, the various reagents have been arranged according to their increasing efficiency of desorption at the $0.1 \mathrm{~N}$ level。 The poorest, $\mathrm{HNO}_{3}$, is at the left; and the best, $\mathrm{HF}_{9}$ is at the right. Increasing de-

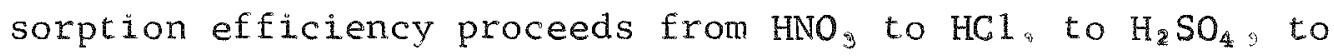
oxalic, to HF。

Note that below the $6 \mathrm{~N}$ level $\mathrm{HCl}$ is not a very good reagent for desorbing protactinium, and one would expect to see hydrolysis in HC1 solutions of $3 \mathrm{~N}$ or lower concentrations.

Note also that in every case there was significant desorption of protactinium by the first concentration used including the three cases where the first reagent, that is, the 0.00 normal solution, was actually wacer. I attribute this to the fact that in spite of the effort to eliminate the last traces of HF by a second evaporation with water and by an extra period of drying, enough HF remained 
to desorb the protactinium regardless of what other reagent was present.

In particular, it should be pointed out that at this trace level the best desorbing reagents are also those which are best for rew taining protactinium in solution at the macro level.

One surprising result was the high degree of desorption by

$1 \mathrm{~N}_{2} \mathrm{SO}_{4}$ which would appear to contradict the results shown earlier in the hydrolysis experiments. When I saw this, I did something that I should have done in the first place; namely. determine the acid concentration of the $1 \mathrm{~N}_{2} \mathrm{SO}_{4}$ solution of protactinium by a direct titration. It turned out to be $0.56 \mathrm{~N}$ instead of 1 N.

There would appear, therefore, to be a rather sharp break between the concentrations at which protactinium will or will not hydrolyze in each reagent. This is one of the things that I am planning to study more carefully in the near future. Table II shows the same sort of thing applied to actinium-227 in equilibrium with its decay products. However, the results are somewhat misleading because the actinium equilibrium mixture (AEM), consists of several different radioelements each behaving according to its own chemical nature. The only noteworthy point in Table II is the large residual per centage in the HF column, which is explained in Figure 9. The spectrum in Figure 9 represents the $18.5 \%$ of the total gamma activ. ity which was left after the actinium equilibrium mixture (or AEM) was leached with $1 \mathrm{~N} H F$.

This is the characteristic gamma spectrum of thorium-227, and it appears to be essentially radiochemically pure. There is a trace of radium-223 present as indicated by the small peak at $156 \mathrm{kev}$; but this may be due to growth, since radium-223 is the first decay 
Table II

$\%$ DESORPTION OF AEM FROM PLATINUM

\begin{tabular}{|c|c|c|c|c|}
\hline Normality & $\mathrm{HNO}_{3}$ & $\mathrm{Na}_{2}$ EDTA & $\mathrm{H}_{2} \mathrm{C}_{2} \mathrm{O}_{4}$ & $\mathrm{HF}$ \\
\hline 0.00 & 61.1 & 41.6 & 40.9 & 52.4 \\
\hline 0.01 & 28.1 & 42.0 & 52.0 & 24.6 \\
\hline 0.1 & 4.2 & 10.2 & 4.7 & 3.7 \\
\hline 1 & 2.9 & $=-$ & 0.9 & 0.9 \\
\hline 3 & 1.1 & $=-$ & $=-$ & $=-$ \\
\hline 6 & 0.7 & -- & -- & -- \\
\hline Residual & 0.6 & 6.1 & 1.5 & 18.5 \\
\hline
\end{tabular}




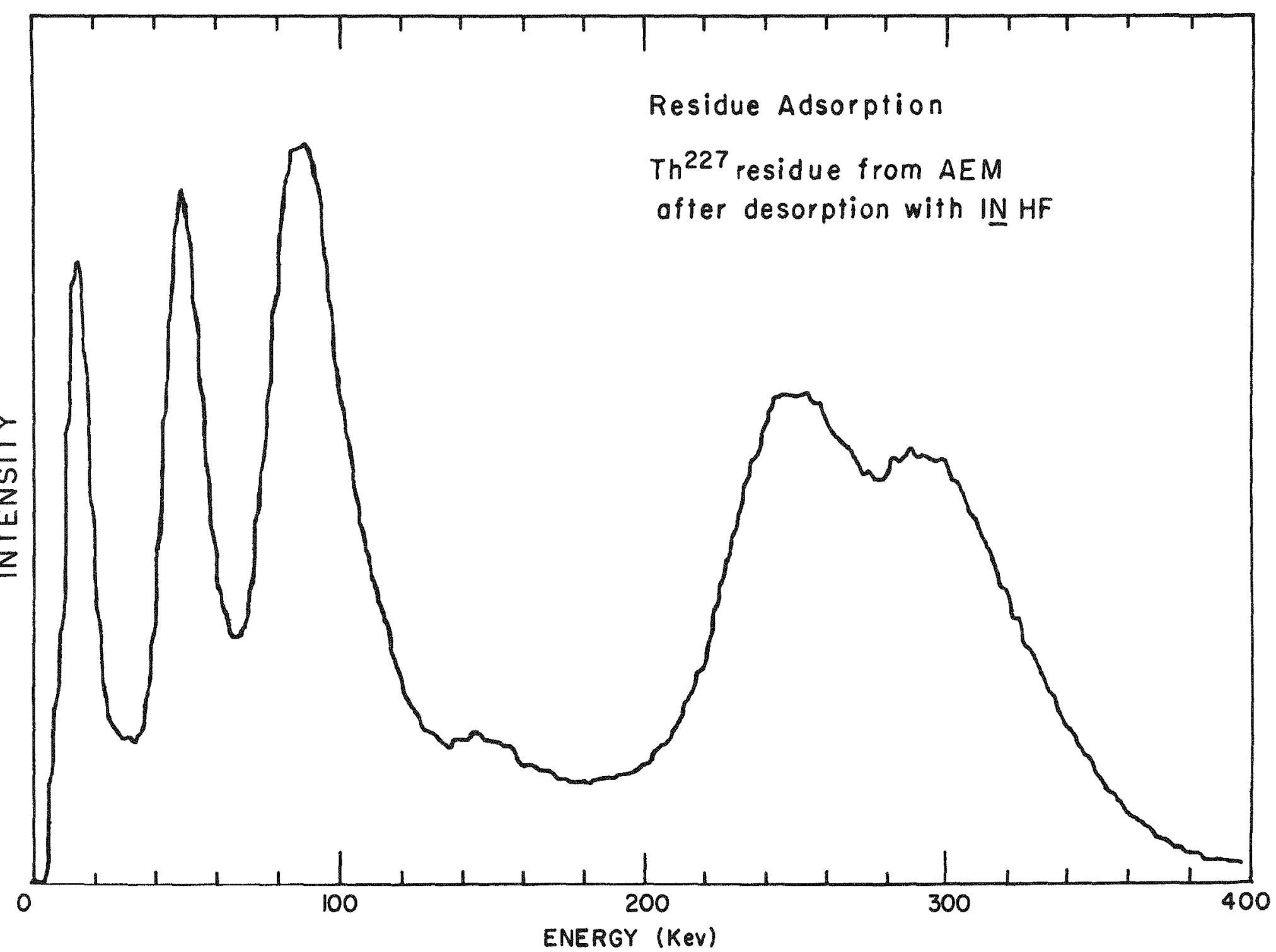

Figure 9 
product of thorium 227. Nothing can be said about actinium 227 , which has no gamma activity of significance。

The best way to determine actinium-227 with high accuracy and a minimum of chemical manipulation is by the method of differential decay, which consists basically of determining the gross alpha count of the sample at various times and then solving a set of simultaneous equations based on the half. lives of the three major components of AEM。

Table III shows the distribution actinium:227 thorium=227 and radium-223 in various concentrations of $\mathrm{HNO}$. In this case, the activity was deposited on a stainless steel disk and desorbed with water and two concentrations of $\mathrm{HNO}_{3}$. The leachings were trans. ferred to separate stainless steel disks alpha-counted periodically and analyzed for the three components.

Note that radium -223 is the most easily desorbed. with actinium -227 rext, and thor 1 um 227 last: but about $95 \%$ of al1 three radioelements had been desorbed atter $0,1 \mathrm{~N} H N O$

By contrast (Table I) less than $5 \%$ of the protactinium was desorbed after $0_{0} 1 \mathrm{~N} \mathrm{HNO}_{3}$ was used, and 1t was not untıl $6 \mathrm{~N}$ HNO; was used that a significantly large percentage of the protactinium was de sorbed。

Table IV shows the distribution of AEM in various concentrations of HF。 Again we see the strong contrast with the behavior of protactin ium. Whereas $0.01 \mathrm{~N}$ HF desorbed $96 \%$ of the protactinium, and $0.1 \underline{N}$ HF removed all but the last $0.3 \%$, both actinium. 227 and thor 1 um -227 remained nearly quantitatively adsorbed at both concentrations. Even radium-223 did not transfer as readily in $H F$ solutions as it had in nitric acid. 
Table III

DISTRIBUTION OF AEM IN $\mathrm{HNO}_{3}$

$\mathrm{HNO}_{3}$
Normality

0.00

0.01

0.1

Total Transferred

Residual

Material Balance

\begin{tabular}{rrr}
\multicolumn{3}{c}{ Per Cent Transferred } \\
\hline$\frac{\mathrm{Ac}^{227}}{12.6}$ & $\frac{\mathrm{Th}^{227}}{2.7}$ & $\frac{\mathrm{Ra}^{23}}{85.9}$ \\
80.6 & 80.7 & 9.7 \\
0.9 & 11.4 & 0.3 \\
94.1 & 94.8 & 95.9 \\
0.5 & 7.5 & 2.4 \\
94.6 & 102.3 & 98.3
\end{tabular}


Table IV

DISTRIBUTION OF AEM IN HF

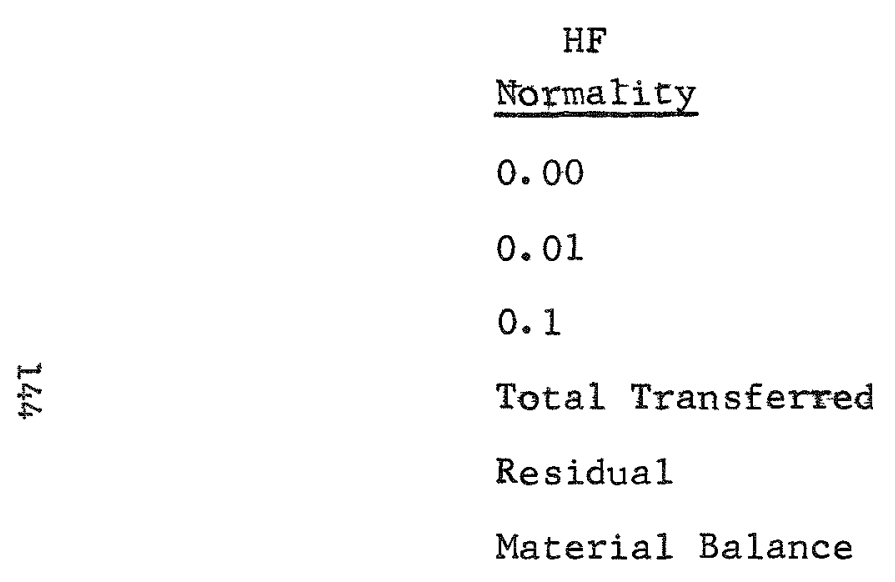

\begin{tabular}{rcr}
\multicolumn{3}{c}{ Per Cent Transferred } \\
\hline$\frac{\mathrm{Ac}^{227}}{4.6}$ & $\frac{\mathrm{Th}^{227}}{223}$ & $\frac{\mathrm{Ra}^{23}}{79.0}$ \\
3.3 & 0.01 & 4.7 \\
0.4 & 2.6 & 2.3 \\
8.3 & 0.8 & 86.0 \\
95.7 & 3.4 & 13.5 \\
104.0 & 99.7 & 99.5
\end{tabular}


It might be well to point out in this connection that although the AEM was initially deposited in 1 N $\mathrm{HNO}_{3}$ solution, the residue was converted to a fluoride by covering it with $0.1 \mathrm{~N} H F$ and drying that before the final evaporation with water.

Figures 10-17 demonstrate graphically the beginnings of what I hope will ultimately be developed as a sequential separation of protactinium, actinium, thorium, and radium by the residue adsorption technique.

A sample of AEM was deposited on each of two platinum disks, dried, covered with water, and dried again. On one of these two disks, a sample of protactinium in $0.01 \mathrm{~N}$ HF was deposited, dried, covered with water, and dried again. Both residues were covered with $1 \mathrm{~N}$ $\mathrm{HNO}_{3}$, dried, and heated for an additional five minutes. They were then leached with water and with several concentrations of nitric acid.

Figure 10 compares the spectra of the two water leachings. Spectrum A shows the activity leached from the AEM residue. Spectrum B shows what was leached from the mixture of protactinium and AEM。 They appear to be identical except for a slight difference in magnitude.

Figure 11 shows what was leached in $0.01 \mathrm{~N} \mathrm{HNO}_{3}$ from the two residues. Again, they are identical except for magnitude.

Figure 12 shows the results of leaching with $0.1 \mathrm{~N} \mathrm{HNO}_{3}$. Here we see the first appearance of protactinium represented by the sma 11 hump at $27 \mathrm{kev}$. Otherwise, the spectra are identical.

Figure 13 shows that in $1 \mathrm{~N} \mathrm{HNO}_{3}$ the protactinium makes a definite appearance with a wellodefined peak at $27 \mathrm{kev}$ in contrast to the appearance of the same region of the AEM spectrum 


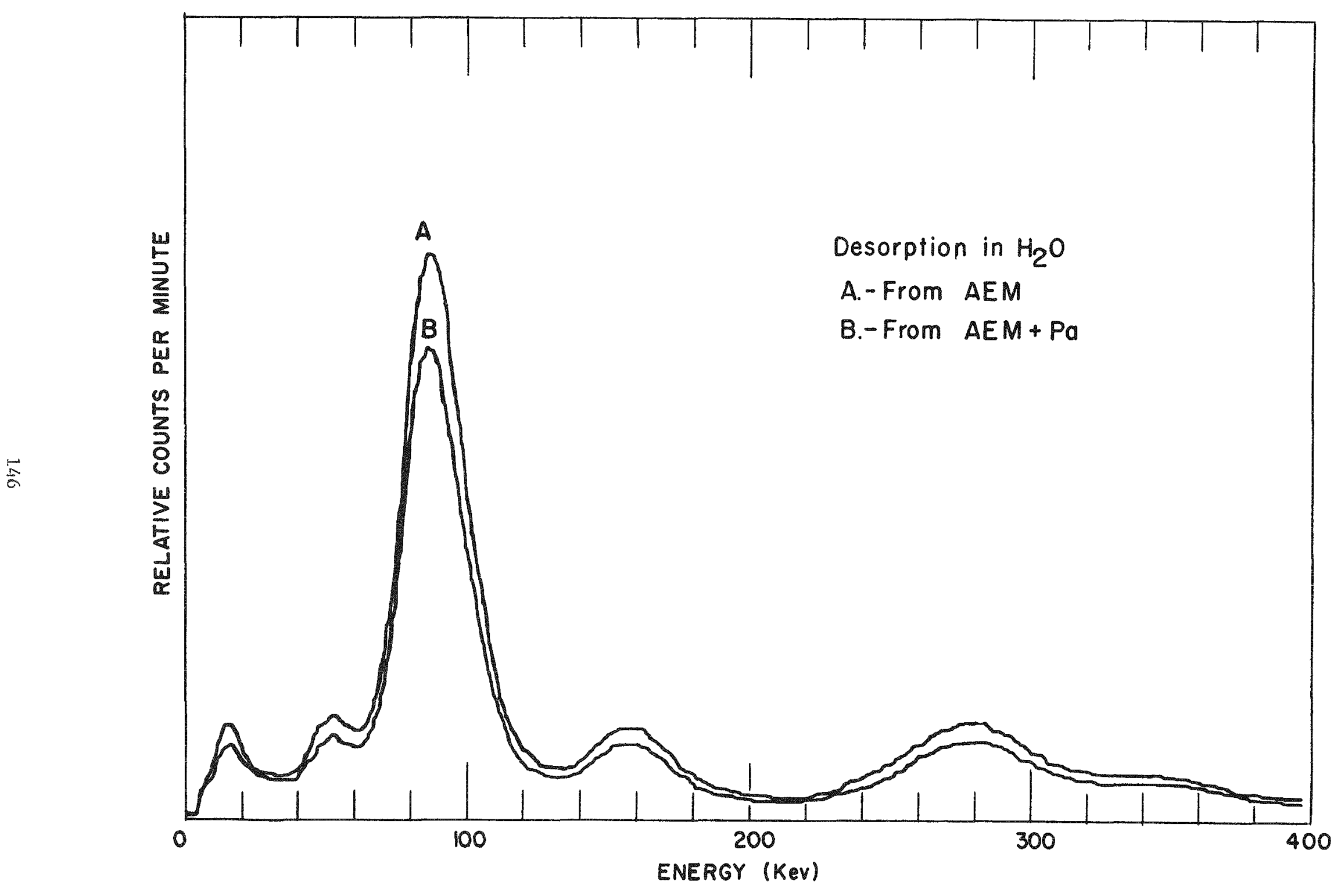

Figure 10 


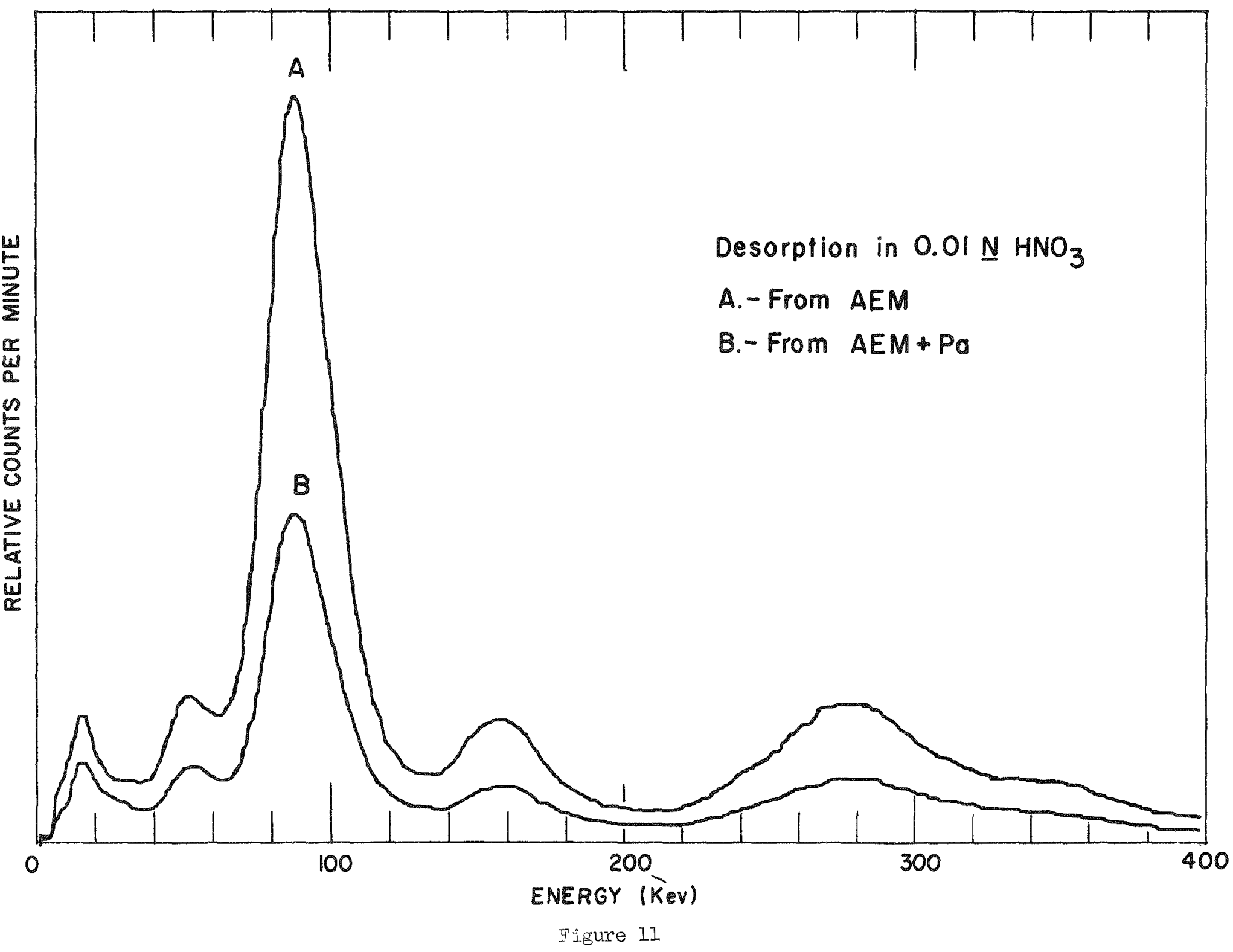




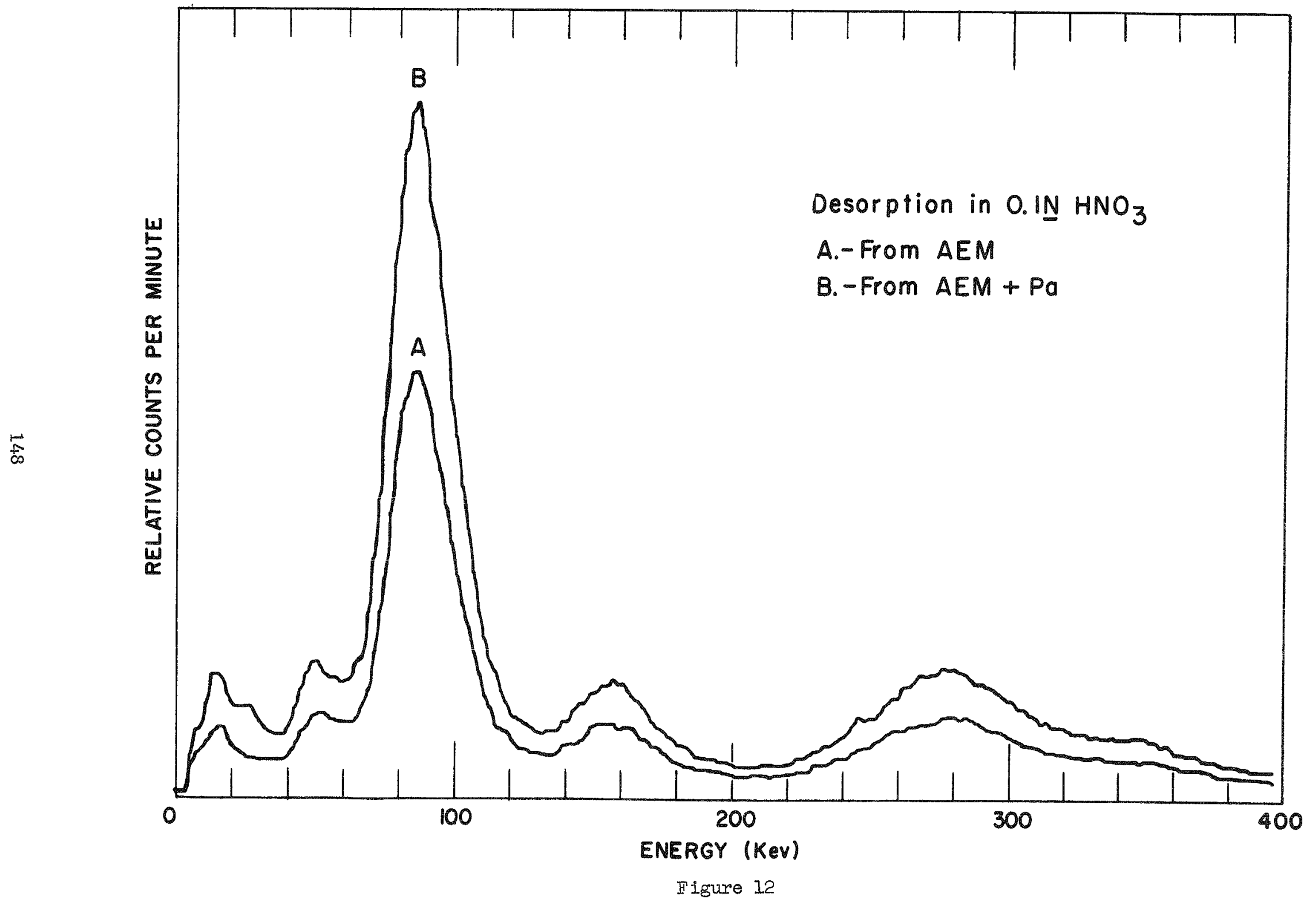




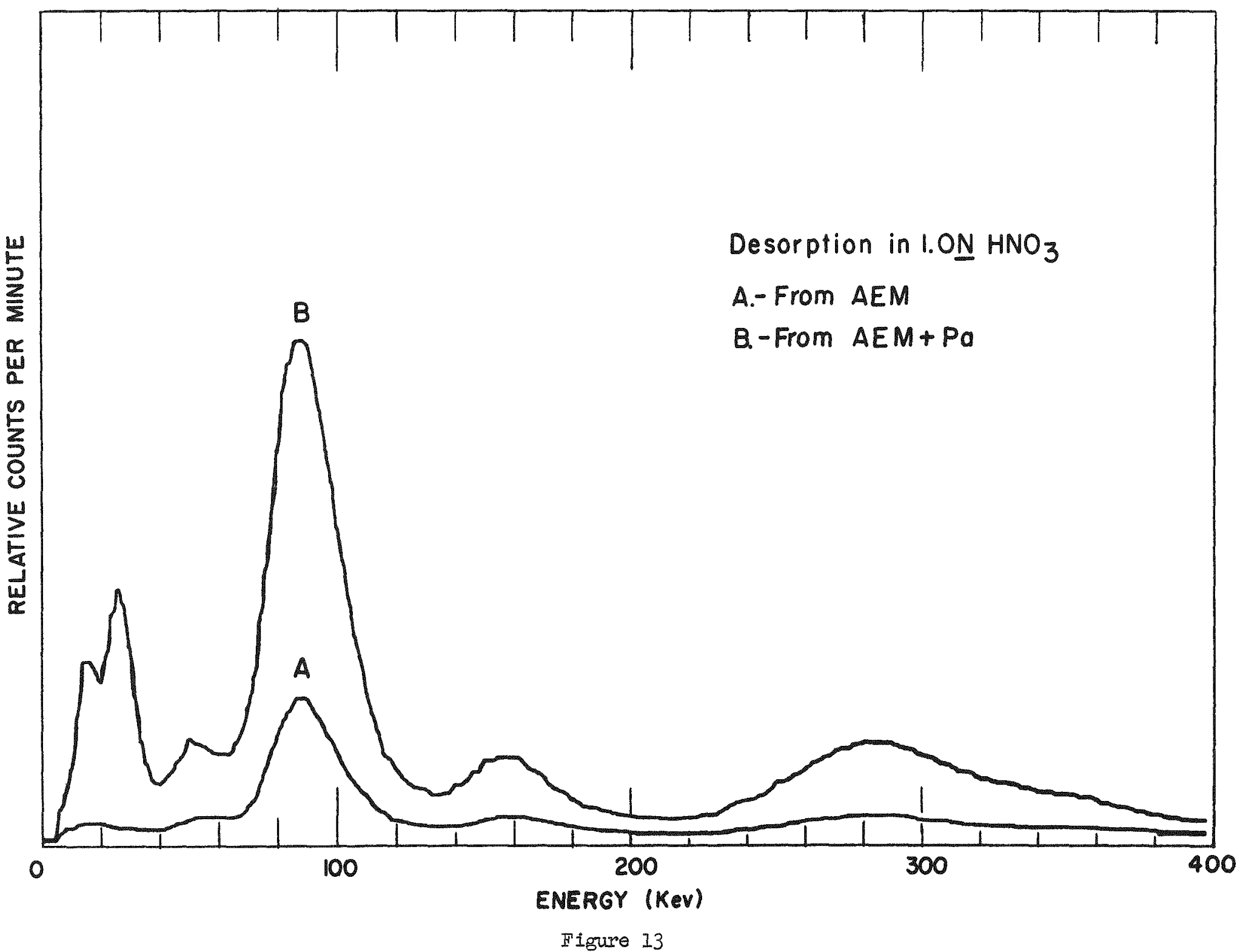


Finally, Figure 14 shows what was left on the two platinum disks after they had both been leached with $1 \mathrm{~N} \mathrm{HNO}_{3}$. The $\mathrm{AEM}$ residue has been almost completely desorbed (Spectrum A) while the protactinium + AEM disk retains nearly all of the protactinium, a smal1 trace of thorium-227 (the peak at $50 \mathrm{kev}$ ), and a trace of radium223 (the peak at $156 \mathrm{kev}$ )。

Incidentally, the small hump on the side of the $27 \mathrm{kev}$ peak $1 \mathrm{~s}$ the $\mathrm{L} X$-ray of actinium at $16 \mathrm{kev}$. It is visible here because the protact $\mathbf{n}$ ium was desorbed in $\mathrm{HF}$ and transferred to a styrene vial. Unlike the glass vials used for the spectra in the earlier figures, the plastic does not seriously attenuate the weak $\mathrm{x}$-rays.

In another experiment a sample of AEM was deposited on a platinum disk and dried. The residue was covered with a sample of protactin ium in a mixture of $0.002 \mathrm{~N} \mathrm{HF}$ and $0.001 \mathrm{~N} \mathrm{H}_{2} \mathrm{SO}_{4}$ 。 This solution was dried, and the residue was converted to a hydroxide with 3 N $\mathrm{NH}_{4} \mathrm{OH}$ and dried。

The residue was leached with two $1 / 2 \mathrm{ml}$ 。 portions of $1 \stackrel{\mathrm{N}}{\mathrm{HNO}_{3}}$ and the leachings transterred to a second platinum disk. This solution was dried, converted to a hydroxide, and dried again.

The second disk was leached twice with $1 / 2 \mathrm{ml}$. portions of $1 \underline{N}$ $\mathrm{HNO}_{3}$ and the solutions were transferred to a third disk。

Figure 15 shows the gamma spectra of the first two platinum disks. They both appear to contain essentia11y pure protactinium- 231 .

The reader should not be misled by the smal1 hump at $65 \mathrm{kev}$ which is the $K_{\alpha} x$-ray of platinum. There appears to be no significant amount of AEM present on these two disks. 


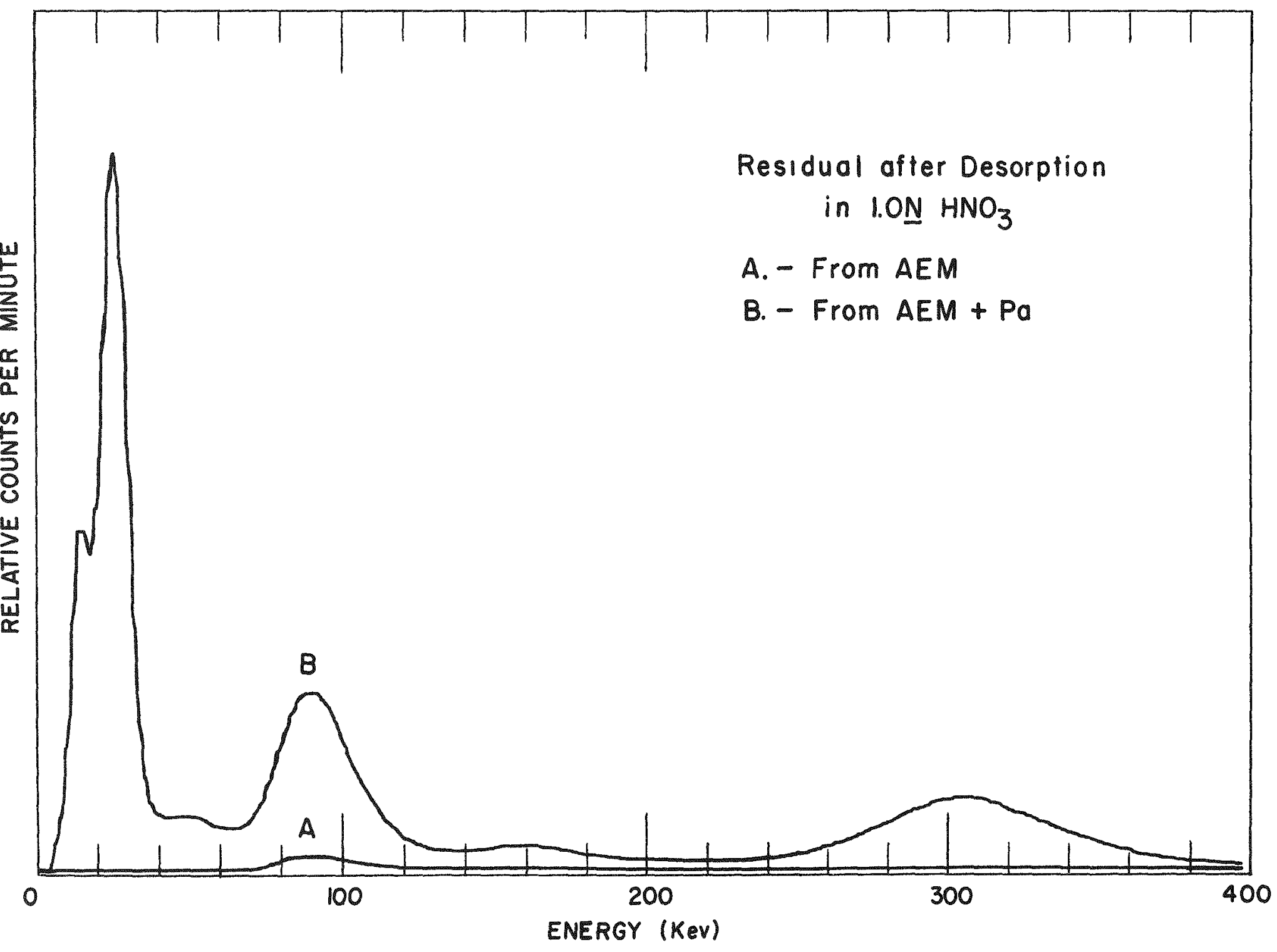

Figure 14 


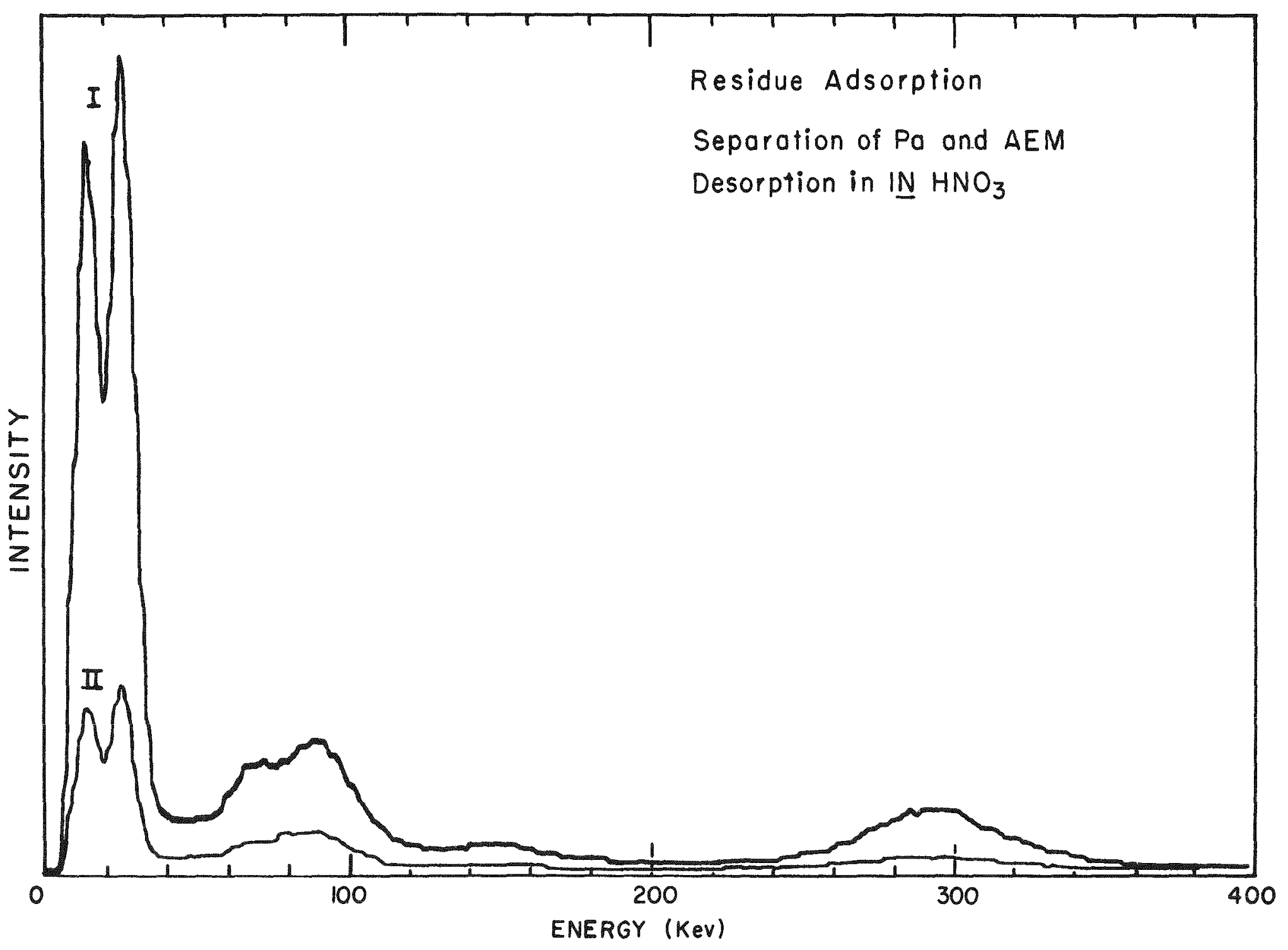

Figure 15 
Figure 16 is a comparison of the 2 nd and $3 \mathrm{rd}$ platinum disks showing that the AEM has moved quantitatively from the first disk to the third without any significant loss to the 2nd disk。 On the other hand, the protactinium, part of which moved to the 2nd disk with the AEM, was left behind when the AEM moved to the 3rd disk.

A small hump in the $27 \mathrm{kev}$ region of Spectrum III indicates that there is still some protactinium in the AEM fraction. Presumably this would disappear if the AEM were transferred under the same con ditions to a fourth disk.

Figure 17 compares the gamma spectra of the first and third disks. It does not show anything new but gives some indication of the relative amounts of gamma activity in the two major fractions.

To sum up, i.t has been shown that:

Hydrolysis and adsorption at the trace level

are not unique characteristics of protactinium--

they are exhibited by actinium at the nanogram

level and by thorium and radium at the pico-

gram level。

Hydrolysis and adsorption of protactinium are not inevitable and unpredictable, but occur under certain definite conditions having to do with the nature and concentration of the solvent.

Hydrolysis and adsorption of trace elements occur under conditions similar to those in which macroconcentrations of the same elements would tend to form precipitates in aqueous solution.

The method of residue adsorption, aside from its obvious potentialities in the carrier-free separation of trace 


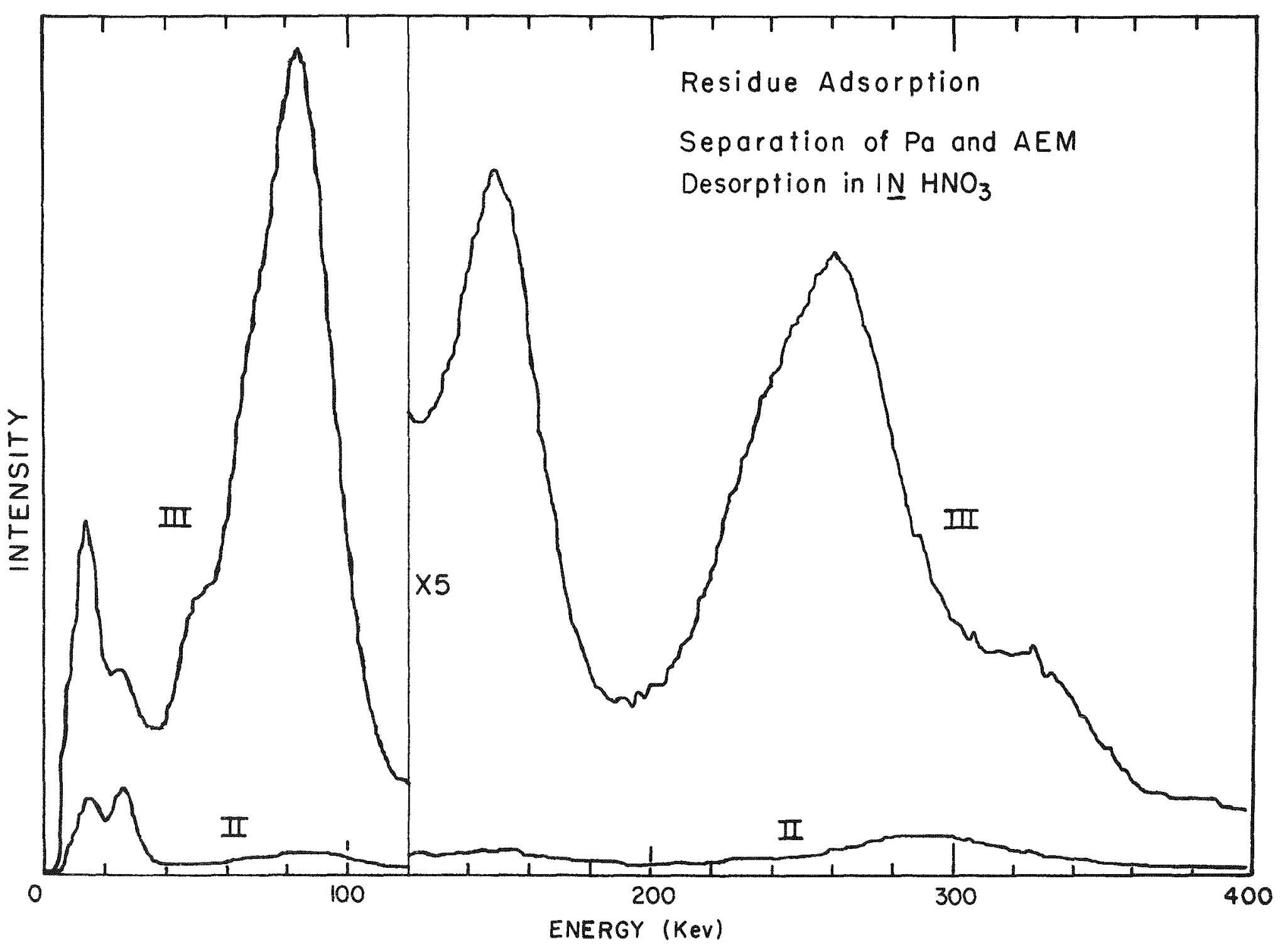

Figure 16 


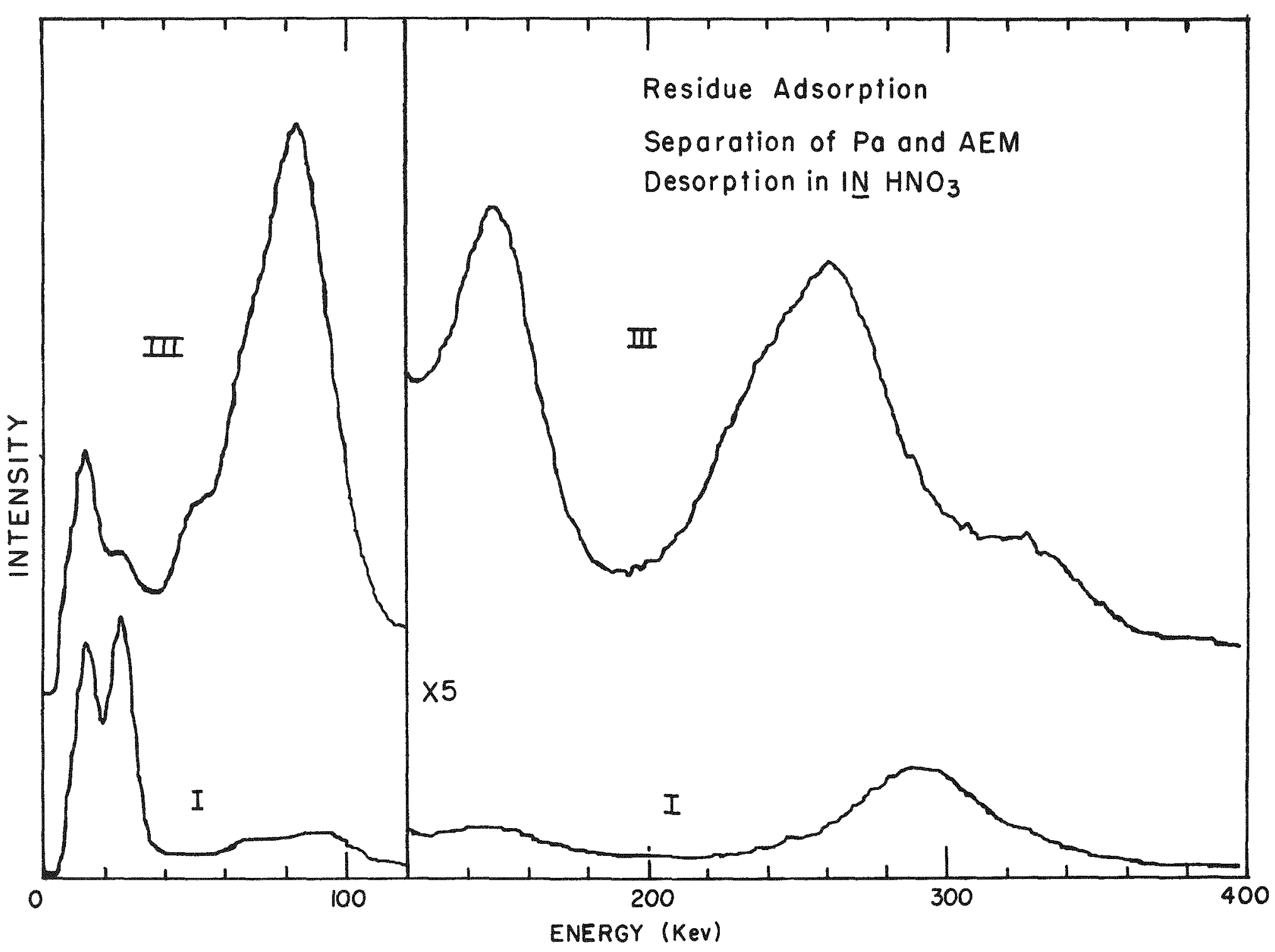

Figure 17 
elements, should prove useful in the study of the fundamental mechanism of the precipitation of slightly soluble compounds. In addition, I hope to be able to use this technique to clarify some aspects of chromatography to which residue adsorption bears a strong family resemblance. 


\title{
OBSERVATIONS ON THE BEHAVIOR OF PROTACTINIUM IN HCI-HF SOLUTIONS
}

\author{
- \\ J. M. Chilton \\ Oak Ridge National Laboratory*
}

In 1962 fifty grams of protactinium-23I as $\mathrm{Pa}_{2} \mathrm{O}_{5}$ was obtained from the United Kingdom Atomic Energy Authority for the purpose of producing, by neutron irradiation, approximately one gram of high-purity uranium-232 for neutron cross-section measurements. A flowsheet was developed to separate the uranium -232 from the irradiated protactinium. The flowsheet was based on dissolving the $\mathrm{Pa}_{2} \mathrm{O}_{5}$ in a mixture of hydrochloric and hydrofluoric acids, loading the uranium on an anion exchange column, and finally eluting and further purifying the uranium. The protactinium was recovered from the ion exchange column raffinate by precipitation with ammonium hydroxide; the precipitate was filtered and ignited to $\mathrm{Pa}_{2} \mathrm{O}_{5}$. During the development and use of this flowsheet a number of qualitative and semiquantitative observations were made relating to the behavior of protactinium. These observations provide the basis for this talk.

The author is indebted to N. Jackson of Harwell, who participated in the study while on loan to this Laboratory, to J. A. Cooper and his analytical chemistry group for their many contributions, and to $O$. K. Tallent for his assistance with the experiments.

\section{SOLUBILITY}

An attempt was made early in the work to obtain solubility values for protactinium oxide in hydrochloric acid by gross alpha counting of the solutions, but later results showed these to be incorrect because of interference by protactinium daughter activity. The results clearly showed that some of the protactinium daughters were preferentially dissolved in hydrochloric acid. About $80 \%$ of the alpha activity in the original material was due to $\mathrm{Pa}^{231}$; but it contributed only 4 to $5 \%$ of the alpha activity in the hydrochloric acid solum tions, the rest resulting from protactinium daughters. In subsequent work hydrochloric acid solutions were heated with $\mathrm{Pa}_{2} \mathrm{O}_{5}$ powder to about $70^{\circ}$ for several hours and then allowed to cool to room temperature overnight. Samples of the supernatant solution were alpha counted and then analyzed by alpha energy spectrometry using a silicon diode detector and a 400 channel alpha pulse height analyzer. The protactinium solubility in 4 to $8 \mathrm{M}$ hydrochloric acid was only 3 to $5 \mathrm{mg} \mathrm{Pa/liter,} \mathrm{substantially} \mathrm{less} \mathrm{than} \mathrm{values} \mathrm{reported} \mathrm{by}$ Thompson.

A rough value for the solubility of protactinium in ammoniacal solutions was obtained by adding $4 \mathrm{M} \mathrm{NH}_{4} \mathrm{OH}$ to mixed $\mathrm{HCl}-\mathrm{HF}$ solutions until no more precipitation could be

\footnotetext{
*Operated by Union Carbide Corporation for the U. S. Atomic Energy Commission.
} 
observed in the supernate. The precipitate was filtered through ashless paper and the filtrate was analyzed for protactinium by alpha pulse analysis. The solubility was consistently 0.35 to $0.40 \mathrm{mg} \mathrm{Pa} /$ liter.

A maximum solubility of $11.2 \mathrm{mg} \mathrm{Pa} / \mathrm{ml}$ was found in $8 \mathrm{M} \mathrm{HCl}-0.6 \mathrm{M} \mathrm{HF}$ solutions used in this study. It was reported that solutions containing approximately $7 \mathrm{mg} \mathrm{Pa} / \mathrm{ml}$ in $8 \mathrm{M} \mathrm{HCl}-0.4 \mathrm{M} \mathrm{HF}$ were used in the isolation and purification of protactinium at Harwell. 2 The protactinium to fluoride ratio is similar in these two solutions. Thus the Harwell report is taken to be support for the high value of $11.2 \mathrm{mg} \mathrm{Pa} / \mathrm{ml}$ found in the fluoride-containing solutions. In a test of dissolution of $\mathrm{Pa}_{2} \mathrm{O}_{5}$ in higher HF concentrations, $62.5 \mathrm{mg}$ of protactinium as the oxide was dissolved in $0.5 \mathrm{ml}$ of $8 \mathrm{M} \mathrm{HCl}-5 \mathrm{M} \mathrm{HF}$ by heating to $80^{\circ}$ for 15 minutes. This corresponds to a solubility of at least $125 \overline{\mathrm{mg} \mathrm{Pa}} / \mathrm{ml}$; however, no analyses were performed on the solution.

\section{ANION EXCHANGE}

The effect of aluminum-to-fluoride ratio on the loading of protactinium onto anion exchange resin was studied by adding various amounts of $\mathrm{AlCl}_{3}$ to $8 \mathrm{M} \mathrm{HCl}-0.4 \mathrm{M} \mathrm{HF}$ conraining approximately $5 \mathrm{mg} \mathrm{Pa/liter}\left(2 \times 10^{-5} \mathrm{M}\right)$, and equilibrating the solutions with weighed amounts of Dowex $-1 \times 8$ resin. The distribution ratio $\mathrm{D}=$ (weight $\mathrm{Pa} / \mathrm{g}$ resin)/ (weight $\mathrm{Pa} / \mathrm{ml}$ solution) increased with increasing aluminum chloride concentration, but good protactinium loading was not obtained until the $\mathrm{Al} / \mathrm{F}$ ratio exceeded one. Protactinium can be eluted from a column of Dowex-l resin with approximately two apparent column volumes of $8 \mathrm{M} \mathrm{HCl}-0.4 \mathrm{M} \mathrm{HF}$ using a fairly slow flow rate.

Table 1. Effect of Aluminum Concentration in $8 \mathrm{M} \mathrm{HCl}=0.4 \mathrm{M} \mathrm{HF}$ on Protactinium Loading onto Dowex-1 Anion Exchange Resin

$\begin{array}{cc}\text { Concentration } \mathrm{AlCl}_{3} & \text { Pa Distribution Ratio } \\ \frac{M}{0.2} & \frac{D}{0} \\ 0.4 & 2.7 \\ 0.6 & 17.7 \\ 0.8 & 40.6 \\ 1.0 & 59.3\end{array}$

\section{SOLVENT EXTRACTION}

The final concentration step and purification of the $U^{232}$ product was accomplished by solvent extraction, and the behavior of protactinium in some promixing extraction systems was investigated briefly. Uranium was extracted by $0.1 \mathrm{M}$ trilaurylamine in diethylbenzene from $8 \mathrm{M} \mathrm{HCl}-0.4 \mathrm{M} \mathrm{HF}$ with an extraction coefficient of only $8.7 \times 10^{-3}$. Extraction measurements were made with $30 \%$ di (2-ethylhexyl)phosphoric acid in diethylbenzene to study further the behavior of protactinium in substituted phosphoric acid systems. The extraction coefficient, $E_{a}^{2}$, was measured as a function of the $\mathrm{AlCl}_{3}$ concentration added to the aqueous phase, $8 \mathrm{M} \mathrm{HCl}-0.7 \mathrm{M} \mathrm{HF}$ containing about $400 \mathrm{mg} \mathrm{Pa} /$ liter $\left(1.7 \times 10^{-3} \mathrm{M}\right)$. The phase ratio was 0.1 to 0.01 voluine of organic per volume of aqueous. Higher 
concentrations of aluminum gave higher extraction coefficients, but these could not be measured accurately. A partial listing of results obtained in these experiments is given in Table 2.

Table 2. Effect of Aluminum Concentration on Extraction of Pa from $8 \mathrm{M} \mathrm{HCl}-0.7 \mathrm{M} \mathrm{HF}$ into 30\% Di (2-ethylhexyl)phosphoric Acid-Diethylbenzene

\begin{tabular}{|c|c|}
\hline $\begin{array}{c}\text { Concentration } \mathrm{AlCl}_{3} \\
M\end{array}$ & $\begin{array}{c}\text { Pa Extraction Coefficient } \\
E_{a}^{\circ}\end{array}$ \\
\hline 0 & 0.05 \\
\hline 0.17 & 0.22 \\
\hline 0.33 & 18 \\
\hline 0.50 & 156 \\
\hline 0.62 & 326 \\
\hline
\end{tabular}

In these experiments the highest extraction coefficient measured was 806. It was observed with an aqueous phase composition of $8 \mathrm{M} \mathrm{HCl}-0.007 \mathrm{M} \mathrm{HF}-0.007 \mathrm{M} \mathrm{AlCl}_{3}$; this reflects the importance of the $\mathrm{Al} / \mathrm{F}$ ratio. The maximum loading of protactinium in this solvent has not been determined, but a value of $20.8 \mathrm{mg} / \mathrm{ml}$ was obtained and may be taken as a measure of the high loadings attainable.

As a final note, it should be mentioned that the physical characteristics of $\mathrm{Pa}_{2} \mathrm{O}_{5}$ solid and the precipitate obtained by hydroxide precipitation are quite similar to the corresponding tantalum compounds. In studying such things as the rate of dissolution of oxides and hydroxides, and the filtration characteristics of the hydroxide, it was found that tantalum was a good substitute for protactinium. Niobium was less satisfactory.

\section{REFERENCES}

1. R. Thompson, AECD-2488 (1946) and AECD-1897 (1948).

2. N. Jackson, private communication.

3. A. J. Fudge and J. L. Woodhead, Chem. Ind., 17, 1122 (1957). 
THE CHEMISTRY OF PROTACTINIUM

G. Bouissieres, M. C. Ferradini, M. Garcon, R. Guillaumont, M. Hussonois, R. Muxart, H. Pezerat, D. Robertson, and T. Stchouzkoy

Institut du Radium, Paris, France

\section{INTRODUCTION}

The researches undertaken at the Institut du Radium of Paris and Orsay are concerned principally with the study of the physical-chemical properties of the element in its two oxidation states and the nuclear reactions in which protactinium is either the target element or the formed element. These include:

1. Study of the distribution of $\mathrm{Pa}(\mathrm{IV})$ and $\mathrm{Pa}(\mathrm{V})$ between aqueous solutions and different organic solvents, using trace $\mathrm{Pa}^{233}$, in order to examine the behavior of protactinium in its two oxidation states with respect to particular solvents and to determine the form of extracted complexes as a means of studying the hydrolysis of protactinium by solvent extraction.

2. Research on protactinium peroxide.

3. Preparation of metallic protactinium.

4. Studies of spallation nuclear reactions $\mathrm{Pa}(\mathrm{p}, \mathrm{xn}) \mathrm{U}$ and $\mathrm{U}(\mathrm{p}, 2 \mathrm{pxn}) \mathrm{Pa}$.

\section{SOLVENT EXTRACTION}

The distribution of penta- and tetravalent protactinium has been studied between aqueous sulfuric or hydrochloric acid solutions and a solution of trin-octylamine (TNOA) in xylene. Greater than $95 \%$ of the Pa(IV) is extracted from hydrochloric acid only if the acidity is at least $10 \mathrm{M}$. On the contrary, $\mathrm{Pa}(V)$ is quantitatively extracted at acidities greater than $6 \mathrm{M} \mathrm{HCl}$. With sulfuric acid solutions $\mathrm{Pa}(\mathrm{IV})$ and $\mathrm{Pa}(\mathrm{V})$ are extracted to more than $95 \%$ in 0.12 and $0.25 \underline{M}$ sulfuric acid, respectively.

Examination of the results of distribution measurements of $\mathrm{Pa}$ (IV) and $\mathrm{Pa}(\mathrm{V})$ between $5 \%$ TNOA in xylene and various aqueous solutions shows that sulfuric acid offers the best separation of $\mathrm{Pa}(\mathrm{V})$ because the distribution coefficients under best conditions are 114,46 , and 0.2 in solutions of sulfuric, hydrochloric, and nitric acid, respectively. Thus, $\mathrm{Pa}(\mathrm{V})$ has the strong tendency to form anionic sulfato-complexes, as already observed by Brown et al. 1 by absorption chromatography with anionic exchange resins.

Compaxison of the extraction results of $\mathrm{Pa}(\mathrm{IV})$ from hydrochloric acid by a tertiary amine with the extraction of the neighboring tetravalent elements (Th, $\mathrm{Zr}, \mathrm{HF}$, and $U(\mathrm{IV})$ ) shows that $\mathrm{Pa}(\mathrm{IV})$ forms some anionic chloro-complexes which are extracted at an acidity of $10 \mathrm{M}$ or greater. This is different from

*Speaker. 
Th(IV) which is practically not extracted by a tertiary amine, even from $12 \mathrm{M}$ HC1, but it is similar to zirconium and hafnium which are quantitatively extracted from 10 to $12 \mathrm{M} \mathrm{HC1}$ and to $\mathrm{U}(\mathrm{IV})$ from $8 \mathrm{M} \mathrm{HC} 1$.

From the analytical point of view $2 t$ is very interesting to see that zirconium and hafnium are not extracted from HCl solutions below $7 \mathrm{M}$ by a solution of 0.1 MNOA. ${ }^{2}$ The separation of protactinium from zirconium and hafnium could be realized by extraction with this amine from 5 to $6 \mathrm{M} \mathrm{HC1}$ solutions. At this acidity about $95 \%$ of the $\mathrm{Pa}(\mathrm{V})$ is extracted, but zirconium and hafnium are not extracted. On the other hand the behavior of $\mathrm{Pa}(\mathrm{IV})$ and $\mathrm{Pa}(\mathrm{V})$ in the extraction by TNOA from sulfuric or hydrochloric acids will permit the separation of the two oxidation states. For example, with $1 \mathrm{M}$ sulfuric or $6 \mathrm{M}$ hydrochloric acid about $95 \%$ of the $\mathrm{Pa}(\mathrm{V})$ is extracted, but only $5 \%$ of the $\mathrm{Pa}(\mathrm{IV})$.

The variation of distribution coefficient with the concentration of TNOA, for a constant acidity, permits the formulation of some hypothesis on the nature of the protactinium complexes in the given media. Results in hydrochloric acid solutions agree with the existence of anionic complexes of protactinium of the type PaOCl $1_{4}$ at $3 \mathrm{M}$ and $\mathrm{PaOCl}_{5}=$ at $6 \mathrm{M} \mathrm{HCl}$, according to the ideas of Casey and Maddock ${ }^{3}$ and Haissinsky et al. 4

Investigation of the distribution of protactinium between aqueous solutions of perchloric acid and benzene solutions of TTA offers the possibility to study some hydrolytic properties of this element. Preliminary experiments with carrier-free $\mathrm{Pa}^{233}$ indicate that from perchloric acid solutions $3 \mathrm{M}$ in perchlorate ion the variation of the extraction coefficient, $\mathbf{E}$, as a function of the TTA concentration is such that the slope of the straight line, $\log E=n \log$ (TTA) is equal to 4 for solutions in which the acidity is between 0.5 and $3 \mathrm{M}$. This slope decreases progressively to 3 as the acid concentration decreases from 0.5 to $0.015 \mathrm{M}$ (Fig. 1). An analogous study with chloride, sulfate, and nitrate is still under way.

In the acidity range between 0.5 and $3 \mathrm{M}$ no modification of the solutions is observed after one month of aging; both the slope of the straight lines and the distribution coefficients remain unchanged. The solutions seem stable (Fig. 2). The value for the slope of the straight line of the plot of $\log E$ vs $\log \mathrm{H}^{+}$is -2 between 0.9 and $3 \mathrm{M}$ acid (0.1 M TTA) (Fig. 3). Below $0.5 \mathrm{M}$ acid the solutions do not seem to be thermodynamically stable. At acidities of $1.5 \times 10^{-3}$ to $2 \times 10^{-2}$ M the slope of the straight $\operatorname{line} \log \mathrm{E}$ vs $\log \mathrm{H}^{+}$is about -1 for fresh solutions.

It seems there are two possible interpretations depending on whether or not we suppose $\mathrm{Pa}(\mathrm{V})$ is complexed with TTA in the aqueous phase. Between 0.9 and 3 M acidity we have the following equilibrium:

$$
\mathrm{Pa}(\mathrm{OH})_{2} \mathrm{~A}^{+2}+4 \mathrm{HA} \rightleftharpoons \mathrm{PaA}_{5}+2 \mathrm{H}^{+}+2 \mathrm{H}_{2} \mathrm{O}
$$

where HA is TTA. Or if we suppose that the extracted form is $\mathrm{Pa}(\mathrm{OH}) \mathrm{A}_{4}$ we have:

$$
\mathrm{Pa}(\mathrm{OH})_{3}^{+2}+4 \mathrm{HA} \rightleftharpoons \mathrm{Pa}(\mathrm{OH})_{4}+2 \mathrm{H}^{+}+2 \mathrm{H}_{2} \mathrm{O}
$$

At lower acidities, between $1.5 \times 10^{-3}$ and $2 \times 10^{-2} \mathrm{M}$, and for Eresh solutions we can suppose:

$$
\mathrm{Pa}(\mathrm{OH})_{2} \mathrm{~A}_{2}^{+}+3 \mathrm{HA} \rightleftharpoons \mathrm{PaA}_{5}+\mathrm{H}^{+}+2 \mathrm{H}_{2} \mathrm{O}
$$

or

$$
\mathrm{PaO}(\mathrm{OH})_{2}^{+}+3 \mathrm{HA} \rightleftharpoons \mathrm{PaOA}_{3}+\mathrm{H}^{+}+2 \mathrm{H}_{2} \mathrm{O} \text {. }
$$

Now, some more experiments are necessary to determine exactly the extracted forms. 
UNCLASSIFIED

ORNL-DWG 63-6952

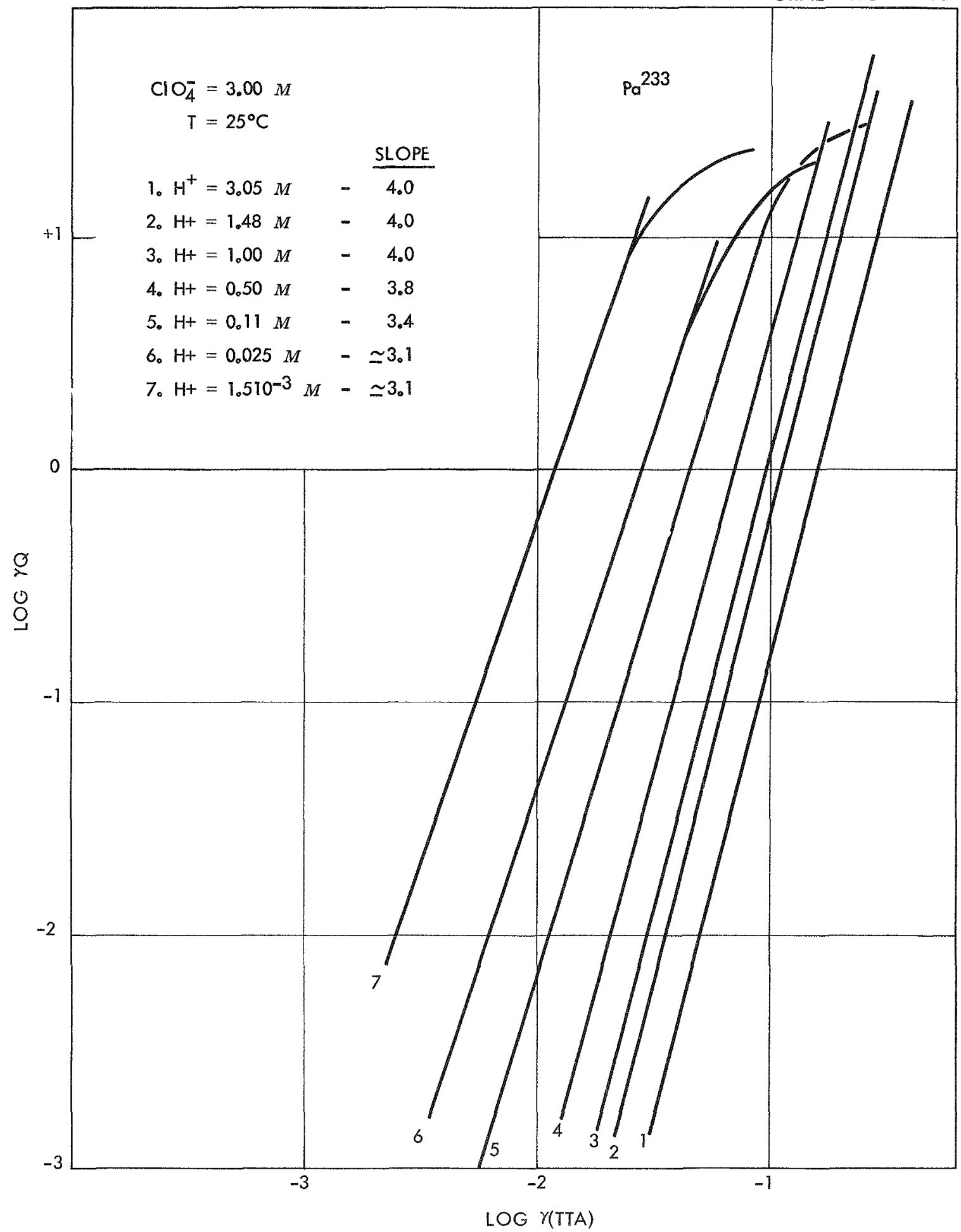

Fig. 1. Effect of TTA Concentration on the Extraction of Protactinium from $3 M$ Perchloric Acid Solution. 


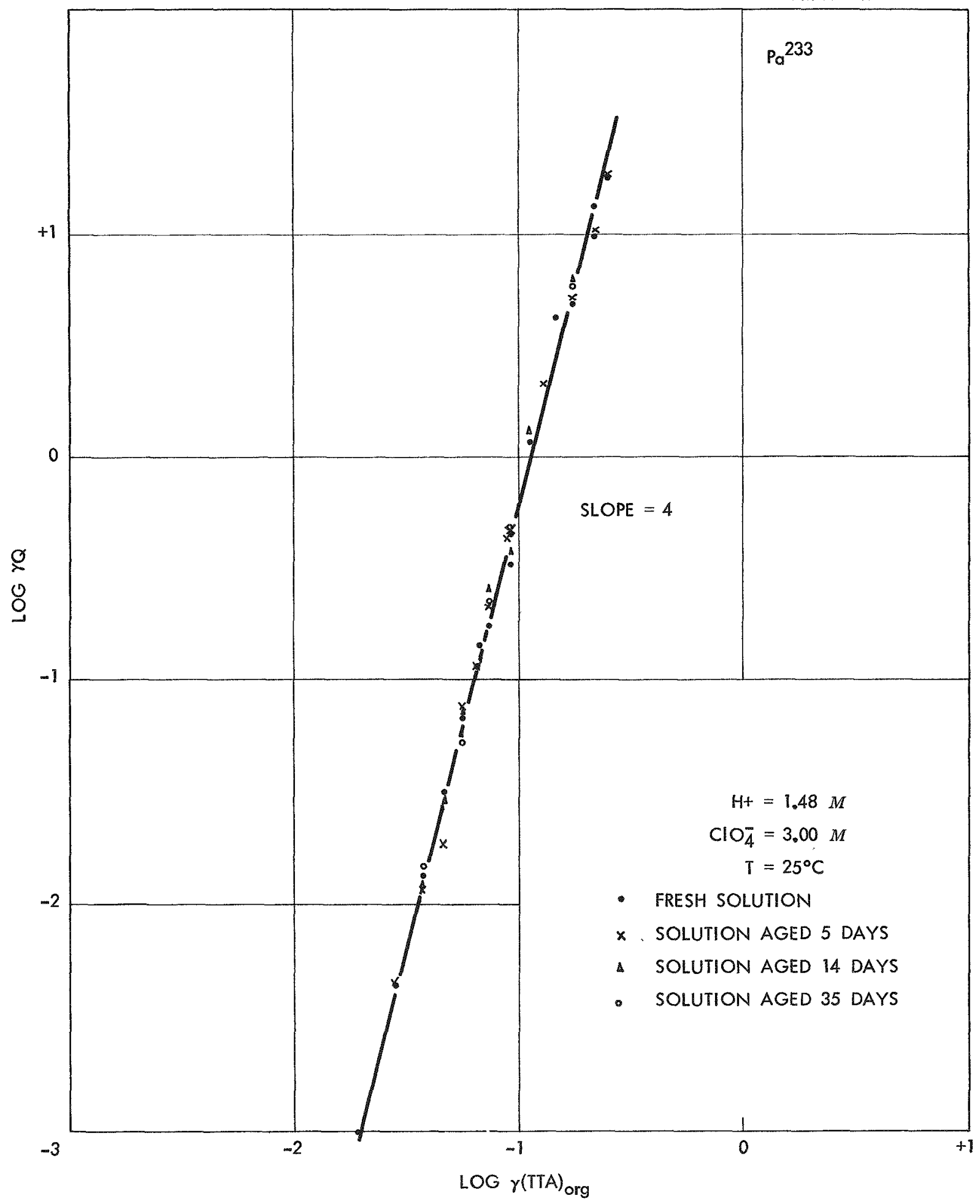

Fig. 2. Effect of Aging on the Extraction of Protactinium from Perchloric Acid Solution by TTA. 


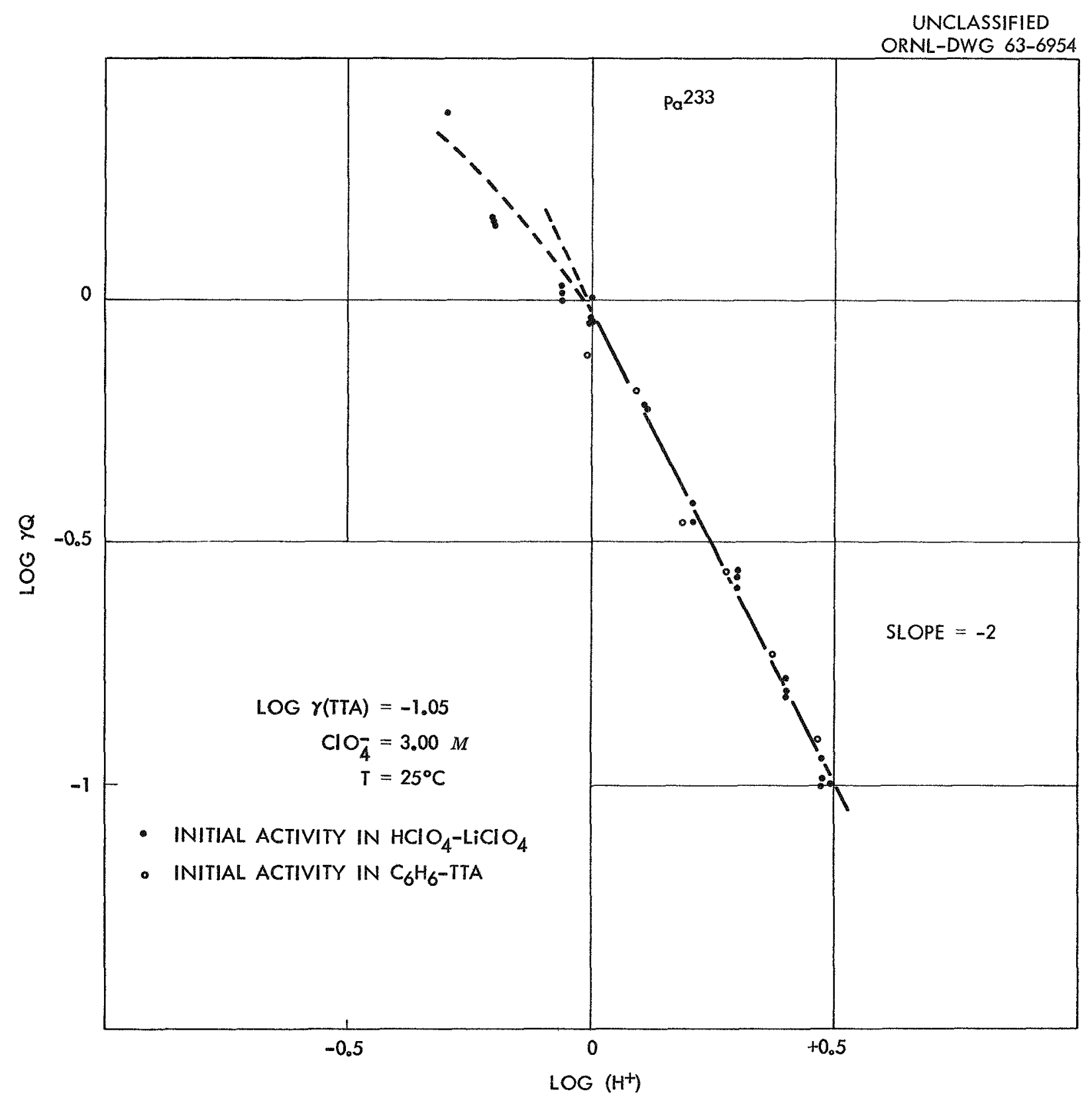

Fig. 3. Effect of $\mathrm{pH}$ on the Extraction of Protactinium from Perchlorate Solutions by TTA. 
The condition of the precipitation of protactinium peroxide formed in sulfuric, nitric, hydrochloric, and perchloric acid media has been studied systematically as a function of the concentrations of the reagents, that of protactinium, and the temperature. Studies are also undertaken on the determination, with the help of appropriate methods (thermogravimetric, potentiometric, amperometric dosages, diffraction of $x$-rays, etc.) of the centesimal composition and the structure of formed compounds, as well as their stability as a function of aging, temperature, etc.

The results show that in all the media studied, the yield and rate of formation of the compound are favored by increasing the hydrogen-peroxide concentration and decreasing the acidity. On the other hand, an increase in the concentration of protactinium tends to increase the rate of precipitation but does not seem to have an appreciable effect on the final solubility of the product.

In the range investigated, an increase in temperature does not have a perceptible effect on the precipitation reaction, except in hydrochloric acid media. By analogy with thorium peroxide 5 there is probably a formation of chlorine in this latter medium and progressive decomposition of the peroxide, which is more rapid the higher the temperature and the acidity.

From an analytical point of view it appears that a sulfuric acid medium would be the most favorable for the precipitation of the peroxides, considering the appreciable solubility of the hydroxide of protactinium in this medium. The optimal conditions are: sulfuric acid, $0.25 \mathrm{M}$ ( 4 volumes); hydrogen peroxide, 9.75 M (1 volume); temperature, $25^{\circ} \mathrm{C}$; precipitation time, 1 hr 30 min. Grosse.

We recall that 0.25 sulfuric acid medium is that al ready recommended by

$x$-ray analysis of a peroxide precipitated in sulfuric medium under the conditions cited above, at $25^{\circ} \mathrm{C}$ and at $60^{\circ} \mathrm{C}$, shows that the compound is amorphous.

By heating in aix at $680^{\circ} \mathrm{C}$ for $30 \mathrm{~min}$, one obtains an oxide of facecentered cubic structure, of which the lattice constant lies between 5.445 and $5.4 .48 \mathrm{~A}$. Upon prolonged heating in air at $1000^{\circ} \mathrm{C}$ a black compound of tetragonal structure is formed, the lattice constants of which are different from those reported in the literature. 6

Considering the observed differences, in some cases with previous values, 6 we have considered a detailed study of the structure and composition of the oxides of protactinium.

\section{PREPARATION OF METALLIC PROTACTINIUM}

Protactinium was first prepared in the metallic state on a macrochemical scale by Grosse and coworkers 8 by reduction of the pentoside by electron bombardment and by decomposition of a halide on an incandescent filament. A second preparation was carried out on a microchemical scale by Fried et al. 6 by reduction of the tetrafluoride with metallic barium. In order to study the properties of the metal, we have begun some preliminary experiments for preparing several milligrams of protactinium in the metallic state.

In regard to special considerations we have chosen, anong the possible methods, reduction by barium of a halide (tetrafluoride) and of a double fluoride of barium and protactinium. 
Some encouraging results have been obtained, notably by reduction of the double fluoride, but many experiments on several milligrams of protactinium are still necessary in order to define the optimum experimental conditions, in particular those which would make possible obtaining a pellet of metal.

$X$-ray analysis of the intermediate compounds has made possible, for example, confirming the monoclinic structure of $\mathrm{PaF}_{4}$ formed by a mixture of $\mathrm{HF}$ and $\mathrm{H}_{2}$, in suitable proportions and at a definite temperature, on the hydrated oxide.9

\section{NUCLEAR REACTIONS}

We have studied nuclear reactions in which protactinium is either the target element or the formed one. The cross sections of the reactions $(p, 2 n)$, $(p, 3 n)$, and $(p, 4 n)$ induced in $\mathrm{Pa}^{231}$ at $155 \mathrm{Mev}$ have been measured. The values obtained are less, within a factor of 6 to 10, than the values calculated by the usual model in two steps. However, agreement is satisfactory in the case of $\mathrm{U}^{238}$.

The excitation functions for the reaction $U(\mathrm{p}, 2 \mathrm{p} \times \mathrm{xn}) \mathrm{Pa}$ have been determined for $\mathrm{U}^{238}$ and $\mathrm{U}^{235}$ in the range of energy included between 40 and $150 \mathrm{Mev}$. They present, except for $\mathrm{x}=i$, a pic towards the lower energies which is more and more important for smaller values of $x$. The values of the thresholds indicate that these pics correspond to an alpha-particle emission. It would seem that this emission is favored when passing from $U^{238}$ to $U^{235}$ (Figs. 4 and 5).

The observed difference between $\mathrm{U}^{238}$ on the one hand and $\mathrm{U}^{235}$ and $\mathrm{Pa}^{231}$ on the other is probably related to a bigger deformation of the $\mathrm{U}^{235}$ and $\mathrm{Pa}^{231}$ nuclei than that of the $U^{238}$ nucleus.

In these experiments the isotopes of uranium and protactinium, formed in $\mathrm{Pa}^{231}$ and $\mathrm{U}$, respectively, were separated by solvent extraction.

\section{REEERENCES}

1. D. Brown, T. Sato, A. J. Smith, and R. G. Wilkins, J. Inorg. Nucl. Chem. 23, 91 (1961).

2. E. Cerrai and C. Testa, Energia Nucleare 6, 707 (1959).

3. A. T. Casey and A. G. Maddock, J. Inorg. Nuc1. Chem. 10, 289 (1959).

4. R. Guillaumont, R. Muxart, G. Bouissieres, M. Haissinsky, J. Chim. Phys. 57, 1019 (1960).

5. J. W. Hamaker, Ch. Koch, TID-5223, I,3 (1952).

6. Sellers, Fried, E1son, Zachariasen, J. Am. Chem. Soc. 76, 5935 (1954).

7. R. Thompson, AECD-1897 (1948).

8. Grosse, Arguss, J. Am. Chem. Soc. 56, 2200 (1934).

9. K. W. Bagnal1, L. Stein, private commuication. 


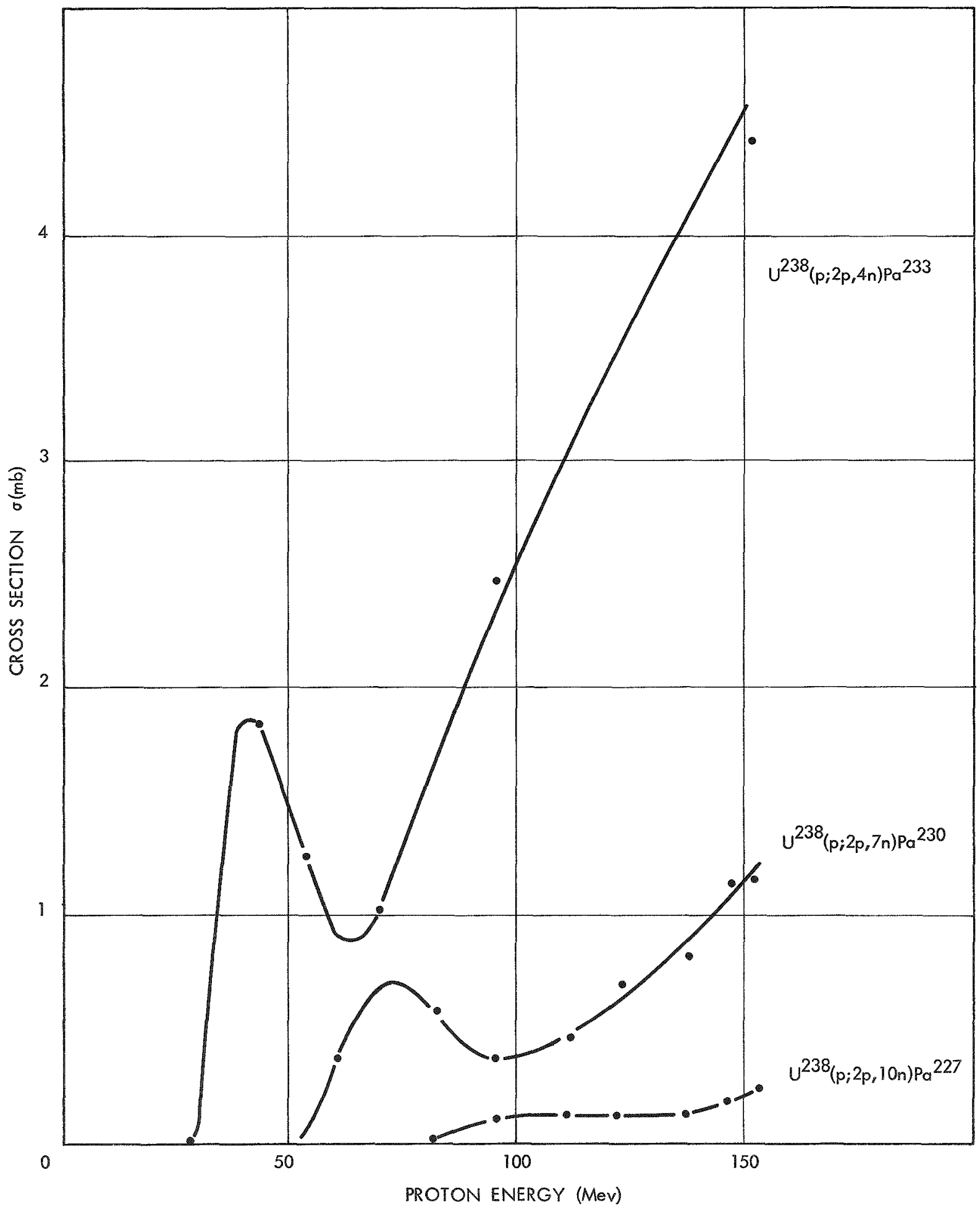

Fig. 4. Yield of the Reaction $U(p ; 2 p, \times n) P a$ for $U^{238}$ as a Function of Proton Eneryy. 
UNCLASSIFIED

ORNL-DWG 63-6956

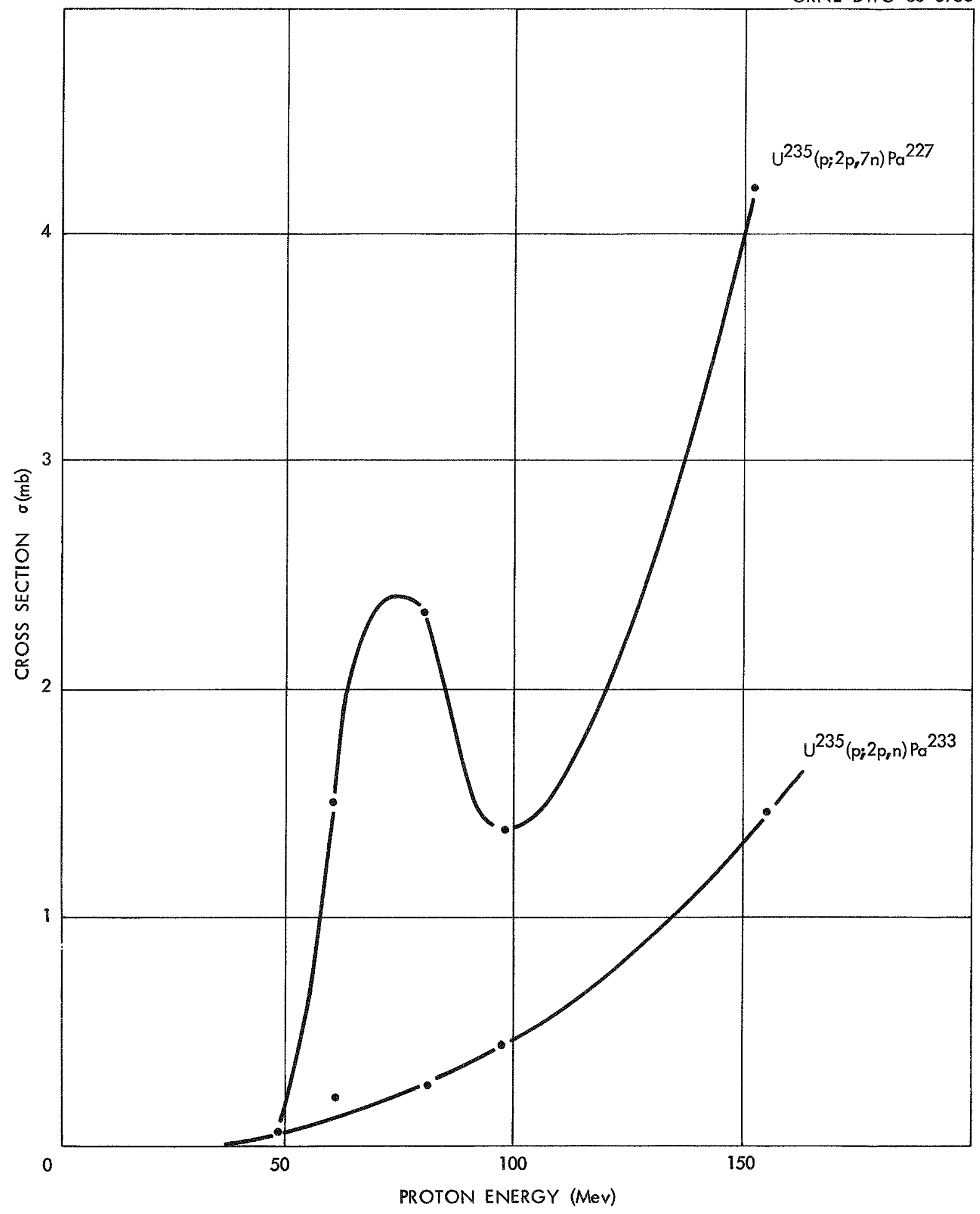

Fig. 5. Yield of the Reaction $U(p ; 2 p, x n)$ for $U^{235}$ as a Function of Proton Energy. 